Pathways through care - organisational, staff and patient characteristics, person-centred care and its association with quality of life in Norwegian nursing homes

Not everything that can be counted counts and not everything that counts can be counted Albert Einstein 
(c) Irene Mari Røen, 2019

Series of dissertations submitted to the Faculty of Medicine, University of Oslo

\section{ISBN 978-82-8377-402-3}

All rights reserved. No part of this publication may be reproduced or transmitted, in any form or by any means, without permission.

Cover: Hanne Baadsgaard Utigard.

Print production: Reprosentralen, University of Oslo. 


\section{Table of contents}

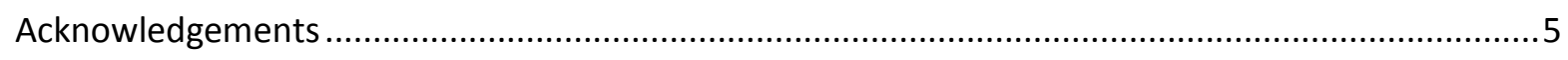

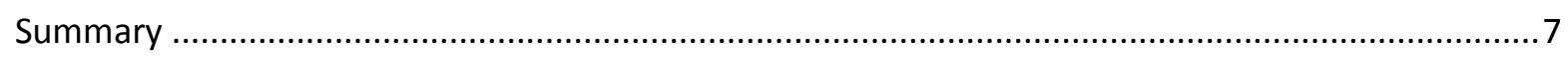

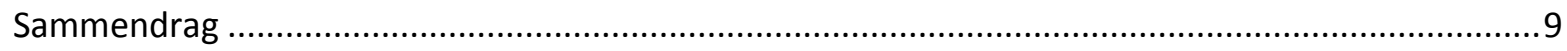

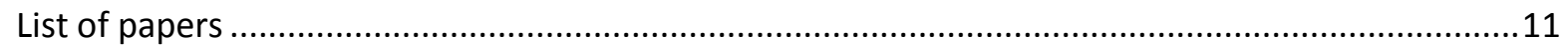

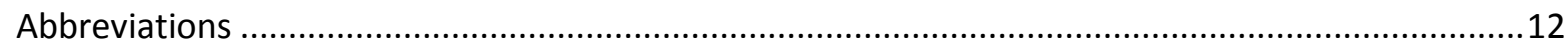

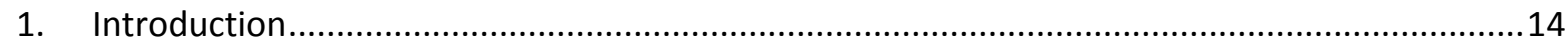

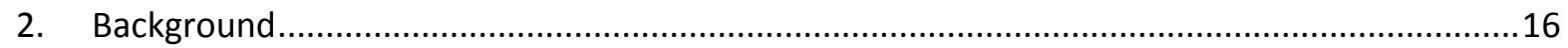

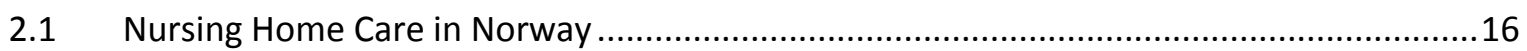

2.1.1 Organisational and staff characteristics of the nursing homes.................................17

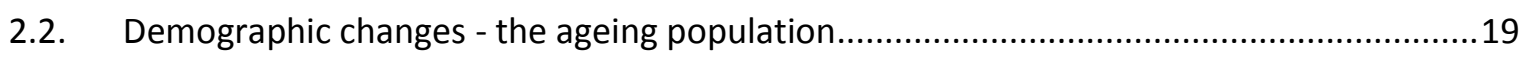

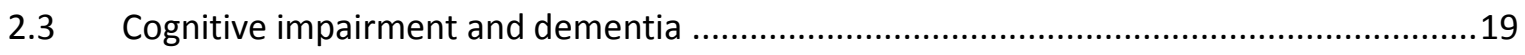

2.3.1 Mild cognitive impairment $(\mathrm{MCl})$, definition and prevalence ...................................19

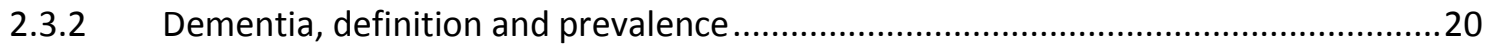

2.3.3 Diagnose/diagnostic criteria of dementia .................................................................. 21

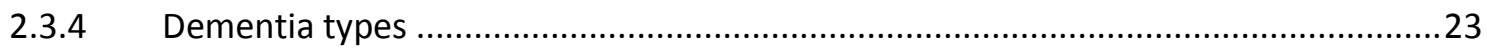

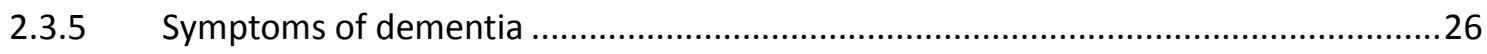

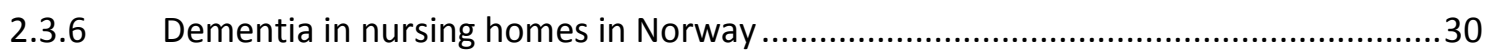

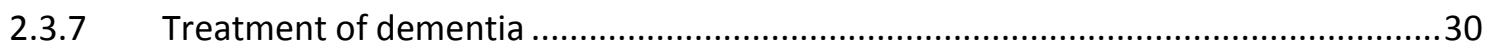

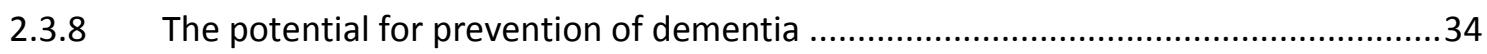

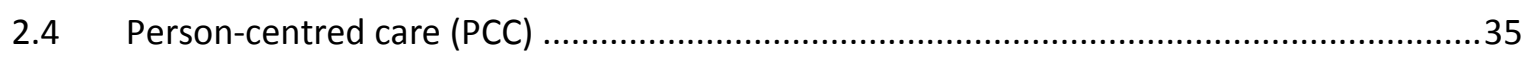

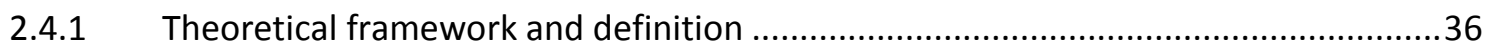

2.4.2 Tom Kitwood and person-centred care.......................................................................

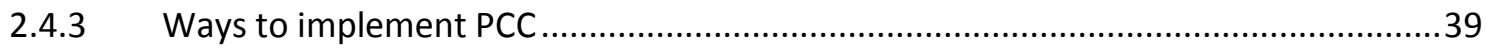

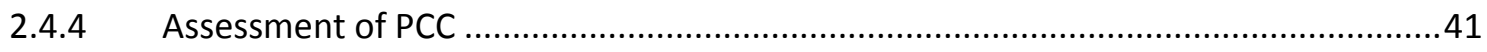

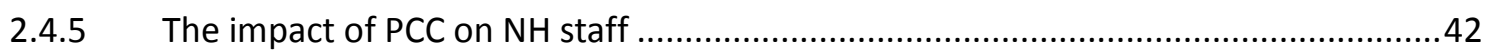

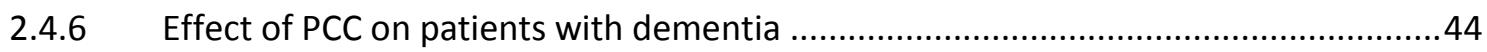

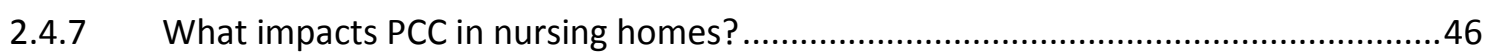

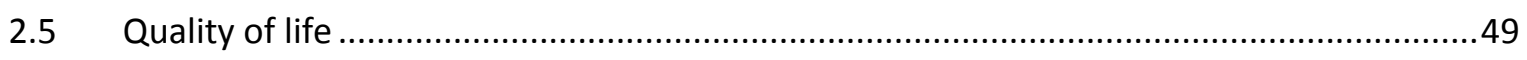

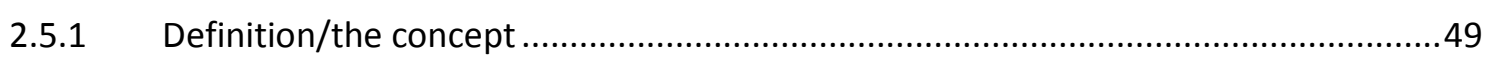

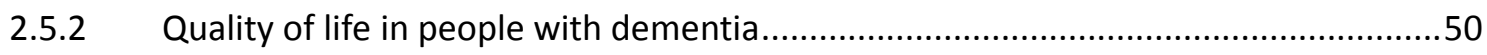

2.5.3 The stability of QoL and factors that impact QoL in people with dementia ...............51

2.5.4 Assessment of QoL in people with dementia..........................................................54 


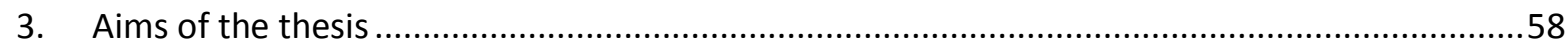

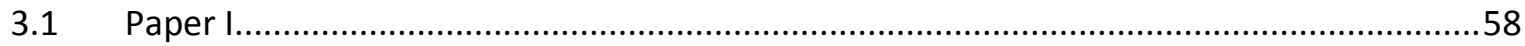

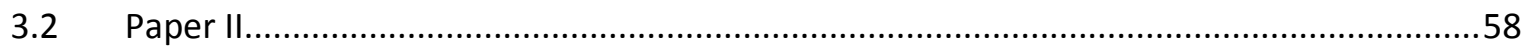

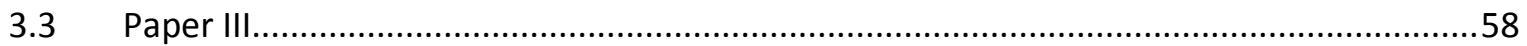

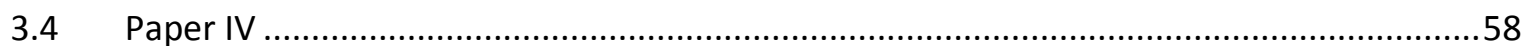

4. Design and methods in the papers included in this thesis......................................................60

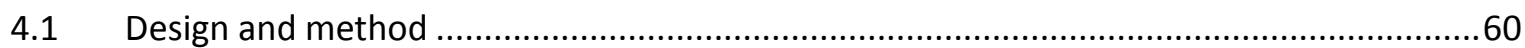

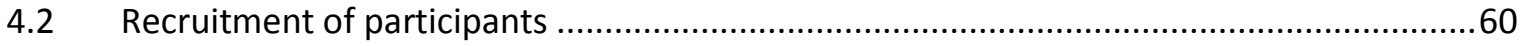

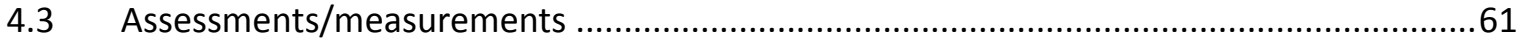

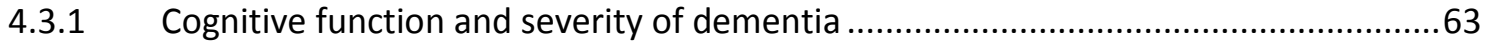

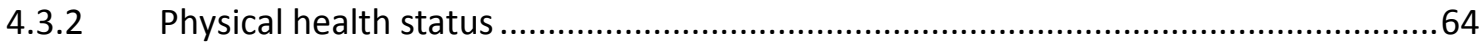

4.3.3 Neuropsychiatric and depressive symptoms, and delirium ......................................65

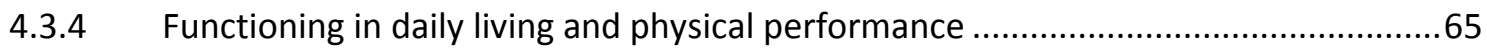

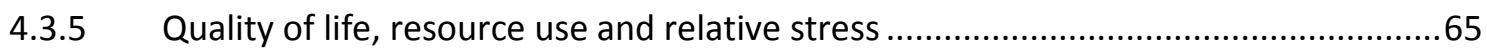

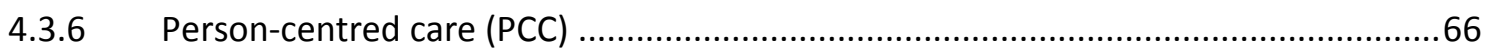

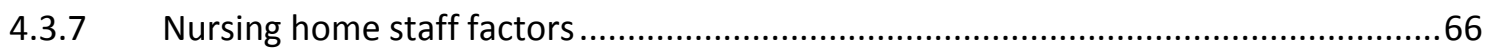

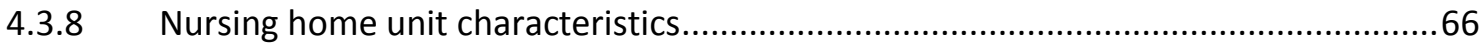

4.3.9 Physical environment in the nursing home unit ...................................................67

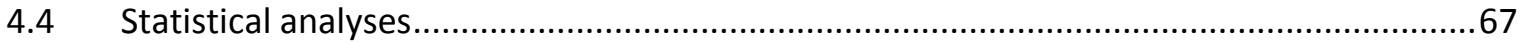

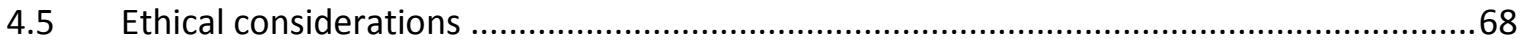

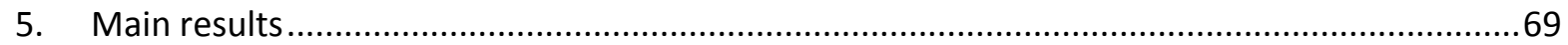

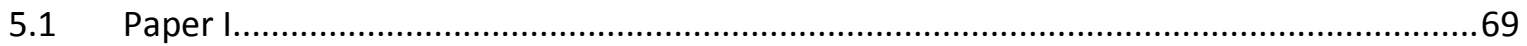

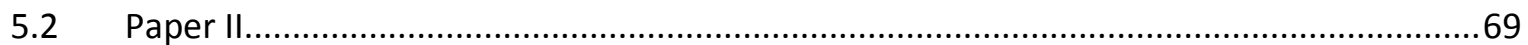

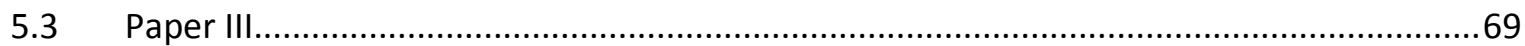

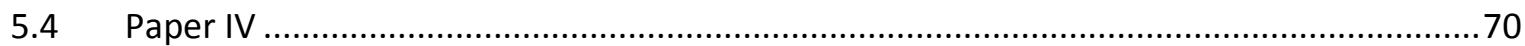

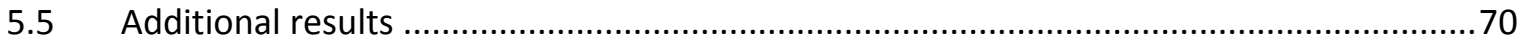

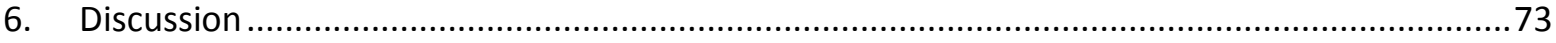

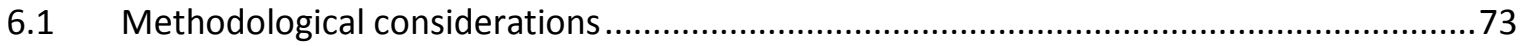

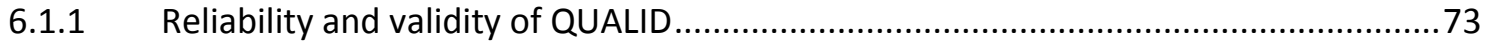

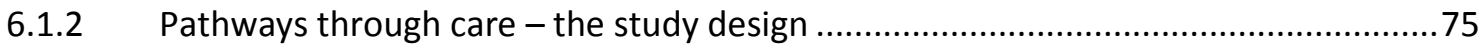

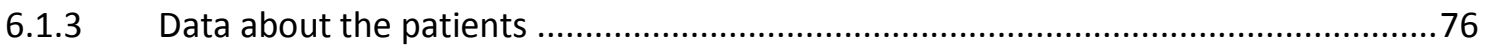

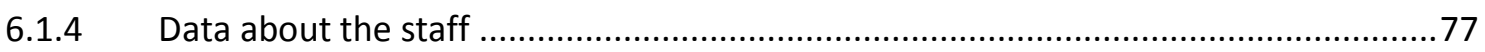

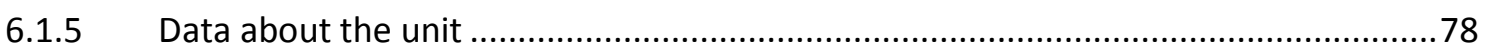

6.1.6 Aggregating staff characteristics into unit variables ................................................ 


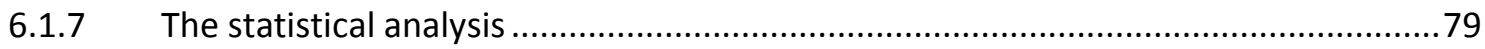

6.1.8 Conclusion of methodological considerations .......................................................... 80

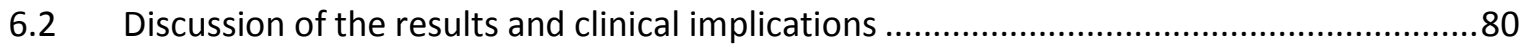

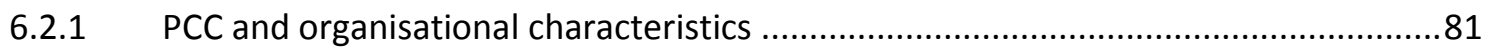

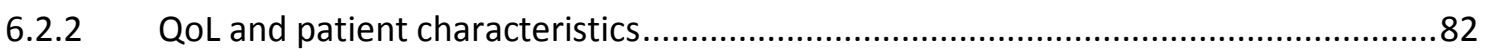

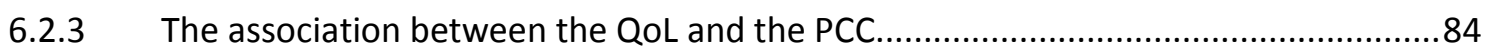

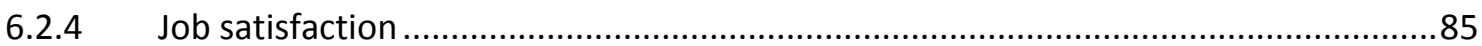

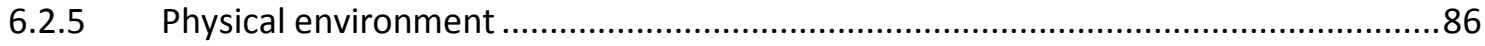

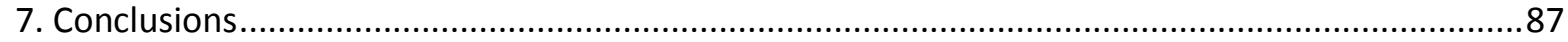

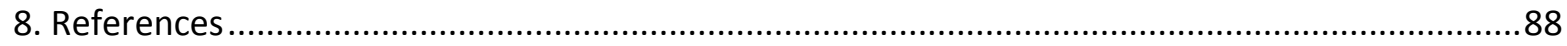





\section{Acknowledgements}

There are a lot of nice and knowledgeable people I would like to thank for their significant contribution to this thesis.

I want to express my sincere gratitude to:

- all the patients and the relatives that were willing to participate in the REDIC-NH project. Without you, there would have been no thesis at all.

- the leaders and staff of the nursing homes where I collected data who took time out of their busy work to welcome me and help me recruit participants and hand out CRFs. Without your help, the data collection about organisational and structural factors in the nursing homes could have never been conducted.

- Lise Berg-Johnsen, Ritt Nielsen, Liv Jorunn Korstad, Anne Ekren, Ellen Hervold, Ellen Bjøralt and Mari Melby Øien in SAM-AKS, and to Karin Torvik in Trøndelag and Reidun Sandvik in Bergen, for organising the collection of patient data in the REDIC-NH project. An extra thanks to those of you who also collected some of the data about the $\mathrm{NH}$.

- Sverre Bergh, you are the nicest and most patient supervisor who has ever lived! A particular gratitude for your encouragement, stimulation, support and never-ending patience in guiding and supervising me throughout this process! Without you, I would have lost my way.

- Geir Selbæk, if it had not been for you, I would have never been in the position of even thinking about pursuing a PhD. Thank you for introducing me to research and for your support through all the years I have worked with you in research, for always sharing your knowledge and for your never-ending educational approach!

- Knut Engedal, for having faith in me when you brought the QUALID scale to Norway, for all your support and prompt responses to requests and for sharing your wisdom through constructive comments that have made important contributions to me and this work!

- Ingelin Testad, for your inspiration, fruitful discussions, and for nice walks and talks. You also invited me to be a visiting student at Kings College, London. All of our conversations and this stay have been very important for me, my learning process and the progression of my English.

- Øyvind Kirkevold, for better, for worse, for richer, for poorer, in sickness and in health, to love and to cherish, till death us do part. Thank you for always being by my side, both as one of my cosupervisors and as my husband, never giving up on me and never letting me feel that my questions were stupid or asked at the wrong time. Your love significantly increases my QoL!

- my co-author Anners Lerdal as a key person in translating the QUALID scale and for always being interested in and supportive about my work.

- my co-author Jurate Saltyte-Benth for solving statistical challenges. 
- AFS-SI for initiating the project and hosting me as a PhD student. Thanks to Susan Juell, leader of the Old Age Department at Innlandet Hospital Trust, for recruiting me into research as a research assistant back in 2005. A special thanks to manager Birger Lillesveen for encouraging me to start this PhD project and for all the support throughout the process.

- all my colleagues at AFS-SI who all have given attention and encouraging support to my work. A particular gratitude to research assistant Merete Unhjem Andreassen for teaching me and supporting me in producing CRFs in the TeleForm programme and to Tom Borza, my research fellow across the corridor, for going up the track - you two just fix everything in a flash and always with a smile!

- Anne Marie Mork Rokstad for introducing me to the philosophy of person centred care, for inspiration and encouragement during the project.

- several brilliant librarians! To those who answer E-mails at Sykehuset Innlandet, to Vigdis Knutsen at the Norwegian National Advisory Unit of Aging and Health that always quickly sent me copies of papers that I requested, and to Monica Stolt Pedersen, without you I would get lost in the search for literature in the beginning of this work, and I definitely would had mess it up with the references at the end! Every day should be a hug-a-librarian-day!

- the Research Council of Norway for funding this PhD project. I feel privileged.

- last, but not least - to my family and friends for asking me about my work and caring about keeping my social life alive. I feel rich - a warm hug to all of you! 


\section{Summary}

One of the most important goals in caring for people living with dementia is to sustain or increase their experience of quality of life. Paying attention to the factors that influence the personal and emotional experiences of having dementia is important in the planning and delivering of care for people with dementia.

The overall objective of this thesis was to explore the association between organisational, staff and patient characteristics, person-centred care and quality of life (QoL) during the disease course of patients with dementia in Norwegian nursing homes and, by this, contribute to the planning of care and treatment for persons with dementia in the municipality.

Secondary goals were to evaluate the psychometric properties of the QoL in late-stage dementia (QUALID) scale and identify trajectories of QoL after admission to the nursing home (NH).

Four studies were conducted. To investigate the psychometric properties of the QUALID scale (Paper I), the scale was translated into Norwegian, and 169 patients were included in the validation study; an additional 53 were included in the analysis of test-retest reliability. The results suggest that the Norwegian version of the QUALID scale is a reliable (ICC 0.83) and valid (internal consistency: Cronbach's $\alpha 0.79$ ) scale for assessing QoL in nursing home patients with dementia. Even though there were modest to strong associations between QUALID and depression, NPS and ADL, the total explained variance of QUALID is $59 \%$, meaning that QUALID measures something in addition to the product of the other scales.

In Studies II and IV, the included patients were from the Resource Use and Disease Course in Dementia - Nursing Home study (REDIC-NH), and $47 \mathrm{NHs}$ in four Norwegian counties participated. A total of 696 patients were included at admission to the $\mathrm{NH}$, and they were followed every six months until death. Patients eligible for inclusion were all patients 65 years or older and younger patients with established dementia at admission. In addition, they should have an expected stay in the NH of more than four weeks, and their life expectation should be at least six weeks.

In Study II, we describe the methods and the data collection in the REDIC-NH study in detail, in addition to presenting demographic data and data on dementia and NPS from the patients at admission to NHs. The prevalence rates of dementia and NPS reported in this study may contribute to a greater understanding of the needs of $\mathrm{NH}$ patients and, thus, increase the knowledge to improve the quality of care for $\mathrm{NH}$ patients. In addition, the findings are valuable information for stakeholders and organisations when planning NH care for these patients.

In Study III, the participants were staff and leaders from 45 of the $47 \mathrm{NHs}$ where patients in the REDIC study were recruited. The NH staff that the head nurse of the NH unit regarded as familiar with the care provided and the structural and organisational conditions in the unit were considered eligible for the study. All unit leaders and $1161 \mathrm{NH}$ staff from 175 units participated in the study. A unit was defined as a group of patients living together with a common living area and having their own care staff during the day time. Data about organisational and structural factors in the $\mathrm{NH}$ at four levels were obtained: from the NH manager, from the head nurse of the $\mathrm{NH}$ unit, from the $\mathrm{NH}$ staff and from an assessment of the physical environment in the units. 
Higher levels of PCC were associated with greater job satisfaction, three years or more of healthrelated education, a lower level of quantitative demands and role conflict, a higher level of perception of mastery, empowering leadership and an innovative climate and perception of group work, in addition to the type of unit and the physical environment in the $\mathrm{NH}$ unit designed for people with dementia. SCU and staff job satisfaction explained most of the variation in PCC. This study showed an association between PCC and organisational, staff and unit characteristics in NHs, indicating that providing PCC in NH care is closely linked to how the staff experience their job situation in addition to both organisational and structural factors and the physical environment.

In Study IV, we explored the trajectories of quality of life (QoL) and its covariates in NH patients by identifying groups of patients following similar trajectories of QoL after $\mathrm{NH}$ admission, and examining which patient, staff, and organisational characteristics at baseline differed between the identified groups. We also assessed the associations between trends in QoL and the same characteristics measured at baseline and over the study period. Of the 696 patients included in Paper II, 694 patients were analysed, as two patients had missing NH data. The data from staff and leaders described in Paper III were used in the analysis.

The overall conclusion of this thesis is that the majority of the patients we followed from admission to $\mathrm{NH}$ had good QoL over the observation period of 30 months, and it is mainly the patient characteristics that influenced the QoL trajectory.

Poor patient QoL was associated with more pain, more severe dementia, more affective symptoms, and poorer staff job satisfaction at baseline, as well as more pain, poorer ADL function, and more severe NPS measured concurrently throughout the first 30 months after admission/follow-up period.

Even though our study failed to find a significant association between patient QoL and PCC, we found an association between patient QoL and staff job satisfaction, which is worth noticing. The degree of PCC in the unit was clearly associated with several staff variables, such as three years or more of health-related education, a lower level of quantitative demands and role conflict, a higher level of perception of mastery, empowering leadership, innovative climate and perception of group work, in addition to the type of unit and the physical environment in the $\mathrm{NH}$ unit designed for people with dementia. Higher staff job satisfaction was also associated with a higher degree of PCC in the unit.

As dementia is a chronic disease, focus on symptom relief and QoL is important. To improve patients' QoL, efforts should focus on reducing pain, reducing NPS and improving ADL function for the patient, as well as improving the job satisfaction of the staff. 


\section{Sammendrag}

Å bedre eller opprettholde livskvalitet er et viktig mål for omsorg og behandling av personer med demens. Å ta hensyn til forholdene som påvirker personlige og følelsesmessige opplevelser ved å få en demenssykdom er viktig i planlegging og gjennomføring av omsorg og behandling for personer med demens.

Hovedmålet med denne avhandlingen var å undersøke sammenhengen mellom organisatoriske- og strukturelle faktorer i sykehjem, egenskaper ved personalet, egenskaper ved personer med demens, og endring i pasientenes livskvalitet i løpet av sykehjemsoppholdet. Forventningen var at avhandlingen kunne bidra med viktig kunnskap i planlegging av behandling og omsorg for personer med demens på sykehjem.

Et delmål ved prosjektet var å oversette og evaluere de psykometriske egenskapene til «Quality of life in late stage dementia» (QUALID) skala.

Avhandlingen består av fire studier. I studie I ble QUALID skalaen oversatt til norsk, og validiteten til den norske versjonen av QUALID ble testet hos 169 pasienter, mens test-retest reliabiliteten ble unders $\varnothing \mathrm{kt}$ hos 53 pasienter. Den norske versjonen av QUALID viste seg å være valid (Cronbach's alpha 0,79$)$ og reliabel $(I C C 0,83)$ til å måle livskvalitet hos personer med demens i sykehjem. Det var moderat til stek assosiasjon mellom QUALID og depresjon, nevropsykiatriske symptomer og aktiviteter i dagliglivet. Disse faktorene forklarer til sammen 59 \% av variasjonen i QUALID-skåre, noe som indikerer at QUALID måler noe i tillegg til summen av de andre skalaene.

I studie II og IV brukte vi data fra "the Resource and Disease Course in dementia - Nursing Home study» (REDIC-NH) hvor 696 pasienter fra 47 sykehjem i fire fylker ble inkludert. Pasientene ble inkludert ved innleggelse i sykehjem og ble kartlagt hver sjette måned fram til død.

Inklusjonskriterier var alle pasienter over 65 år, samt yngre pasienter med demensdiagnose ved innleggelse. Pasientene skulle ha et forventet opphold på mer enn fire uker i sykehjem, og en forventet overlevelse på mer enn seks uker.

I studie II ble metode og datainnsamling i REDIC-NH studien detaljert beskrevet, og noen baselinedata, demografiske opplysninger, data om demens og nevropsykiatriske symptom hos pasientene ved innleggelse i sykehjem ble presentert. Resultatene i denne studien bidrar til $\varnothing \mathrm{kt}$ forståelse av behovene til sykehjemspasienter, og kan derfor føre til bedre kvalitet på helse- og omsorgstilbudet i sykehjem. Dette vil kunne gi nyttig informasjon til planleggere og beslutningstakere i planlegging, bygging og drift av sykehjem.

Studie III så på sammenhengen mellom personsentrert omsorg (PSO) og organisatoriske faktorer ved sykehjemmet. Pleiere og ledere fra 45 av de 47 sykehjemmene i REDIC-NH ble inkludert. Personalet, som leder for enheten mente hadde god kjennskap til strukturelle og organisatoriske forhold i enheten, ble spurt om å delta i studien. Data om strukturelle- og organisatoriske forhold $\mathrm{i}$ sykehjemmet ble innhentet fra sykehjemsleder, enhetsleder, pleiepersonalet, og gjennom en kartlegging av de fysiske omgivelsene. 
Vi fant at høyere grad av PSO var assosiert med bedre jobbtilfredshet hos personalet, tre år eller mer helse-relatert utdanning, lavere grad av kvantitative jobbkrav og rollekonflikt, høyere grad av mestring, bemyndigende ledelse, innovativt klima og opplevelse av gruppearbeid, i tillegg til enhetstype (regulær eller skjermet) og at fysiske omgivelser i sykehjemmet var tilpasset personer med demens. Skjermet enhet og jobbtilfredshet forklarte det meste av variasjonen i PSO. Studien viste en assosiasjon mellom PSO og organisatoriske-, personal- og enhetskarakteristika, noe som indikerer at å gi god PSO i sykehjem har nær sammenheng med hvordan personalet opplever sin jobbsituasjon, i tillegg til organisatoriske og strukturelle forhold inkludert fysiske omgivelser.

I studie IV unders $\varnothing$ kte vi utvikling av livskvalitet hos pasientene over tid, og definerte tre grupper pasienter med distinkte livskvalitetsforløp etter innleggelse i sykehjem. Videre unders $\varnothing$ kte vi assosiasjonen mellom gruppenes pasient-, personal- og organisatoriske forhold ved baseline og gjennom studieperioden, og livskvalitet ved baseline og gjennom oppholdet på sykehjemmet. Data fra sykehjem manglet for to pasienter, så 694 av de 696 pasientene som er beskrevet i studie II er med $\mathrm{i}$ analysene i studie IV. Redusert livskvalitet var assosiert med mer smerte, alvorligere grad av demens, og mer affektive symptomer hos pasientene, og dårligere jobbtilfredshet hos personalet ved baseline, i tillegg til mer smerte, dårligere ADL-funksjon og alvorligere grad av nevropsykiatriske symptom hos pasientene målt samtidig underveis de første 30 månedene etter innleggelse $i$ sykehjem.

Hovedkonklusjonen i avhandlingen er at de fleste av pasientene vi fulgte fra innleggelse i sykehjem hadde god livskvalitet, og at det i størst grad er forhold hos pasienten selv som påvirker livskvaliteten.

Selv om studien ikke kunne påvise en assosiasjon mellom pasientens livskvalitet og graden av PSO, så fant vi en assosiasjon mellom pasientens livskvalitet og personalets jobbtilfredshet som er verdt å legge merke til. Bedre jobb tilfredshet var også assosiert med høyere grad av PSO i sykehjemsenheten.

Demens er en kronisk sykdom og fokus på å redusere symptom og øke livskvalitet er viktig. $\AA$ redusere smerte og nevropsykiatriske symptom og legge forholdene til rette for å bedre ADL funksjonen for pasienten er viktige tiltak for å bedre pasientens livskvalitet, i tillegg til å øke jobbtilfredsheten for personalet. 


\section{List of papers}

I Roen, I., Selbaek, G., Kirkevold, O., Engedal, K., Lerdal, A., \& Bergh, S. (2015). The Reliability and Validity of the Norwegian Version of the Quality of Life in Late-Stage Dementia Scale. Dement Geriatr Cogn Disord, 40(3-4), 233-242. doi:10.1159/000437093

II Roen, I., Selbaek, G., Kirkevold, O., Engedal, K., Testad, I., \& Bergh, S. (2017). Resource Use and Disease Couse in dementia - Nursing Home (REDIC-NH), a longitudinal cohort study; design and patient characteristics at admission to Norwegian nursing homes. BMC Health Serv Res, 17(1), 365. doi:10.1186/s12913-017-2289-x

III Roen, I., Kirkevold, O., Testad, I., Selbaek, G., Engedal, K., \& Bergh, S. (2017). Personcentered care in Norwegian nursing homes and its relation to organizational factors and staff characteristics: a cross-sectional survey. Int Psychogeriatr, 1-12.

doi:10.1017/s1041610217002708

IV Roen, I., Benth, J S., Kirkevold, O., Testad, I., Selbaek, G., Engedal, K., \& Bergh, S. Exploring the trajectories of Quality of Life and its covariates in nursing home patients: A longitudinal study. Submitted, 2018. 



\section{Abbreviations}

$A D$

CDR

CMAI

CSDD

DCM

DSM-5

FTD

GMHR

GP

ICD-10 International Statistical Classification of Diseases and Related Health Problems, 10th revision

LBD

$\mathrm{MCl}$

MMC

MOBID-2

$\mathrm{NH}$

NPI

NPS

P-CAT

PCC

PDD

PSMS

QoC

QoL

QPS-Nordic

QUALID

Alzheimer's disease

Clinical Dementia Rating Scale

Cohen-Mansfield Agitation Inventory

Cornell Scale for Depression in Dementia

Dementia Care Mapping

Diagnostic and Statistical Manual of Mental Disorders, fifth edition

Fronto-temporal dementia

General Medical Health Rating Scale

general practitioner

Lewy body dementia

Mild cognitive impairment

Marte Meo counselling

Mobilization-Observation-Behaviour-Intensity-Dementia Pain Scale

nursing home

Neuropsychiatric Inventory

neuropsychiatric symptoms

Person-Centred Care Assessment Tool

person centred care

Parkinson's disease dementia

Physical Self-Maintenance Scale

quality of care

quality of life

General Nordic Questionnaire for Psychosocial and Social Factors at Work Quality of Life in Late-Stage Dementia Scale 
REDIC Resource Use and Disease Course in Dementia

RN registered nurse

RU regular units

SCU special care units

SCUEQS Special Care Unit Environmental Quality Scale

SMTD Structured milieu therapy for people with dementia

TESS-NH Therapeutic Environment Screening Survey for Nursing Homes

VaD vascular dementia

VAS Visual Analogue Scale

VPM VIPS practice model 


\section{Introduction}

\section{Brief presentation of the thesis}

To date, there is no cure for any of the brain disorders causing dementia, and attention to the factors that influence the personal and emotional experience of having dementia is important for planning and delivering care for people living with dementia.

There are approximately 36 million people living with dementia in the world today (35.6 million in 2010, according to Prince), a number expecting to double every 20 years; in 2050, it is estimated that almost 132 million people will have dementia (Prince et al., 2013). In Norway, approximately 80,000 persons are living with dementia (Godager \& Thorjussen, 2016; Prince et al., 2013), and approximately 10,000 persons develop dementia each year (Engedal, Haugen, Brækhus, \& Nasjonal kompetansetjeneste for aldring og, 2018).

During the course of the dementia, the person will have an increasing need for help and assistance in his or her daily life, first as home-based care and in the end as institutional care. In Norway, institutional care will usually be through an admission to a nursing home (NH).

The focus of this thesis is the associations between organisational characteristics of the Norwegian $\mathrm{NH}$, staff characteristics and individual patient characteristics including the quality of life (QoL) for the patients. Gaining knowledge about the factors associated with the QoL of people with dementia, especially for people recently admitted to nursing homes, is important, and finding variables associated with a change in QoL of people with dementia is essential to developing interventions aiming to improve the QoL.

A longitudinal design was chosen for the study, as a longitudinal design gives the possibility to analyse the stability of associations over time and, to some degree, see the direction of associations.

This PhD thesis provides new knowledge and useful information that is important for creating better care for persons with dementia, which should be given attention when planning nursing home care.

\section{Origins of the thesis}

In 2010, the Centre for Old Age Psychiatric Research, Innlandet Hospital Trust, where I was working as a project coordinator, received an assignment from the Norwegian Directorate of Health to design a project aiming to evaluate the use of health and social services in healthcare and the extent of informal help that is provided to persons with dementia, in order to provide an estimate of the costs of dementia-related illness in Norway and identify factors predicting resource use and costs. Therefore, the project Resource Use and Disease Course in Dementia (REDIC) was founded, and a total of 5,630 persons were included in the project. Of those, 696 persons were included at admission to a nursing home. I was employed to coordinate the data collection in the nursing home part of the REDIC project when the idea of doing a PhD study connected to the project came up. A project plan was developed and sent to the Research Council of Norway, which granted the project. 
The research project described in this thesis shares some aims with the REDIC project: to develop knowledge that may improve the QoL of people with dementia.

The structure of the thesis

This thesis has the following structure: Chapter 2.1 provides information about how Norwegian nursing homes are organised, both in terms of the staff and the physical environment of the $\mathrm{NH}$. Chapter 2.2 describes the ageing population in the world, which will influence the need for healthcare services in the future. In Chapter 2.3, cognitive decline and dementia is described before the main themes of Papers III and IV, person-centred care and quality of life, are discussed in Chapter 2.4 and 2.5, respectively. In Chapter 3, the aims of the thesis are described, and the main results from the studies included in the thesis are described in Chapter 5. Chapter 6 contains the discussion, first methodological considerations in Chapter 6.1 and then discussion of the results and clinical implications in Chapter 6.2. Conclusions are disclosed in Chapter 7, and finally, Chapter 8 gives the reference list. 


\section{Background}

This thesis is about how organisational characteristics in nursing homes are associated with staff characteristics and individual patient characteristics during the course of the dementia.

\subsection{Nursing Home Care in Norway}

The healthcare services for elderly people in Norway are public, and the jurisdiction lies within the local municipalities. They include social services (such as housing and home services), in-home nursing and institutional care (mainly in nursing homes $(\mathrm{NHs})$ ). The institutions provide both longand short-term care and rehabilitation. All Norwegian municipalities have NHs, and the total number of places (beds) in Norway is about 39,000 . About $90 \%$ of the municipalities have special care units for people with dementia, covering about $25 \%$ of the total number of beds in NHs (Gjøra, Eek, \& Kirkevold, 2015). Most of the NHs in Norway are funded by the local municipalities, thus financially covered by the tax system. Although all Norwegians have access to healthcare regardless of their economic situation, persons in NHs pay for non-medical services, such as hairdressing and chiropody. Approximately $84 \%$ of the patients in in long-term stay in NHs have dementia, and most of them are living in regular units that are not specialised for people with dementia (Helvik, Engedal, Benth, \& Selbaek, 2015; Selbaek, Kirkevold, \& Engedal, 2007). Persons admitted to NHs without dementia have other diseases or chronic conditions that would cause the need for $\mathrm{NH}$ admission. They are often younger persons with chronic conditions, persons with end-stage diseases or patients staying short-term for rehabilitation or respite care (Vossius, Selbæk, Benth, \& Bergh, 2018; Vossius et al., 2015).

When the first NHs were built in the 1950s, developed from the earlier poorhouse tradition, the purpose of the NH was to be a place for older people to live or as housing (Daatland \& Gottschalk, 2000). Since then, many reforms have been carried out, and the responsibility for the NHs moved from the municipalities to the counties in 1969 and back to the municipalities in 1988. The focus for the NHs has shifted from housing, to a place for active treatment and to today's idea as a home for patients (Helse- og omsorgstjenesteloven, 2011). The Municipalities' Health Services Act outlines the responsibility of the NHs for diagnosis and treatment of illness, rehabilitation and care for patients (Helse- og omsorgstjenesteloven, 2011). In addition to The Municipalities' Health Services Act, the provision of care in the NH is regulated by the Regulation of Quality of Care (Kvalitetsforskriften, 2003) and The Guarantee of Dignity (Verdighetsgarantien, 2011), comprising two pages of text that are easy-to-read and understand. They focus particularly on the patients' rights to plan their day-to-day lives in the $\mathrm{NH}$, ensuring that the basic needs of the patient are satisfied, such as psychological needs, preservation of dignity and self-respect, choice within daily routine and physical and social needs. The Norwegian government has also introduced several white papers and plans aiming to increase the quality of care (Helse- og omsorgsdepartementet, 2007, 2015; Meld.St. nr. 29, 2013; St.meld. nr. 25 (2005-2006), 2006). The purpose of these plans is to ensure that care for the elderly is organised in a way that contributes to dignified, meaningful and secure ageing. A recent study investigating care practice to gain a deeper understanding of the difficulties of implementing new regulations in $\mathrm{NH}$ found that the staff knew little about the quality regulations, and that the quality of their work was guided by other factors in their nursing practice (Sandvoll, Kristoffersen, \& Hauge, 2012). The staff appeared to be committed to daily routines and 
seemed to know what to do. The authors stated that a combination of having routines and always knowing what to do made daily nursing care become a "taken-for-granted activity". They concluded that nursing practices are strongly embedded, new regulations are challenging to implement and improving practice requires systematic and deeply rooted practical changes in everyday action and thinking (Sandvoll et al., 2012).

There are several types of units in Norwegian nursing homes, such as long-time stay or regular units (RU) for persons who need 24-hour care for the rest of their lives and special care units for persons with dementia (SCU), which consist of units or wards that offer services specially adapted for persons with dementia. In 2014, about $25 \%$ of the beds in Norwegian NH were SCUs (Gjøra et al., 2015). The SCUs usually have fewer beds than RUs and often have a higher staff/patient ratio (better staffing). In addition, the staff often has more education in dementia care. Most NHs also has rehabilitative/short time stay/respite care units, and some $\mathrm{NHs}$ also have palliative/hospice care units.

Patients live, on average, 2.2 years in a Norwegian NH (Vossius et al., 2018), and elderly patients die more often in NHs than in hospitals (Mørk et al., 2017). Dementia is one of the main causes for admission to long-term units in a nursing home (Wergeland, Selbaek, Bergh, Soederhamn, \& Kirkevold, 2015), and more than $84 \%$ of people receiving $\mathrm{NH}$ care in Norway have dementia (Helvik et al., 2015).

\subsubsection{Organisational and staff characteristics of the nursing homes}

Since the 1990s, the treatment approach in dementia care has shifted from a mostly one-sided pharmacological treatment to a more psychosocial approach.

In this thesis, an important aim was to look at the influence of organisational factors on personcentred care (PCC) and quality of life (QoL). Thus, three important organisational characteristics in Norwegian NHs will be described: leadership, nursing home staff and the physical environment of the nursing homes.

\section{Leadership}

Leadership is one of the factors that exhibit certain variations in Norwegian nursing homes. The legislation says that a registered nurse (RN) must be responsible for the NH (Forskrift for sykehjem m.v., 1988). However, it is not stated how many patients can be under the responsibility of one RN. In some NHs, the care is the responsibility of the ward nurse, whilst in other places, it is the responsibility of the manager of the $\mathrm{NH}$. There are also variations in the number of administrative tasks that are assigned to the RN responsible for the nurse services; nevertheless, this individual is usually also the unit's administrative leader.

\section{Nursing home staff}

In Norway, it is mandatory for all NHs to have a physician be responsible for the medical examinations, diagnoses and treatment, whereas a registered nurse (RN) is responsible for the medical care and nursing (Forskrift for sykehjem m.v., 1988).

The rest of the NH staff are, for the most part, registered nurses, assistant nurses and unlicensed healthcare workers, which will be denoted as nursing home staff (NH staff) throughout this thesis. 
The mean number of full-time staff per patient in Norwegian NHs is 1.0 (SD 0.3) (Vossius et al., 2015). Nursing home physicians provide medical care, and a recent report showed that the mean number of doctor minutes/NH patient per week was 23 (SD 15) (Vossius et al., 2015).

The NH staff educational level is as follows: assistants with no formal health education; auxiliary nurses with two years of vocational education; and RNs with three years of college- or universitylevel education. A large proportion of the NH staff work part-time. Some studies have looked at the proportion of RNs, auxiliary nurses and assistants: Between $25-30 \%$ of the staff are RNs, more than $60 \%$ auxiliary are nurses and the rest are assistants (Gjøra et al., 2015; O. Kirkevold \& Engedal, 2006; $\varnothing$. Kirkevold, Eek, \& Engedal, 2012).

Only very few NHs in Norway have a physician employed in a full-time position. More often, a general practitioner (GP) is paid for a few hours a week to visit the $\mathrm{NH}$ once a week and/or on request. However, there has been a change in recent years towards more NH physicians in full-time positions, resulting in a quite large variation between $\mathrm{NHs}$.

\section{The physical environment of the nursing homes}

It is well known that the physical environment of the $\mathrm{NH}$ impacts the well-being of the patients and the work satisfaction of the nursing staff (Calkins, 2018; Chaudhury, Cooke, Cowie, \& Razaghi, 2018; Haugan, Woods, Høyland, \& Kirkevold, 2015). In 1861, Florence Nightingale explained that a good and well-designed physical environment promoted health and patient safety, including air quality, temperature, light and psychosocial features, such as scenic views and the proximity of staff and patients (Nightingale, 1992).

The physical environment of the NH covers a variety of characteristics, such as the architecture of the $\mathrm{NH}$ units, access to a garden and outdoor activities, visual and auditory noise and colours on the walls. The importance of the physical environment has been increasingly recognised as a therapeutic resource in $\mathrm{NHs}$, and a recent literature review concluded that the physical environment of care settings is important in improving the patients' QoL and in improving quality of care (QoC) practices (Chaudhury et al., 2018).

In the 1960s and 1970s, when a lot of Norwegian NHs were built, they were usually built as NHs with large wards with up to 20-30 patients, most of whom were often accommodated in rooms with two or more patients. In 2003, the regulations changed, and all patients should be offered a single bedroom (Kvalitetsforskriften, 2003). Later, through a new regulation, the government decided to fund only small NH wards that are designed for people with dementia (Husbanken, 2018). In the big cities and urban areas of Norway, even new NHs with smaller units are often built with several floors, giving the patients little access to gardens and parks on the ground floor, whilst in the rural areas, the NHs are smaller with better access to the ground floor and outdoor activities.

As described, $\mathrm{NHs}$ from different time periods are quite different from each other, but the government, through their regulations and funding when re-furnishing old $\mathrm{NHs}$, are trying to encourage the construction of more dementia-friendly $\mathrm{NHs}$.

Based on clinical experiences, evidence-based information and the fact that $\mathrm{NH}$ have had an increasing proportion of patients with dementia, it has been a slow change from large hospital-like wards to more "home-like" smaller units (typically 8-12 beds). However, there is still a way to go. 
Even though most new NH units now have less than 16 beds, they are often clustered in large institutional buildings and the "home-likeness" of the units can be debated.

Recent reviews about the physical environment have supported functional abilities, meaningful relationships and high QoL for people living with dementia (Calkins, 2018); therefore, it must be designed to support a care philosophy where the relationship between the nurse and the patient prevails (Haugan et al., 2015).

\subsection{Demographic changes - the ageing population}

The world's population is experiencing demographic changes. Over the next 25 years, the number of people age 60 years and above will reach 1.25 billion, which is expected to be $22 \%$ of the total population in the world (Prince et al., 2013).

In Norway, there are approximately 875,000 people over the age of 65 , about $16.6 \%$ of the Norwegian population. The number of people over 65 years of age is expected to be 1,415,000 in 2040, which will be $22.4 \%$ of the total population (Rogne, Syse, \& Statistisk Sentralbyrå, 2017).

The prevalence of dementia increases with increasing age, and the worldwide prevalence of dementia is estimated to reach 65.7 million by the year 2030 (Prince et al., 2013). In Norway, the number of people with dementia was estimated to be $78,000,1.5 \%$ of the total population, in 2016 (Vossius et al., 2015).

\subsection{Cognitive impairment and dementia}

Cognition includes the ability to learn, solve problems, remember and use stored information in a useful way, which are important skills for maintaining good health and successful ageing (see definition of cognition on page 26). A variety of diseases affect cognition, and many of the diseases are associated with age.

Dementia is not a specific disease, but an overall term that describes a variety of symptoms associated with a decline in cognition that reduces a person's ability to perform everyday activities. Dementia symptoms are often categorised into cognitive symptoms, neuropsychiatric symptoms and motor symptoms. Cognitive symptoms can have a series of causes and can be treatable, stable or progressive, depending on the causes of the disease. Possibly treatable cognitive symptoms can be caused by normal pressure hydrocephalus, subdural hematoma or depression. Irreversible and progressive dementia symptoms can be caused by many different diseases, and Alzheimer's disease $(A D)$, vascular dementia (VaD), Lewy body dementia (LBD) and fronto-temporal dementia (FTD) are the most common.

\subsubsection{Mild cognitive impairment (MCI), definition and prevalence}

$\mathrm{MCl}$ describes the intermediate stage between normal cognitive function and dementia and covers a range of diseases impairing both memory and other cognitive domains (Morley et al., 2015; Roberts \& Knopman, 2013). There are different diagnostic criteria for $\mathrm{MCl}$ depending on the culture and tradition, but amongst the most used in Norway are the Winblad criteria (see Text Box 1). MCl has several risk factors, both non-modifiable such as age, male gender and genetic factors, and modifiable such as level of education, vascular risk factors and cardiovascular diseases (Roberts \& Knopman, 2013). A clinical presentation of $\mathrm{MCl}$ with memory problems is characterised as amnestic $\mathrm{MCl}(\mathrm{aMCl})$, whilst $\mathrm{MCl}$ with problems in one or more cognitive domains other than memory is 
characterised as non-amnestic $\mathrm{MCl}$ (naMCl) (Petersen, 2016; Roberts \& Knopman, 2013). Persons with $\mathrm{MCl}$, especially $\mathrm{aMCl}$, are more likely to develop dementia than people without $\mathrm{MCl}$ (Mitchell \& Shiri-Feshki, 2009). Several studies have investigated the prevalence of $\mathrm{MCl}$, and in review papers, the estimates have differed depending on the definition of $\mathrm{MCl}$ and the cohort studied. The overall prevalence has been reported to be between $12 \%$ and $18 \%$ in persons 60 years and above (Petersen, 2016), between $10 \%$ and $20 \%$ after the age of 65 (Langa \& Levine, 2014) and $16 \%$ in persons over 70 years (Morley et al., 2015).

\section{Text box 1. Winblad diagnostic criteria $\mathrm{MCl}$}

Not normal, not demented (Does not meet criteria (DSM IV, ICD 10) for a dementia syndrome) Cognitive decline

- Self and/or informant report and impairment on objective cognitive tasks and/or

- Evidence of decline over time on objective cognitive tasks and/or Preserved basic activities of daily living/minimal impairment in complex instrumental functions

\subsubsection{Dementia, definition and prevalence}

Dementia is a chronic and irreversible syndrome that includes cognitive impairment, reduced ability in daily life functioning compared to earlier and changes in social functioning. Several underlying diseases may lead to dementia. Reduced memory is often the first cognitive symptom, followed by impaired orientation, reasoning, spatial orientation and language problems. Nevertheless, the pace of symptoms; onset, sudden vs gradual; and progression decline over months or years are connected to the underlying disease (Gale, Acar, \& Daffner, 2018). During the course of the dementia, nearly all patients develop neuropsychiatric symptoms (NPS), such as irritability, depression, changes in personality and motor symptoms (Selbaek, Engedal, Benth, \& Bergh, 2014). The occurrence of different cognitive symptoms will vary from patient to patient, depending on the type of dementia and the severity of the dementia. For example, in some people with frontotemporal dementia (FTD), memory may be intact in an early phase of the disease and changes of behaviour are the hallmark (Prince et al., 2013). However, this is not true for all people with FTD, see Chapter 2.3.4.4.

In this thesis, the ICD-10 criteria for dementia have been applied. According to these criteria, dementia can be divided into three stages: mild, moderate and severe (World Health Organization (WHO), 1993). In mild dementia, the person's memory loss and decline in cognitive functions affect the person's capacity to cope with everyday activities, but the person is still mostly independent of help from others. In moderate dementia, the person's memory loss or decline in cognitive functions makes the person depend on help for most tasks aside from the most basic activities, and the person with dementia cannot live independently. In severe dementia, the person will no longer be able to retain new information, often failing to recognise even close relatives, and continuous care is required (World Health Organization (WHO), 1993). With the introduction of the ICD-11 in June 2018, these criteria are to be changed. See Chapter 2.3.3 for more details.

The prevalence of dementia increases with increasing age, and age-specific prevalence rates for dementia in Europe increase from $1.6 \%$ in the $60-64$ age group to $21.7 \%$ in the $85-89$ age group and to $43.1 \%$ in the $90+$ age group (Prince et al., 2013). The number of people with dementia in Norway in 2016 was estimated to be $78,000,1.5 \%$ of the total population (Vossius et al., 2015). However, this number should be interpreted with caution because good-quality research on prevalence of dementia in Norway has not been performed (Strand et al., 2014). Recent studies have suggested 
that the prevalence of dementia has been changing over time, as age-specific prevalence and incidence of dementia might have decreased over the two last decades (Matthews et al., 2016), and some dementia diseases can be prevented through truly modifiable lifestyle factors (Di Marco et al., 2014). Although the prevalence of dementia is decreasing, as the ageing population increase throughout the world, the number of people with dementia is expected to double within the next 20 years.

\subsubsection{Diagnose/diagnostic criteria of dementia}

A dementia diagnosis is based on the presence of defined symptoms and signs and the absence of other diseases with similar symptoms. Usually, dementia is diagnosed using one of the following international recognised sets of criteria:

- The International Statistical Classification of Diseases and Related Health Problems, $10^{\text {th }}$ revision (ICD-10) Version 1993 (World Health Organization (WHO), 1993).

- The Diagnostic and Statistical Manual of Mental Disorders, fifth edition (DSM-5) (American Psychiatric Association \& American Psychiatric Association DSM Task Force, 2013).

In Norway, dementia is generally diagnosed according to the ICD-10 criteria, which will gradually be replaced by the ICD-11 criteria once they are translated into Norwegian and implemented in the healthcare system. The ICD-10 criteria were used in the studies in this thesis and in clinical practice in Norway at the time this thesis was written. Therefore, the main focus in this thesis is the ICD-10 criteria, but they will be compared to the DSM- 5 and the ICD-11 criteria.

The diagnostic procedure contains two stages. First, the dementia syndrome is diagnosed according to standardised criteria, and then the specific disease causing the dementia syndrome is diagnosed. Dementia according to the ICD-10 criteria is categorised as a mental and behavioural disorder, and the dementia syndrome includes the following criteria:

I. Both of the following:

1. Memory impairment, especially for new information

2. Impairment of other cognitive functions (judgement, planning, thinking, abstraction)

Mild: Affects the person's capacity to cope with everyday activities but not so severe as to be incompatible with independent living

Moderate: The person cannot live independently

Severe: Continuous care is required

II. Clear consciousness

III. Impairment in emotional control or motivation, or change in social behaviour in at least one of the following:

1. Emotional instability

2. Irritability

3. Apathy

4. Coarsening of social behaviour

IV. A duration of at least six months 
The DSM-5 was published in 2013 and replaced the term dementia with major and mild neurocognitive disorder ( $N C D$ ), attempting to reduce the stigma associated with the word dementia. The core feature of neurocognitive disorder is a cognitive decline in one or more cognitive domains, based on a concern about cognitive decline from the patient or others, and performance in an objective assessment lower than expected, focusing on a decline in function rather than a deficit. The DSM-5 distinguishes between major and mild NCD related to the degree of cognitive deficit interfering with independence. People with major NCD need assistance, whilst those with mild NCD may live independently. This categorisation highlights the importance of assessing the person's cognitive abilities as well as their ADL function.

The criteria in the previous DSM-IV and the ICD-10 were quite similar for dementia and cognitive decline, but the new DSM-5 is different from the ICD-10. With the introduction of the DSM-5, more biomarkers were introduced in the diagnostic criteria for neurocognitive disorders, especially in the diagnosis of etiological diseases as Alzheimer's disease, whilst the ICD-10 criteria place a greater emphasis on clinical symptoms. The main change in the DSM-5 compared to the DSM-IV in terms of cognitive decline and dementia was the introduction of mild and major neurocognitive disorder, replacing the previous terms "amnestic disorders" and "dementia". A Norwegian study from 2008 comparing the criteria for diagnosing dementia in the Norwegian-translated version of the ICD-10 and the DSM-IV criteria in a geriatric outpatient population found an excellent agreement between the two sets of criteria (Naik \& Nygaard, 2008).

The diagnostic criteria for major neurocognitive disorder according to the DSM-5 are as follows:

A. Evidence of significant cognitive decline from a previous level of performance in one or more cognitive domains (complex attention, executive function, learning and memory, language, perceptual-motor, social cognition) based on:

a. Concern from the individual, a knowledgeable informant, or the clinician that there has been a significant decline in cognitive function; and

b. A substantial impairment in cognitive performance, preferably documented by standardised neuropsychological testing or, in its absence, another qualified clinical assessment.

The cognitive deficits interfere with independence in everyday activities (i.e. at a minimum, requiring assistance with complex instrumental activities of daily living, such as paying bills or managing medications).

B. The cognitive deficits do not occur exclusively in the context of a delirium.

C. The cognitive deficits are not better explained by another mental disorder (e.g. major depressive disorder, schizophrenia) (American Psychiatric Association \& American Psychiatric Association DSM Task Force, 2013).

With the introduction of the ICD-11 criteria in June 2018, there are some small but important changes in the diagnosis of neurocognitive disorders, $\mathrm{MCl}$ and dementia. In the ICD-11, mild neurocognitive disorder has been introduced, characterised by a subjective experience of cognitive decline and objective evidence of impairment in at least one cognitive domain but no interference with independence of ADL function. This will probably replace the Winblad criteria for $\mathrm{MCl}$. Dementia in the ICD-11 criteria is defined as a decline in two or more cognitive domains. In contrast 
to the ICD-10 criteria, impairment of memory is not a criterion in ICD-11. The cognitive impairment should interfere with the ADL function, as in the ICD-10, but the criterion of a minimum six-month duration of the cognitive decline has been removed from the ICD-11 criteria (World Health Organization (WHO), 2018).

Further revision of the diagnostic criteria for dementia will always be necessary, as new knowledge will be discovered and announced over time. New scientific knowledge and technological advances will be included in the revision of the diagnostic criteria, reflecting the current understanding about cognitive impairment and dementia. Maybe in the future, newly developed methods for dementia diagnosis, like Magnetic Resonance Imaging (MRI), Positron Emission Tomography (PET) and biomarkers in blood and cerebrospinal fluid, will define the revised diagnostic criteria, which will be even more based on biology than the DSM- 5 criteria are today.

Diagnosing dementia can be realised by a general practitioner (GP), at a memory clinic or at another specialised geriatric, neurological or old age psychiatry outpatient clinics. In Norway, it is recommended that elderly people with an uncomplicated development of symptoms and wellrecognised symptoms of dementia should be diagnosed by a GP, whilst younger people and persons with fast development of symptoms or unclear symptoms should be referred to specialised units (Helsedirektoratet, 2017).

\subsubsection{Dementia types}

Dementia may be caused by different diseases and injuries affecting the brain, the most prevalent of which being Alzheimer's disease ( $A D)$, vascular dementia (VaD), mixed $A D / V a D$, fronto-temporal dementia (FTD), Lewy body dementia (LBD)/Parkinson's disease dementia (PDD) and secondary dementias as caused by, for example, alcohol abuse (Gale et al., 2018; Prince et al., 2013). These are described below.

\subsubsection{Alzheimer's disease}

Alzheimer's disease (AD) is the most common disease causing dementia from middle age to the elderly (Gale et al., 2018). About $60 \%$ of people with dementia have $A D$, a neurodegenerative disorder characterised by amyloid plaques and neurofibrillary tangles leading to death of brain cells. The mechanisms behind the neurodegeneration are not fully understood, but several risk factors for developing $A D$ are known. The most important is ageing; higher age leads to a higher risk for AD. Several lifestyle risk factors for AD have been identified, such as obesity, hypertension, diabetes, hypertension and vascular disorders, in addition to a low level of education, poor physical activity and midlife depression (Livingston, Barber, et al., 2017). AD can affect all areas of the brain with functions and abilities lost as different areas are affected, but it is thought to start in the medial temporal lobe. The first symptoms of $A D$ are usually memory problems about recent events, problems with communication, apathy, problem with executive function and changes in behaviour (Galvin \& Sadowsky, 2012).

\subsubsection{Vascular dementia}

Vascular dementia $(\mathrm{VaD})$ is caused by cerebrovascular diseases, infarctions or haemorrhagic strokes and is a common cause of cognitive impairment (Gale et al., 2018). About $20 \%$ of people living with dementia have $\mathrm{VaD}$. The onset of $\mathrm{VaD}$ is often more sudden, with a stepwise decline in function compared to patients with AD. VaD most commonly occurs from blood vessel blockage or damage, leading to infarcts (strokes) or bleeding in the brain. The symptoms will depend on the location of 
the cerebrovascular disease and the number and size of the brain injuries. When the blood vessel blockage occurs over large areas, it is known as multi-infarct dementia (MID), and when the infarcts are deep in the brain (in the white matter), this is known as sub-cortical vascular dementia or Binswanger's disease. People with VaD often have difficulty with motor function, especially slow gait and poor balance, in addition to changes in cognition. Impaired judgment and impaired ability to make decisions and difficulties in planning or organising are often the initial symptoms, as opposed to the memory loss often associated with the initial symptoms of $A D$. VaD is often associated with hypertension, atherosclerosis and an inadequate blood flow to the brain. There is usually a history of cerebral vascular accidents (CVAs) with failure to fully recover afterwards, resulting in memory impairment. VaD may be accompanied by dysphasia, hemiplegia, dysphagia and/or visual impairment. People may have a combination of both $A D$ and $V a D$, called mixed dementia.

\subsubsection{Mixed Dementia}

Mixed dementia occurs in patients with a neurodegenerative disorder such as AD, Lewy body disease (LBD) or Pick body disease, in addition to a cerebrovascular disease (CVD) (Zekry, Hauw, \& Gold, 2002). AD combined with VaD is most common, followed by AD with DLB, and AD with VaD and DLB. Vascular dementia with DLB is less common (Schneider, Arvanitakis, Bang, \& Bennett, 2007). Symptoms in mixed dementia may vary depending on the type of changes there are in the brain and the regions in the brain that are affected. Recent studies have suggested that mixed dementia is more common than previously recognised, with about half of older people with dementia having pathologic evidence of more than one cause of dementia. It is also shown that the likelihood of having mixed dementia increases with age (Custodio et al., 2017).

\subsubsection{Fronto-temporal dementia}

Fronto-temporal dementia (FTD) is a common term for several degenerative brain diseases causing dementia and is one of the most common forms of early-onset dementia (before the age of 65) (Mendez, 2017; Rosness, Engedal, \& Chemali, 2016). The first symptoms of FTD are often changes in behaviour or personality followed by lack of insight, causing FTD to be mistaken for other psychiatric or neurological diseases. According to several researchers, there are two main types of FTD: behavioural variant (bvFTD), affecting more than $50 \%$ of patients; and primary progressive aphasia (PPA) (Finger, 2016). Genetic components are established risk factors for FTD, and approximately $40 \%$ of individuals with FTD have a family history of dementia (Rosness et al., 2016).

\subsubsection{Lewy body dementia/Parkinson's disease with dementia}

Lewy body dementia (LBD) is an umbrella term including two clinical diagnoses: Dementia with Lewy bodies (DLB) and Parkinson's disease dementia (PDD). DLB and PDD share the same biological process, but with different symptoms in the early stage of the disease (Jellinger, 2018). The two diagnoses are different concerning the order of onset symptoms (DLB has early dementia symptoms, whilst PDD starts with parkinsonism), but with progression of the diseases, the underlying pathological processes and the symptoms become similar and can be seen as a result of the same underlying disease instead of two different diseases (Walker, Possin, Boeve, \& Aarsland, 2015).

Lewy bodies are abnormal aggregations of the protein alpha-synuclein in neurons. When they aggregate in the brain, dementia can result. Alpha-synuclein also aggregates in the brains of people 
with PDD, in which it is accompanied by severe neuronal loss in the substantia nigra. Whilst people with DLB and PDD both have Lewy bodies, the onset of the disease is marked by motor impairment in PDD and cognitive impairment in DLB. People with DLB have early symptoms of sleep disturbances, well-formed visual hallucinations, slowness, gait imbalance or other parkinsonian movement features, which also may occur without memory impairment. People with Parkinson's disease have early motor symptoms with slowness, rigidity, tremor and changes in gait, and as the Parkinson's disease progresses, it often results in dementia.

Recent estimates suggest that DLB is responsible for $4 \%$ to $16 \%$ of cases of dementia seen in the clinic, but the true prevalence of DLB is probably higher, due to the fact that DLB can be challenging to diagnose (Vann Jones \& O'Brien, 2014).

\subsubsection{Secondary dementias}

The most common secondary dementia is $\mathrm{VaD}$, described in Chapter 2.3.4.2, but there are many other types of secondary dementias, such as alcohol-induced dementia, dementia associated with later stages of neurological diseases, dementia as a result of infectious diseases such as CreutzfeldtJakob disease and other causes as brain tumours, normal pressure hydrocephalus and traumatic lesions of the brain.

Creutzfeldt-Jakob disease: Prion diseases are very rare, impair memory and coordination and cause behaviour changes. They result from a misfolded protein (prion), which causes other proteins to malfunction throughout the brain, and may be hereditary, sporadic or caused by a known prion infection. A specific form called variant Creutzfeldt-Jakob disease is believed to be caused by consumption of products from cattle affected by mad cow disease.

Normal pressure hydrocephalus (NPH): Symptoms include walking difficulties, memory loss and urine incontinence. NPH causes less than $5 \%$ of the dementia cases. The mechanism is an impaired reabsorption of cerebrospinal fluid, and the consequent build-up of fluid in the cerebral ventricles with increasing pressure in the brain. People with a history of brain haemorrhage and meningitis are at increased risk for developing normal pressure hydrocephalus. The condition can sometimes be corrected with surgical installation of a shunt in the brain to drain excess fluid.

Alcohol-related dementia: Alcohol use has been associated with changes in cognitive function and dementia, but the relationship between alcohol use and cognitive health in general and dementia in particular is complex (Rehm et al., 2017). A recently published study, based on data from over one million patients with different dementia diagnoses, has shown that overuse of alcohol is a significant risk factor for developing dementia, especially early onset dementia (debut before 65 years of age). Of the 57,000 patients affected by early dementia, $57 \%$ were related to chronic overuse of alcohol. Overall, alcohol abuse was associated with three times' greater risk for all types of dementia (Schwarzinger, Pollock, Hasan, Dufouil, \& Rehm, 2018). Excessive use of alcohol may also cause Wernicke-Korsakoff Syndrome or Korsakoff's psychosis and, thereby, a cognitive impairment. However, a presentation of these diseases is beyond the scope of this thesis. 


\subsubsection{Symptoms of dementia}

The most characteristic symptoms of dementia are impairment in memory, language, problem solving and other cognitive skills that affect the person's ability to perform everyday activities. The symptoms that the person will experience depend, amongst other factors, on the severity of the dementia and the aetiology of the dementia, as different dementia diseases are associated with distinct patterns of symptoms. In the early phase of the disease, the different types of dementia have different patterns of symptoms, but as the disease progresses, the symptoms tend to become more global and difficult to separate between the different underlying diseases. It may be useful to categorise the symptoms of dementia into cognitive symptoms, neuropsychiatric symptoms and motor symptoms.

\subsubsection{Cognitive symptoms in dementia}

Understanding the concept of cognition is important to describe and understand cognitive impairment. Teri gives the following definition of cognition: Cognition is the foundation that underlies all daily activities, from the most basic to the most complex (Teri, McCurry, \& Logsdon, 1997). General intellectual ability, memory, language, visual-spatial skills, perception and complex problem solving are areas included in the concept of cognition, and each of these areas represents complex domains. The term memory, for example, refers to several activities as remote memory (the abilities to remember past events), recent memory (learn new information), prospective memory (remember and plan for future events), procedural memory (perform familiar activities) and incidental memory (learn without directed effort) (Teri et al., 1997). Cognitive symptoms in dementia includes impairment in all these areas of cognition, such as memory and learning impairment, deterioration in attention abilities, difficulties communicating or finding words (aphasia), difficulties with reasoning or problem solving (apraxia), problems with orientation and in handling complex tasks, problems with planning and organising (executive functions), visuospatial functioning, problems recognising and identifying objects (agnosia) and weakened intellectual abilities. The cognitive symptoms will vary depending on both the cause of dementia and the stage of dementia. For example, persons with AD will have difficulties remembering recent conversations, names or events as an early clinical symptom, whilst the first cognitive symptoms that a person with FTD will experience are often executive dysfunction.

\subsubsection{Motor symptoms in dementia}

Dementia may cause motor symptoms. To perform precise movements, the brain continuously receives a lot of information from sensory organs, giving information about where one is in the room, the position of one's joints, the direction one moves, etc. This information is processed together with information about the purpose of the movement, earlier experiences and information from the environment in which one moves. This interaction involves several parts of the brain, and motor symptoms in dementia may occur because of damage to both the cerebral cortex and the white substance. In addition to direct damage to the areas of the brain that affect motor function, it is also important to be aware that other aspects of a dementia disease can affect the ability to move. Cognitive symptoms and NPS, such as apathy and loss of initiative, can cause people to stop their habitual physical activities. Likewise, depression, feeling of shame and a desire to keep the condition hidden could lead to inactivity and isolation. Functions other than voluntary 
movement are also included in motor symptoms, such as incontinence (Gove et al., 2017) and dysphagia (Painter, Le Couteur, \& Waite, 2017) caused by damage to non-striated muscles. Motor symptoms in dementia have profound effects on the person's quality of life.

\subsubsection{Neuropsychiatric symptoms (NPS) in dementia}

Prevalence, incidence, persistence

The term neuropsychiatric symptoms (NPS), or behavioural and psychological symptoms in dementia (BPSD) as called by the International Psychogeriatric Association (IPA), describes a heterogeneous group of symptoms and signs of disturbed perception, thought content, mood and behaviours that frequently occur in patients with dementia, including psychiatric symptoms (such as delusions, hallucinations, depressive symptoms, anxiety and euphoria) and behavioural symptoms (such as agitation, aggression, apathy and disinhibition) (Selbaek, Engedal, \& Bergh, 2013). NPS are recognised as an essential part of the dementia syndrome, and almost all people with dementia will experience some type of NPS during the course of the dementia disease (Steinberg et al., 2008). Even though NPS in dementia occur regardless of the underlying cause, some types of behaviour are more common in certain types of dementia; for example, depression is more common in vascular dementia, and hallucinations are more common in Lewy body dementia than in Alzheimer's disease (Kales, Gitlin, \& Lyketsos, 2015). People with fronto-temporal dementia more often exhibit changes in behaviour, such as disinhibition, wandering, social inappropriateness and apathy. NPS occur at all stages of dementia, although their type and prominence depend on the stage (Kales et al., 2015). As dementia becomes more severe, most NPS occur more frequently (Selbaek et al., 2007), and NPS are highly prevalent in NH patients (Bergh, Engedal, Roen, \& Selbaek, 2011; Selbaek et al., 2013). Several NH studies of people with dementia have been performed, finding the same NPS pattern: aberrant motor behaviour, depression, anxiety and euphoria decline over time, psychosis remains constant and apathy, agitation, irritability and disinhibition increase over time (Selbaek et al., 2013; R. Wetzels, Zuidema, Jansen, Verhey, \& Koopmans, 2010).

There are several Norwegian studies, both cross-sectional and longitudinal, that have investigated the prevalence and course of NPS in NHs. A cross-sectional study with 1,163 NH patients of whom $81 \%$ had dementia found that $72 \%$ of the participants with dementia had clinically significant NPS, as assessed by the Neuropsychiatric Inventory (NPI). Clinically significant NPS were defined as an NPI item score of four or above (Steinberg et al., 2004). The frequencies of NPS increased with the severity of the dementia (Selbaek et al., 2007). A study from 2011 including 169 patients with dementia from seven NHs that were monitored by five NPI assessments over 16 months reported that $91.7 \%$ of the patients had at least one clinically significant NPS at one or more assessments over the study period. Irritability (63.5\%), agitation (51.0\%) and disinhibition (50.0\%) had the highest cumulative prevalence, whilst irritability (42.6\%), disinhibition (37.8\%) and depression (31.5\%) had the highest cumulative incidence. Delusion, agitation and irritability were enduring symptoms, whilst the other symptoms had high resolution rates. In this study, the severity of the NPS did not vary significantly over time (Bergh et al., 2011). A recent Norwegian study investigating the prevalence and persistence of clinically significant NPS assessed with the NPI studied the association between severity of dementia and specific NPS sub-syndromes over time in NH patients with dementia. It reported a high prevalence and persistence throughout the study period. The mean NPI agitation sub-syndrome score increased, whereas the mean NPI affective and psychosis 
sub-syndrome scores remained unchanged. More severe dementia was associated with higher NPI agitation, psychosis and affective sub-syndrome scores. For the sub-syndromes agitation and psychosis, the association remained unchanged over time, whilst the affective sub-syndrome declined over time (Helvik et al., 2016). These results are supported by a systematic review investigating prevalence and course of NPS in NH patients with dementia, including 28 studies with 8,468 and 1,458 persons participating in the prevalence and longitudinal studies, respectively. The review stated that $82 \%$ of $\mathrm{NH}$ patients had at least one NPS. Individual symptoms varied, with agitation and apathy having the highest prevalence. The persistence of individual NPS varied substantially, but having at least one NPS was highly persistent across the included studies, confirming that clinically significant NPS are common in NH patients with dementia (Selbaek et al., 2013).

In 2016, the Alzheimer's Association convened a Research Roundtable, where experts from broad fields (academia, industry, regulatory agencies) discussed the latest understanding of NPS, declaring that NPS affect almost all individuals with dementia over the course of the disease, and that although NPS fluctuate, they rarely remit completely. NPS are painful and distressing both for the person with dementia and their family, and they are associated with impairment in activities of daily living, poor quality of life, earlier institutionalisation, accelerated disease progression, increased mortality, caregiver stress and increased cost of care. The effects on both patients and caregivers are severe (Gaugler, Yu, Krichbaum, \& Wyman, 2009; Lanctot et al., 2017).

\section{Causes of NPS}

Cognitive decline caused by the dementia disease cannot alone explain how NPS develop (Kales et al., 2015; T Kitwood, 1997). Numerous factors have been identified concerning the person with dementia, the caregiver and environmental factors. This is illustrated in a model by Kales et al. (Figure 1). Factors related to the person with dementia can be due to neurological damage, acute medical conditions, unmet needs, premorbid personality and psychiatric illnesses. Factors related to the caregivers, family and/or professional can be due to stress or lack of competence. The way they treat the person with dementia can cause NPS. Environmental factors can be experienced as stressors for people with dementia due to their difficulties in processing and responding to environmental stimuli as, for example, changes in routine, too many or misleading stimuli, lack of stimuli, change in physical or social environment and demands exceeding functional ability (Kales et al., 2015). 


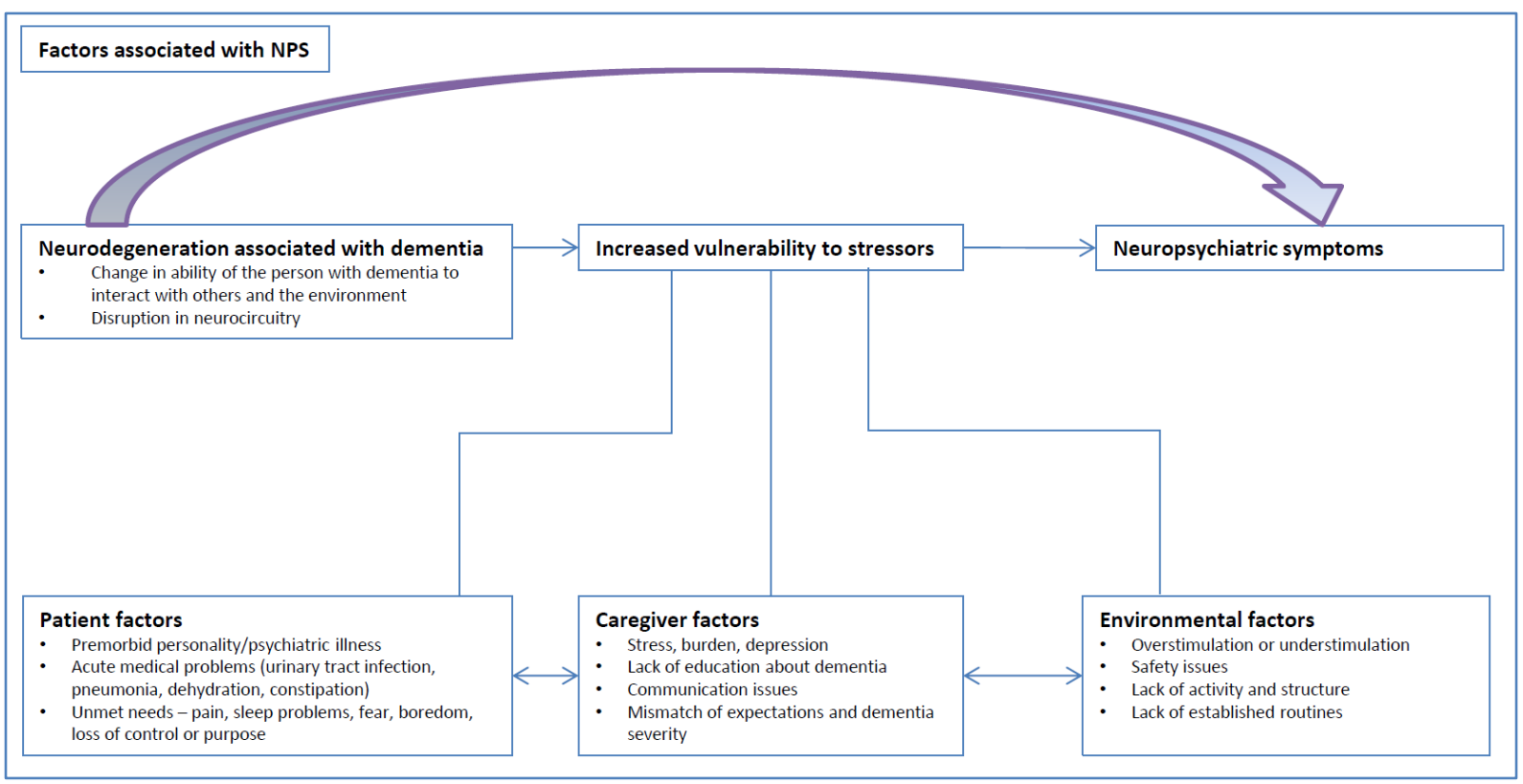

Figure 1 A conceptual model describing how interactions between the person with dementia, caregiver and environmental factors cause neuropsychiatric symptoms in dementia. Adapted from Kales (Kales et al., 2015).

\section{Assessment of NPS}

A variety of scales and tools are available to describe and document NPS. In a systematic review by Gitlin et al., 45 assessment scales with reported psychometric properties that identify NPS in people with dementia were described, showed that clinicians and researchers have a robust set of assessment tools from which to choose (Gitlin, Marx, Stanley, Hansen, \& Van Haitsma, 2014). Gitlin et al. stated that it is not possible to indicate which assessment tools are best, as the assessment tools vary considerably. The choice of an assessment tool should be based on which symptoms to assess, the setting, who to assess, how the assessment will occur and the amount of time and resources available for assessing the NPS. Assessment tools used for assessment of NPS in people with dementia in $\mathrm{NH}$ are generally based on information provided by NH staff, although proxybased information could be difficult to consider as it relies on the skills of the informant. The Neuropsychiatric Inventory (NPI) (Cummings et al., 1994), the Cohen-Mansfield Agitation Inventory (CMAI) (Cohen-Mansfield, 1996) and the Cornell Scale for Depression in Dementia (CSDD) (Alexopoulos, Abrams, Young, \& Shamoian, 1988) are examples of tools developed to assess NPS in people with dementia, and they are suitable in $\mathrm{NHs}$.

The Neuropsychiatric Inventory (NPI) is a well-established rating scale for the assessment of NPS in dementia, and it is widely used both in clinical practice and in research (Cummings et al., 1994; Selbaek \& Engedal, 2012). It was originally designed to be based on information from family carers, but this limited its clinical use in inpatient settings, and a NH version was later developed (NPI-NH) (Wood et al., 2000). NPI-NH includes 12 items of NPS: delusions, hallucinations, depression/dysphoria, anxiety, agitation/aggression, euphoria, disinhibition, irritability/lability, apathy, aberrant motor activity, sleep and night time behavioural disorders, and appetite and eating disorders. Each item is scored as present or not present during the last four weeks, and if present, the symptom is scored according to the severity (score 1-3; mild to severe) and the frequency (score 1-4; occasionally to very frequently). The severity score and frequency score are multiplied, giving an item score ranging from 0-12. Then, the 12 items are added together, giving a 
maximum score of 144 , where a higher score indicates more severe symptoms. A caregiver distress score may be additionally assigned for each item, ranging the perception of distress of each symptom from 0-5 (not at all to very severe or extreme). A brief form of the NPI, the NPIquestionnaire (NPI-Q) (Kaufer et al., 2000), has been developed to be more suitable in clinical practice.

The Cohen-Mansfield Agitation Inventory (CMAI) (Cohen-Mansfield, 1996) is a scale that systematically assesses agitation. It consists of 29 items, and each item is rated on a seven-point frequency scale from 1 (never) to 7 (several times an hour). The CMAl is rated by the caregivers, based on the occurrence of agitation in the last two weeks. The CMAI is used both for clinical assessments and in research. A short version of the CMAI, the Brief Agitation Rating Scale (BARS) (Finkel, Lyons, \& Anderson, 1993), has been developed to include the 10 most frequently occurring items from the CMAI: hitting, grabbing, pushing, pacing/aimless wandering, repetitious mannerisms, restlessness, screaming, repetitive sentences or questions, strange noises and complaining; it uses the same seven-point frequency scale in the rating. A shorter version of the BARS, including nine items but excluding the item screaming, has been translated and tested in a $\mathrm{NH}$ population in Norway. It was found to be a user-friendly version that assesses clinically relevant dimensions of agitation in dementia (Sommer \& Engedal, 2011).

The Cornell Scale for Depression in Dementia (CSDD) (Alexopoulos et al., 1988) is a widely used scale for assessing depressive symptoms in dementia in NHs. The CSDD consists of 19 items categorised in five groups: mood-related signs, behavioural disturbance, physical signs, cyclic functions and ideational disturbance. Each item is rated as absent (0), mild or intermittent (1), or severe (2), based on symptoms occurring the last week prior to the assessment, giving a score range of 0-38. The CSDD has been translated to Norwegian, tested and found valid and reliable for use both for elderly inpatients (Barca, Engedal, \& Selbaek, 2010) and outpatients (Knapskog, Barca, \& Engedal, 2011).

\subsubsection{Dementia in nursing homes in Norway}

The prevalence of dementia amongst patients in $\mathrm{NHs}$ is high. A review of 30 studies dated back to 1986 reported a median prevalence of $58.6 \%$ in the NH population (Seitz, Purandare, \& Conn, 2010). Other studies have reported an even greater prevalence of dementia in $\mathrm{NH}$, with a rate of $62 \%$ in the UK, 69.5\% in Helsinki and Finland and above 84\% in Norway (Helvik et al., 2015; HosiaRandell \& Pitkala, 2005; Matthews \& Dening, 2002).

A systematic review from 2013 reported that dementia is strongly associated with $\mathrm{NH}$ admission (Wang, Shamliyan, Talley, Ramakrishnan, \& Kane, 2013), a result supported by a later Norwegian study (Wergeland et al., 2015).

\subsubsection{Treatment of dementia}

At present, there is no cure for dementia, but there are treatment options that can relieve the neuropsychological symptoms (NPS) of dementia as well as slow the progress of the cognitive impairment in dementia. The treatment approaches for relieving the NPS could be divided into two main groups: non-pharmacologic and pharmacologic treatment (Kales et al., 2015). Nonpharmacological approaches involve psychosocial therapy, milieu therapy and person-centred care. The terms non-pharmacological and psychosocial treatment are used interchangeably (Brodaty \& Arasaratnam, 2012), and the term psychosocial approach will be used in this thesis. 
In clinical practice, treatment of dementia is quite complex, and the approach will often be a combination of medications and psychosocial approaches. Sometimes, the goal of the treatment, can achieved with a psychosocial approach or pharmacological treatment, whereas other times, there is need of a combination of the two. For example, when a person with dementia is agitated and does not want to take necessary medication (e.g. insulin), the staff uses a psychosocial approach to make the person feel safe and calm to then be able to understand and cooperate. Or, sometimes, the opposite may occur, as a person with dementia may be aggressive, agitated and uncooperative because of pain and need painkillers to be able to participate in an activity.

Based on a thorough review of the existing literature, the Norwegian Directorate of Health formulated a national guideline for treatment of dementia (Helsedirektoratet, 2017). This guideline strongly recommends the following four treatment approaches: physical activities (Forbes, Thiessen, Blake, Forbes, \& Forbes, 2013; Laver, Dyer, Whitehead, Clemson, \& Crotty, 2016), psychosocial approaches and activity (Dahm, Dalsbø, Håvelsrud, \& Reinar, 2014a, 2014b; Richter, Meyer, Mohler, \& Kopke, 2012; Woods, Aguirre, Spector, \& Orrell, 2012), environmental/psychological actions for NPS (Brasure et al., 2016; Richter et al., 2012; Spector, Revolta, \& Orrell, 2016) and day care centres (Reinar et al., 2011).

\subsubsection{Pharmacological treatment for dementia}

The effects of the most common pharmacological treatment of dementia are to prevent further cognitive decline or treat NPS. Although the Norwegian national guideline for treatment of dementia recommends pharmacological treatment for persons with dementia, the same guideline states that anti-inflammatory medication, statins, herbal products and sleeping medication are not recommended for treatment of either cognitive symptoms or NPS in persons with dementia (Helsedirektoratet, 2017).

\section{Cognitive symptoms}

Acetylcholine helps nerve cells to communicate with each other, and acetylcholinesterase inhibitors can temporarily reduce or delay the decline in cognitive functions by preventing acetylcholinesterase from breaking down acetylcholine in the brain. Donepezil (Aricept), rivastigmine (Exelon) and galantamine (Reminyl) are examples of acetylcholinesterase inhibitors used to reduce dementia symptoms in mild to moderate Alzheimer's disease (AD), Lewy body dementia (LBD), Parkinson's disease dementia (PDD) and mixed dementia. In the Norwegian national guideline for treatment of dementia, there is a weak recommendation against prescribing acetylcholinesterase inhibitors and memantine for people with $\mathrm{MCl}$, a strong recommendation for prescribing acetylcholinesterase inhibitors for people with $A D$ and mixed $A D / \mathrm{VaD}$ of a mild and moderate degree, and a weak recommendation for prescribing acetylcholinesterase inhibitors for people with $A D$ or mixed $A D / V a D$ of a severe degree. Further, there is a weak recommendation against prescribing acetylcholinesterase or memantine for people with VaD or FTD, but a weak recommendation for prescribing acetylcholinesterase for LDB and PDD (Helsedirektoratet, 2017).

\section{Motor symptoms}

Pharmacological treatment against motor symptoms caused by dementia is complicated due to anticholinergic toxicity, which increases the motor symptoms and may lead to delirium (Tune, 2001). 
In the Norwegian national guideline for treatment of dementia, there is a weak recommendation to prescribe certain psychotropic medication for the treatment of certain NPS in persons with dementia, but a special warning is given about giving medication to persons with LBD/PDD and FTD because they often do not tolerate this type of medication due to serious side effects, such as malignant neuroleptic syndrome and extrapyramidal symptoms (Helsedirektoratet, 2017).

Two types of antipsychotic medicines are licensed in Norway to treat NPS: haloperidol and risperidone. However, they are only recommended to be prescribed as a short-term treatment for people with dementia with psychosis, agitation or aggression. Although both medicines are licenced, risperidone is preferred due to the more severe adverse effects of haloperidol.

In the Norwegian national guidelines for treatment of dementia, there is a weak recommendation to prescribe antidepressants for severe depression or if depression is suspected as an underlying cause of anxiety. Otherwise, psychosocial approaches are the treatment of choice (Helsedirektoratet, 2017).

There are also certain behaviours that do not respond to pharmacological treatments, such as refusal of care, repetitive vocalisations and arguing (Gitlin, Winter, Dennis, Hodgson, \& Hauck, 2010).

\subsubsection{Psychosocial approach for treatment of dementia}

Based on the relatively moderate effects of pharmacological treatment in persons with dementia, psychosocial approaches should be the treatment of choice for cognitive symptoms, motor symptoms and NPS.

\section{Cognitive symptoms}

As described in Chapter 2.3.5.1, the cognitive symptoms in dementia include impairment in all areas of cognition, and symptoms will vary dependent on both the cause and the stage of dementia (Teri et al., 1997). The decline in cognitive function leads to loss of social functioning for the person with dementia, and the goal for the psychosocial approach for treatment of cognitive symptoms can be defined as approaches to improve the relationship between the person's cognitive status and the person's ability to adapt to the environment.

The Guideline on Supporting People with Dementia and Their Carers in Health and Social Care (The National Institute for Health and Care Excellence, 2018), which has been developed to offer advice about supporting people with dementia and their carers in health and social care, gives an overview about therapeutic interventions targeting cognitive decline in dementia. It is divided in two main groups: strategies for promoting independence (including interventions for promoting independence as communication, ADL skill training, activity planning, assistive technology, adaptive aids (including low-level technology) and environmental modifications, telecare, exercise/promoting mobility, rehabilitation programmes and combining of interventions); and maintenance of cognitive function: psychological interventions (cognitive stimulation, cognitive training and cognitive rehabilitation, reminiscence, snoezelen, validation therapy). The guideline states that there is evidence supporting the use of cognitive stimulation approaches for people with mild to moderate dementia, and that there are indications of improvements in QoL to accompany 
the improvements in cognitive function. It also points out that the largest and most successful trials highlight the importance of appropriate, respectful, person-centred carer attitudes in implementing such approaches (The National Institute for Health and Care Excellence, 2018).

The guideline from the National Institute for Health and Care Excellence (NICE) (The National Institute for Health and Care Excellence, 2018), which was updated in June 2018, recommends activities that are tailored to the person's preferences, cognitive stimulation therapy and group reminiscence therapy for people with mild and moderate dementia to improve cognition.

The Norwegian national guideline for treatment of dementia (Helsedirektoratet, 2017) gives a strong recommendation for physical activity to improve cognitive outcome and ADL function (Forbes et al., 2013; Laver et al., 2016).

\section{Motor symptoms}

Psychosocial approaches to treat, or revive, motor symptoms should prevent falls, support gait problems, address problems with swallowing, support eating and support impairment of other ADL symptoms affected by the motor symptoms. Logemann et al. found that honey-thickened liquids showed the best effect in reducing aspiration in a study on dysphagia (Logemann et al., 2008). The guideline from NICE recommends cognitive rehabilitation or occupational therapy to support functional ability in people living with mild to moderate dementia (The National Institute for Health and Care Excellence, 2018).

\section{Neuropsychiatric symptoms (NPS)}

Managing NPS in dementia is one of the most challenging aspects in caring for people with dementia (Gitlin et al., 2010). Psychosocial approaches should always be the treatment of choice for NPS, with pharmacological treatment as a secondary option (de Oliveira et al., 2015; Kales et al., 2015; Lichtwarck et al., 2018; Moniz Cook et al., 2012). An important approach in treating NPS should be the prevention of the development of NPS, but according to a recent review, no studies have examined the impact of prevention of NPS (Kales et al., 2015).

Person-centred care (PCC) and milieu therapy for people with dementia can be seen as an effort to prevent NPS, and both are described elsewhere in the thesis. Furthermore, Kales et al. claimed that due to the complex causes of NPS, a one-size-fits-all solution does not exist, and management requires a caregiver- and patient-centred focus.

A recent review article (Abraha et al., 2017) aiming to provide an overview of psychosocial approach for NPS has identified many interventions. It included 38 systematic reviews and 142 primary studies published from 2009 to 2015 that had evaluated psychosocial approaches to treat NPS. They categorised the interventions into four groups: sensory stimulation interventions (such as acupressure, aromatherapy, massage therapy, light therapy and sensory garden), cognitive/emotion-oriented interventions (such as cognitive stimulation, music and dance therapy, snoezelen, transcutaneous electrical nerve stimulation, reminiscence therapy, validation therapy, simulated presence therapy), behaviour management techniques and other therapies (such as exercise therapy, pet therapy, SCU). The researchers found that music therapy and techniques for management of behaviour involving caregiver-oriented and staff-oriented interventions exhibited 
the best evidence, but they concluded that the evidence for the efficacy of non-pharmacological interventions is limited due to methodological factors (Abraha et al., 2017).

A resent systematic overview (Dyer, Harrison, Laver, Whitehead, \& Crotty, 2017) reporting findings from systematic reviews of randomised controlled trials of pharmacological and psychosocial approaches for NPS supported the idea that psychosocial approaches should be the first-line therapy for NPS. The review paper concluded that functional analysis-based interventions should be used as first-line management of NPS whenever possible, because these interventions do not have any adverse effects (Dyer et al., 2017). Functional analysis-based interventions to manage NPS are based on a functional analysis of the person's behaviour and will require the carer to understand the function or meaning behind the NPS that a person experiences (Moniz Cook et al., 2012).

In a review from 2014 including 40 studies, Testad et al. reported that agitation could be treated with personalised pleasant activities, and depressive symptoms could be improved by reminiscence therapy (Testad et al., 2014).

It is believed that psychosocial approaches make a vital contribution to dementia care, but the lack of consensus about how to evaluate effectiveness of interventions makes comparisons between different studies and interventions difficult (Livingston et al., 2014; Livingston, Sommerlad, et al., 2017; Moniz-Cook et al., 2008).

In conclusion, there is evidence for the use of music therapy, reminiscence therapy and personalised pleasant activities for certain NPS but, unfortunately, a lack of evidence for the efficacy of other psychosocial approaches for the treatment of NPS. However, as Cooper et al. stated in their systematic review about interventions to improve QoL for persons with dementia, lack of evidence of efficacy is not evidence of lack of efficacy (Cooper et al., 2012).

\subsubsection{The potential for prevention of dementia}

In 2017, The Lancet Commission for Dementia Prevention, Intervention and Care summarised the major advances that had been made and the new knowledge about what should be done to prevent and treat dementia. The commission made recommendations for prevention and treatment of dementia by using the best available evidence. When the evidence was incomplete, they summarised the balance of evidence and explained its strengths and limitations. Key Message 2 is about prevention, but all the recommendations are found in Text Box 2 .

Important points to prevent dementia would be to treat hypertension in middle-aged and older individuals, improve education, motivate and facilitate physical activity and social activity, reduce smoking and prevent and treat hearing loss. Treatment of depression, diabetes and obesity would also contribute to the prevention of dementia. 
Text Box 2. Key messages

The Lancet Commission on Dementia Prevention, Intervention and Care (Livingston, Sommerlad, et al., 2017)

1. The number of people with dementia is increasing globally, although incidence in some countries has decreased.

2. Be ambitious about prevention. We recommend active treatment of hypertension in middleaged (45-65 years) and older people (aged older than 65 years) without dementia to reduce dementia incidence. Interventions for other risk factors, including more childhood education, exercise, maintaining social engagement, reducing smoking, and management of hearing loss, depression, diabetes and obesity, may have the potential to delay or prevent a third of dementia cases.

3. Treat cognitive symptoms. To maximise cognition, people with Alzheimer's disease or dementia with Lewy bodies should be offered cholinesterase inhibitors at all stages or memantine for severe dementia. Cholinesterase inhibitors are not effective in mild cognitive impairment.

4. Individualise dementia care. Good dementia care spans medical, social and supportive care; it should be tailored to unique individual and cultural needs, preferences and priorities and should incorporate support for family carers.

5. Care for family carers. Family carers are at a high risk of depression. Effective interventions, including STrAtegies for RelaTives (START) and Resources for Enhancing Alzheimer's Caregiver Health intervention (REACH), reduce the risk of depression, treat the symptoms and should be made available.

6. Plan for the future. People with dementia and their families value discussions about the future and decisions about possible attorneys to make decisions. Clinicians should consider one's capacity to make different types of decisions at diagnosis.

7. Protect people with dementia. People with dementia and society require protection from possible risks of the condition, including self-neglect, vulnerability (including to exploitation), managing money, driving or using weapons. Risk assessment and management at all stages of the disease is essential, but it should be balanced against the person's right to autonomy.

8. Manage neuropsychiatric symptoms. Management of the neuropsychiatric symptoms of dementia, including agitation, low mood or psychosis, is usually psychological, social and environmental, with pharmacological management reserved for individuals with more severe symptoms.

9. Consider end of life. A third of older people die with dementia, so it is essential that professionals working in end-of-life care consider whether a patient has dementia, because they might be unable to make decisions about their care and treatment or express their needs and wishes.

10. Technology. Technological interventions have the potential to improve care delivery but should not replace social contact.

In the conclusion, they stated that: continued progress will build on what has long informed dementia care: to prevent the preventable, treat the treatable and care for both the person living with dementia and the carer (Livingston, Sommerlad, et al., 2017).

\subsection{Person-centred care (PCC)}

In the 1920s, Martin Buber suggested an alternative approach in medical practice where the patient first must be seen as a person and not as a disease (Cohn, 2001). In the 1950s, psychologist Carl Roger introduced a person-centred approach in the therapeutic relations between the therapist and the patient, balanced to release the patient's own creative ability (Rogers, 1961) and, thereby, founded the person-centred approach to care: "Rogers proposed that a person-centred 
approach, based on acceptance, caring, empathy, sensitivity, and active listening, promotes optimal human growth" (Brownie \& Nancarrow, 2013). In the 1980s, psycho-gerontologist Tomas Marris Kitwood (best known as Tom Kitwood and further described in Chapter 2.4.2), built his theory of PCC in dementia on these two pillars, proposing that dementia should be understood as an interaction between neurological impairment and psychosocial factors, physical health, individual psychology and the environment, with a focus on social context.

The Norwegian national guideline for treatment of dementia (Helsedirektoratet, 2017) also strongly recommends PCC both as an organisational and an individual approach for people with dementia and states that the Working Group considers PCC dementia care to be an overall value and an indicator of good care for people with dementia and their carers. PCC applies to all recommendations given in this guideline (Helsedirektoratet, 2017).

\subsubsection{Theoretical framework and definition}

Four main components to implement PCC are described (D. J. Brooker et al., 2016) and presented in the VIPS framework (D Brooker, 2004): (V) valuing people with dementia and those who care for them; (I) treating people as individuals; $(P)$ looking at the world from the perspective of the person with dementia; and (S) a positive social environment in which the person living with dementia can experience relative well-being (D Brooker, 2004). Valuing people with dementia and those who care for them means that all people, patients and carers in the NH should be nurtured, and the NH should have a mutual vision about providing PCC, stating that all people, patients and carers should be nurtured.

McCormack and McCance have developed a person-centred nursing framework, suggesting that to deliver person-centred care, it is necessary to consider the conditions and the care environment for providing effective care through the care processes (McCormack \& McCance, 2006). Their personcentred nursing framework comprises four constructs:

- Prerequisites, which focus on the attributes of the nurse

- The care environment, which focuses on the context in which care is delivered

- Person-centred processes, which focus on delivering care through a range of activities

- Expected outcomes, which are the results of effective person-centred nursing (McCormack \& McCance, 2006)

Brooker stated that the term person-centred care means different things to different people in different contexts:

"In my discussions with practitioners, researchers, people with dementia and their families, it is obvious that the concepts in person-centred care are not easy to understand or articulate in a straightforward manner. To some it means individualized care, to others it is a value base. There are people who see it as a set of techniques to work with people with dementia and to others it is a phenomenological perspective and a means of communication" (D Brooker, 2004, p. 216).

PCC is not a method for caring, but a philosophy of care. As a carer, it is necessary to have methods to implement the ideas and content of PCC into practice (Fazio, Pace, Flinner, \& Kallmyer, 2018). 


\subsubsection{Tom Kitwood and person-centred care}

In Kitwood's theory, rejection of the focus on treating dementia as a disease is important. He used the term person-centred care to bring together ideas and ways of working that emphasised communication and relationships and challenged the traditional medical model of care, resulting in a focus on processes, schedules and staff and organisational needs (Fazio et al., 2018). PCC for people with dementia is based on the approach of seeing dementia as a dialectic condition between personal, social and neurological factors that understand dementia as a combination of the person's personality, life history, physical health condition and neurological impairment, in addition to social psychology (T Kitwood, 1997). The basic meaning of personal factor is that a person has a core self, and it is important to recognise each person as unique and strive to understand his or her life history and value the person's preferences and beliefs, regardless of the cognitive decline. The impact of the social environment on the well-being of people with dementia and the need to preserve their personhood are important. Personhood is a central idea in PCC, defined by Kitwood as a "standing or status that is bestowed upon one human being, by others, in the context of relationship and social being" (T Kitwood, 1997). The neurological part of dementia is the neuropathological process that is going on in the person's brain, causing progressive decline in cognition and impairment in function.

Since the concept of PCC in dementia care was introduced by Kitwood in the 1990s, it has been regarded as a guiding principle to good quality of care $(Q \circ C)$ in dementia care (D. Brooker, 2007; Fazio et al., 2018; Li \& Porock, 2014; Manthorpe \& Samsi, 2016). PCC is an important approach towards people with dementia and their care, based on seeing dementia as the dialectic process described above. Kitwood challenged the earlier view in bio-medical traditions in medical professions, which claimed that the behaviour of people with dementia was entirely due to neuropathological process, arguing that the people's experience of dementia arises out of this dialectical relationship between physical health/neurological impairment and social/psychological factors, all preserving the person's personhood. The essential psychological needs of people with dementia, according to Kitwood, include five needs that are closely connected: comfort (feeling of trust coming from others), attachment (finding security and familiarity that make the person feel safe), inclusion (being involved as a part of a group), occupation (being involved in life) and identity (distinguishes a person and what makes him or her feel unique), all as expressions of people's need for love. Kitwood claimed that these needs are common to all human beings, but they are more obvious for people with dementia because they are more vulnerable and dependent on others to take initiative to satisfy these needs.

Kitwood described different types of interactive processes that may occur in dementia care and lead to impairing the personhood of the person with dementia. Kitwood proposed that interactions between carers (or other persons) and a person with dementia have the potential to either uphold or undermine the personhood of people with dementia, and he proposed that more damaging interactions were related to the care culture rather than being intentional. He called these processes malignant social psychology, and claimed they have a malign effect on personhood and, thereby, contribute to the development of dementia (Text Box 3). An example of malignant social psychology is objectification, which describes when a person with dementia is treated as if he/she had no opinions and feelings. It could be a carer is changing the person's clothes whilst talking to another member of the staff over the head of the person with dementia, without any consideration that the person with dementia is present. Another type of malignant social psychology is treachery, 
which describes what happens when different forms of deception are used to manipulate or gain control over a person with dementia. For example, this happens when a carer says something that is not true to a person with dementia, and the person feels betrayed and humiliated.

\section{Text Box 3.}

Malignant social psychology, adapted from Kitwood (T Kitwood, 1997)

- Treachery: using forms of deception to distract or manipulate a person with dementia or force him or her into compliance.

- Disempowerment: not allowing a person to use the abilities he or she does have; failing to help him or her to complete actions he or she has initiated.

- Infantilisation: treating a person very condescendingly, as someone lacking sensitivity might treat a very young child.

- Intimidation: inducing fear in a person, through use of treats or physical power.

- Labelling: using a category such as dementia or 'organic mental disorder' as the main basis for interacting with a person and explaining his or her behaviour.

- Stigmatisation: treating a person as if he or she were a diseased object, an alien or an outcast.

- Outpacing: providing information, presenting choices, etc., at a rate too fast for the person to understand; putting him or her under pressure to do things more rapidly than he or she can bear.

- Invalidation: failing to acknowledge the subjective reality of a person's experience and especially what he or she is feeling.

- Banishment: sending a person away or excluding him or her, physically or psychologically.

- Objectification: treating a person as if he or she were a lump of dead matter; to be pushed, lifted, filled, pumped or drained, without proper reference to the fact that he or she is a sentient being.

- Ignoring: carrying on (in conversation or action) in the presence of a person as if he or she were not there.

- Imposition: forcing a person to do something, overriding desire or denying the possibility of choice on his or her part.

- Withholding: refusing to give attention when it has been asked for or meet an evident need; for example, for affectionate contact.

- Accusation: blaming a person for actions or failures of action that arise from his or her lack of ability or his or her misunderstanding of the situation.

- Disruption: disturbing a person's action or inaction; crudely breaking his or her "frame of reference".

- Mockery: making fun of a person's "strange" action or remarks; teasing, ridiculing, humiliating, making jokes at his or her expense.

- Disparagement: telling a person that he or she is incompetent, useless, worthless, etc.; giving messages that are damaging to his or her self-esteem.

Kitwood argued that through good communication, called positive person work, a person's dementia symptoms may improve; he outlined 12 different forms of positive person work (Text Box 4). One example of positive person work is recognition, when a carer acknowledges that a person with dementia is a person by speaking to a person with dementia by his or her preferred name, affirming the views of the person with dementia or simply thanking a person with dementia. Play is 
another form of positive person work, describing how people with dementia enjoy themselves as they undertake activities that stimulate spontaneity, self-expression and fun.

Positive person work contrasts with malignant social psychology, intending to fulfil the psychological needs of people living with dementia that Kitwood identified and, thereby, maintaining their personhood and well-being.

\section{Text Box 4.}

Positive person work, adapted from Kitwood (T Kitwood, 1997)

- Recognition: to recognise and acknowledge a person as having unique thoughts, feelings and preferences, for example, greeting a person by his or her preferred name.

- Negotiation: facilitate the person's preferences in care and his or her daily life through consultation and support the person's involvement in the decision-making process, for example, serving patients food that he or she enjoys.

- Collaboration: partnership between the carer and the person to carry out an activity or task, for example, having a bath or getting dressed in a comfortable way for the person.

- Play: provide appropriate activities and enable self-expression, for example, rolling a ball, sharing a joke or playing a game.

- Giving: accepting kindness the person with dementia gives, for example, the person with dementia may want to give a nurse a flower from the garden.

- Timalation: as a form of interaction, such as aromatherapy, which stimulates the senses.

- Celebration: celebrate the person's achievements, not just during celebratory occasions, such as birthdays or anniversaries, but also join the person who is happy and celebrating by clapping, whistling, singing or smiling.

- Relaxation: relax in solitude with a low level of intensity and recognition, for example, listening to music or spending time in the garden.

- Validation: accepting his or her reality, even if it is as a result of hallucinations or misperceptions.

- Holding: provide a safe psychological environment to enable people to express themselves. For example, stay beside a person with dementia who is distressed and validate his or her experiences without trying to stop or ignore him or her.

- Creation: encourage the person to be creative, for example, spontaneous singing or dancing.

- Facilitation: enable the person to do what he or she otherwise would not be able to do, for example, accompany a person to go for a walk outside of the unit.

\subsubsection{Ways to implement PCC}

Transforming the complex concepts of PCC into practice is a challenge. There are several ways to implement PCC in the care for people with dementia, some of which are described below.

VIPS practice model (VPM)

VPM is an operationalisation of the VIPS framework for achieving person-centred care in Norwegian nursing homes and home care (Rosvik, Kirkevold, Engedal, Brooker, \& Kirkevold, 2011). The VIPS framework consists of 24 indicators to ensure that the provided care is person-centred (D. Brooker, 2007), earlier described under theoretical framework and definition (Chapter 2.4.1, page 36). The main element in VPM is a consensus meeting that lasts $45-60$ minutes where the staff 
discuss the patients' situation using the indicators in the VIPS framework to identify the most important situation to arbitrate. The analysis emphasises how the patient might experience the situation and how other factors, such as cognitive impairment, personality, psychosocial needs, physical health and life story, might influence the situation and are used as a background to implement PCC (D Brooker, 2004; Rosvik et al., 2011).

\section{Dementia Care Mapping (DCM)}

DCM was developed by Kitwood and Bredin in the 1980s as a tool for developing and evaluating dementia care settings in the UK (T. Kitwood \& Bredin, 1992). DCM is defined both as a tool for intensive in-depth observation of the patients with a standard coding system for observed behaviour and as a cyclic process for developing PCC in clinical practice, including briefing staff, conducting mapping observations, data analysis and report preparation, feedback to staff and action planning. To conduct a DCM observation, a healthcare person should be qualified through an initial training and skills development program to become an authorised dementia care mapper (mapper). A review of research literature realised by Brooker reported that DCM plays a role to improve quality of life and quality of care through practice development, and that research showed some evidence regarding the efficacy of DCM. The advantages of DCM are that it is standardised, international, quality-controlled and responsive to change (D. Brooker, 2005). A recent systematic review concluded that there are certain organisational features and contexts that are required for successful and sustained use of DCM: good leadership, organisational and management support and mappers who have the qualities, skills and time to undertake such a role (Surr, Griffiths, \& Kelley, 2018).

\section{Marte Meo counselling (MMC)}

MMC is a video-supported counselling method developed by Maria Aarts (Aarts \& Gogol, 2008). Aarts described essential elements that occur in human dialogue by analysing the small elements in the dialogue, and Aarts claimed that disease and changes in normal function can disturb this communication process. The basic principle in $\mathrm{MMC}$ is to build on what each person does and understand and highlight the positive communication and interaction elements to support the development of good interactions. MMC was developed to support parents or professional carers to become aware of how to facilitate interactions in challenging relationships with children or clients (Aarts \& Gogol, 2008); it has been adopted to enable staff to recognise and improve communication and interactions with people with dementia (Einang Alnes, Kirkevold, \& Skovdahl, 2011). MMC highlights that effective communication between people with dementia and their caregivers can facilitate greater contact and mutuality in interpersonal interactions, but the learning climate in the unit appear to influence the outcomes (Alnes, Kirkevold, \& Skovdahl, 2013).

\section{Structured milieu therapy for people with dementia (SMTD)}

SMTD is a method to implement person-centred care for people with dementia, developed in Norway (Røen \& Storlien, 2015). The method was developed in an in-hospital unit at the department for Old Age Psychiatry at Innlandet Hospital Trust, and it has been (non-systematically) tested in a NH setting. It was found to reduce the use of anti-psychotic medication, increase ADL function and increase depressive symptoms (A. Rokstad, 2012). The increase in depressive symptoms was interpreted as being caused by the staff becoming more aware of how the patients 
experienced their daily life in the NH. The SMTD has not been translated to English. SMTD is a practical model consisting of a combination of education and coaching built on a person-centred approach adapted after John Gunderson (Gunderson, 1978; Røen \& Storlien, 2015; Taft, Delaney, Seman, \& Stansell, 1993). The model is based on five therapeutic processes; safety, structure, support, involvement and acknowledgement, which are seen as separate building blocks in creating a therapeutic milieu for people with dementia. The NH environment itself is considered to promote and enable positive changes in a direction. SMTD includes planning tools developed for ensuring implementation of PCC in three areas in the nursing home. One planning tool focuses on diurnal rhythm and leadership at the unit where the person lives. This planning tool gives an overview and a plan about the tasks that need to be done during a shift, including distribution of the personnel responsible for carrying out these tasks. Another planning tool gives an overview of the activities and happenings offered to the patients that are adapted to their ability to perform and engage. The last planning tool is an individual care and treatment plan that is developed and tailor-made for each patient, focusing on how the staff should behave and approach the person with dementia based on knowledge of dementia, familiarity to the patient and the principles of user involvement. SMTD builds on a team-based approach, with an agreement on who is accountable for coordinating and documenting assessment findings and follow-up actions, by creating a system where the staff have defined patients, areas and tasks for which they are responsible. The tools for planning and introducing PCC treatment at the three levels have been developed to support and ensure the implementation of PCC.

\subsubsection{Assessment of PCC}

A variety of tools to assess PCC practices are described in the literature. Wilberforce conducted a systematic review of assessment tools for PCC in the care of older adults relevant to long-term care, identifying 11 different assessment tools described in 22 papers (Wilberforce et al., 2016). In his review, Wilberforce concluded that there is limited evidence to support which assessment tool to choose to evaluate PCC, due to the low methodological quality of the testing of the properties of all the assessment tools included in their review (Wilberforce et al., 2016). However, two of them, the Person-Centred Care Assessment Tool (P-CAT) and the Client Centred Care Questionnaire (CCCQ), stood out as the ones that had been highly tested beyond the initial development stages. The P-CAT was chosen for the studies in this thesis.

The four most used assessment tools, according to Wilberforce, are presented below.

The Person-Centred Care Assessment Tool (P-CAT) (Edvardsson, Fetherstonhaugh, Nay, \& Gibson, 2010)

The P-CAT consists of 13 items divided in three sub-scales, expressed as statements about the content of care (seven items), the environment (two items), and the organisation (four items), formulated to assess staff perceptions of the practice in the unit where they work. The participants indicate on a 5-point Likert-scale ranging from 1 (disagree completely) to 5 (agree completely) how they perceive the care in the unit. The total score is between 13-65, where higher scores indicate a higher level of PCC. The P-CAT was chosen in the studies in the present thesis due to the psychometric properties of good quality both clinically and in research (Edvardsson et al., 2010; Edvardsson \& Innes, 2010; A. M. Rokstad, Engedal, Edvardsson, \& Selbaek, 2012; Wilberforce et al., 2016). The P-CAT is the only tool designed for self-assessing PCC by staff in NH that has been tested 
beyond the initial development stages (Wilberforce et al., 2016) and has been translated and tested in Norwegian settings (A. M. Rokstad et al., 2012).

The Individualised Care Instrument (ICI) (Chappell, Reid, \& Gish, 2007).

The $\mathrm{ICl}$ assesses individualised care of people with dementia in long-term care facilities. The original assessment tool consists of four sub-scales, covering three components: knowing the person (13 items, scored on a 4-point Likert scale), patient autonomy (15 items, scored on a 5-point Likert scale), communication between professionals and patients (seven items) and communication between professionals (11 items); the last two are scored on a 5-point Likert scale. A higher score indicates a higher level of PCC.

A factor analysis showed that a shorter version could be used. The short version consists of the same four sub-scales as the original, but with a reduced number of items; knowing the person has six items, patient autonomy has eight items, communication between professionals and patients has three items and communicating between professionals has five items (Chappell et al., 2007; Wilberforce et al., 2016).

The Person-Centred Climate Questionnaire (PCQ) (staff version) (Edvardsson, Sandman, \& Rasmussen, 2009)

The PCQ comes in two versions: a staff and a patient version, to assess to what extent the psychosocial environment of the healthcare setting seems to be person-centred. The staff version has 14 statements about the atmosphere in the ward, comprising three sub-scales: safety (six items), everydayness (four items), and community (four items). A 6-point Likert-scale is used for the responses. The total score ranges from 14: a climate that is minimally person-centred to 84: a climate maximally person-centred. The psychometric properties of the Norwegian version of the PCQ-staff version has been evaluated and found to have satisfactory validity and reliability estimates (Bergland, Kirkevold, \& Edvardsson, 2012). The PCQ-patient version has 17 statements about the same issues as the staff version, comprising three sub-scales: safety (10 items), everydayness (four items), and hospitality (four items).

The Client Centred Care Questionnaire (CCCQ) (de Witte, Schoot, \& Proot, 2006)

The CCCQ is a unidimensional scale consisting of 15 items that cover five central values: autonomy, continuity of life, uniqueness, comprehensiveness and fairness, and three additional values: equality, partnership and interdependence. Each item is scored on a 5-point Likert scale, giving a total score ranging from 15 to 75, where higher scores indicate a higher level of PCC. Factor analysis supported the unidimensional structure, and Cronbach's alpha was 0.94 .

\subsubsection{The impact of PCC on NH staff}

PCC has been the subject of several intervention studies, reporting positive effects on the symptoms in people with dementia, but its impact on the care staff remains unclear. A systematic review by Barbosa et al. aimed to assess the impact of PCC approaches on stress, burnout and job satisfaction of staff caring for people with dementia in residential aged care facilities. Seven studies were included and addressed different PCC approaches, including DCM, stimulation-oriented 
approaches, multisensory stimulation and emotion- and behavioural-oriented approaches. Five studies assessed staff burnout, four assessed staff stress and three assessed job satisfaction. The authors pointed out that there were differences in the design, outcome, number of participants and more, and there were methodological weaknesses in the included studies. This made it difficult to provide a conclusion, but in summary, they reported a tendency towards a positive effect of PCC on staff (Barbosa, Sousa, Nolan, \& Figueiredo, 2015).

Edvardsson et al. conducted a study to explore whether staff perceptions of the provision of person-centred care were associated with increased job satisfaction, and if so, to what extent perceived person-centredness could predict staff job satisfaction. They included 297 residential care staff members from seven care facilities in Victoria, Australia, who completed a survey of job satisfaction and scored the person-centred care assessment tool (P-CAT). They found a significant association between perceived person-centred care provision and job satisfaction amongst the staff. Person-centred care could explain nearly half of the variation in job satisfaction amongst the care staff, and the authors' concluded that there was evidence to indicate that the personcentredness of a ward is associated with the staff's satisfaction with work (Edvardsson, Fetherstonhaugh, McAuliffe, Nay, \& Chenco, 2011).

Hunter et al. conducted a study to examine the contribution of organisational and personal factors to self-reported person-centred residential dementia care (PCRDC), including five aspects: autonomy, personhood, knowing the person, comfort care and support for relationships. They included 109 long-term care staff from two Canadian long-term care homes that completed assessment tools evaluating self-reported person-centred care, organisational support for personcentred care, beliefs about personhood in dementia and burnout. Their hypotheses covered several factors thought to impact PCC: organisational support for PCC, higher level of professional qualification, age, years of education, gender, beliefs about personhood and burnout, and their positive or negative associations with self-reported PCRDC. They found positive associations between organisational factors with all the five aspects of PCRDC and concluded that organisational characteristics are associated with several aspects of person-centred dementia care. Individual characteristics, including gender, beliefs about personhood and burnout, appear to be more important to some aspects of person-centred dementia care (e.g. respect for personhood and comfort care) than others (Hunter, Hadjistavropoulos, Thorpe, Lix, \& Malloy, 2015).

A systematic review and meta-synthesis of 39 qualitative papers aimed to understand what underlies the successful implementation of psychosocial approaches in care homes. They conclude that the implementation of psychosocial approaches enabling people living with dementia in care homes to connect with others and have a good quality of life relies on a wide range of factors such as staff skills, job roles, tailored interventions, staff time and attitudes (Lawrence, Fossey, Ballard, Moniz-Cook, \& Murray, 2012).

A study by Lehuluante et al. from 2012 looked at nurses' satisfaction with care and work and explored the extent a person-centred unit climate influenced the satisfaction with care. Registered nurses at a university hospital in Sweden $(n=206)$ completed the Satisfaction with Nursing Care and Work Assessment Scale and the Person-Centred Climate Questionnaire in a cross-sectional explorative study. They found that the majority of respondents were satisfied with the care and work situation. Furthermore, a significant association between a person-centred psychosocial 
climate in the units and the nurses' satisfaction with care and work was found. They concluded that care promoting and implementing a person-centred philosophy of care can be one way to improve nurses' satisfaction with care and work. Although this study was conducted in acute care environments, there is no reason that the results would not apply to nursing homes (Lehuluante, Nilsson, \& Edvardsson, 2012).

\subsubsection{Effect of PCC on patients with dementia}

An increasing amount of literature has evaluated patient outcomes of PCC, showing significant benefits of the interventions (Li \& Porock, 2014; Testad et al., 2014).

\section{Randomised controlled trials (RCTs)}

Chenoweth et al. included 298 people with dementia from 15 residential care facilities in Australia in a cluster-randomised trial, randomly assigned to PCC, Dementia Care Mapping (DCM) or usual care (Chenoweth et al., 2009). Inclusion criteria for the patients were persistent need-driven behaviours that made it difficult to provide good quality care, and the NHs were selected because of their task-focused care approach, in addition to similar management structures, level of staffing, size and standards. The PCC intervention contained a two-day training, two visits and regular telephone calls from the researchers to assist development and implementation of PCC. External dementia care mappers (two of the researchers) and two trained internal care staff performed the DCM intervention. The main outcome was agitation, assessed with the Cohen-Mansfield Agitation Inventory (CMAI). Other outcomes were NPS other than agitation, assessed by the Neuropsychiatric Inventory Nursing home version (NPI-NH), and quality of life assessed with the Quality of Life in Late-Stage Dementia Scale (QUALID). At the end of the four-month treatment phase, the PCC and the DCM intervention groups had a reduction in agitation compared with usual care. There were no effects on the other symptoms assessed (Chenoweth et al., 2009).

A study by Rokstad et al. examined whether the DCM or the VIPS practice model (VPM) was more effective at dementia-specific education for nursing home staff (A. M. Rokstad et al., 2013). They included 624 nursing home patients with dementia in a 10-month cluster-randomised controlled trial, 446 completed the study period. The main outcome was agitation, assessed by the Brief Agitation Rating Scale (BARS), and secondary outcomes were other NPS, assessed by the 10-item version of the Neuropsychiatric Inventory Questionnaire (NPI-Q); depression, assessed by the Cornell Scale for Depression in Dementia (CSDD); and quality of life, assessed with the QUALID scale. The study failed to show significant changes in the BARS score both between the DCM and the control group and between the VPM and the control group after 10 months. Significant group differences were found for changes in the secondary outcomes. The NPI-Q sum score and the NPI-Q sub-scales agitation and psychosis were all in favour of the two interventions versus control, the QUALID score was in favour of DCM versus control and the CSDD score was in favour of VPM versus control.

Two other studies, both from the Netherlands (Dichter et al., 2015; van de Ven et al., 2013), also used DCM to implement PCC in people with dementia in NH. Van de Ven et al. had agitation as the primary outcome, and Dichter et al. had QoL and challenging behaviour as the primary outcome. Neither of these studies showed positive results from using DCM to implement PCC (Dichter et al., 2015; van de Ven et al., 2013). 
In another study, Fossey et al. included 346 patients from 12 specialist nursing homes for people with dementia in England in a 10-month cluster-randomised controlled trial (Fossey et al., 2006). The intervention comprised weekly staff training and ongoing support, focusing on alternatives to drug treatment for agitated behaviour. The control group received care as usual. The main outcome was agitation, assessed by the CMAI, and medication reviews were performed every three months. The intervention did not have an effect on the levels of agitation compared to care as usual, but a significant lower proportion of patients used antipsychotics in the intervention nursing home compared to the control group after the intervention (Fossey et al., 2006).

A cluster RCT conducted by Ballard et al tested the Well-Being and Health for People with Dementia (WHELD) intervention at 69 UK nursing homes (Ballard et al., 2018). The WHELD interventions combined training on PCC for care staff, promoting tailored person-centred activities and social interactions for the patients and giving NH staff and doctors updated knowledge on psychotropic medications for persons with dementia. Of the 847 people included, randomised to WHELD or treatment as usual (TAU), 553 completed the nine-month study period. Primary outcome was quality of life, assessed with the proxy version of the Dementia Quality of Life (DEM-QoL - proxy); secondary outcomes were agitation assessed with the CMAl; NPS assessed with the NPI-NH; antipsychotic use; global deterioration assessed with the Clinical Dementia Rating scale (CDR); depressive symptoms assessed with the CSDD; unmet needs assessed with the Camberwell Assessment of Need for the Elderly (CANE); mortality; quality of interactions assessed with the Quality of Interactions Scale (QUIS); pain assessed with the Abbey Pain Scale; and cost calculated using cost function figures compared with usual costs. The WHELD intervention conferred a statistically significant improvement in QoL, agitation, overall NPS and positive care interactions. The benefits were greatest in people with moderate to severe dementia. There were no statistically significant differences between WHELD and TAU for the other outcomes. The intervention did not reduce use antipsychotic drug use, which was at a low, but stable, level in both treatment groups. The WHELD intervention reduced costs compared to TAU (Ballard et al., 2018).

\section{Observational studies}

A Swedish descriptive study by Sjøgren et al. investigated the relationship between person-centred care and the ability to perform activities of daily living, quality of life, levels of pain, depressive symptoms and agitated behaviours amongst people with dementia in NHs (Sjogren, Lindkvist, Sandman, Zingmark, \& Edvardsson, 2013). They included 1,261 residents with dementia and 1,169 staff from 151 residential care units throughout Sweden. Person-centredness was assessed with the P-CAT, QoL with the QUALID scale, pain with the Pain Assessment in Advanced Dementia (PAINAD), depressive symptoms with the CSDD, agitation with the CMAI, ADL ability with the MultiDimensional Dementia Assessment Scale (MDDAS) and the prevalence of cognitive impairment was investigated with the Geriatric Rating Scale (GRS). They found a correlation between PCC as reported by care staff and the residents' ability to perform ADL activity and their QoL; residents in units with higher levels of PCC had higher ratings on QoL and ADL ability compared to residents in units with lower levels of PCC (Sjogren et al., 2013).

\section{Review studies}

In 2014, Fossey et al. published a systematic review where the objective was to determine the availability of person-centred interventions and training manuals for dementia care staff with 
clinical trial evidence of efficacy. They identified 170 training manuals for PCC, and each of the interventions included a sustained period of joint working and supervision with a trained mental health professional in addition to an educational element. Few of the interventions had been evaluated in clinical trials. A meta-analysis of randomised control trials indicated that personcentred training interventions conferred significant benefits in improving agitation and reducing the use of antipsychotics. The researchers concluded that there is a widespread use of person-centred interventions and training manuals that are not evidence-based (Fossey et al., 2014).

A recent systematic review and meta-analysis of the effectiveness of PCC in clinical practice for people with dementia done by Kim and Park provided evidence for the effects of PCC (Kim \& Park, 2017). They identified 19 intervention studies including 3,985 participants, 17 studies from longterm care facilities and two studies were from homecare settings. Their conclusion was that PCC interventions reduced agitation, NPS and depression, and improved QoL. They claimed that an educational strategy that promotes learning and skill development of care staff is needed, and that the feasibility and effectiveness of the intervention, the severity of the patient's disease and the type of intervention and duration should be considered as part of the intervention design (Kim \& Park, 2017).

\subsubsection{What impacts PCC in nursing homes?}

Maintaining the identity and personhood of the person with dementia is a key element of personcentred care. By adopting this approach, the life and value of the person becomes central. Therefore, how care is organised and delivered is important; creating a social environment where people with dementia are valued and nurtured is considered fundamental to this approach (D Brooker, 2004; Edvardsson, Winblad, \& Sandman, 2008; T Kitwood, 1997). What impacts these important processes in developing and implementing PCC in NH is important knowledge. Kitwood proposed that interactions have the potential to either uphold or undermine the personhood of people with dementia, and that the more damaging interactions were related to the care culture rather than being intentional (T Kitwood, 1997).

Killett et al. claimed that the culture of care in institutions for older people has an influence on the care that is provided (Killett et al., 2016). They conducted a study to investigate the relationship between care home culture and the residents' experience of care, asking the research question: "What are the individual circumstances, organisational cultures and practices most likely to encourage, or inhibit, the provision of high quality of care for older people living in residential and nursing homes?" They included 11 care homes in the UK and performed a comparative case study using in-depth observation and interviews, examining experiences of care reflecting both high quality care and poor care. They found that the 11 care homes provided care of different quality, from care homes that provided excellent care consistently to care homes where positive care only occurred accidently. Their analysis indicated how organisational cultures of care homes impact the quality of care $(\mathrm{Q} O C)$ the residents received, and they identified seven inter-related cultural elements that were associated to the QoC (Text Box 5), indicating how organisational cultures of care homes impact the quality of care the residents receive. They examined the dynamic relationship between these elements to show how organisational culture is locally produced and shifting. In conclusion, they stated that organisational cultures in a care home are not achieved only through importing organisational values or the 'right' leader or staff, but that finding ways of resolving the everyday demands of practice in ways that are consistent with espoused values was 
necessary. It is through everyday practice that assumptions continuously evolve, either consistently with or divergently from the espoused values. A leader should be aware of and engaged in the staff's on-going problem solving and how staff deal with these values in delivery of care. Their conclusion was that a lack of skills at all levels of care and unsupportive cultures of care are frequently cited as barriers to the implementation of PCC (Killett et al., 2016).

\section{Text Box 5.}

Elements of organisational culture with importance to quality of care (Killett et al., 2016)

1. There is shared purpose in providing best possible person-centred care. To achieve this, there is consistent espousal of values at an organisational level and at an individual level.

2. Management mediate external pressures to not negatively impact care, as demonstrated in the attitude, skills and behaviour of managers.

3. Staff are empowered to take responsibility for resident well-being through management and leadership, exhibited through the values and attitudes of the organisation.

4. Staff and managers are open to change for the benefit of residents, as shown in their attitudes and behaviours.

5. These values, attitudes and behaviours support the following artefacts (observable practices):

6. There is a sense of community between all involved in the home.

7. Person-centred activity and engagement are integral to care work. This is supported by consistent organisational policies and procedures, knowledge and skills.

8. 7. The care home environment is actively used to the benefit of residents through the knowledge and understanding of the staff.

Abbott et al. conducted a study to identify nursing home staff's perceptions of facilitators and barriers to learning about and meeting residents' preferences and the reasons why the staff experience that the residents change their minds about preferences (Abbott, Heid, \& Van Haitsma, 2016). They included $36 \mathrm{NH}$ staff members having daily contact with residents in addition to a fiveyear experience with actively assessing residents and attempting to meet the residents' preferences. The experienced staff's reflections were seen as unique and thought to be valuable, and both focus-group sessions and interviews were conducted. The staff revealed several key findings regarding their perceptions, enumerating more barriers than facilitators with facility policies as the most frequently cited barrier. Facility characteristics as policies, resources, scheduling, staffing ratios and safety were cited as restricting the ability for the staff to fulfil preferences or acting in opposition to residents' rights. The social environment was also be a barrier in some situations (Abbott et al., 2016).

Sjøgren et al. conducted a cross-sectional study to explore factors that characterised NH units that were perceived as being highly person-centred, focusing on organisational, environmental, residential and staff characteristics (Karin Sjögren, Lindkvist, Sandman, Zingmark, \& Edvardsson, 2017). They included 1,460 residents and 1,213 staff from 151 residential care units, and data characterising the organisation, the environment and the degree of person-centred care in the units were obtained. The staff provided both self-reported data on themselves and proxy ratings about the residents. 
The study found that units with highly person-centred care were characterised by having a shared philosophy of care, a satisfactory leadership, an interdisciplinary collaboration, social support from colleagues and leaders and a dementia-friendly physical environment. The staff in the units with higher levels of person-centred care had more time to spend with residents, and the size of the units was smaller. These units also had a higher proportion of staff with continuing education in dementia care, and they had a higher proportion of staff receiving regular supervision, compared to units with lower levels of person-centred care. The authors concluded that to improve personcentred care in residential care units, it is important to target organisational and environmental factors, such as implementing a shared philosophy of care, improving how staff uses their working time, improving the physical environment, providing interdisciplinary support and support from leaders and colleagues. They recommended that managers and leaders that want to facilitate person-centred care in daily practice need to consider their own role in supporting, encouraging, and supervising the staff (Karin Sjögren et al., 2017).

Popham and Orrell aimed to answer the question, "What matters for people with dementia in care homes?" through conducting a qualitative study (Popham \& Orrell, 2012). They included participants from five care homes in London and conducted focus group interviews with residents with dementia, their family carers, the staff and the care home managers. In addition, the environment in the care home was evaluated by the Sheffield Care Environment Assessment Matrix (SCEAM), an environmental assessment tool that evaluates the design, layout and usage of the environment. The researchers identified four main themes from these interviews: activities and interaction; freedom and safety; dignity and privacy; and design and environment. The authors commented that the life in care homes can be over-regulated by focusing on organisational tasks at the expense of person-centred care. They concluded that the design and organisation of care homes focuses on the priorities of the staff and managers rather than the needs of the residents and family carers (Popham \& Orrell, 2012).

A recent review article conducted by Molony and colleagues investigating person-centred assessments and care planning in a very broad manner stated that many persons living with dementia do not receive person-centred assessments and care planning because requirements and practices reflect the needs of the staff and the settings more than the needs of the people with dementia (Molony, Kolanowski, Van Haitsma, \& Rooney, 2018). As a summary of the discussion in the review article, they constructed five recommendations intended to increase the use of assessments and care planning to focus on the needs of the people with dementia (Text Box 6). 
Text Box 6.

Recommendations to increase the use of assessment and care planning practices.

(Molony et al., 2018).

1. Perform regular, comprehensive person-centred assessments and timely interim assessments.

2. Use assessments as an opportunity for information gathering, relationship building, education and support.

3. Approach assessments and care planning with a collaborative team approach.

4. Use documentation and communication systems to facilitate the delivery of person-centred information between all care providers.

5. 5. Encourage advance planning to optimise physical, psychosocial and fiscal well-being and increase awareness of all care options, including palliative and hospice care.

In summary, there is evidence for the positive effects of PCC, but it is not easy to implement, sustain or register the effects in the care of people with dementia in NHs.

\subsection{Quality of life}

Although quality of life (QoL) as a concept is quite complex and difficult to define, it has been used as an outcome for making decisions in health issues since the 1960s and 1970s (Pennacchini, Bertolaso, Elvira, \& De Marinis, 2011). One of the first publications about QoL in the medical field was by Elkinton, who described ethical issues related to the development of new technology in medical treatment that could lead to adverse effects for the patients involved:

"What every physician wants for every one of his patients old or young, is not just the absence of death but life with a vibrant quality that we associate with a vigorous youth. This is nothing less than a humanistic biology that is concerned, not with material mechanisms alone, but with the wholeness of human life, with the spiritual quality of life that is unique to man. Just what constitutes this quality of life for a particular patient and the therapeutic pathway to it often is extremely difficult to judge and must lie with the consciousness of the physician" (Elkinton, 1966).

QoL became a MeSH term (Medical Subject Heading) at MEDLINE (US National Library of Medicine) in 1977, defined as "a generic concept reflecting concern with the modification and enhancement of life attributes, e.g. physical, political, moral and social environment; the overall condition of human life" (Pennacchini et al., 2011).

\subsubsection{Definition/the concept}

QoL is a concept including philosophic, psychologic and social-political domains and has been widely used in medical and philosophical literatures for the past four decades (Pennacchini et al., 2011). QoL does not have a universal definition, probably due to its wide variety of use, giving a challenge in the use and common understanding of the concept.

The World Health Organisation (WHO) has defined QoL as “...individual's perception of their position in life in the context of the culture and value systems in which they live and in relation to their goals, expectations, standards and concerns" (WHOQOL-GROUP, 1995). WHO's definition further states that QoL is affected by the person's “...physical health, psychological state, level of 
independence, social relationships, personal beliefs and their relationship to salient features of their environment". This definition is difficult concerning people with dementia because it implies communication of their own perception, which is difficult due to cognitive decline. A decline in memory, attention or language may affect the person's capacity to describe how they are feeling.

\subsubsection{Quality of life in people with dementia}

In long-term wards in Norwegian $\mathrm{NHs}$, over $84 \%$ of the residents are living with dementia (Helvik et al., 2015). As there is no cure for dementia, helping people to live well with dementia is important, and appropriate care should be offered to improve or maintain the QoL of people with dementia (Moniz-Cook et al., 2008; Moyle, Fetherstonhaugh, Greben, \& Beattie, 2015). Even though it is difficult to define QoL, the concept is important to use as an assessment of the residents' perceived quality of care. As such, in persons not able to communicate how they consider the quality of care they receive, describing effects on QoL is an important outcome assessment in research care (Banerjee et al., 2009).

Focus on the residents' QoL can help to enhance respect for the people with dementia and improve the care provided (Moyle et al., 2015). QoL is often used as an outcome assessment in healthcare research in people with dementia, and there are several studies on QoL of people with dementia. A PubMed search on 16 September 2018 combining the search terms dementia and quality of life revealed 6,400 citations. Interpreting the results of these studies is troubled by the lack of consensus on how to define and assess QoL, and, consequently, the understanding of QoL amongst people with dementia is limited.

QoL for patients with dementia was first defined by Lawton, who described it as a "multidimensional concept encompassing emotional, physical, social and environmental domains of a person's wellbeing" (Lawton, 1994). Lawton stated that the QoL in people with dementia included the same areas as in people in general and described QoL as a combination of internal dimensions (perceived QoL and psychological well-being) and external dimensions (behavioural competence and external environmental factors). Assessment of cognition, activities of daily living and behaviour are already included in the typical diagnostic workup of Alzheimer's disease, but efforts should be made to improve the assessment of positive states and behavioural engagement (Lawton, 1994).

In dementia research, Lawton's model has become the universal conceptualisation of QoL in dementia (figure 2). 


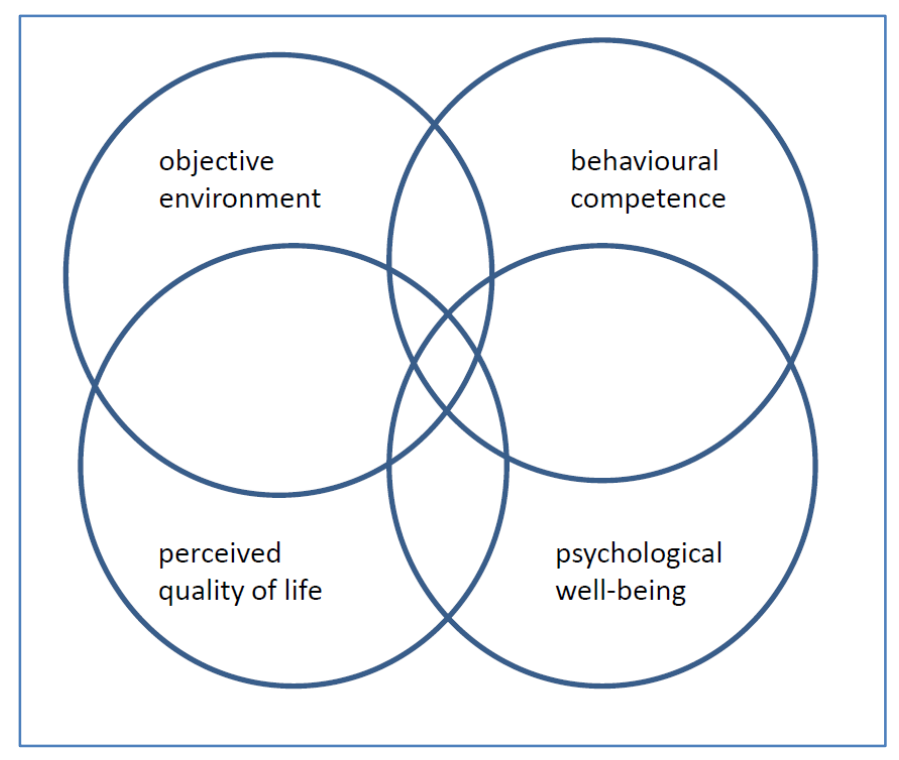

Figure 2 Lawton's description of QoL in people with dementia includes four dimensions: behavioural competence (e.g. physical health, functional and cognitive abilities, and social behaviour), psychological well-being, objective environment (e.g. social support, accommodation) and perceived quality of life.

\subsubsection{The stability of QoL and factors that impact QoL in people with dementia}

Measuring QoL in people with dementia is important to gain knowledge about factors that have an impact on QoL. A review investigating the association between QoL and sociodemographic characteristics, cognition and NPS claimed that there is no simple association between QoL and other easily measurable clinical characteristics in dementia (Banerjee et al., 2009).

\section{Cross-sectional studies on QoL in people with dementia in NHs}

Several studies have investigated QoL in NH patients, both self-reported and proxy-reported (family and staff), where age, ADL, dementia severity, pain, psychiatric disorders, pulmonary diseases and neuropsychiatric symptoms (NPS) were found to be associated with reduced QoL in NH patients with dementia (Klapwijk, Caljouw, Pieper, van der Steen, \& Achterberg, 2016; Rostad et al., 2017; R. B. Wetzels, Zuidema, de Jonghe, Verhey, \& Koopmans, 2010).

A hypothesis by Holopainen and colleagues predicted that the factors associated with QoL of people with dementia could be divided in three groups: sociodemographic factors, factors related to dementia and the social and caring environment. They found that Lewy body disease, early onset dementia, depression at an early or middle stage of the disease, anxiety, agitation, pain, dependence on others in daily activities and need for assistance with washing and dressing were dementia factors associated with decreased QoL, and that contact with family members or other patients in the care facility, being accepted, heard and understood, getting help when needed, being able to take part in activities, being in a home-like environment, sufficient number of staff and staff that have received training in dementia care were social and care environment factors associated with improved QoL. In addition, a lack of opportunity for communication and interaction, loneliness and a feeling of not belonging were found to have a reducing effect of QoL of people with dementia. They did not find evidence for an association between sociodemographic factors and QoL (Holopainen, Siltanen, Pohjanvuori, Makisalo-Ropponen, \& Okkonen, 2017). 
Klapwijk et al. explored the association between QoL and demographic, psychosocial, functional and physical characteristics in NH residents with moderate to very severe dementia. They included 288 residents from 12 Dutch NHs, assessing QoL with the six QUALIDEM domains: care relationship, positive affect, negative affect, restless tense behaviour, social relations and social isolation. They concluded that better QoL in persons with dementia was independently associated with lower age, better ADL, lower dementia severity, less pain and no psychiatric disorders, pulmonary diseases and NPS (Klapwijk et al., 2016).

In a recent review article, Martyr et al. carried out a correlational meta-analysis of factors associated with QoL, well-being, and life satisfaction in people with dementia (Martyr et al., 2018). They included 198 QoL studies from 272 articles until 7 January 2016, and they found that social engagement and better functional ability were associated with better QoL and poorer physical and mental health and poorer carer well-being were associated with poorer QoL (Martyr et al., 2018).

Anderson et al. examined associations between staff characteristics, QoC and QoL for residents, using published peer-reviewed literature from the last 20 years (Anderson, Bird, MacPherson, \& Blair, 2016). They found that when the staff were trained to interact empathetically and humanely with the patients in their care, the residents experienced fewer depressive symptoms, less functional dependence, better food intake and fewer psychotropic medications were prescribed. The review concluded that associations exist between potentially adjustable staff characteristics and QoC onwards to QoL of the residents (Anderson et al., 2016).

\section{Longitudinal studies on QoL in NHs}

Studies following QoL in people with dementia over time in NHs have found QoL to be rather stable.

Mjørud et al. studied factors associated with QoL in people with dementia in NHs (Mjorud, Kirkevold, Rosvik, Selbaek, \& Engedal, 2014), and they did a follow-up study over 10 months to determine which factors were associated with a change in QoL (Mjorud, Rosvik, Rokstad, Kirkevold, \& Engedal, 2014). In the first study, 661 participants were included, and QoL was assessed with the QUALID scale. They found that NPS (NPI-affective; NPI-agitation; NPI-apathy), apathy, severity of dementia and impairment in activities of daily living were associated with reduced QoL (Mjorud, Kirkevold, Rosvik, Selbaek, et al., 2014). In the follow-up study, they included 198 participants, finding that QoL improved in $30.8 \%$, was unchanged in $14.7 \%$ and deteriorated in $54.6 \%$ of the patients. Changes in QUALID scores were significantly associated with QUALID baseline scores and changes in NPS. The authors concluded that the results in this follow-up study implies that a lower baseline score (better QoL) results in a larger change in QoL (towards a worse QoL), and that changes in QoL are mostly associated with changes in NPS. They also found that QoL did not deteriorate in almost 50\% of the participants (Mjorud, Rosvik, et al., 2014).

Oudman and Veurink conducted a study to assess the change in QoL in patients with severe dementia in a psychogeriatric ward in a NH including 75 patients at baseline, of whom 32 patients participated in a two-year follow-up. QoL was assessed with the QUALIDEM scale, and the average 
QUALIDEM scores had improved for $59.4 \%$ of the participants at follow-up. The improvement was significant on the subscales feeling at home, social isolation and negative affect, but the overall change in QoL was small and non-significant, 3.0\%. The authors concluded that QoL is stable or improves despite the global cognitive deterioration, particularly in the more severe stages of dementia, and claimed that this should receive more attention in order to comfort family members in accepting the dementia process (Oudman \& Veurink, 2014).

Van der Zon et al. included 290 residents in a two-year, multi-centre, observational cohort study to assess the course of QoL in NH residents with dementia and study its predictors. The total QUALIDEM score did not change over two years, but an increase in QoL was observed in six subscales: care relationship, negative affect, restless tense behaviour, positive self-image, social isolation and feeling at home. A decline in QoL was observed in three subscales: positive affect, social relations and having something to do. The most frequently found predictors were gender and NPI-NH scores (van der Zon et al., 2018).

Review studies on QoL in people with dementia

A review done by Kok et al. found that patients with dementia living in SCU had significantly more behaviour changes, more agitation/aggression, more depression and anxiety, more cases of global cognitive impairment and a better psychosocial functioning compared to patients in regular units (RU) (Kok, Berg, \& Scherder, 2013). When it comes to QoL, they found that there were almost no studies on SCU for patients with dementia, though generally aspects of QoL were found to be better in the SCU group compared to the RU. They found no differences in QoL between smallscale, homelike SCU and SCUs with large wards. This also applies to the longitudinal studies that were included in the review (Kok et al., 2013).

Chaudhury et al. performed a literature review including 94 empirical studies and nine reviews published after 2000 (Chaudhury et al., 2018). They focused on physical environment in long-term care facilities and found that unit size, spatial layout, homelike character, sensory stimulation and environmental characteristics of social spaces have an influence on residents' behaviour and QoL. They concluded that the physical environment in the care settings is important in improving the residents' QoL and quality of care practices (Chaudhury et al., 2018).

Cooper et al. reviewed 20 randomised controlled trials reporting the effectiveness of psychosocial approaches in improving the QoL or well-being of people with dementia (Cooper et al., 2012). For people with dementia living in full-time care, they found only one intervention that showed an effect on the patients' QoL: Group Cognitive Stimulation Therapy. The authors concluded that there is a lack of evidence for any intervention that increases the QoL or well-being of people with dementia. They also commented that lack of evidence of efficacy is not evidence of lack of efficacy, which the authors suggested can be explained by the intervention's effect on the patients' QoL taking time to manifest. The authors also pointed out that interventions to improve QoL of people with dementia in care homes not only has a possibility to improve or have no effect, but they might harm the overall QoL, as well (Cooper et al., 2012).

Anderson et al. conducted a systematic review to examine the association between staff characteristics, quality of care $(\mathrm{Q} o \mathrm{C})$ and QoL for residents, including 35 papers published over the last 20 years (Anderson et al., 2016). The authors suggested that there are relationships between 
potentially adjustable staff characteristics and QoC that are transferred to the residents' QoL. They stated that, "When staff treat and interact empathetically and humanly in care, there is a relationship with better mood for residents, delayed functional dependence, and better food intake" (Anderson et al., 2016).

Bradshaw et al. conducted a systematic review including 31 studies of care home life and found four key themes that affect good QoL in care homes: acceptance and adaptation, connectedness, homelike environment and caring practices (Bradshaw, Playford, \& Riazi, 2012). They concluded that to have good QoL in a care home, there must be an understanding of the residents' experience living there, in addition to an understanding of how the residents' experience is affected by the conditions in the care home. The review also supported and extended the finding that a positive approach to living in care homes is associated with effective coping and adaptation; it stated that these competences of the residents need to be encouraged and appreciated to "redefine the care home as one that promotes choice, not one that simply takes it away" (Bradshaw et al., 2012).

It is difficult to conclude which individual, staff or organisational factors are most strongly associated with QoL in persons with dementia. Several studies have reported associations between QoL and patient factors such as age, ADL, dementia severity, pain, psychiatric disorders, pulmonary diseases and NPS such as affective symptoms, agitation and apathy (Klapwijk et al., 2016; Mjorud, Kirkevold, Rosvik, Selbaek, et al., 2014; Mjorud, Rosvik, et al., 2014; Rostad et al., 2017; R. B. Wetzels et al., 2010). However, the concept of QoL for people with dementia is complex, and it is associated with more than individual factors (Holopainen et al., 2017). This complexity is confirmed in several studies, documenting that QoL is associated with social engagement and functional ability (Martyr et al., 2018), staff characteristics (Anderson et al., 2016) and resident coping and adaptation (Bradshaw et al., 2012), and that patients, staff, the physical environment and organisational relationships are carefully woven together, as shown in the study by Popham and Orrell (Popham \& Orrell, 2012). There is also evidence that QoL remains stable over time (Oudman \& Veurink, 2014).

In summary, there is evidence that many different factors impact the QoL for people with dementia, and that the relationship between those factors is quite complex. Nevertheless, QoL is stable over time, despite the changes that the dementia disease causes in the lives of people with dementia.

\subsubsection{Assessment of QoL in people with dementia}

Assessment of QoL has become an important outcome both as an assessment in intervention studies and as an indicator of quality of care for people with dementia (Bowling et al., 2015; Dichter, Schwab, Meyer, Bartholomeyczik, \& Halek, 2016; Moniz-Cook et al., 2008). Dementia leads to a progressive cognitive and functional decline, which influences the person's performance of activities of daily living and affects their social behaviour. Therefore, it is important to include QoL as an independent outcome for people with dementia (S. Robertson et al., 2017). A precise assessment of QoL is valuable both in clinical work and in research to evaluate the effect of interventions designed to improve healthcare and helping people living well with dementia (S. Robertson et al., 2017). Therefore, several dementia-specific QoL scales have been developed, and some of them are presented below. 


\subsubsection{Scales to assess QoL in people with dementia}

Some QoL assessment scales are designed for self-rating: collecting information from the person with dementia, some assessment scales are based on proxy ratings: collecting data from both family and/or healthcare proxies, and other assessment scales collect information both from the person with dementia and their proxies (Dichter, Schwab, et al., 2016; S. Robertson et al., 2017).

The assessment scales described in this thesis are chosen based on the recommendations from four papers covering a broad research on dementia-specific QoL assessment scales (Aspden, Bradshaw, Playford, \& Riazi, 2014; Bowling et al., 2015; Dichter, Schwab, et al., 2016; Missotten, Dupuis, \& Adam, 2016). These four papers also include the Quality of Life in Late-Stage Dementia Scale (QUALID) and the Quality of Life in Alzheimer's Disease (QoL-AD) assessment scales, both of which are used in three of the papers (QUALID in Papers I, II and IV, QoL-AD in Paper II) in this thesis.

The Quality of Life in Late-Stage Dementia Scale (QUALID) (Weiner et al., 2000)

The QUALID is a brief, proxy-based instrument assessing QoL in people with dementia (Weiner et al., 2000). The assessment scale has been developed for use in the assessment of QoL in patients with late-stage dementia living in nursing homes. The assessment scale consists of 11 items. Each item is rated on a 5-point Likert scale, producing a sum score between 11-55, with the lowest score indicating the best QoL. The assessment scale is administered as a structured, proxy-based interview. The informant can either be a family member or a healthcare worker who has spent a considerable part of at least three of the last seven days with the person. The QUALID has been translated and validated in Swedish, Spanish and Norwegian (Dichter, Schwab, et al., 2016). The Norwegian version of the QUALID scale was first presented at an international conference in 2009 (Røen, Selbaek, \& Lerdal, 2009) and has been used in several studies and tested in two Norwegian studies previously to its use in Paper I in this thesis (Barca, Engedal, Laks, \& Selbaek, 2011; Mjorud, Kirkevold, Rosvik, \& Engedal, 2014).

Barca et al. used the QUALID scale in a study including 82 patients from $\mathrm{NHs}$ and 74 patients from geriatric departments (Barca et al., 2011) . A factor analysis resulted in two factors: discomfort (consisting of the items appears sad, cries, apparent discomfort, appears physically uncomfortable, verbalisation suggests discomfort, being irritable and aggressive and appears comfortable (Cronbach's alpha $=0.85)$ ) and comfort (consisting of the items smiles, cries (negative), enjoys eating, enjoys touching/being touched and enjoys social interaction (Cronbach's alpha $=0.66)$ ). Using linear regression analyses, they found that characteristics associated with lower QoL (total QUALID score) were a diagnosis of major depression, a lower score on Mini-Mental Status Examination (MMSE), impaired function in activities of daily living and female gender. Characteristics that were associated with the subscale discomfort were major depression, a lower score on MMSE and living in a department of geriatric psychiatry. The only characteristic associated with the subscale comfort was impaired function in activities of daily living (Barca et al., 2011).

Mjørud et al. performed a principal component analysis of the QUALID scale when used amongst people with dementia in NH (Mjorud, Kirkevold, Rosvik, \& Engedal, 2014). They identified three components of QoL: tension, (consisting of the items facial expression of discomfort, appears physically uncomfortable, verbalisation suggests discomfort, being irritable and aggressive and appears calm), well-being (consisting of the items smiles, enjoys eating, enjoys touching/being touched and enjoys social interaction) and sadness (consisting of the items appears sad, cries and 
facial expression of discomfort). They also found that the mean scores on the components tension and well-being increased significantly with increasing severity of dementia (Mjorud, Kirkevold, Rosvik, \& Engedal, 2014).

The Quality of Life in Alzheimer's Disease (QoL-AD) (R.G. Logsdon, Gibbons, McCurry, \& Terri, 1999)

The QoL-AD is a brief assessment scale including 13 self-report items and 15 caregiver-report items. To ensure the usefulness of the scale, simple and direct language was used, in addition to a detailed instruction for the interviewer. The QoL-AD can be filled out by the patient, the caregiver or both, and includes appraisal of the patient's physical condition, mood, interpersonal relationship, ability to participate in meaningful activities, financial situation, an overall assessment of self as a whole and quality of life as a whole. The items are rated from 1: being poor to 4: being excellent, giving a range from 13-52, with a higher score indicating a better QoL (R.G. Logsdon et al., 1999). In a paper from 2002, the reliability and validity of the QoL-AD were assessed, concluding that the QoL-AD was reliable and valid for individuals with MMSE scores greater than 10 (R. G. Logsdon, Gibbons, McCurry, \& Teri, 2002). According to Bowling's systematic review (Bowling et al., 2015), the QoL-AD is widely used and seems to be the best-studied QoL scale included in their comprehensive review. The QoL-AD has been translated and validated in English, Brazilian, Taiwan, Japanese, Mandarin Chinese, Cantonese, French, Spanish, Turkish and Portuguese (Dichter, Schwab, et al., 2016). The QoL-AD has also been translated into Norwegian and used in several studies, but no studies have yet to be published about the psychometric properties of the Norwegian version of the QoL-AD.

The QUALIDEM (Ettema, Droes, de Lange, Mellenbergh, \& Ribbe, 2007)

The QUALIDEM is a proxy-based assessment scale to assess QoL in persons with dementia focusing on the psychosocial domains of QoL. The QUALIDEM consists of two versions: one version for people with mild to severe dementia consisting of 37 items and one version for those with severe dementia consisting of 18 items. The 37-item version includes the following nine domains of QoL: care relationship, positive affect, negative affect, restless tense behaviour, positive self-image, social relations, social isolation, feeling at home and having something to do, and the 18 -item version includes the following six domains: care relationship, positive affect, negative affect, restless tense behaviour, social relationship and social isolation. Each item is rated from 0: never to 3: frequently, and the indicative items are scored opposite to the contra-indicative items. The scores on the subscales are calculated by adding up the item scores, giving a range from 0-111 for the 37-item version, and a range from 0-63 for the 18-item version, with a higher score indicating a better QoL (Dichter, Ettema, et al., 2016). The QUALIDEM was originally developed in the Netherlands as a research instrument, and it has been translated and validated in English and German in addition to the original Dutch version (Dichter, Schwab, et al., 2016). The QUALIDEM has been translated into Norwegian, but it has not yet been studied for psychometric properties.

The DEMQOL and DEMQOL-Proxy (Smith et al., 2005).

The DEMQOL is an assessment scale for assessing health-related QoL for people with dementia. It consists of 28 items for the person with dementia, presented by an interviewer for selfadministration by the person with dementia, and 31 items for proxy assessment (DEMQOL-Proxy), which were developed to be answered by caregivers. A comprehensive and detailed interview guide has been developed. The DEMQOL aims to assess QoL in people with mild to moderate 
dementia. DEMQOL relates only to areas of QoL that are affected by the health condition, and it is related to the impact of the symptoms and functional status. The items in the DEMQOL cover five domains divided into the following subscales: daily activities and looking after self, health and wellbeing, cognitive functioning, social relationships and self-concept. According to Bowling, the DEMQOL is amongst the best measures of health-related quality of life (HRQOL) for people with mild to moderate dementia (Bowling et al., 2015). Chua et al. recently conducted a study to explore the structural validity of the DEMQOL and DEMQOL-Proxy including 868 self-reports (DEMQOL) and 909 proxy reports (DEMQOL-Proxy) from a community memory service in South London. Their conclusion was that the DEMQOL and DEMQOL-Proxy total scores are likely to be accurate measures of individual differences in HRQOL, but the subscale scores should not be used (Chua et al., 2016). The DEMQOL and DEMQOL-Proxy have been further developed and tested for use in economic evaluations: DEMQOL-U and DEMQOL-Proxy-U, and found to be useful together with the European Quality of Life-5 Dimensions (EQ-5D), as they are more sensitive to patients with mild dementia (Mulhern et al., 2013). Both versions of the DEMQOL have been translated and validated in German and Spanish (Dichter, Schwab, et al., 2016). Both versions have also been translated to Norwegian, but no studies about the psychometric properties of the assessments have yet to be published, to the best of our knowledge.

\subsubsection{Self-rated vs proxy-rated QoL}

QoL is subjective, and reporting QoL is ideally done by the person him/herself. However, the cognitive decline in dementia decreases the person's ability to understand abstract concepts, recollect and describe their current situation. At some point, people with dementia become unable to meaningfully assess their own QoL, and clinicians or researchers must rely on assessments from proxy. Researchers have found consistent differences between self-reported and proxy-reported QoL in community settings, with self-reported QoL receiving higher scores than proxy-reported QoL (Banerjee et al., 2009; Beerens et al., 2015; Ydstebo et al., 2018). This suggests that proxies differ systematically from the person with dementia in how they evaluate the patient's QoL. Proxyreported QoL becomes more important in care home studies, as more patients have severe dementia than in the community and, therefore, are less able to self-report their QoL. To understand findings from research and making interventions meaningful, it is essential that QoL assessments of patients with dementia are valid (S. Robertson et al., 2017). 


\section{Aims of the thesis}

The overall aim of the thesis was to explore the association between organisational, staff and individual characteristics and person-centred care and quality of life during the disease course of patients with dementia to be able to improve the planning of care and treatment for persons with dementia in the municipality (illustrated in figure 3).

The specific aims for each paper are described below:

\subsection{Paper I}

The Reliability and Validity of the Norwegian Version of the Quality of Life in Late-Stage Dementia Scale

- To translate the Quality of Life in Late-Stage Dementia (QUALID) Scale into Norwegian.

- To evaluate the test-retest reliability and validity of the scale.

\subsection{Paper II}

Resource Use and Disease Course in Dementia - Nursing Home (REDIC-NH), a longitudinal cohort study: design and patient characteristics at admission to Norwegian nursing homes

- To describe the methods and the data collection in the REDIC-NH study.

- To present selected data about patients at admission to the nursing home.

\subsection{Paper III}

Person-centred care in Norwegian nursing homes and its relation to organisational factors and staff characteristics: a cross-sectional survey

- To explore and understand the association between person-centred care and organisational, staff and unit characteristics in nursing homes.

\subsection{Paper IV}

Exploring the trajectories of quality of life and its covariates in nursing home residents: A longitudinal study.

- To identify groups of residents following similar trajectories of quality of life after nursing home admission.

- To examine which resident, staff and organisational characteristics at baseline differ between the identified groups.

- To assess the associations between the trend in quality of life and the same characteristics measured at baseline and over the study period. 


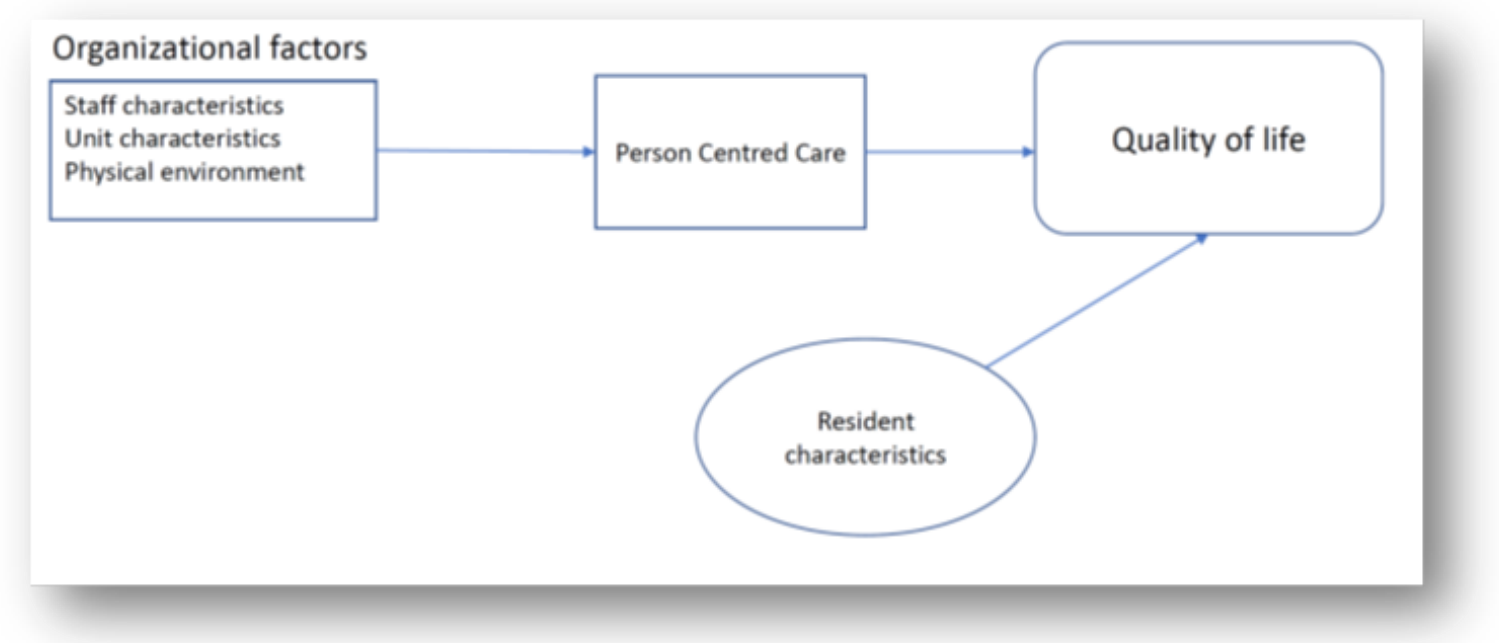

Figure 3 Illustration of the hypothesis of the thesis that person-centred care, as a product of several administrative factors, is a key element in the improvement of quality of life for persons with dementia in nursing homes. 


\section{Design and methods in the papers included in this thesis \\ 4.1 Design and method}

Paper I describes the translation of the Quality of Life in Late-Stage Dementia (QUALID) scale into Norwegian, according to the procedures described by Acquadro et al. (Acquadro, Jambon, Ellis, \& Marquis, 1996), and the testing of validity and test-retest reliability.

Three persons translated the English version of QUALID into Norwegian, and these translations were aggregated into one Norwegian version once a faculty research group agreed upon a preliminary version. This version was translated back into English by a native British translator and the English back-translated version was sent to one of the developers of the original QUALID for comments. The final Norwegian version of QUALID was agreed upon after a revision based on these comments and a discussion in the research group.

For testing validity and test-retest reliability of the Norwegian version of the QUALID scale, a quantitative cross-sectional design was used.

In Paper II, we describe the method for collecting data in a quantitative longitudinal observational cohort study, in addition to presenting data from the baseline data collection.

In Paper III, a quantitative cross-sectional design was used. Data about organisational and structural factors in the $\mathrm{NHs}$ at four levels were obtained: from the $\mathrm{NH}$ manager, from the head nurse of the $\mathrm{NH}$ unit, from the $\mathrm{NH}$ staff and from the assessment of the physical environment in the units.

In Paper IV, an observational quantitative longitudinal cohort design over the course of 30 months was applied, using the same patient data as in Paper II and the same NH data as in Paper III.

\subsection{Recruitment of participants}

The participants in all four papers (patients, staff and leaders) were recruited from nursing homes in Norway.

\section{Paper I}

Seven NHs in two counties participated in a project assessing all the patients in their nursing homes. The seven $\mathrm{NHs}$ had a total of 271 residents, of which 210 gave informed consent and were included in the project. Inclusion criteria for the present study were patients in the NHs with mild, moderate or severe dementia according to the Clinical Dementia Rating scale (CDR) with a minimum of a four-week NH stay. Of the 210 participants in the project, 169 had dementia and were included in the validation study, whilst 53 were included in the test-retest analysis.

\section{Paper II}

Participants in Paper II were from the Resource Use and Disease Course in Dementia - Nursing Home study (REDIC-NH), from which $47 \mathrm{NHs}$ in four Norwegian counties participated. In total, 696 were included at admission to the $\mathrm{NH}$, and they were followed every six months until death. Patients eligible for inclusion were all patients 65 years or older and younger patients with established dementia at admission. In addition, they should have had an expected stay in the $\mathrm{NH}$ of more than four weeks, and their life expectation should have been at least six weeks. Thirty-eight 
of the $47 \mathrm{NHs}$ collected information about all patients eligible for inclusion, and of 1331 eligible patients in these $38 \mathrm{NHs}, 607$ were included and 724 were excluded. A summary of the number of participants at each assessment are given in table 1.

Table 1. Number of participants at each assessment in the REDIC-NH cohort.

\begin{tabular}{|c|c|c|c|c|c|c|}
\hline & Baseline & $\begin{array}{l}\text { 6-month } \\
\text { FU }\end{array}$ & $\begin{array}{l}\text { 12-month } \\
\text { FU }\end{array}$ & $\begin{array}{l}\text { 18-month } \\
\text { FU }\end{array}$ & $\begin{array}{l}\text { 24-month } \\
\text { FU }\end{array}$ & $\begin{array}{l}\text { 30-month } \\
\text { FU }\end{array}$ \\
\hline Number included & 696 & 543 & 446 & 372 & 307 & 252 \\
\hline Number assessed & 696 & 509 & 428 & 350 & 295 & 237 \\
\hline Number that left the study & & 153 & 250 & 324 & 389 & 444 \\
\hline - Due to death & & 115 & 191 & 261 & 384 & 425 \\
\hline - Due to other reasons & & 38 & 59 & 63 & 5 & 9 \\
\hline - $\quad$ NH withdrawn & & 2 & 2 & 3 & & 2 \\
\hline - Patient withdrawn & & 4 & 8 & 9 & & \\
\hline $\begin{array}{l}\text { - Moved to another } \\
\text { unit or NH }\end{array}$ & & 15 & 21 & 23 & 3 & 2 \\
\hline $\begin{array}{ll}\text { - } & \text { Moved home } \\
\text { - } & \text { Other }\end{array}$ & & 17 & 28 & 28 & 2 & 5 \\
\hline
\end{tabular}

$\mathrm{FU}=$ Follow up; $\mathrm{NH}=$ nursing home

\section{Paper III}

Participants in this study were staff and leaders from 45 of the $47 \mathrm{NHs}$ from which patients in the REDIC study were recruited. The NH staff that the head nurse of the $\mathrm{NH}$ unit regarded as familiar with the care provided and the structural and organisational conditions of the unit were considered eligible for the study. All unit leaders and $1161 \mathrm{NH}$ staff from 175 units participated in the study. We did not collect information about the staff who did not participate in the study, including the total number of staff in each unit. A unit was defined as a group of patients living together with a common living area and having their own care staff during the day time.

\section{Paper IV}

In Paper IV, 694 patients of the 696 patients included in Paper II were analysed, as two patients had missing NH data. The same staff and leaders from the $175 \mathrm{NH}$ units included in Paper III were included.

\subsection{Assessments/measurements}

In Papers I, II and IV, several of the assessment tools used were the same (see Table 2), and the data collection procedure was similar in these three studies. Data were collected by healthcare professionals, mostly registered nurses (all data collectors were nurses in Paper I, and $74 \%$ in Papers II and IV). All data collectors participated in a two-day course about the principles of the data collection and the assessment tools used in the studies. Data about the patients were obtained through structured interviews with the patients, their next of kin and the caregivers in the NHs. Demographic data were collected from the NH records. 
Table 2. Data collected in Papers I, II and IV

\begin{tabular}{|c|c|c|c|c|}
\hline \multirow{2}{*}{ Assessment } & \multirow[b]{2}{*}{ Description } & \multicolumn{3}{|c|}{ Paper } \\
\hline & & $\mathrm{I}$ & II & IV \\
\hline \multicolumn{5}{|l|}{ Physical health } \\
\hline Blood pressure and pulse & & & $\mathrm{x}$ & \\
\hline Body Mass Index & & & $\mathrm{x}$ & \\
\hline General Medical Health Rating (GMHR) & Four-category scale rating physical health & & $\mathrm{x}$ & $\mathrm{x}$ \\
\hline $\begin{array}{l}\text { Mobilization-Observation-Behaviour-Intensity- } \\
\text { Dementia Pain Scale (MOBID-II) (Including VAS) } \\
\end{array}$ & Assessment of pain in patients with dementia & & $\mathrm{x}$ & $\mathrm{x}$ \\
\hline $\begin{array}{l}\text { Unified Parkinson's Disease Rating Scale (UPDRS), six- } \\
\text { item version }\end{array}$ & Assessment of extra-pyramidal symptoms & & $\mathrm{x}$ & \\
\hline Edmonton Symptom Assessment System (ESAS-r) & $\begin{array}{l}\text { Assessment of pain and distressing symptoms such as fatigue, } \\
\text { drowsiness, nausea, appetite disturbances, dyspnoea, } \\
\text { depression, anxiety and well-being }\end{array}$ & & $\mathrm{x}$ & \\
\hline Karnofsky Performance Status (KPS) & Functional performance status & & $\mathrm{x}$ & \\
\hline $\begin{array}{l}\text { Resident Assessment Instrument (RAI), subscales skin } \\
\text { and nutrition }\end{array}$ & Distressing symptoms, care and treatment provided & & $\mathrm{x}$ & \\
\hline Charlson's co-morbidity index & Co-morbid conditions & & $\mathrm{x}$ & \\
\hline \multicolumn{5}{|l|}{ Cognitive function and dementia } \\
\hline Mini-Mental State Examination (MMSE) & Screening for cognitive impairment & $\mathrm{x}$ & $\mathrm{x}$ & \\
\hline Severe Impairment Battery -8 (SIB-8) & Cognitive impairment in severe dementia & & $\mathrm{x}$ & \\
\hline $\begin{array}{l}\text { Informant Questionnaire on Cognitive Decline in the } \\
\text { Elderly (IQCODE) }\end{array}$ & Informant-rated scale of estimated cognitive decline & & $\mathrm{x}$ & \\
\hline Clinical Dementia Rating Scale (CDR) & Level of dementia (cognition and function) & $\mathrm{x}$ & $\mathrm{x}$ & $\mathrm{x}$ \\
\hline $\begin{array}{l}\text { Functional Assessment Staging of Alzheimer's Disease } \\
\text { (FAST) }\end{array}$ & Level of dementia (cognition and function) & & $\mathrm{x}$ & \\
\hline Diagnoses & Type of dementia according to an algorithm* & & $\mathrm{x}$ & $\mathrm{x}$ \\
\hline \multicolumn{5}{|l|}{ Neuropsychiatric and depressive symptoms } \\
\hline $\begin{array}{l}\text { Neuropsychiatric Inventory Nursing Home version } \\
\text { (NPI-NH) }\end{array}$ & Neuropsychiatric symptoms & $\mathrm{x}$ & $\mathrm{x}$ & $\mathrm{x}$ \\
\hline Neuropsychiatric Inventory-Questionnaire (NPI-Q) & A brief assessment of neuropsychiatric symptoms & & $\mathrm{x}$ & \\
\hline Cornell Scale for Depression in Dementia & Depression in persons with dementia. & $\mathrm{x}$ & $\mathrm{x}$ & \\
\hline Confusion Assessment Method (CAM) & Assesses the occurrence of delirium & & $\mathrm{x}$ & \\
\hline \multicolumn{5}{|l|}{ Functioning in daily living and physical symptoms } \\
\hline Physical Self-Maintenance Scale (PSMS) & Measures basal ADL & $\mathrm{x}$ & $\mathrm{x}$ & $\mathrm{x}$ \\
\hline Life-Space Assessment (LSA) & Assessment of life-space mobility & & $\mathrm{x}$ & \\
\hline Short Physical Performance Battery (SPPB) & Chair stand, balance and walking & & $\mathrm{x}$ & \\
\hline \multicolumn{5}{|l|}{ Quality of life } \\
\hline $\begin{array}{l}\text { Quality of Life in Alzheimer's Disease - patient rated } \\
\text { (QoL-AD) }\end{array}$ & Measures disease-specific QoL & & $\mathrm{x}$ & \\
\hline $\begin{array}{l}\text { Quality of Life in Alzheimer's Disease - staff rated } \\
\text { (QoL-AD) }\end{array}$ & Measures disease-specific QoL & & $\mathrm{x}$ & \\
\hline $\begin{array}{l}\text { Quality of Life in Alzheimer's Disease - patient or staff } \\
\text { rated (QoL-AD) }\end{array}$ & Measures disease-specific QoL & & $\mathrm{x}$ & \\
\hline Quality of Life in Late-Stage Dementia (QUALID) & Measures QoL in severe dementia & $\mathrm{x}$ & $\mathrm{x}$ & $\mathrm{x}$ \\
\hline EQ-5D (including VAS) & Measures health-related QoL & & $\mathrm{x}$ & \\
\hline Medication regular prescription & Drug type and daily dose & & $\mathrm{x}$ & \\
\hline \multicolumn{5}{|l|}{ Cost of care } \\
\hline Resource Utilisation in Dementia (RUD) & Formal and informal care before $\mathrm{NH}$ admission & & $\mathrm{x}$ & \\
\hline $\begin{array}{l}\text { Resource Utilisation in Dementia - Formal Care (RUD- } \\
\text { FOCA) }\end{array}$ & $\begin{array}{l}\text { Measures direct care time required in nursing when living in a } \\
\mathrm{NH}\end{array}$ & & & \\
\hline \multicolumn{5}{|l|}{ Caregiver burden } \\
\hline Relative Stress Scale (RSS) & Assessment of caregiver burden & & $\mathrm{x}$ & \\
\hline
\end{tabular}

\footnotetext{
* The algorithm is presented in Text Box 7, page 64.
} 


\subsubsection{Cognitive function and severity of dementia}

To measure global cognition, we used the Mini-Mental State Examination (MMSE) (Folstein, Folstein, \& McHugh, 1975), a screening questionnaire for cognitive decline that examines cognitive abilities such as orientation, attention, calculation, recall, language skills and construction. The MMSE is scored on a scale from 0-30, where a higher score indicates better cognition. The severity of the dementia was assessed with the Clinical Dementia Rating Scale (CDR) (Hughes, Berg, Danziger, Coben, \& Martin, 1982), a global rating scale covering six domains (memory, orientation, judgement and problem solving, community affairs, home and hobbies, and personal care) of cognitive and functional performance, based on all available information to evaluate the patient.

The following scales were also used for assessing cognitive function and dementia. The eightquestion version of Severe Impairment Battery (SIB-8) (Schmitt et al., 2009) ranges from 0-16, where a higher score indicates better cognitive function. Changes in ADL and cognitive functioning over the last 10 years were assessed with the Informant Questionnaire of Cognitive Decline in the Elderly (IQCODE), a proxy-based scale with 16 items giving detailed clinical information about debut, course and symptoms of dementia, scored 1-5, where a mean score of 3.44 and above indicates dementia (Jorm, 2004). The Functional Assessment Staging of Alzheimer Disease (FAST) scale, ranging from 0-7 with a higher score defining lower function, was used to give a more detailed assessment at the severe stage of dementia (Reisberg, 1988).

Mild cognitive impairment $(\mathrm{MCl})$, dementia or no cognitive impairment, and if dementia, the dementia subtypes, were diagnosed independently by two medical doctors, one psychiatrist and one internal physician specialising in psychiatry, both of whom were experienced old age psychiatrists and researchers. They could also consult a third specialist, also a psychiatrist, to reach a consensus. Diagnoses were based on all available information in the collected data, including an algorithm to collect information about the first symptoms and the development of the patients' cognitive impairment, which was developed for the REDIC study. Dementia was diagnosed according to the International Classification of Diseases, version 10, research criteria (ICD-10 (World Health Organization (WHO), 1993), and MCI was diagnosed according to Winblad's criteria (Winblad et al., 2004). Alzheimer's disease, vascular dementia, and mixed AD/VaD were diagnosed according to the ICD-10 criteria (World Health Organization (WHO), 1993); Lewy body dementia was diagnosed according to the DLB consortium criteria (McKeith et al., 2005); and fronto-temporal dementia was diagnosed according to the Manchester-Lund criteria (Neary et al., 1998). 


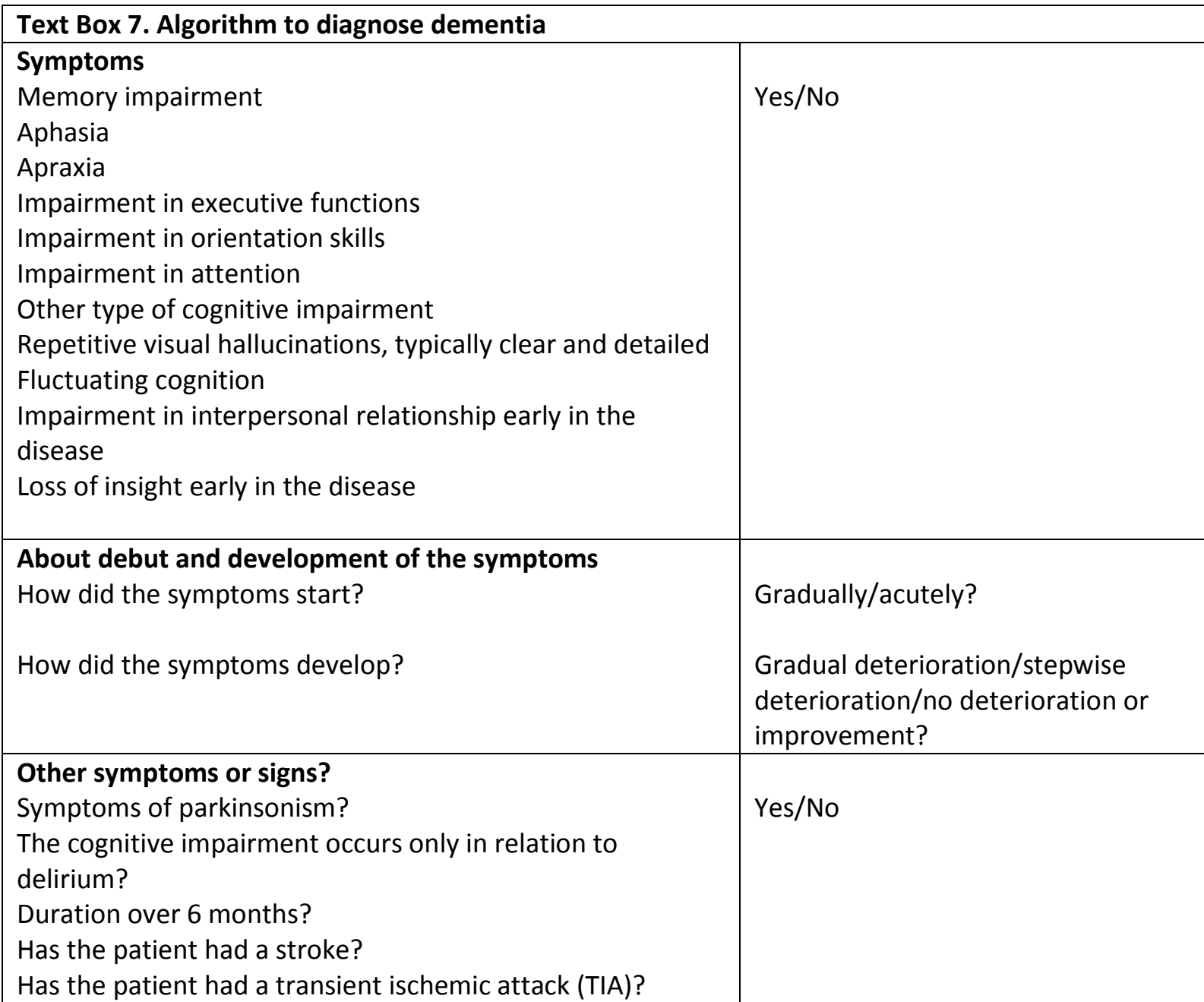

\subsubsection{Physical health status}

An examination of broad physical health measures was done: blood pressure, pulse, weight and height were measured following a standard procedure. General physical health was assessed with the General Medical Health Rating Scale (GMHR) (Lyketsos et al., 1999), which is a global rating scale consisting of one item rated as excellent, good, fair or poor. The Mobilisation-ObservationBehaviour-Intensity-Dementia Pain Scale (MOBID-2) (Husebo et al., 2007) was used for assessing pain. MOBID-2 consists of 10 items, each item ranging from 0-10, with a higher score indicating more severe pain. Additionally, the overall pain was assessed on a 10-point visual analogue scale (VAS). The Unified Parkinson's Disease Rating Scale (UPDRS-6) (Ballard et al., 1997), ranging from 024, with a higher score indicating more severe symptoms, was used to assess extrapyramidal symptoms. The Edmonton Symptom Assessment System (ESAS) (Bruera, Kuehn, Miller, Selmser, \& Macmillan, 1991), ranging from 0-10, with a higher score indicating more severe symptoms, was used to assess physical symptoms. The Karnofsky Performance Status Scale (KPS) (Crooks, Waller, Smith, \& Hahn, 1991), an 11-item rating scale from normal functioning (100) to dead (0), was used to assess the patients' overall functioning. Two subscales from the Residents Assessment Instrument (RAI-NH) (Morris et al., 1990) were used to evaluate the patients' skin and nutrition condition. Finely, the Charlson comorbidity index (Charlson, Pompei, Ales, \& MacKenzie, 1987), with 18 different groups of diseases, was used for assessment of comorbidity. 


\subsubsection{Neuropsychiatric and depressive symptoms, and delirium}

We used the Neuropsychiatric Inventory 12 -item Nursing Home version (NPI-NH) (Cummings et al., 1994; Selbaek, Kirkevold, Sommer, \& Engedal, 2008) and the Cornell Scale for Depression in Dementia (CSDD) (Alexopoulos et al., 1988) to assess NPS and depressive symptoms.

An NPI item score is calculated by multiplying the frequency (0-4) and the severity (0-3), producing an item score (0-12) where a higher score indicates more severe symptoms. A clinically significant NPS (CS-NPS) is defined as an NPI item score of four and above (Steinberg et al., 2004). NPI subsyndrome scores were calculated based on a previous principal component analysis: NPI-agitation (agitation/aggression, disinhibition and irritability), NPI-psychosis (delusions and hallucinations) and NPI-affective (depression and anxiety) (Selbaek \& Engedal, 2012; Selbaek et al., 2014).

The CSDD includes 19 items, with ratings on individual items on a scale from 0-2. A score of 1 represents mild or intermittent symptoms, and a score of 2 denotes severe symptoms. The total score is achieved by multiplying the ratings for all 19 items (0-38 points), where a higher score indicates more severe depression.

The brief Neuropsychiatric Inventory-Questionnaire (NPI-Q) (Kaufer et al., 2000) was completed at baseline by the patient's next of kin to assess NPS symptoms from the debut of dementia and prior to nursing home admission. The Confusion Assessment Method (CAM) (Inouye et al., 1990), a fourstep algorithm assessing delirium symptoms, was performed to detect delirium.

\subsubsection{Functioning in daily living and physical performance}

We used the Physical Self-Maintenance Scale (PSMS) (Lawton \& Brody, 1969) to assess the patients' functional status. The PSMS is a six-item scale (scored 1-5) ranging from 6-30, where a higher score indicates a lower level of functioning.

We also used the Life-Space Assessment (LSA) (Baker, Bodner, \& Allman, 2003) to assess the range, independence and frequency of the patient's movement over the preceding two weeks, ranging from 0-20 with a higher score indicating more movement, and the Short Physical Performance Battery (SPPB) (Guralnik et al., 1994), ranging from 0-12 with a higher score indicating better physical performance, to assess balance and gait speed.

\subsubsection{Quality of life, resource use and relative stress}

To assess QoL, we used the Quality of Life in Alzheimer's disease (QoL-AD) scale (R. G. Logsdon et al., 2002), the EQ-5D (EuroQol Group, 1990) and the Quality of Life in Late-Stage Dementia scale (QUALID) (Roen et al., 2015; Weiner et al., 2000).

The QoL-AD consists of 13 items rated from 1-4 (range 13-52), with a higher score indicating a better QoL, and was completed by both the patient and the caregiver. The QUALID is a proxy-based assessment scale consisting of 11 items with scores from 1-5, ranging from 11-55, with lower scores indicating a better QoL. For more information on the QoL-AD and QUALID, see Chapter 2.5.4.1. The EQ-5D is developed by the EuroQoL Group to provide a simple, generic measure of health status for clinical and economic evaluation. The EQ-5D is a brief self-reported instrument comprising five dimensions: mobility, self-care, usual activities, pain/discomfort and anxiety/depression, that are thought to describe health status. Each of the five dimensions is divided into five levels of perceived problems, from level 1 - indicating no problems to level 5 - indicating extreme problems. The EQ-5D 
includes a visual analogue scale ranging from 0 (worst imaginable health state) to 100 (best imaginable health state). The EQ-5D user guide (EuroQol Research Foundation, 2018) describes various ways to summarise data collected using the EQ-5D: as a descriptive system; as a health profile; as a measure of overall self-rated health status; or as an index value, determined both by the data collected and by the results the researcher wants to present.

We collected information about the cost of care with the Resource Utilisation in Dementia Questionnaire (RUD) (Wimo, Jonsson, \& Zbrozek, 2010), which assesses the use of formal and informal care the last month before admission to the $\mathrm{NH}$. To assess caregiver burden during the last month before NH admission, we used the Relative Stress Scale (RSS) (Greene, Smith, Gardiner, \& Timbury, 1982; Ulstein, Bruun Wyller, \& Engedal, 2007). The RSS includes 15 items scored from 0-4, where a higher score denotes a higher caregiver burden.

\subsubsection{Person-centred care (PCC)}

We used the Person-Centred Care Assessment Tool (P-CAT) (Edvardsson et al., 2010; A. M. Rokstad et al., 2012) to assess the degree of PCC in the NH unit. The P-CAT consists of 13 items formulated to assess the staff perceptions of person-centred care in the unit where they work. The staff indicated on a 5-point Likert scale, ranging from 1 (disagree completely) to 5 (agree completely), how they perceived the care in the unit. The total score ranges from 13-65, with higher scores indicating a higher level of PCC. See also Chapter 2.4.4.

\subsubsection{Nursing home staff factors}

We collected NH staff data through questionnaires containing demographic information such as age, gender, Norwegian as a first language, number of years of health-related and relevant continuing education, experience in the current job and percentage of full-time position. The staff's work-related psychosocial factors were assessed with the General Nordic Questionnaire for Psychosocial and Social Factors at Work (QPS-Nordic) (Dallner et al., 2000). The QPS-Nordic covers essential social and psychological factors at work, including 129 items that encompass 11 background items, 38 single items and 80 items distributed in 13 scales. We included 32 items from ten sub-scales: quantitative demands, decision demands, learning demands, perception of mastery, empowering mastership, fair leadership, role clarity, role conflict, innovative climate and perception of group work. The respondents indicated how relevant each statement was for their situation on a 5 -point Likert scale, from 1 (very seldom or never) to 5 (very often or always). Each sub-scale consists of 3-4 items, giving a subscale score of 3-15 or 4-20.

Staff general job satisfaction was collected through a single question: How would you describe the general experience of your job satisfaction? This could be answered with one of the following alternatives: very bad, bad, unsure, quite good, good or excellent.

\subsubsection{Nursing home unit characteristics}

Through a questionnaire distributed to the head nurse of the $\mathrm{NH}$ unit, we collected data about organisational and structural factors in the $\mathrm{NH}$, such as type of unit (SCU or RU), the unit size (number of patients), the day time staff/patient ratio (the number of NH staff working per patient during the day time), the number of units for which the head nurse was responsible and the number of hours the $\mathrm{NH}$ physician was working per patient per week in the $\mathrm{NH}$ unit. 


\subsubsection{Physical environment in the nursing home unit}

To assess the physical environment of the unit, we used the Special Care Unit Environmental Quality Scale (SCUEQS), which is a summary scale embedded in the Therapeutic Environment Screening Survey for Nursing Homes (TESS-NH) (Sloane et al., 2002).

The TESS-NH was developed to describe the ability of physical environments in NHs to address therapeutic goals for persons with dementia. The TESS-NH contains 84 discrete items and one global rating, and the SCUEQS consists of 18 of the TESS-NH items. The SCUEQS measures maintenance, cleanliness, safety, lighting, physical appearance/home likeness, orientation/cueing and noise (Sloane et al., 2002). Scores range from 0-41, where higher scores indicate a better physical environment.

The TESS-NH was translated into Norwegian and back-translated according to the procedures described by Acquadro (Acquadro et al., 1996). The American version of the TESS-NH was translated into three Norwegian versions by three researchers, aggregated into one Norwegian version, and a faculty research group agreed on a preliminary version. This version was translated back into English by Allegro Language Services. The English back-translated version was sent to Prof. Sloane, the developer of the original TESS-NH, to get his comments. The final Norwegian version of the TESS-NH was agreed upon after a revision based on Prof. Sloane's responses and a discussion in the research group. The Norwegian version has not been tested for psychometric properties.

\subsection{Statistical analyses}

In the studies presented in this thesis, several types of statistical software were used. In all the papers, different versions of IBM SPSS (Armonk, NY: IBM Corp), from v21 in Paper I to v25 in Paper IV, were used. In Paper III, MLwiN v2.36 (Centre for Multilevel Modelling, University of Bristol) was used to check for a clustering effect of the units, and in Paper IV, SAS v 9.4. (Cary, NC: SAS Institute Inc.) was used in the longitudinal analysis and to check for clustering effects.

The Internal consistency of QUALID was tested with Cronbach's Alpha (Paper I). Furthermore the inter-rater reliability was analysed with the intra-class correlation (ICC) coefficient. The validity of QUALID was analysed by testing the correlations between the QUALID score and relevant characteristics and then adjusted for each other in a multilinear regression model.

In Paper II, the baseline data were presented, and data from the people with dementia were compared with those without dementia. The Independent Student's t-test, Pearson Chi-square Test, Fisher's Exact Test or the Mann-Whitney U Test was performed, depending on the distribution of the data.

In Paper III, the Independent Student's t-test and the Mann-Whitney U test were performed to compare different unit characteristics and P-CAT scores in regular units and special care units. To analyse how staff characteristics, unit characteristics and organisational factors were associated with the P-CAT score, multilevel linear regression models were used.

In Paper IV, the effects of patient characteristics, unit characteristics (organisational factors) and staff characteristics on QoL in a longitudinal perspective were analysed using a linear mixed model with random effects for patients, units and the interaction between the patients and units. 
To identify which characteristics were associated with higher odds of belonging to the different QoL groups, we used a nominal regression model with group belonging as the outcome variable and characteristics measured at baseline as explanatory variables. To identify which patient, staff and unit characteristics were associated with QoL (QUALID score) over time, we used an AIC-reduced linear mixed model.

\subsection{Ethical considerations}

Studies I, II and IV were approved by The Regional Ethics Committee for Medical Research in SouthEastern Norway. In addition, Study I was approved by the Norwegian Data Inspectorate and the Norwegian Directorate of Health. In the three studies including information about the patients (Studies I, II and IV), the patients with the capacity to consent gave informed consent. In Study I, the next of kin of the patients were informed about the study, and they had the possibility to reject on behalf of their relatives. In Studies II and IV, the next of kin gave written consent on behalf of the patient if the patient lacked the capacity to consent.

Many persons with moderate and severe dementia have, due to their cognitive decline, reduced or no capacity to consent. It is, therefore, difficult to assess if they want to participate in research. Research should be based on informed consent (Rickham, 1964), but without inclusion of these vulnerable persons without the capacity to consent in research, it will be difficult to gain new knowledge about dementia. Only doing research on patients with mild or no dementia would not be sufficient to gain new knowledge, so not including vulnerable persons in research is also ethically questionable. In conclusion, the ethical questions and the negative aspects of including patients with no or reduced capability to consent in research are outweighed by the possible new knowledge gained that could be of importance for the individual, the group of patients and society.

In Study III, the NH staff gave information anonymously, and no personal information about health matters was collected.

Since all these studies were observational studies and no interventions were carried out, the studies did not aim to change the care for the individual or group of participants. If there was a change in the care, it presumably should be an improvement, as the staff and the leaders were aware that there was a research project going on in their $\mathrm{NH}$. The patients were tested with the MMSE and asked about their quality of life, which can be experienced as stressful; due to that, it may be difficult to answer and awaken thoughts and feelings about their situation. The staff used some of their working time to score the different assessment tools and answer the questionnaires, which may be experienced as stressful in a busy working situation.

The data that were collected are potentially sensitive data, and, therefore, careful consideration is required, particularly when many of the participants have reduced capacity to consent.

However, collecting this information is seen as good clinical practice and should be a source for important knowledge about the patient, not a burden. 


\section{Main results}

\subsection{Paper I}

The Reliability and Validity of the Norwegian Version of the Quality of Life in Late-Stage Dementia (QUALID) Scale

This paper describes the translation and the test of the psychometric properties of the Norwegian translation of the QUALID scale.

\section{Validity}

The Cronbach's alpha was 0.79, which is acceptable (Field, 2013) and all the items contributed positively to the total Cronbach's alpha. There was a strong association between the QUALID score and depression (standardised regression coefficient $[S R C]=0.754 ; p<0.001$ ) and a moderate association between the QUALID score and the level of physical functioning $(S R C=0.250 ; p<0.001)$ and agitation (SRC $=0.285 ; \mathrm{p}<0.001)$.

Test - retest reliability

The intra-class correlation was 0.83, which can be considered as good reliability (Cicchetti, 1994).

\subsection{Paper II}

Resource Use and Disease Course in Dementia - Nursing Home (REDIC-NH), a longitudinal cohort study; design and patient characteristics at admission to Norwegian nursing homes

This paper described in detail the design, content and methods of the collection of patient-related data in the REDIC study. Furthermore, the baseline data from the REDIC study are presented, and patients with and without dementia are compared.

Nearly $84 \%$ of the patients had dementia, and those with dementia were older (mean age 86.5 vs. 84.1 years; $p=0.002)$, less often unmarried/divorced/widowed (67.6\% vs. $79.3 \% ; p=0.015)$ and less often admitted from hospital (13.6 \% vs. $21.7 \%$; $p=0.046)$. Of the total number of patients with dementia, $37.0 \%$ were in special care units (SCU), $52.0 \%$ in regular units (RU) and $11.0 \%$ in respite and rehabilitation units. For patients without dementia, the proportions were $8.8 \%, 72.6 \%$ and $18.6 \%$, respectively, and these differences were statistically significant $(p<0.001 ;<0.001 ; 0.024)$. Patients with dementia had less pain (Mean MOBID-2 score 1.96 vs. 2.84; $P<0.001$, and overall MOBID-2 pain score 2.17 vs. 3.42; $\mathrm{p}<0.001$ ). Fewer patients with dementia had impaired vision, and patients with dementia were prescribed less sedative medication but more anti-dementia medication than patients without dementia. Depression and anxiety were the most common NPS symptoms, and patients with dementia more often experienced delusions, hallucinations, agitation, anxiety, disinhibition, irritability and aberrant motor behaviour compared to patients without dementia.

\subsection{Paper III}

Person-centred care in Norwegian nursing homes and its relation to organizational factors and staff characteristics: A cross-sectional survey

This paper aimed to explore and understand the association between PCC and organisational, staff and unit characteristics in $\mathrm{NH}$.

NH Staff $(n=1161)$ and the leaders for $175 \mathrm{NH}$ units from the REDIC study were included. Data about PCC, staff characteristics, staff's work-related psychosocial factors and organisational and 
structural factors were collected, in addition to an assessment of the physical environment in the units.

Most of the NH staff were female (96.6\%), about half (56.4\%) were between 40 and 59 years old, and nearly all (91.9\%) had Norwegian as their first language. Most of the staff (60.8\%) had a position of $75 \%$ full-time or more, $29.9 \%$ had three years or more of health-related education and $27.4 \%$ had received relevant continuing education. About half (49.7\%) had worked 5-15 years at the $\mathrm{NH}$ unit and $69.2 \%$ of the staff rated their job satisfaction as good or excellent. Of the 175 units, 62 (35.4\%) were SCU, and we found that there were differences between the RU and the SCU in the number of beds per unit $(p<0.001)$, staff/patient ratio $(p=0.007)$, head nurse for number of units $(p=0.009)$, physical environment $(p=0.033)$ and PCC $(p<0.001)$. A multilevel linear regression analysis showed that high staff job satisfaction and three years or more health-related education were positively associated with more PCC (higher P-CAT score). Of the QPS-N sub-scales, perception of mastery, empowering leadership, innovative climate and perception of group work were positively associated with more PCC (higher P-CAT score), whilst quantitative demands and role conflict were negatively associated with more PCC (P-CAT score) in the unit. Type of unit (RU/SCU) and the physical environment were associated with more PCC (higher P-CAT score).

\subsection{Paper IV}

\section{Exploring the trajectories of Quality of Life and its covariates in nursing home residents: A longitudinal study.}

The aim of this paper was to identify groups of residents following similar trajectories of QoL after admission to a NH to examine which resident, staff, and organisational characteristics at baseline differed between these groups and assess the associations at baseline and over the study period between the trend in QoL and the identified characteristics.

Residents ( $n=694$ ) and staff ( $n=1161$ ) from $175 \mathrm{NH}$ units participated in this study.

Using a growth mixture model, three resident groups following similar trajectories of QoL were identified ( $n=686$ ): one group was named good QoL ( $n=368,53.6 \%)$, one moderate QoL $(n=226$, $32.9 \%)$ and the last and smallest group was named poor QoL ( $n=92,13.4 \%)$. All the groups' QoL decreased over the 30-month follow-up period.

We found that more severe dementia, more pain and more severe affective symptoms at baseline were associated with higher odds of belonging to the moderate and the poor QoL group compared to the good QoL group, whilst more severe agitation at baseline was associated with higher odds of belonging to the poor QoL group compared to the good QoL group.

We found that more severe dementia, more pain, lower ADL function and more severe NPS (except for the NPI-psychosis sub-syndrome) were associated with decreasing QoL, and better staff job satisfaction was associated with increasing QoL during the study period.

\subsection{Additional results}

In Paper III, P-CAT scores were the outcome, and in Paper IV, P-CAT scores at the staff level were aggregated to an explanatory variable with QUALID scores as the outcome. The distribution of the mean P-CAT score (unit level) is shown in Figure 4. 


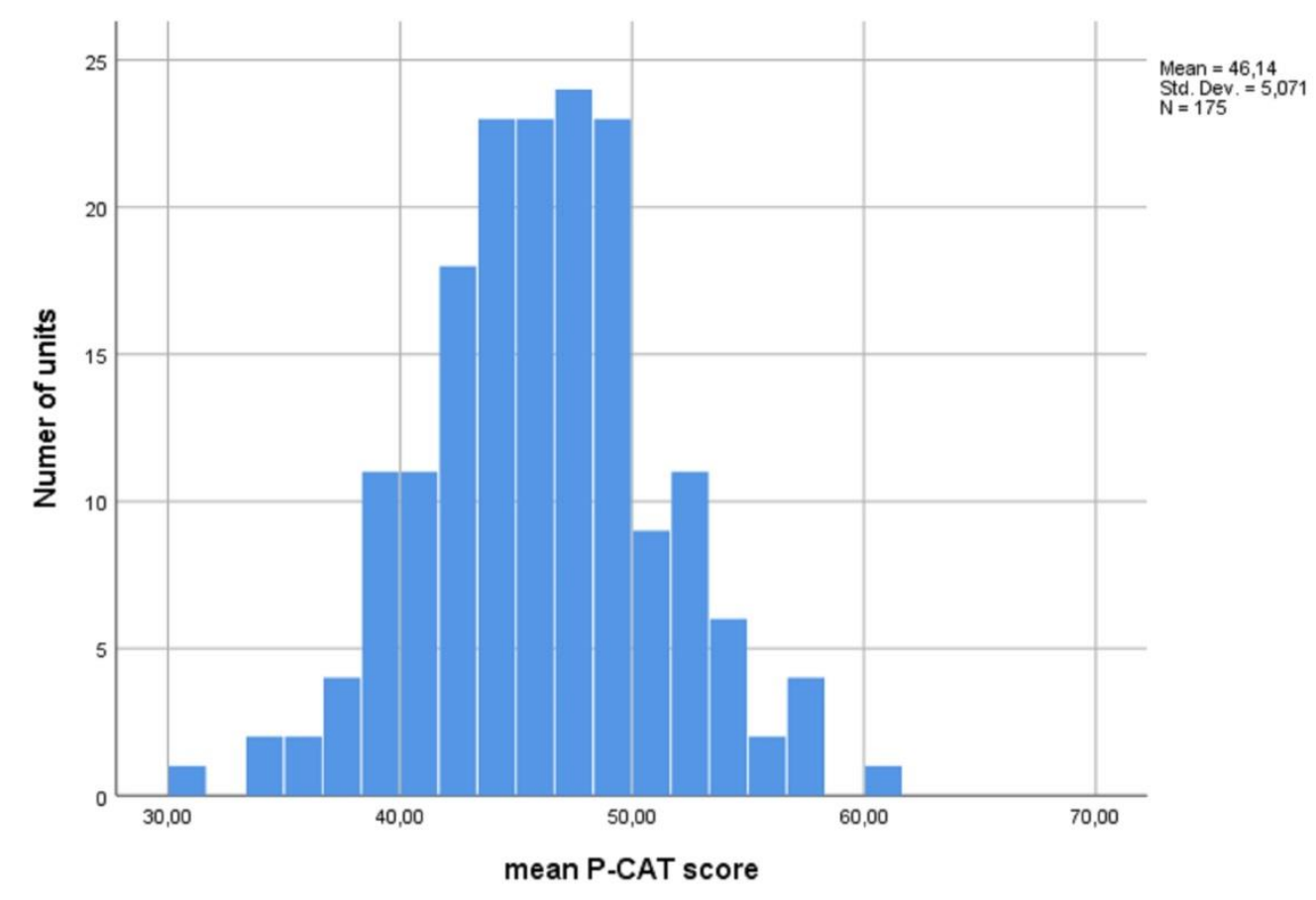

Figure 4 Distribution of mean P-CAT score for each unit $n=175$

Since job satisfaction was strongly associated with the P-CAT in Paper III, and it was the only unit characteristic that was associated with QUALID scores in Paper IV, it was interesting to further explore the characteristic job satisfaction. By analysing the staff's job satisfaction scores in an empty linear multilevel model with staff as level 1 and unit as level 2, the ICC was $12.4 \%$. Job satisfaction was strongly associated with several of the QPS-Nordic sub-scales (see Table 3), but with none of the other staff characteristics or unit characteristics described in Paper III. The distribution of mean job satisfaction score at the unit level is shown in Figure 5.

Table 3. Linear multi-level multivariate regression analysis; job satisfaction as dependent variable

\begin{tabular}{|l|l|}
\hline & Multivariate Correlation coefficient (p-value) \\
\hline QPS-N. Quantitative demands & $-0.043(<0.001)$ \\
\hline QPS-N. Decision demands & $-0.003(0.817)$ \\
\hline QPS-N. Learning demands & $-0.015(0.317)$ \\
\hline QPS-N. Perception of mastery & $0.056(<0.001)$ \\
\hline QPS-N. Empowering leadership & $0.042(<0.001)$ \\
\hline QPS-N. Fair leadership & $0.040(<0.001)$ \\
\hline QPS-N. Role clarity & $0.020(0.153)$ \\
\hline QPS-N. Role conflict & $-0.027(0.038)$ \\
\hline QPS-N. Innovative climate & $0.026(0.063)$ \\
\hline QPS-N. Perception of group work & $0.072(<0.001)$ \\
\hline
\end{tabular}

QPS-N=QPS-Nordic

The association between job satisfaction and the P-CAT, with the P-CAT as the dependent variable, gave a regression coefficient $=3.24$ at the staff level (Table 3, Paper III). The association between mean job satisfaction score and mean P-CAT score at the unit level, with the P-CAT as the dependent variable, gave a regression coefficient $=5.6$ (See Figure 6). 


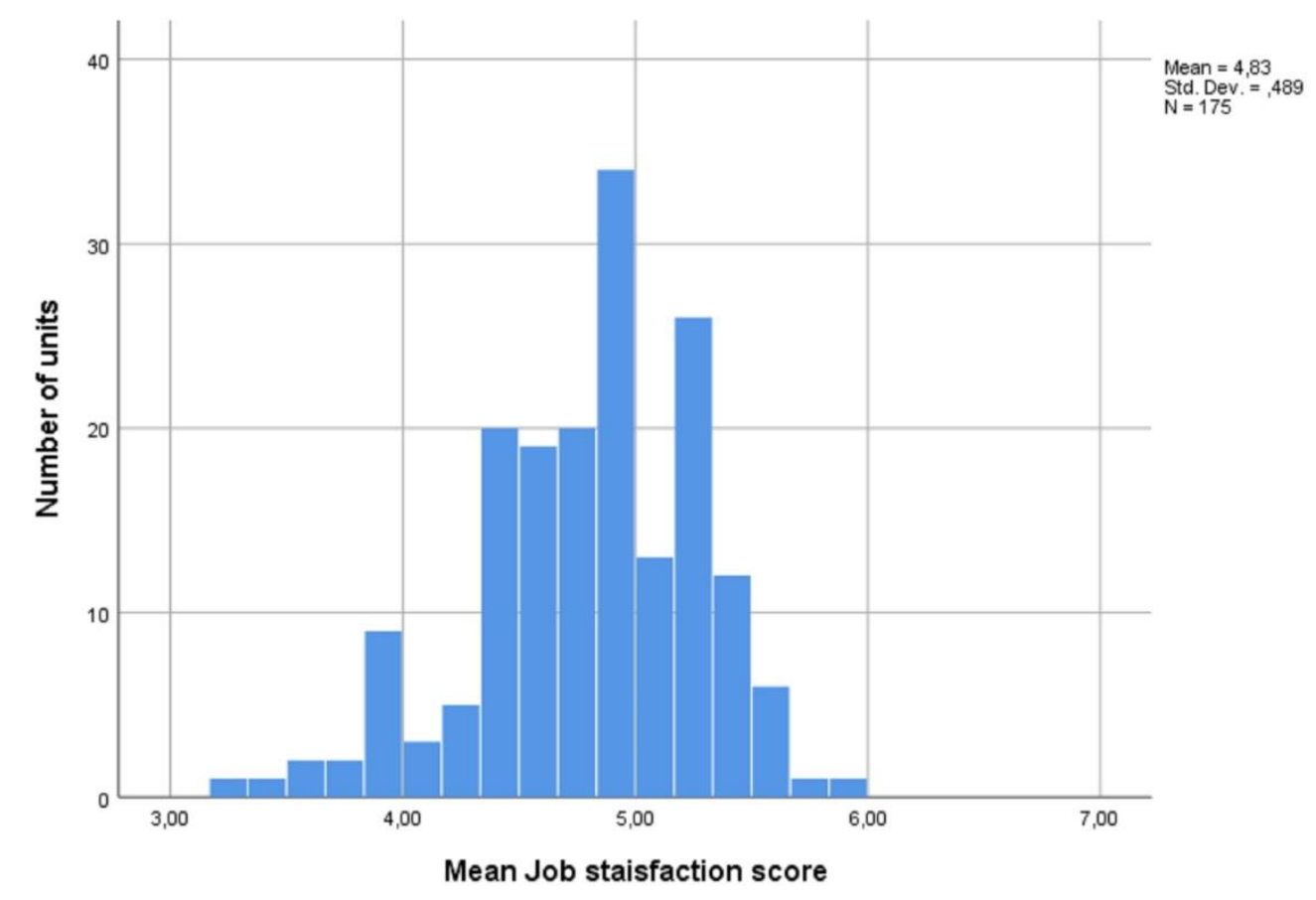

Figure 5 Distribution of mean job satisfaction score at unit level ( $n=175)$

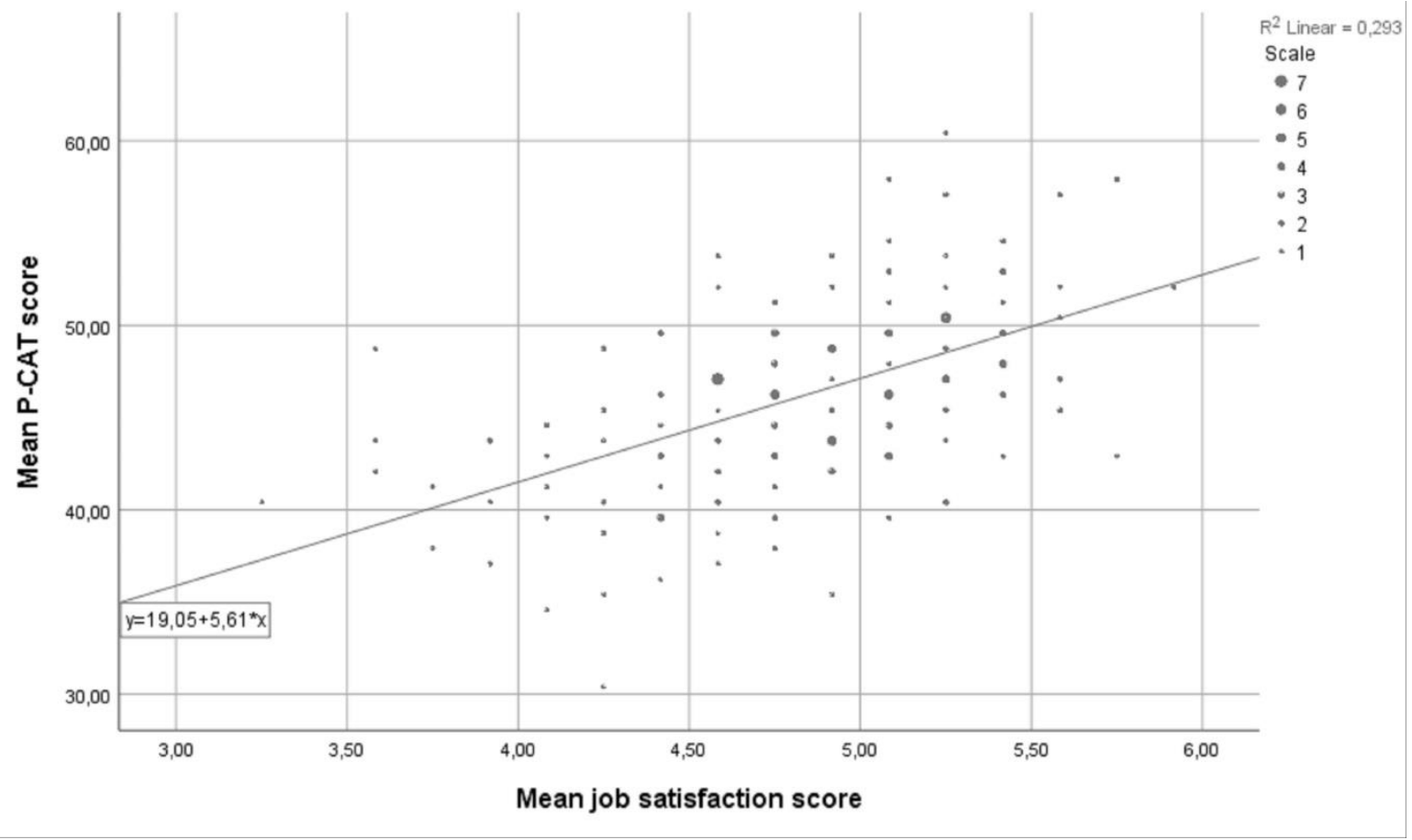

Figure 6 Association between mean job satisfaction and mean P-CAT 


\section{Discussion}

The discussion is divided in two main sections: methodological considerations in Chapter 6.1 and discussion of the results in Chapter 6.2.

\subsection{Methodological considerations}

Data collected for research should be reliable and valid, securing that the results of the study are valid. It is also important to collect data that are necessary to answer the research questions in the study. The results should be generalisable, so it is important that the participants of the study are representative of the total population. Representativeness is also important in terms of NHs and municipalities included in the study.

As all the sub-studies of this thesis were performed in a real clinical setting, they have several methodological challenges. In this section, the challenges, possible weaknesses, limitations and strength of the sub-studies, and how they are met, will be described.

\subsubsection{Reliability and validity of QUALID}

As described in detail in Paper I, the translation of the QUALID was done according to the procedures described by Acquadro et al. (Acquadro et al., 1996). Three translators, all medical doctors with extensive experience in examining persons with dementia, translated the English version of QUALID into Norwegian. These translations were aggregated into one Norwegian version, which a faculty research group agreed upon as a preliminary version. This version was translated back to English by a native British translator (registered nurse), fluent in English and Norwegian. The English back-translated version was sent to Prof. Myron Weiner, who had developed the original QUALID, for comments. Prof. Weiner only had some small suggestions for changes in the back-translated version, and the final Norwegian version of QUALID was agreed upon after a revision based on Prof. Weiner's responses and a discussion in the research group. The items that required the most discussion in the faculty research group were item $\mathrm{H}$ (if the subject enjoys eating) and item I (if the subject enjoys touching/being touched), as the word enjoy translated to nyter in Norwegian sounds unfamiliar. In the final Norwegian version, the Norwegian word nyter was chosen for enjoy in item $\mathrm{H}$, and the Norwegian word liker (Eng: likes) was chosen in item I. Even though the translation was performed in accordance with standard procedures (Acquadro et al., 1996), the meaning and understanding of an item may be different in different languages, so small adaptions have to be done like the ones described above. Therefore, the Norwegian version of QUALID may be valid and useful in a Norwegian setting, but due to minor differences in the expressions in different languages, it is not certain that the Norwegian QUALID assesses QoL in the same way as the original QUALID. In addition to the minor differences in language expression, there might be cultural differences in different geographical areas due to ethnicity, sociodemographic differences and traditions leading to differences in QoL, or how QoL is expressed and assessed, that may cause differences in the QUALID score between countries.

A quantitative cross-sectional design was used for testing the psychometric properties of the Norwegian version of the QUALID scale. A total of 169 residents with dementia from seven NH were included in the validity test, and 53 of them were included in the test-retest analysis. 
There is no consensus of a definition of QoL and, thus, no criterion that describes all aspects of QoL. A validity test must, therefore, be partly based on factors that are found to be associated with QoL and factors that seem to be important for QoL (face validity). Thus, for the validity testing, we used the MMSE, CDR, CSDD, PSMS and NPI-NH to collect data on cognitive impairment and degree of dementia, depression, physical performance and NPS, which, according to previous studies, were useful characteristics to assess validity of a QoL scale (Ettema et al., 2007; Falk, Persson, \& Wijk, 2007; Garre-Olmo et al., 2010; R.G. Logsdon et al., 1999). Based on the previous discussion (Chapter 2.5) on the concept of QoL and difficulties on assessing QoL in persons with dementia, no gold standard test for QoL exists against which QUALID could be validated. A validity study of the QUALID with other dementia-specific QoL instruments could have been performed, as were done in developing the DEMQOL. In that study, the correlation between the two QoL instruments were lower than expected, and the authors suggested that different QoL instruments may measure related, but different, constructs of QoL (Smith et al., 2005). It can be argued that QoL scales do not measure QoL, and that only a clinical judgment, for example, by interviewing the patient and carer can assess QoL. However, clinical judgment is not a feasible procedure to assess QoL in NH patients with severe dementia. Our findings that the Norwegian version of the QUALID is associated with the same characteristics as other translated versions of the QUALID (Falk et al., 2007; Garre-Olmo et al., 2010; Weiner et al., 2000): depression, function in ADL and agitation, strengthen the conclusion that the Norwegian version of the QUALID is valid and measures the same characteristics as the original version of the QUALID.

The psychometric properties of the QUALID were analysed according to standard procedures (Terwee et al., 2007), and the internal consistency was high. All items except for enjoys eating contributed to the Cronbach's $\alpha$. Enjoys eating in a Norwegian setting may be equivalent to whether the resident likes the food, which may be unlike the meaning in other countries, where enjoys eating may also include the whole setting with a meal with, for example, a nicely decorated table with light and a tablecloth and a comfortable atmosphere with a little chat around the table; it is not just about the food. However, removing "Enjoys eating" from the scale did not reduce the Cronbach's $\alpha$, and it was kept in the Norwegian QUALID scale. The stable Cronbach's $\alpha$ is in line with other studies of the QUALID. However, in other studies, there were some variations regarding which items were the least consistent with other items. In the original version and the Swedish version of the QUALID, the item cries had a low correlation with the other items, and in the Spanish version of the QUALID, the items irritable and aggressive had a low correlation with the other items. Cronbach's $\alpha$ either did not increase or was barely impacted when these items were removed from the scale. The correlation between different items in various versions of the QUALID may be because several studies are from different countries, with varied populations and distinct settings. The stable Cronbach's $\alpha$ across the different countries, although different items did not contribute to the Cronbach's $\alpha$, strengthens the decision to keep all the items in the Norwegian version of the QUALID.

To assess the test-retest reliability, the QUALID scale was administrated two times within nine days. The same person (geriatric nurse) interviewed the same informants (the resident's primary carer) for both assessments. The test-retest method has two challenges. First, the patient's QoL may have changed during the period between the two measurements, and second, the carers who were interviewed may have remembered how they answered the different items in the previous interview. To reduce the possible bias in a change in QoL between assessments, a Visual Analogue 
Scale (VAS) was added to assess if there had been a change in the residents' overall QoL since the previous interview. In this way, patients with changes in QoL could be excluded from the test-retest reliability study. Concerning the possibility about remembering former answers, it is unlikely that the carer remembers details in his/her scoring of the 11 items up to nine days later. The fact that the results for the whole sample (included those participants with changes on the VAS scale) had lower ICC than the results from the participants with unchanged QoL strengthens the assumption that the carer answered for the current situation and did not remember and repeat the same answers as in the previous interview.

The same carer who knew the patient well was interviewed twice. This is a correct procedure for a test-retest reliability study, but to test if different carers interpret and score the items similarly or differently, an inter-rater reliability test should be performed. An inter-rater reliability test was not feasible in this study, as an interview with the same primary carer by two researchers would have given a biased result with too high of an agreement between the scores. Alternatively, if two raters of the QUALID listened to the same interview of a carer, it would also have resulted in an artificially high agreement.

\subsubsection{Pathways through care - the study design}

The main aim of this thesis was to find associations between organisational characteristics of Norwegian NHs, staff and individual patient characteristics and QoL in the patients. Most previous studies of QoL in NHs have used a cross-sectional design. A cross-sectional design makes it difficult to determine the direction of an association; for example, does depression lead to reduced QoL, or does reduced QoL leads to depression (the chicken and the egg question). Furthermore, any fluctuation in the associations over time are impossible to identify. Therefore, we chose a longitudinal design in this study, as this gives the opportunity to analyse the stability of associations over time. In Paper IV, for example, the two approaches on the analysis of QoL: 1) baseline characteristics associated with the three different trajectories of QoL; and 2) longitudinal characteristics associated with QoL at the different measurement points, address if the associations are stable over time and not only a snapshot.

To possibly explore the data from different views and understand eventual associations, we used a stepwise approach in the project, from the description of the data collection and patient characteristics (Paper II) to the longitudinal mixed-model analysis (Paper IV).

The design of the description of the data collection, scales that were used and the baseline characteristics in Paper II should not be controversial and are thoroughly discussed in the paper. The challenges about the patient data are described in Chapter 6.1 .3 below.

The data about the staff characteristics, unit characteristics and physical environment were collected once (cross-sectional), as these characteristics were considered to be quite stable over time; thus, it was not necessary to collect them at several occasions. A discussion of the quality of these data is found in Chapters 6.1.4 and 6.1.5, whilst a discussion on the challenges with the merging of staff characteristics into unit variables is found in Chapter 6.1.6.

In Paper IV, trajectory groups of the patients' QoL, assessed with the QUALID, are described in a longitudinal design. The analysis of the association between the QoL and the organisational 
characteristics was done in two ways (see Discussion 6.1.7), and the method strengthened the findings.

\subsubsection{Data about the patients}

The inclusion of patients, procedures for collecting data and the variables in the complete dataset are described in detail in Paper II. However, some methodological issues about the patient data need a more in-depth reflection.

One of the main concerns in the studies is the representativeness of the included patients, which should be discussed on two levels: inclusion of $\mathrm{NHs}$ in the study and inclusion of participants from each $\mathrm{NH}$. First, the $47 \mathrm{NHs}$ included in the thesis were not selected at random. They represent a convenience sample. Thus, it can be argued that the selected nursing homes were biased regarding standard of care and organisation. This is less likely, as the organisation of the nursing homes in Norway only have small variations (described in Chapter 2.1). The selection of nursing homes may, of course, also influence the selection of the patients and, thereby, the generalisability of the results from the study. However, the distribution of the patient characteristics in this population differs little from other nursing home studies in Norway (Paper II). The reasons for the selection of the nursing homes were a combination of practical issues (collaborating study centres that could collect data) and the idea of including small and large NHs located in urban and rural areas. Thus, the included nursing homes covered a variation of Norwegian NHs regarding the number of patients, the care standards and the organisational characteristics.

The aim was to include all the patients admitted to the nursing homes included in the study at the time they were offered a long-term stay at the nursing homes. However, less than half of the eligible patients were included. Nine of the $47 \mathrm{NHs}$ did not collect data about eligible participants. Furthermore, of the 1,331 eligible patients in the remaining $38 \mathrm{NHs}, 607$ were included and 724 were excluded because 205 declined inclusion, 191 died before inclusion took place and 328 were excluded for unknown reasons (Paper II). Based on data collected from these $38 \mathrm{NHs}$, we have information about gender and age of those who did not participate in the study. In these nursing homes, the included patients were about one year older ( 84.5 years vs 83.6 ), and there was a greater proportion of women (64.4\% vs 56.6) compared with those not included in the study. The distribution of gender and mean age of the included participants are comparable with the included patients in other Norwegian nursing home studies (Selbaek et al., 2007). We, therefore, assume that the participants in our study are representative of patients admitted to nursing homes for long-term stays in Norway. Due to changes in healthcare services in Norway over the last several years, where hospitals refer patients to nursing homes for further treatment, Norwegian nursing homes have more patients for short-term stays and rehabilitation today than in the past. It is, therefore, necessary to underline that the conclusions drawn in this thesis are about patients that have an expected stay in a nursing home of more than four weeks.

The data collectors' difference in experience of data collection during the study may be a challenge regarding the reliability of the data. Many nursing home staff collected the data over a long period of time, whilst other data collectors collected data from only a few participants. The quality of the data is dependent on the data collector's competence and experience in using scales. In our project, all nursing home staff that collected data attended the same two-day course on the use of the assessment scales prior to collecting the data, and the data were collected in the nursing homes 
by interviewing a staff member who knew the patient well. In addition, the data collection was performed under supervision of 10 research nurses that had completed a five-day training designed for this purpose. The data collected were either data such as age, gender, length of nursing home stay and prescribed drugs and, thus, easy to register correctly, or data collected with standardised assessment tools that are widely used both clinically and in research and had been tested for validity and reliability in other nursing home studies in Norway.

Previous studies have shown that the proportion of patients in nursing homes that probably have dementia but do not have a dementia diagnosis in their medical record is about 50\% (Selbaek, Kirkevold, \& Engedal, 2008). As it was impossible to perform a medical examination of each included patient, it was decided to give all the participants a research dementia diagnosis to decide whether a person had dementia or not. This research dementia diagnosis was based on all available information collected about the patient, and the procedure for giving the patients a research dementia diagnosis based on strict criteria is described in Paper II and in Chapter 4.3.1 in this thesis. It is important to emphasise that this is not a clinical dementia diagnosis, but rather a dementia diagnosis with the purpose to categorise the patients at a group level. This method will probably diagnose the patients based on broader and more exact information than clinical diagnoses of dementia in NHs. It could, therefore, be argued that the research diagnosis of dementia in REDIC is valid for the purpose of research as it is strictly criteria-based, although the patients have not undergone a clinical examination and MRI/blood tests.

Even though the collection of data in the REDIC-NH cohort had several challenges as mentioned above, it is worth emphasising some important strengths of the study. It is a quite large sample of participants, with assessments of several variables from admission and every six months up to three years. It only used standardised, internationally well-accepted assessment tools. The data were collected from probably the most representative sample of nursing homes with a broad dataset. The longitudinal design made it possible to analyse associations themselves and the stability of the associations during the study time, not only associations as in cross-sectional studies.

\subsubsection{Data about the staff}

Since this thesis is about how organisational characteristics of the NH may influence the course of dementia in NHs focusing on PCC and the participants' QoL, it was important to explore how staff characteristics were associated with PCC and the participants' QoL. Data about staff characteristics were an important part of the organisational factors of the $\mathrm{NH}$, and the descriptions of the staff characteristics are found in detail in Paper III.

The main challenge doing research on NH staff is to obtain correct information about who is included and excluded in the study from the total cohort of $\mathrm{NH}$ staff. The staff were employed in different proportions of a full-time position. Some of the staff had positions as small as $10 \%$ of a full-time position, whereas other had several small positions at different $\mathrm{NH}$ units or even at different institutions. Since data were collected from more than one unit in many of the included $\mathrm{NHs}$, it was difficult to decide the criteria for which of the staff to include in the study. It may also have been difficult for staff who worked at more than one NH unit to distinguish between the different units when answering the questionnaire. To avoid having staff with only shallow experience at the unit answering the questionnaire, the leaders of the units (head nurse) were 
asked to judge which staff members had enough experience to answer the questionnaire about PCC and psychosocial factors in the unit.

All the data from the staff were either demographic data, such as gender, age, education and experiences at the current job, or standardised questionnaires that have been tested for validity and reliability (such as the QPS-Nordic and P-CAT scale). One exception was the question about overall job satisfaction, which has been used in other Norwegian projects but without any references to methodological issues. This question has high face validity, as it was shown to have a high association with both the primary outcomes and other explanatory factors in the present thesis, described in Papers III and IV.

The outcome in Paper III is to what extent the different units practice PCC, measured with the PCAT scale. The P-CAT was scored by the staff, so it is a measurement of the staff's perception of the PCC in their unit. One limitation of using this scale is that the staff may know which answers are expected from them, according to knowledge about PCC, and they may have scored the different items according to that (Lintern, Woods, \& Phair, 2000). Thus, the scale may overestimate the degree of PCC in the NH unit, especially for staff who have recently had training in PCC. However, the P-CAT scale is developed and found to be valid for PCC in Australia (Edvardsson et al., 2010), and the psychometric properties of the Norwegian version of the P-CAT have been tested and found to be satisfactory for the use in a nursing home care setting (A. M. Rokstad et al., 2012). Furthermore, in the empty model of the multi-level analysis with the P-CAT as an outcome (described in Paper IV and shown in Table 3, Paper IV) the ICC was 34\%, which indicates a quite good agreement in the scores of the P-CAT between the staff who work in the same unit. On the other hand, a high ICC between staff at the same unit may also be due to the fact that the staff has the same knowledge about what is expected from the answers. In the univariate analysis, neither education nor advanced education were significantly associated with the P-CAT score, indicating that the effect of education on the P-CAT score may be minor (three years or more health-related education turned out to be significant in the multivariate analysis).

To measure work-related psychosocial factors, several subscales of the QPS-Nordic were used. The strengths of using these scales are that QPS-Nordic was developed in Nordic countries with quite similar healthcare systems, and that the subscales have been used in several studies in many different fields. One challenge with the questions in the QPS-Nordic is that they give sensitive information about the staff's meaning of and relation to their leaders. To ensure absolute anonymity of the care staff, they returned the questionnaire in a stamped envelope directly to the researchers, instead of through the NH management.

\subsubsection{Data about the unit}

The unit characteristics were based on facts, thus, there should be few challenges to collect these data. However, some points should be considered. The staff/patient ratio was based on the staffing at the NH unit at day time. This has been done in several Norwegian NH studies (Gjøra et al., 2015; $\varnothing$. Kirkevold et al., 2012) and has been considered as a valid measurement for staff density. Lately, other approaches have been used as "total man year/number of patients" (Vossius et al., 2015). However, this approach gives more challenges than the day time approach, as several units may share the same staff during the evenings, nights and weekends. The NH physicians are often employed for the whole institution, and the time used is not specified for each unit. Thus, the 
minutes per patient is usually for the whole institution and then assumed as the same for each unit at that institution - over time.

The greatest challenge regarding unit characteristics was to find a good way to describe the physical environment that could be used in the statistical analysis. There were no such tools or scales developed in Norway, in other Nordic countries or translated to Norwegian. We ended up with the Therapeutic Environment Screening Survey for Nursing Homes (TESS-NH), which was translated into Norwegian (see Paper III). Embedded in the TESS-NH is the Special Care Unit Environmental Quality Scale (SCUEQS), a summary scale containing a subset of data that can be used as a scale for the quality of physical environment. This instrument was used in the analysis in Paper IV. The SCUEQS consists of 18 of the TESS-NH items and measures maintenance, cleanliness, safety, lighting, physical appearance/home likeness, orientation/cueing and noise. The psychometric properties of the Norwegian version were not tested. Not all the items in the TESS questionnaire are suitable for use in Norway, but the 18 items in the SCUEQS are useful. Almost all participating $\mathrm{NH}$ units were assessed with the TESS-NH by the same person, and this person also discussed the scale and agreed on the procedure together with the two other persons that scored the TESS-NH.

All the 175 units, except for one, gave complete information about the unit. This strengthens the validity of the data.

Data about the staff and the unit characteristics were collected only once, during the period from October 2013 to December 2014, and, thereby, the individual data from some of the participants could have been collected years after the data about the staff and unit characteristics. This procedure assumed that the staff and unit characteristics are quite stable. Regarding the unit characteristics, it is less likely that there were changes in staffing, the physical environment or the number of beds over the study period. Regarding the data on the staff characteristics, changes may, of course, have occurred over the study period, such as a shift in leadership, staff members quitting and new staff members starting. Nevertheless, it was not possible within the frame of our project to collect data on staff characteristics at several occasions.

\subsubsection{Aggregating staff characteristics into unit variables}

The staff characteristics were collected at an individual level. Since the link between the staff and the patients was the unit, the data from the staff had to be aggregated into a mean score for the $\mathrm{NH}$ unit. This was done for the P-CAT score, job satisfaction and the QPS-Nordic sub-scales, as the mean scores of the variables at each unit were used as the unit score. The high ICC for the P-CAT score (Table 3 in Paper III) and the clear association at the individual staff level between P-CAT scores and the other variables merged into unit variables justify this practise. Figures 4,5 and 6 (page 71 and 72) show that the pattern of P-CAT scores and job satisfaction at the staff level were maintained after the aggregation to the unit level. This method has also been applied in other studies, for example, to use staff members' attitudes about patient safety as a measurement for a unit's safety culture (Bredesen, Bjoro, Gunningberg, \& Hofoss, 2015).

\subsubsection{The statistical analysis}

The analysis of the validity and reliability of QUALID is a standard statistical procedure, described in Paper I and will not be further pursued here. The descriptive analysis of the material in REDIC is also 
uncomplicated and needs no further explanations (Paper II). The analysis in Papers III and IV are more complicated, and the decisions made need some more considerations.

When exploring the association between the P-CAT scores and several staff characteristics, a standard linear regression model could not be used. First, since the staff at the same unit work in the same environment, share the same leaders and will probably influence each other regarding the questions in the sub-scale of the QPS-Nordic, it was necessary to adjust for cluster effects. Second, the data were at two levels, staff and unit. If information about the unit had been attributed to each staff member, the units with a high number of staff employed would have dominated those units with lower numbers. On the other hand, if staff data had been merged into the unit level, information about each staff member would have been lost. Both of these challenges were solved by using a multi-level (or mixed model) linear regression (described in Paper III).

The analyses of factors associated with QoL are even more complex. In Paper IV, the association between the patients' QoL, patient characteristics and unit characteristics are analysed in a longitudinal perspective. Linear mixed models (multi-level) also handle this situation (described in Paper IV). The interpretations of the regression coefficients are similar to ordinary linear models. In addition to the longitudinal model, a growth mixture model was estimated to identify potential groups of patients that followed similar trajectories in QUALID scores throughout the study period. The factors associated with ending up in good, moderate or poor QoL were analysed. This is described in detail in the statistical section of Paper IV and the outcomes are in Figure 1, Tables 2 and 3 .

\subsubsection{Conclusion of methodological considerations}

Despite the described challenges in the design and analyses that may have weakened the results in this thesis, the fact that the patients were followed for a long time from admission to the nursing homes (to death or 30 months), in addition to the use of broad mapping with standardised tools and a considerable information about the units and from the staff, strengthens the conclusions in this thesis.

\subsection{Discussion of the results and clinical implications}

As described, the aim of the thesis was to explore the association between organisational, staff and individual characteristics and person-centred care and quality of life during the disease course of patients with dementia. Thus, we designed a study where staff characteristics and organisational characteristics were taken into consideration. Today, PCC is state-of-the-art in dementia care, and several studies have shown that implementing PCC leads to reduced NPS and better QoL. Since there is no cure for dementia, a reasonable outcome in this thesis would be QoL for patients with dementia (see introduction).

We designed a study to answer the following hypothesis: staff and unit characteristics would be associated with degree of PCC in the units compared to other characteristics, and a high degree of PCC would result in better QoL in people with dementia in nursing homes. Our study partly confirmed this hypothesis. We found an association between the staff's perception of PCC, assessed with the P-CAT, and some staff and unit characteristics (Paper III), but no association between the P-CAT scores and the patients' QoL was found (Paper IV). 


\subsubsection{PCC and organisational characteristics}

In Paper III, we found that the staff's perception of PCC care was dependent on several staff and unit characteristics. This is thoroughly discussed in Paper III. However, some aspects need to be further discussed.

\subsubsection{Job satisfaction}

First, the increased score on job satisfaction was strongly associated with a higher P-CAT score. This is in line with several other studies (Brownie \& Nancarrow, 2013; Sjogren, Lindkvist, Sandman, Zingmark, \& Edvardsson, 2015; van den Pol-Grevelink, Jukema, \& Smits, 2012). However, using a cross-sectional design, it is not possible to know whether high job satisfaction leads to better PCC or if it is the other way around, that the ability for the staff to provide a high degree of PCC improves the staff's job satisfaction. All the studies we have found that explored the association between PCC and job satisfaction focused on the effect that PCC has on job satisfaction, meaning that job satisfaction was the dependent variable and PCC was the independent variable in the analysis. Ashburner et al. performed an action research study that confirmed that PCC positively affected the nurses' job satisfaction and work conditions (Ashburner, Meyer, Johnson, \& Smith, 2004). The same study also reported that PCC improved the nurses' capacity to meet the individual needs of the patients with dignity and respect, and that PCC also led to increased social interaction between patients (Ashburner et al., 2004). In a literature review, van den Pol-Grevelink et al. investigated whether various forms of PCC affected job satisfaction in different ways, and if there were particular dimensions of job satisfaction that were affected differently than other dimensions (van den Pol-Grevelink et al., 2012). Van den Pol-Grevelink et al. had a quite broad definition of PCC, including snoezelen (sense stimulation) and demand-oriented care (the patient as a consumer, i.e. focusing on responding to the needs and wants of the patients). Nevertheless, they found that all seven publications included in the review showed that PCC had positive effects on at least one dimension of job satisfaction: general job satisfaction, job demands on psychogeriatric wards, emotional exhaustion and/or personal accomplishment. They also found that some dimensions of job satisfaction, like contact with supervisor and contact with colleagues, were not affected by PCC. Some studies reported that PCC had negative effects on some dimensions of job satisfaction, such as social support, autonomy and job demands. The studies also reported different effects from different forms of PCC; positive effects on job satisfaction were most often from emotion-oriented care, snoezelen and small-scale living homes, whereas negative effects on job satisfaction were reported from demand-oriented care (van den Pol-Grevelink et al., 2012).

Sjøgren at al. found that higher levels of PCC were associated with higher levels of staff job satisfaction, lower levels of job strain, lower levels of stress of conscience, higher levels of a supportive psychosocial unit climate and a higher proportion of staff with continuing education in dementia care (K. Sjögren, Lindkvist, Sandman, Zingmark, \& Edvardsson, 2015).

In a systematic review that looked at the residential care staff's stress, burnout and job satisfaction, Barbosa et al. found it difficult to compare the results due to the studies' differences in design and outcome (Barbosa et al., 2015). However, they concluded that there was a tendency towards a positive effect of PCC on the staff.

To sum up, the results of several studies have shown that PCC may lead to better job satisfaction. However, in this thesis, the hypothesis is that better job satisfaction leads to more PCC. It is 
possible that a good work environment lead to better job satisfaction that makes it easier to improve the PCC. The finding that the perception of mastery is associated with PCC strengthens the assumption. And, at last, it could be a combination: PCC leads to better job satisfaction, and good job satisfaction makes it easier to have a person-centred approach with the patients - a positive circle. A negative circle may also be possible, in that failure to have PCC leads to reduced work satisfaction that, again, reduces the motivation to work in a person-centred way. Further research is needed to decide where and how to intervene in such processes.

\subsubsection{Empowering leadership}

We found that the QPS-Nordic variable "empowering leadership" was positively associated with PCC. One of the main changes described as essential in the process towards better PCC in a unit is the democratisation of the decision making (Brownie \& Nancarrow, 2013). Tom Kitwood stated that the autonomy of the staff to make decisions in caring situations is an important part of performing PCC (T Kitwood, 1997). The results from the study described in Paper III support Kitwood's assumption. Three other variables of the QPS-Nordic were significantly associated with PCC: role conflict (a negative association), innovative climate and perception of group work (both positive associations). This is in line with the findings in a study about the value of leadership when implementing PCC in NHs (A. M. Rokstad, Vatne, Engedal, \& Selbaek, 2015). They concluded that leaders have an important role when implementing PCC in NH settings. Leaders should draw up a clear and consistent professional vision, be continuously supportive to the care staff and take an active part in the care practice as role models (A. M. Rokstad et al., 2015). It is a leader's responsibility to facilitate these issues, but the staff also must work together with the leader in implementing PCC.

\subsubsection{Type of unit and physical environment}

The two unit characteristics that were significantly associated with PCC in the multivariate model (Paper III, Table 3) were the type of unit and the SCUEQS score. The staff in the SCUs scored significantly better on the P-CAT than the staff in the RUs. In the study described in Paper III, the SCUs had fewer beds, a higher staff-patient ratio and had a home-like environment more often than the RUs. Staff-patient ratio and number of beds were significantly associated with P-CAT scores in the univariate analysis, but not in the multivariate analysis. This may be because the variables number of beds and staff-patient ratio are a part of the type of ward variable.

SCUs are expected to be different from RUs in several ways that could benefit the patients, and it is reasonable to assume that the differences in physical environment are an important part of the positive "effect" of an SCU on the patients' symptoms (Reimer, Slaughter, Donaldson, Currie, \& Eliasziw, 2004). The other unit variable that was sustained significantly in the multivariate analysis was the SCUEQS score, indicating that the physical environment is of importance for implementing PCC. This is in line with previous studies, stating that physical environment also plays an important role in the provision of PCC (Chaudhury et al., 2018; Edvardsson et al., 2008).

\subsubsection{QoL and patient characteristics}

More severe dementia, more pain, poorer ADL function and more severe NPS of the patients were associated with an overall decrease in QoL (Paper IV, Tables 3 and 4). This was expected, as the results in Paper I showed that the Norwegian version of QUALID was associated with the severity of depression, NPS and ADL impairment. The same association has also been reported for QUALID 
scores in other countries, like Sweden, Spain and the US (Falk et al., 2007; Garre-Olmo et al., 2010; Weiner et al., 2000).

Several cross-sectional studies have shown that proxy-evaluated QoL in people with dementia is associated with several characteristics such as ADL function, cognition and the severity of NPS (Klapwijk et al., 2016; Mjorud, Kirkevold, Rosvik, Selbaek, et al., 2014; R. B. Wetzels et al., 2010). In addition, one previous longitudinal study on QoL in NHs explored factors that could be associated with a change in QoL of the patients (Mjorud, Rosvik, et al., 2014) and found that only a low baseline score on the QUALID was associated with changes in QUALID scores after 10 months. When Mjørud et al. introduced changes in other variables as explanatory variables, a change in the NPI-Q-10 score over 10 months was associated with changes in QUALID scores. In Paper IV in this thesis, we examined the baseline characteristics that were associated with various trajectory groups of QoL of the patients (Table 3, Paper IV). Furthermore, an analysis of the characteristics that were associated with QoL were performed, with time-dependent variables assessed every six months over 30 months (Table 4, Paper IV). In Paper IV, we reported that the degree of dementia (CDR-SOB score), pain (MOBID2 score) and agitation (sub-syndrome of NPI) were associated with the QoL trajectory group belonging, and all these characteristics were also associated with QoL over the six follow-up assessments together with function in ADL (PSMS score), affective symptoms and apathy (both sub-syndromes of NPI) and the QPS-Nordic variable work satisfaction. It is reasonable to believe that the different approaches in the analysis between our study and the study by Mjørud et al. may explain much of the difference in the findings. It is also worth to notice that the change in QoL over time was quite modest both in the present study and in the study by Mjørud et al.

(Mjorud, Rosvik, et al., 2014). This is also in line with a literature review by Kok et al. that concluded the following: "For the variable 'quality of life', no differences were found over time" (Kok et al., 2013). A recent Norwegian study that focused on anxiety and QoL using a similar method as described in the present thesis (Paper IV, Figure 1 and Table 3) also found minor changes in QoL over time (Goyal, Bergh, Engedal, Kirkevold, \& Kirkevold, 2018). Goyal et al. identified two trajectory groups of patients based on scores on the QUALID scale. The baseline patient characteristics that were associated with reduced QoL were anxiety and depression, NPI subsyndrome agitation, low performance on ADL and the use of antipsychotics (Goyal et al., 2018). In a multivariate analysis, the patient's CDR-SOB score was not associated with the patient's QoL trajectory group. In addition, the study by Goyal et al. only included persons with dementia, whilst about $15 \%$ of the patients in this thesis did not have dementia. This may be one explanation for the difference between the two studies in the association between the CDR-SOB and the QoL.

Mjørud et al. found that only 50\% of the patients had a decline in QoL over 10 months (Mjorud, Rosvik, et al., 2014). Goyal et al. found two trajectory groups with only minor changes in QoL over a period of 12 months. In a two-year follow up study, Oudman and Veurink found that the changes in QoL were small and non-significant (<3\%) (Oudman \& Veurink, 2014). Van der Zon et al. found that the total QUALIDEM scores did not change over a period of two years (van der Zon et al., 2018). The study presented in Paper IV showed a minor decline in QoL over 36 months, with the largest decline in the group that had the most reduced QoL at baseline (Figure 1 and Table 2, Paper IV). However, the association between the QoL and the described patient characteristics was stable over time (Table 4, Paper IV), with some minor differences from the trajectory analysis (Table 3, Paper IV), indicating that a change in these characteristics is associated with a change in QoL. This is also in line with the other studies. Mjørud et al. found that changes in the QUALID scores were 
significantly associated with QUALID baseline scores and changes in NPS. Thus, growing evidence has demonstrated that cognition, pain, ADL function and NPS are associated with QoL, which indicates that a change in these characteristics will influence the QoL in patients in nursing homes.

Thus, the clinical implications will be to approach these characteristics by preventing and reducing pain, adapting the environment to retain the ADL function as long as possible and implementing PCC to prevent NPS.

\subsubsection{The association between the QoL and the PCC}

In the trajectory analysis, no clustering effects within the units were seen. Belonging to different trajectory groups of QoL (good, moderate or poor QoL) was not associated with the unit of the patients. Furthermore, no association with the P-CAT scores (good vs. moderate QoL, OR 1; and good vs. bad QoL, OR 1.05) (Paper IV, Table 3) was revealed in the univariate analysis. Therefore, PCAT scores were not included in the multivariate analysis. In the linear mixed models (multi-level) analysis, no association between the QUALID and P-CAT scores was found. The linear regression coefficient was 0.005 with a p-value of 0.919 (Paper IV, Table 4), thus, there was no association at all. At first glance, this is difficult to understand and deserves closer attention.

It is also remarkable that none of the QPS-Nordic variables were associated with QoL in the unadjusted (bivariate) model. However, several of these variables were strongly associated with PCC (see Paper III), even after adjusting for job satisfaction in the multivariate model. This strengthens the impression that the P-CAT scores and QoL are not associated with each other in this study.

It may be that the P-CAT does not measure the performed PCC, but more so measures how much the staff intend or wish to perform PCC. The individual NH staff scores on the P-CAT have a high ICC at the unit level, indicating a high agreement between the staff in each unit on how PCC is in their unit. The variation of the P-CAT at the unit level (Figure 4, page 71) should make it possible to find associations between the P-CAT scores and other characteristics, if any, and the distribution of the P-CAT scores at the unit level represents the individual level well (Paper III and the additional results above). However, the P-CAT scale has been quite widely used, and PCC as a phenomenon has become commonly known, so the staff know the right answers without carrying out PCC. It is possible that the results would have been different if $P C C$ had been measured with another assessment tool, such as Dementia Care Mapping (DCM) (T. Kitwood \& Bredin, 1992).

However, it might also be that the findings are correct, and there is no association between PCC and QoL. I do not find that likely, and it could be that either the QUALID does not measure QoL sufficiently, or, as discussed above, the P-CAT does not cover the concept of PCC or the staff knew what the right answers were on the P-CAT. I tend to believe that the last assumption is correct. Tracy Lintern described that after a teaching programme, the staff scored higher on attitude on a PCC mapping tool; however, that did not change the scores on the same item for Dementia Care Mapping (DCM), indicating that the staff learned the "correct" answers but not how to implement them in practice (Lintern et al., 2000).

To sum up, according to the results of the present thesis, it may be that a combination of patient characteristics, such as severity of pain, cognitive dysfunction and severity of affective symptoms, and the staff's job satisfaction, are essential for the patients' QoL in NH. However, other factors 
may also influence the QoL of the patients in NH. In PCC, the relationship between NH staff and the person with dementia is essential (Wilberforce et al., 2016), and, consequently the staff's attitude and work methods are important parts of improving the patient's QoL in NHs (Anderson et al., 2016). How the staff cares for and communicates with the patient by developing a relationship through day-to-day contact that supports the patient and gives them a sense of identity (Edvardsson et al., 2008; T Kitwood, 1997), and the association between the staff's job satisfaction and quality of patient care, are described by Robertson et al. (A. Robertson et al., 1995). They reported that staff and patients who are in what they called high-satisfaction wards, where staff offer patients more choices, independence, personal attention, supervision, information and privacy, and were more likely to converse with patients during care tasks, positively influenced both job satisfaction and the quality of patient care (A. Robertson et al., 1995). These activities may not be directly assessed with the P-CAT or considered as a part of PCC when assessing PCC, but they are something else and may be an important part of the patients' perception of quality of care, their QoL and the staff's job satisfaction.

\subsubsection{Job satisfaction}

A strong association between the staff's job satisfaction (individual level) and the P-CAT score at the individual level was found. This association was still present after the data were aggregated from individual characteristics to unit characteristics (Paper III and additional results above). The job satisfaction score was also the only organisational characteristics in the longitudinal regression analysis that was associated with the QUALID score, even though the ICC of job satisfaction was quite modest $(12.4 \%)$. The job satisfaction seems to be a product of several of the psychosocial measurements measured by the QPS-Nordic sub-scale (see Table 3, page 71). Thus, an alternative hypothesis to the one presented in Figure 3 (page 59) may be drawn (see Figure 7 below). Adjusted for patient characteristics, the job satisfaction as a result of leadership and psychosocial environment is a key element in raising the QoL for people with dementia in nursing homes.

It may also simply be that a good atmosphere where the patients and staff have a good harmony and respect each other is comfortable and enjoyable for everyone - good QoL for the patients and high job satisfaction for the staff. 


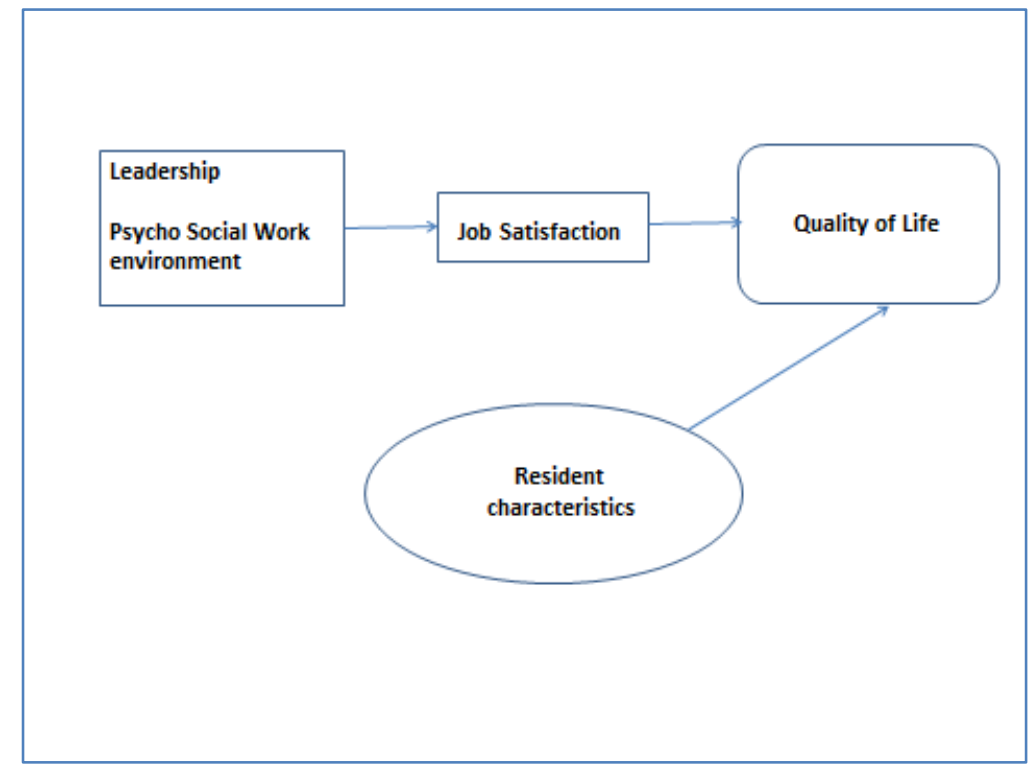

Figure 7 Alternative hypothesis: Adjusted for patient characteristics, job satisfaction as a result of leadership and psychosocial environment is a key element in raising the QoL for people with dementia in nursing homes.

\subsubsection{Physical environment}

Several studies have investigated the association between physical environment and PCC, and most of them are summed up in a recent review article (Chaudhury et al., 2018). Chaudry et al. concluded that the physical environment in care settings is important for improving the patients' QoL and quality of care practices, highlighting the influence of unit size, spatial layout, home-like character, sensory stimulation and specific areas for dining, bathing and outdoor activities. They also emphasised the relationship between a therapeutic physical environment and the importance of appropriately inspired organisational policies and care practices. In the study presented in Paper III, the sum score of the SCUEQS was used and, thus, the different characteristics of the physical environment were not analysed separately. The SCUEQS variables are maintenance, cleanliness, safety, lighting, physical appearance/home-likeness, orientation/cueing and noise. Even though these characteristics are not identical to the characteristics Chaudhury described, there are overlaps between them, like home-like environment and lighting. It seems that despite different methods and different characteristics, characteristics that make the environment positive for everybody are positive for persons with dementia in NHs. 


\section{Conclusions}

The overall conclusion of this thesis is that the majority of the patients we followed from admission to $\mathrm{NH}$ had good QoL over the observation period of 30 months. In addition, mainly patient variables were found to influence the QoL trajectory.

Poor patient QoL was associated with more pain, more severe dementia, more affective symptoms, and poorer staff job satisfaction at baseline, as well as more pain, poorer ADL function, and more severe NPS were simultaneously measured over the first 30 months after admission/follow-up period.

Even though our study failed to find a significant association between patient QoL and PCC, we found an association between patient QoL and staff job satisfaction, which is worth noticing. The degree of PCC in the unit was clearly associated with several staff variables, such as three years or more of health-related education, a lower level of quantitative demands and role conflict, a higher level of perception of mastery, empowering leadership, innovative climate and perception of group work, in addition to the type of unit and the physical environment in the $\mathrm{NH}$ unit designed for people with dementia. Higher staff job satisfaction was also associated with a higher degree of PCC in the unit.

As dementia is a chronic disease, a focus on symptom relief and QoL is important. To improve patients' QoL, efforts should focus on reducing pain, reducing NPS and improving ADL function for the patient, as well as improving the job satisfaction of the staff.

Clinical implications are further discussed in Chapter 6.2. 


\section{References}

Aarts, M., \& Gogol, S. (2008). Marte Meo : basic manual. Eindhoven: Aarts Productions.

Abbott, K. M., Heid, A. R., \& Van Haitsma, K. (2016). "We can't provide season tickets to the opera": Staff perceptions of providing preference based person centered care. Clin Gerontol, 39(3), 190-209. doi:10.1080/07317115.2016.1151968

Abraha, I., Rimland, J. M., Trotta, F. M., Dell'Aquila, G., Cruz-Jentoft, A., Petrovic, M., . . Cherubini, A. (2017). Systematic review of systematic reviews of non-pharmacological interventions to treat behavioural disturbances in older patients with dementia. The SENATOR-OnTop series. BMJ Open, 7(3), e012759. doi:10.1136/bmjopen-2016-012759

Acquadro, C., Jambon, B., Ellis, D., \& Marquis, P. (1996). Language and translation issues. In B. Spilker (Ed.), Quality of Life and Pharmacoeconomics in Clinical Trials (2. ed., pp. 575-585). Philadelphia: Lippincott-Raven.

Alexopoulos, G. S., Abrams, R. C., Young, R. C., \& Shamoian, C. A. (1988). Cornell Scale for Depression in Dementia. Biol Psychiatry, 23(3), 271-284.

Alnes, R. E., Kirkevold, M., \& Skovdahl, K. (2013). The influence of the learning climate on learning outcomes from Marte Meo counselling in dementia care. J Nurs Manag, 21(1), 130-140. doi:10.1111/j.1365-2834.2012.01436.x

American Psychiatric Association, \& American Psychiatric Association DSM Task Force. (2013). Diagnostic and statistical manual of mental disorders. DSM-5. Arlington, VA: American Psychiatric Association.

Anderson, K., Bird, M., MacPherson, S., \& Blair, A. (2016). How do staff influence the quality of longterm dementia care and the lives of residents? A systematic review of the evidence. Int Psychogeriatr, 28(8), 1263-1281. doi:10.1017/s1041610216000570

Ashburner, C., Meyer, J., Johnson, B., \& Smith, C. (2004). Using Action Research to Address Loss of Personhood in a Continuing Care Setting. Illness, Crisis \& Loss, 12(1), 23-37. doi:10.1177/1054137303259739

Aspden, T., Bradshaw, S. A., Playford, E. D., \& Riazi, A. (2014). Quality-of-life measures for use within care homes: a systematic review of their measurement properties. Age Ageing, 43(5), 596-603. doi:10.1093/ageing/afu089

Baker, P. S., Bodner, E. V., \& Allman, R. M. (2003). Measuring life-space mobility in communitydwelling older adults. J Am Geriatr Soc, 51(11), 1610-1614.

Ballard, C., Corbett, A., Orrell, M., Williams, G., Moniz-Cook, E., Romeo, R., . . Fossey, J. (2018). Impact of person-centred care training and person-centred activities on quality of life, agitation, and antipsychotic use in people with dementia living in nursing homes: A clusterrandomised controlled trial. PLoS Med, 15(2), e1002500. doi:10.1371/journal.pmed.1002500

Ballard, C., McKeith, I., Burn, D., Harrison, R., O'Brien, J., Lowery, K., . . Ince, P. (1997). The UPDRS scale as a means of identifying extrapyramidal signs in patients suffering from dementia with Lewy bodies. Acta Neurol Scand, 96(6), 366-371.

Banerjee, S., Samsi, K., Petrie, C. D., Alvir, J., Treglia, M., Schwam, E. M., \& del Valle, M. (2009). What do we know about quality of life in dementia? A review of the emerging evidence on the predictive and explanatory value of disease specific measures of health related quality of life in people with dementia. Int J Geriatr Psychiatry, 24(1), 15-24. doi:10.1002/gps.2090

Barbosa, A., Sousa, L., Nolan, M., \& Figueiredo, D. (2015). Effects of Person-Centered Care Approaches to Dementia Care on Staff: A Systematic Review. Am J Alzheimers Dis Other Demen, 30(8), 713-722. doi:10.1177/1533317513520213

Barca, M. L., Engedal, K., Laks, J., \& Selbaek, G. (2011). Quality of life among elderly patients with dementia in institutions. Dement Geriatr Cogn Disord, 31(6), 435-442.

doi:10.1159/000328969 
Barca, M. L., Engedal, K., \& Selbaek, G. (2010). A reliability and validity study of the cornell scale among elderly inpatients, using various clinical criteria. Dement Geriatr Cogn Disord, 29(5), 438-447. doi:10.1159/000313533

Beerens, H. C., Zwakhalen, S. M., Verbeek, H., Ruwaard, D., Ambergen, A. W., Leino-Kilpi, H., . . . Hamers, J. P. (2015). Change in quality of life of people with dementia recently admitted to long-term care facilities. J Adv Nurs, 71(6), 1435-1447. doi:10.1111/jan.12570

Bergh, S., Engedal, K., Roen, I., \& Selbaek, G. (2011). The course of neuropsychiatric symptoms in patients with dementia in Norwegian nursing homes. Int Psychogeriatr, 23(8), 1231-1239. doi:10.1017/s1041610211001177

Bergland, A., Kirkevold, M., \& Edvardsson, D. (2012). Psychometric properties of the Norwegian Person-centred Climate Questionnaire from a nursing home context. Scand J Caring Sci, 26(4), 820-828. doi:10.1111/j.1471-6712.2012.00979.x

Bowling, A., Rowe, G., Adams, S., Sands, P., Samsi, K., Crane, M., . . Manthorpe, J. (2015). Quality of life in dementia: a systematically conducted narrative review of dementia-specific measurement scales. Aging Ment Health, 19(1), 13-31. doi:10.1080/13607863.2014.915923

Bradshaw, S. A., Playford, E. D., \& Riazi, A. (2012). Living well in care homes: a systematic review of qualitative studies. Age Ageing, 41(4), 429-440. doi:10.1093/ageing/afs069

Brasure, M., Jutkowitz, E., Fuchs, E., Nelson, V. A., Kane, R. A., Shippee, T., ... Kane, R. L. (2016). AHRQ Comparative Effectiveness Reviews. In Nonpharmacologic Interventions for Agitation and Aggression in Dementia. Rockville (MD): Agency for Healthcare Research and Quality (US).

Bredesen, I. M., Bjoro, K., Gunningberg, L., \& Hofoss, D. (2015). Patient and organisational variables associated with pressure ulcer prevalence in hospital settings: a multilevel analysis. $B M J$ Open, 5(8), e007584. doi:10.1136/bmjopen-2015-007584

Brodaty, H., \& Arasaratnam, C. (2012). Meta-analysis of nonpharmacological interventions for neuropsychiatric symptoms of dementia. Am J Psychiatry, 169(9), 946-953. doi:10.1176/appi.ajp.2012.11101529

Brooker, D. (2004). What is person-centered care in dementia? Reviews in Clinical Gerontology, 13(3), 215-222.

Brooker, D. (2005). Dementia care mapping: a review of the research literature. Gerontologist, 45 Spec No 1(1), 11-18.

Brooker, D. (2007). Person-Centred Dementia Care. Making Services Better. London: Jessica Kingsley.

Brooker, D. J., Latham, I., Evans, S. C., Jacobson, N., Perry, W., Bray, J., . . Pickett, J. (2016). FITS into practice: translating research into practice in reducing the use of anti-psychotic medication for people with dementia living in care homes. Aging Ment Health, 20(7), 709718. doi:10.1080/13607863.2015.1063102

Brownie, S., \& Nancarrow, S. (2013). Effects of person-centered care on residents and staff in agedcare facilities: a systematic review. Clin Interv Aging, 8, 1-10. doi:10.2147/cia.s38589

Bruera, E., Kuehn, N., Miller, M. J., Selmser, P., \& Macmillan, K. (1991). The Edmonton Symptom Assessment System (ESAS): a simple method for the assessment of palliative care patients. J Palliat Care, 7(2), 6-9.

Calkins, M. P. (2018). From Research to Application: Supportive and Therapeutic Environments for People Living With Dementia. Gerontologist, 58(suppl_1), S114-s128. doi:10.1093/geront/gnx146

Chappell, N. L., Reid, R. C., \& Gish, J. A. (2007). Staff-based measures of individualized care for persons with dementia in long-term care facilities. Dementia, 6(4), 527-547. doi:10.1177/1471301207084372

Charlson, M. E., Pompei, P., Ales, K. L., \& MacKenzie, C. R. (1987). A new method of classifying prognostic comorbidity in longitudinal studies: development and validation. J Chronic Dis, 40(5), 373-383. 
Chaudhury, H., Cooke, H. A., Cowie, H., \& Razaghi, L. (2018). The Influence of the Physical Environment on Residents With Dementia in Long-Term Care Settings: A Review of the Empirical Literature. Gerontologist, 58(5), e325-e337. doi:10.1093/geront/gnw259

Chenoweth, L., King, M. T., Jeon, Y. H., Brodaty, H., Stein-Parbury, J., Norman, R., . . Luscombe, G. (2009). Caring for Aged Dementia Care Resident Study (CADRES) of person-centred care, dementia-care mapping, and usual care in dementia: a cluster-randomised trial. Lancet Neurol, 8(4), 317-325. doi:10.1016/s1474-4422(09)70045-6

Chua, K. C., Brown, A., Little, R., Matthews, D., Morton, L., Loftus, V., . . Banerjee, S. (2016). Quality-of-life assessment in dementia: the use of DEMQOL and DEMQOL-Proxy total scores. Qual Life Res, 25(12), 3107-3118. doi:10.1007/s11136-016-1343-1

Cicchetti, D. V. (1994). Guidelines, criteria, and rules of thumb for evaluating normed and standardized assessment instruments in psychology. Psychological Assessment, 6(4), 284290. doi:10.1037/1040-3590.6.4.284

Cohen-Mansfield, J. (1996). Conceptualization of agitation: results based on the Cohen-Mansfield Agitation Inventory and the Agitation Behavior Mapping Instrument. Int Psychogeriatr, 8 Supp/ 3, 309-315; discussion 351-304.

Cohn, F. (2001). Existential medicine: Martin Buber and physician-patient relationships. J Contin Educ Health Prof, 21(3), 170-181. doi:10.1002/chp.1340210308

Cooper, C., Mukadam, N., Katona, C., Lyketsos, C. G., Ames, D., Rabins, P., . . Livingston, G. (2012). Systematic review of the effectiveness of non-pharmacological interventions to improve quality of life of people with dementia. Int Psychogeriatr, 24(6), 856-870. doi:10.1017/s1041610211002614

Crooks, V., Waller, S., Smith, T., \& Hahn, T. J. (1991). The use of the Karnofsky Performance Scale in determining outcomes and risk in geriatric outpatients. J Gerontol, 46(4), M139-144.

Cummings, J. L., Mega, M., Gray, K., Rosenberg-Thompson, S., Carusi, D. A., \& Gornbein, J. (1994). The Neuropsychiatric Inventory: comprehensive assessment of psychopathology in dementia. Neurology, 44(12), 2308-2314.

Custodio, N., Montesinos, R., Lira, D., Herrera-Perez, E., Bardales, Y., \& Valeriano-Lorenzo, L. (2017). Mixed dementia: A review of the evidence. Dement Neuropsychol, 11(4), 364-370. doi:10.1590/1980-57642016dn11-040005

Daatland, S. O., \& Gottschalk, G. (2000). Future Housing for Elderly. Innovations and perspectives from the Nordic countries. Copenhagen Nordic Council of Ministers.

Dahm, K. T., Dalsb $\varnothing$, T. K., Håvelsrud, K., \& Reinar, L. M. (2014a). Effekt av fysisk aktivitet og omsorgstiltak for personer med demens (978-82-8121-928-1). Retrieved from Oslo:

Dahm, K. T., Dalsb $\varnothing$, T. K., Håvelsrud, K., \& Reinar, L. M. (2014b). Effekt av psykologiske tiltak for personer med demens. In Rapport fra Kunnskapssenteret, Vol. nr 28-2014.

Dallner, M., Elo, A.-L., Gamberale, F., Hottinen, V., Knardahl, S., \& Lindström, K. (2000). Validation of the general Nordic questionnaire (QPSNordic) for psychological and social factors at work. Retrieved from Copenhagen:

de Oliveira, A. M., Radanovic, M., de Mello, P. C., Buchain, P. C., Vizzotto, A. D., Celestino, D. L., . . Forlenza, O. V. (2015). Nonpharmacological Interventions to Reduce Behavioral and Psychological Symptoms of Dementia: A Systematic Review. Biomed Res Int, 2015, 218980. doi:10.1155/2015/218980

de Witte, L., Schoot, T., \& Proot, I. (2006). Development of the client-centred care questionnaire. J Adv Nurs, 56(1), 62-68. doi:10.1111/j.1365-2648.2006.03980.x

Di Marco, L. Y., Marzo, A., Munoz-Ruiz, M., Ikram, M. A., Kivipelto, M., Ruefenacht, D., . . Frangi, A. F. (2014). Modifiable lifestyle factors in dementia: a systematic review of longitudinal observational cohort studies. J Alzheimers Dis, 42(1), 119-135. doi:10.3233/jad-132225

Dichter, M. N., Ettema, T. P., Schwab, C. G. G., Meyer, G., Bartholomeyczik, S., Halek, M., \& Dröes, R. (2016). QUALIDEM - User Guide. Retrieved from Witten:

Dichter, M. N., Quasdorf, T., Schwab, C. G., Trutschel, D., Haastert, B., Riesner, C., . . Halek, M. (2015). Dementia care mapping: effects on residents' quality of life and challenging 
behavior in German nursing homes. A quasi-experimental trial. Int Psychogeriatr, 27(11), 1875-1892. doi:10.1017/s1041610215000927

Dichter, M. N., Schwab, C. G., Meyer, G., Bartholomeyczik, S., \& Halek, M. (2016). Linguistic validation and reliability properties are weak investigated of most dementia-specific quality of life measurements-a systematic review. J Clin Epidemiol, 70, 233-245. doi:10.1016/j.jclinepi.2015.08.002

Dyer, S. M., Harrison, S. L., Laver, K., Whitehead, C., \& Crotty, M. (2017). An overview of systematic reviews of pharmacological and non-pharmacological interventions for the treatment of behavioral and psychological symptoms of dementia. Int Psychogeriatr, 1-15. doi:10.1017/s1041610217002344

Edvardsson, D., Fetherstonhaugh, D., McAuliffe, L., Nay, R., \& Chenco, C. (2011). Job satisfaction amongst aged care staff: exploring the influence of person-centered care provision. Int Psychogeriatr, 23(8), 1205-1212.

Edvardsson, D., Fetherstonhaugh, D., Nay, R., \& Gibson, S. (2010). Development and initial testing of the Person-centered Care Assessment Tool (P-CAT). Int Psychogeriatr, 22(1), 101-108. doi:10.1017/s1041610209990688

Edvardsson, D., \& Innes, A. (2010). Measuring Person-centered Care: A Critical Comparative Review of Published Tools. Gerontologist, 50(6), 834-846. doi:10.1093/geront/gnq047

Edvardsson, D., Sandman, P. O., \& Rasmussen, B. (2009). Construction and psychometric evaluation of the Swedish language Person-centred Climate Questionnaire - staff version. J Nurs Manag, 17(7), 790-795. doi:10.1111/j.1365-2834.2009.01005.x

Edvardsson, D., Winblad, B., \& Sandman, P. O. (2008). Person-centred care of people with severe Alzheimer's disease: current status and ways forward. Lancet Neurol, 7(4), 362-367. doi:10.1016/s1474-4422(08)70063-2

Einang Alnes, R., Kirkevold, M., \& Skovdahl, K. (2011). Insights gained through Marte Meo counselling: experiences of nurses in dementia specific care units. Int J Older People Nurs, 6(2), 123-132. doi:10.1111/j.1748-3743.2010.00229.x

Elkinton, J. R. (1966). Medicine and the quality of life. Ann Intern Med, 64(3), 711-714.

Engedal, K., Haugen, P. K., Brækhus, A., \& Nasjonal kompetansetjeneste for aldring og, h. (2018). Demens : sykdommer, diagnostikk og behandling. Tønsberg: Forl. aldring og helse akademisk.

Ettema, T. P., Droes, R. M., de Lange, J., Mellenbergh, G. J., \& Ribbe, M. W. (2007). QUALIDEM: development and evaluation of a dementia specific quality of life instrument--validation. Int J Geriatr Psychiatry, 22(5), 424-430. doi:10.1002/gps.1692

EuroQol Group. (1990). EuroQol: A new facility for the measurement of health-related quality of life. Health Policy, 16(3), 199-208.

EuroQol Research Foundation. (2018, 2018). EQ-5D User Guides. Retrieved from https://euroqol.org/publications/user-guides/

Falk, H., Persson, L.-O., \& Wijk, H. (2007). A psychometric evaluation of a Swedish version of the Quality of Life in Late-Stage Dementia (QUALID) scale. Int Psychogeriatr, 19(6), 1040-1050.

Fazio, S., Pace, D., Flinner, J., \& Kallmyer, B. (2018). The Fundamentals of Person-Centered Care for Individuals With Dementia. Gerontologist, 58(suppl_1), S10-s19. doi:10.1093/geront/gnx122

Field, A. (2013). Discovering statistics using IBM SPSS statistics : and sex and drugs and rock ' $n$ ' roll (4th ed. ed.). Los Angeles: SAGE.

Finger, E. C. (2016). Frontotemporal Dementias. Continuum (Minneap Minn), 22(2 Dementia), 464489. doi:10.1212/con.0000000000000300

Finkel, S. I., Lyons, J. S., \& Anderson, R. L. (1993). A brief agitation rating scale (BARS) for nursing home elderly. J Am Geriatr Soc, 41(1), 50-52.

Folstein, M. F., Folstein, S. E., \& McHugh, P. R. (1975). "Mini-mental state". A practical method for grading the cognitive state of patients for the clinician. J Psychiatr Res, 12(3), 189-198. 
Forbes, D., Thiessen, E. J., Blake, C. M., Forbes, S. C., \& Forbes, S. (2013). Exercise programs for people with dementia. Cochrane Database Syst Rev(12), Cd006489.

doi:10.1002/14651858.CD006489.pub3

Forskrift av 14. Nov $1988 \mathrm{nr} .932$ om sykehjem og boform for held øgns omsorg og pleie, (1988).

Fossey, J., Ballard, C., Juszczak, E., James, I., Alder, N., Jacoby, R., \& Howard, R. (2006). Effect of enhanced psychosocial care on antipsychotic use in nursing home residents with severe dementia: cluster randomised trial. Bmj, 332(7544), 756-761. doi:10.1136/bmj.38782.575868.7C

Fossey, J., Masson, S., Stafford, J., Lawrence, V., Corbett, A., \& Ballard, C. (2014). The disconnect between evidence and practice: a systematic review of person-centred interventions and training manuals for care home staff working with people with dementia. Int J Geriatr Psychiatry, 29(8), 797-807. doi:10.1002/gps.4072

Gale, S. A., Acar, D., \& Daffner, K. R. (2018). Dementia. The American Journal of Medicine. doi:10.1016/j.amjmed.2018.01.022

Galvin, J. E., \& Sadowsky, C. H. (2012). Practical guidelines for the recognition and diagnosis of dementia. J Am Board Fam Med, 25(3), 367-382. doi:10.3122/jabfm.2012.03.100181

Garre-Olmo, J., Planas-Pujol, X., Lopez-Pousa, S., Weiner, M. F., Turon-Estrada, A., Juvinya, D., . . . Vilalta-Franch, J. (2010). Cross-cultural adaptation and psychometric validation of a Spanish version of the Quality of Life in Late-Stage Dementia Scale. Qual Life Res, 19(3), 445-453. doi:10.1007/s11136-010-9594-8

Gaugler, J. E., Yu, F., Krichbaum, K., \& Wyman, J. F. (2009). Predictors of nursing home admission for persons with dementia. Med Care, 47(2), 191-198. doi:10.1097/MLR.0b013e31818457ce

Gitlin, L. N., Marx, K. A., Stanley, I. H., Hansen, B. R., \& Van Haitsma, K. S. (2014). Assessing neuropsychiatric symptoms in people with dementia: a systematic review of measures. Int Psychogeriatr, 26(11), 1805-1848. doi:10.1017/s1041610214001537

Gitlin, L. N., Winter, L., Dennis, M. P., Hodgson, N., \& Hauck, W. W. (2010). Targeting and managing behavioral symptoms in individuals with dementia: a randomized trial of a nonpharmacological intervention. J Am Geriatr Soc, 58(8), 1465-1474. doi:10.1111/j.15325415.2010.02971.x

Gjøra, L., Eek, A., \& Kirkevold, $\varnothing$. (2015). Nasjonal kartlegging av tilbudet til personer med demens 2014. Demensplan 2015 (ISBN 978-82-8061-247-2). Retrieved from Tønsberg:

Godager, G. C., \& Thorjussen, C. B. H. (2016). Demens i norske kommuner 2015-2040. Prognoser basert på internasjonale studier: Helseøkonomiske analyser.

Gove, D., Scerri, A., Georges, J., van Houten, P., Huige, N., Hayder-Beichel, D., . . Morris, V. C. (2017). Continence care for people with dementia living at home in Europe: a review of literature with a focus on problems and challenges. J Clin Nurs, 26(3-4), 356-365. doi:10.1111/jocn.13582

Goyal, A. R., Bergh, S., Engedal, K., Kirkevold, M., \& Kirkevold, O. (2018). Trajectories of quality of life and their association with anxiety in people with dementia in nursing homes: A 12month follow-up study. PLOS ONE, 13(9), e0203773. doi:10.1371/journal.pone.0203773

Greene, J. G., Smith, R., Gardiner, M., \& Timbury, G. C. (1982). Measuring behavioural disturbance of elderly demented patients in the community and its effects on relatives: a factor analytic study. Age Ageing, 11(2), 121-126.

Gunderson, J. G. (1978). Defining the therapeutic processes in psychiatric milieus. Psychiatry, 41(4), 327-335.

Guralnik, J. M., Simonsick, E. M., Ferrucci, L., Glynn, R. J., Berkman, L. F., Blazer, D. G., . . Wallace, R. B. (1994). A short physical performance battery assessing lower extremity function: association with self-reported disability and prediction of mortality and nursing home admission. J Gerontol, 49(2), M85-94.

Haugan, G., Woods, R., Høyland, K., \& Kirkevold, $\varnothing$. (2015). Er smått alltid godt i demensomsorgen? Kunnskapsstatus om botilbud (16). Retrieved from 
Helse- og omsorgsdepartementet. (2007). Demensplan 2015: "Den gode dagen". Oslo: Helse- og omsorgsdepartementet.

Helse- og omsorgsdepartementet. (2015). Demensplan 2020: "Et mer demensvennlig samfunn". Oslo: Helse- og omsorgsdepartementet.

Lov av 24. Jun 2011 nr. 30 om kommunale helse- og omsorgstjenester m.m. (helse- og omsorgstjenesteloven), (2011).

Helsedirektoratet. (2017). Nasjonal faglig retningslinje om demens. Retrieved from Oslo: https://helsedirektoratet.no/retningslinjer/nasjonal-faglig-retningslinje-om-demens

Helvik, A. S., Engedal, K., Benth, J. S., \& Selbaek, G. (2015). Prevalence and Severity of Dementia in Nursing Home Residents. Dement Geriatr Cogn Disord, 40(3-4), 166-177. doi:10.1159/000433525

Helvik, A. S., Engedal, K., Wu, B., Benth, J. S., Corazzini, K., Roen, I., \& Selbaek, G. (2016). Severity of Neuropsychiatric Symptoms in Nursing Home Residents. Dement Geriatr Cogn Dis Extra, 6(1), 28-42. doi:10.1159/000442250

Holopainen, A., Siltanen, H., Pohjanvuori, A., Makisalo-Ropponen, M., \& Okkonen, E. (2017). Factors associated with the quality of life of people with dementia and with quality of lifeimproving interventions: Scoping review. Dementia (London), 1471301217716725. doi:10.1177/1471301217716725

Hosia-Randell, H., \& Pitkala, K. (2005). Use of psychotropic drugs in elderly nursing home residents with and without dementia in Helsinki, Finland. Drugs Aging, 22(9), 793-800.

Hughes, C. P., Berg, L., Danziger, W. L., Coben, L. A., \& Martin, R. L. (1982). A new clinical scale for the staging of dementia. Br J Psychiatry, 140, 566-572.

Hunter, P. V., Hadjistavropoulos, T., Thorpe, L., Lix, L. M., \& Malloy, D. C. (2015). The influence of individual and organizational factors on person-centred dementia care. Aging Ment Health, 20, 1-9. doi:10.1080/13607863.2015.1056771

Husbanken. (2018). Veileder for søknadsprosess og bruk av investeringstilskudd til sykehjemsplasser og omsorgsboliger. Retrieved from Oslo:

Husebo, B. S., Strand, L. I., Moe-Nilssen, R., Husebo, S. B., Snow, A. L., \& Ljunggren, A. E. (2007). Mobilization-Observation-Behavior-Intensity-Dementia Pain Scale (MOBID): development and validation of a nurse-administered pain assessment tool for use in dementia. J Pain Symptom Manage, 34(1), 67-80. doi:10.1016/j.jpainsymman.2006.10.016

Inouye, S. K., van Dyck, C. H., Alessi, C. A., Balkin, S., Siegal, A. P., \& Horwitz, R. I. (1990). Clarifying confusion: the confusion assessment method. A new method for detection of delirium. Ann Intern Med, 113(12), 941-948.

Jellinger, K. A. (2018). Dementia with Lewy bodies and Parkinson's disease-dementia: current concepts and controversies. J Neural Transm (Vienna), 125(4), 615-650. doi:10.1007/s00702-017-1821-9

Jorm, A. F. (2004). The Informant Questionnaire on cognitive decline in the elderly (IQCODE): a review. Int Psychogeriatr, 16(3), 275-293.

Kales, H. C., Gitlin, L. N., \& Lyketsos, C. G. (2015). Assessment and management of behavioral and psychological symptoms of dementia. Bmj, 350, h369. doi:10.1136/bmj.h369

Kaufer, D. I., Cummings, J. L., Ketchel, P., Smith, V., MacMillan, A., Shelley, T., . . DeKosky, S. T. (2000). Validation of the NPI-Q, a brief clinical form of the Neuropsychiatric Inventory. J Neuropsychiatry Clin Neurosci, 12(2), 233-239. doi:10.1176/jnp.12.2.233

Killett, A., Burns, D., Kelly, F., Brooker, D., Bowes, A., La Fontaine, J., . . O'NEeill, M. (2016). Digging deep: How organisational culture affects care home residents' experiences. . Ageing Soc, 36(1), 160-188. doi:10.1017/S0144686X14001111

Kim, S. K., \& Park, M. (2017). Effectiveness of person-centered care on people with dementia: a systematic review and meta-analysis. Clin Interv Aging, 12, 381-397. doi:10.2147/cia.s117637

Kirkevold, O., \& Engedal, K. (2006). The quality of care in Norwegian nursing homes. Scand J Caring Sci, 20(2), 177-183. doi:10.1111/j.1471-6712.2006.00396.x 
Kirkevold, $\varnothing$., Eek, A., \& Engedal, K. (2012). Development of residential care services facilitated for persons with dementia in Norway. Aging Clin Exp Res, 24(1), 1-5. doi:10.1007/bf03325351

Kitwood, T. (1997). Dementia reconsidered: the person comes first. Buckingham, UK: Open University Press.

Kitwood, T., \& Bredin, K. (1992). Towards a theory of dementia care: personhood and well-being. Ageing Soc, 12, 269-287.

Klapwijk, M. S., Caljouw, M. A., Pieper, M. J., van der Steen, J. T., \& Achterberg, W. P. (2016). Characteristics Associated with Quality of Life in Long-Term Care Residents with Dementia: A Cross-Sectional Study. Dement Geriatr Cogn Disord, 42(3-4), 186-197. doi:10.1159/000448806

Knapskog, A. B., Barca, M. L., \& Engedal, K. (2011). A comparison of the validity of the Cornell Scale and the MADRS in detecting depression among memory clinic patients. Dement Geriatr Cogn Disord, 32(4), 287-294. doi:10.1159/000334983

Kok, J. S., Berg, I. J., \& Scherder, E. J. (2013). Special care units and traditional care in dementia: relationship with behavior, cognition, functional status and quality of life - a review. Dement Geriatr Cogn Dis Extra, 3(1), 360-375. doi:10.1159/000353441

Forskrift om kvalitet i pleie- og omsorgstjenestene for tjenesteyting etter lov av 19. november 1982 nr. 66 om helsetjenesten i kommunene og etter lov av 13. desember $1991 \mathrm{nr} .81$ om sosiale tjenester m.v., (2003).

Lanctot, K. L., Amatniek, J., Ancoli-Israel, S., Arnold, S. E., Ballard, C., Cohen-Mansfield, J., . . Boot, B. (2017). Neuropsychiatric signs and symptoms of Alzheimer's disease: New treatment paradigms. Alzheimers Dement (N Y), 3(3), 440-449. doi:10.1016/j.trci.2017.07.001

Langa, K. M., \& Levine, D. A. (2014). The diagnosis and management of mild cognitive impairment: a clinical review. Jama, 312(23), 2551-2561. doi:10.1001/jama.2014.13806

Laver, K., Dyer, S., Whitehead, C., Clemson, L., \& Crotty, M. (2016). Interventions to delay functional decline in people with dementia: a systematic review of systematic reviews. BMJ Open, 6(4), e010767. doi:10.1136/bmjopen-2015-010767

Lawrence, V., Fossey, J., Ballard, C., Moniz-Cook, E., \& Murray, J. (2012). Improving quality of life for people with dementia in care homes: making psychosocial interventions work. Br J Psychiatry, 201(5), 344-351. doi:10.1192/bjp.bp.111.101402

Lawton, M. P. (1994). Quality of life in Alzheimer disease. Alzheimer Dis Assoc Disord, 8 Suppl 3 , 138-150.

Lawton, M. P., \& Brody, E. M. (1969). Assessment of older people: self-maintaining and instrumental activities of daily living. Gerontologist, 9(3), 179-186.

Lehuluante, A., Nilsson, A., \& Edvardsson, D. (2012). The influence of a person-centred psychosocial unit climate on satisfaction with care and work. J Nurs Manag, 20(3), 319-325. doi:10.1111/j.1365-2834.2011.01286.x

Li, J., \& Porock, D. (2014). Resident outcomes of person-centered care in long-term care: a narrative review of interventional research. Int J Nurs Stud, 51(10), 1395-1415.

doi:10.1016/j.ijnurstu.2014.04.003

Lichtwarck, B., Selbaek, G., Kirkevold, O., Rokstad, A. M. M., Benth, J. S., Lindstrom, J. C., \& Bergh, S. (2018). Targeted Interdisciplinary Model for Evaluation and Treatment of Neuropsychiatric Symptoms: A Cluster Randomized Controlled Trial. Am J Geriatr Psychiatry, 26(1), 25-38. doi:10.1016/j.jagp.2017.05.015

Lintern, T., Woods, B., \& Phair, L. (2000). Training is nor enough to change care practice. Journal of Dementia Care, 8(2), 15-17.

Livingston, G., Barber, J., Marston, L., Rapaport, P., Livingston, D., Cousins, S., . . Cooper, C. (2017). Prevalence of and associations with agitation in residents with dementia living in care homes: MARQUE cross-sectional study. BJPsych Open, 3(4), 171-178.

doi:10.1192/bjpo.bp.117.005181 
Livingston, G., Kelly, L., Lewis-Holmes, E., Baio, G., Morris, S., Patel, N., . . Cooper, C. (2014). Nonpharmacological interventions for agitation in dementia: systematic review of randomised controlled trials. Br J Psychiatry, 205(6), 436-442. doi:10.1192/bjp.bp.113.141119

Livingston, G., Sommerlad, A., Orgeta, V., Costafreda, S. G., Huntley, J., Ames, D., . . Mukadam, N. (2017). Dementia prevention, intervention, and care. Lancet, 390(10113), 2673-2734. doi:10.1016/s0140-6736(17)31363-6

Logemann, J. A., Gensler, G., Robbins, J., Lindblad, A. S., Brandt, D., Hind, J. A., . . Miller Gardner, P. J. (2008). A randomized study of three interventions for aspiration of thin liquids in patients with dementia or Parkinson's disease. J Speech Lang Hear Res, 51(1), 173-183. doi:10.1044/1092-4388(2008/013)

Logsdon, R. G., Gibbons, L. E., McCurry, S. M., \& Teri, L. (2002). Assessing quality of life in older adults with cognitive impairment. Psychosom Med, 64(3), 510-519.

Logsdon, R. G., Gibbons, L. E., McCurry, S. M., \& Terri, L. J. (1999). Quality of life in Alzheimer's disease: patient and caregiver reports. Ment Health Aging, 5, 21-32.

Lyketsos, C. G., Galik, E., Steele, C., Steinberg, M., Rosenblatt, A., Warren, A., . . Brandt, J. (1999). The General Medical Health Rating: a bedside global rating of medical comorbidity in patients with dementia. J Am Geriatr Soc, 47(4), 487-491.

Manthorpe, J., \& Samsi, K. (2016). Person-centered dementia care: current perspectives. Clin Interv Aging, 11, 1733-1740. doi:10.2147/cia.s104618

Martyr, A., Nelis, S. M., Quinn, C., Wu, Y. T., Lamont, R. A., Henderson, C., . . Clare, L. (2018). Living well with dementia: a systematic review and correlational meta-analysis of factors associated with quality of life, well-being and life satisfaction in people with dementia. Psychol Med, 1-10. doi:10.1017/s0033291718000405

Matthews, F. E., \& Dening, T. (2002). Prevalence of dementia in institutional care. Lancet, 360(9328), 225-226. doi:10.1016/s0140-6736(02)09461-8

Matthews, F. E., Stephan, B. C., Robinson, L., Jagger, C., Barnes, L. E., Arthur, A., \& Brayne, C. (2016). A two decade dementia incidence comparison from the Cognitive Function and Ageing Studies I and II. Nat Commun, 7, 11398. doi:10.1038/ncomms11398

McCormack, B., \& McCance, T. V. (2006). Development of a framework for person-centred nursing. J Adv Nurs, 56(5), 472-479. doi:10.1111/j.1365-2648.2006.04042.x

McKeith, I. G., Dickson, D. W., Lowe, J., Emre, M., O'Brien, J. T., Feldman, H., . . Consortium on, D. L. B. (2005). Diagnosis and management of dementia with Lewy bodies: third report of the DLB Consortium. Neurology, 65(12), 1863-1872. doi:10.1212/01.wnl.0000187889.17253.b1

Meld.St. nr. 29. (2013). Morgendagens omsorg. Oslo: Helse- og omsorgsdepartementet.

Mendez, M. F. (2017). Early-Onset Alzheimer Disease. Neurol Clin, 35(2), 263-281. doi:10.1016/j.ncl.2017.01.005

Missotten, P., Dupuis, G., \& Adam, S. (2016). Dementia-specific quality of life instruments: a conceptual analysis. Int Psychogeriatr, 28(8), 1245-1262. doi:10.1017/s1041610216000417

Mitchell, A. J., \& Shiri-Feshki, M. (2009). Rate of progression of mild cognitive impairment to dementia--meta-analysis of 41 robust inception cohort studies. Acta Psychiatr Scand, 119(4), 252-265. doi:10.1111/j.1600-0447.2008.01326.x

Mjorud, M., Kirkevold, M., Rosvik, J., \& Engedal, K. (2014). Principal component analysis of the Norwegian version of the quality of life in late-stage dementia scale. Dement Geriatr Cogn Disord, 37(5-6), 265-275. doi:10.1159/000356497

Mjorud, M., Kirkevold, M., Rosvik, J., Selbaek, G., \& Engedal, K. (2014). Variables associated to quality of life among nursing home patients with dementia. Aging Ment Health, 1-9. doi:10.1080/13607863.2014.903468

Mjorud, M., Rosvik, J., Rokstad, A. M., Kirkevold, M., \& Engedal, K. (2014). Variables associated with change in quality of life among persons with dementia in nursing homes: a 10 months follow-up study. PLOS ONE, 9(12), e115248. doi:10.1371/journal.pone.0115248

Molony, S. L., Kolanowski, A., Van Haitsma, K., \& Rooney, K. E. (2018). Person-Centered Assessment and Care Planning. Gerontologist, 58(suppl_1), S32-s47. doi:10.1093/geront/gnx173 
Moniz-Cook, E., Vernooij-Dassen, M., Woods, R., Verhey, F., Chattat, R., De Vugt, M., ... Orrell, M. (2008). A European consensus on outcome measures for psychosocial intervention research in dementia care. Aging Ment Health, 12(1), 14-29. doi:10.1080/13607860801919850

Moniz Cook, E. D., Swift, K., James, I., Malouf, R., De Vugt, M., \& Verhey, F. (2012). Functional analysis-based interventions for challenging behaviour in dementia. Cochrane Database Syst Rev(2), Cd006929. doi:10.1002/14651858.CD006929.pub2

Morley, J. E., Morris, J. C., Berg-Weger, M., Borson, S., Carpenter, B. D., Del Campo, N., . . Vellas, B. (2015). Brain health: the importance of recognizing cognitive impairment: an IAGG consensus conference. J Am Med Dir Assoc, 16(9), 731-739. doi:10.1016/j.jamda.2015.06.017

Morris, J. N., Hawes, C., Fries, B. E., Phillips, C. D., Mor, V., Katz, S., ... Friedlob, A. S. (1990). Designing the national resident assessment instrument for nursing homes. Gerontologist, 30(3), 293-307.

Moyle, W., Fetherstonhaugh, D., Greben, M., \& Beattie, E. (2015). Influencers on quality of life as reported by people living with dementia in long-term care: a descriptive exploratory approach. BMC Geriatr, 15, 50. doi:10.1186/s12877-015-0050-z

Mulhern, B., Rowen, D., Brazier, J., Smith, S., Romeo, R., Tait, R., . . Banerjee, S. (2013). Development of DEMQOL-U and DEMQOL-PROXY-U: generation of preference-based indices from DEMQOL and DEMQOL-PROXY for use in economic evaluation. Health Technol Assess, 17(5), v-xv, 1-140. doi:10.3310/hta17050

Mørk, E., Beyrer, S., Haugstveit, F. V., Sundby, B., Karlsen, H., \& Wettergreen, J. (2017) Kommunale helse- og omsorgstjenester 2016. Statistikk om tjenester og tjenestemottakere. In, (pp. 59). Oslo - Kongsvinger: Statistisk sentralbyrå.

Naik, M., \& Nygaard, H. A. (2008). Diagnosing dementia -- ICD-10 not so bad after all: a comparison between dementia criteria according to DSM-IV and ICD-10. Int J Geriatr Psychiatry, 23(3), 279-282. doi:10.1002/gps.1874

Neary, D., Snowden, J. S., Gustafson, L., Passant, U., Stuss, D., Black, S., . . Benson, D. F. (1998). Frontotemporal lobar degeneration: a consensus on clinical diagnostic criteria. Neurology, 51(6), 1546-1554.

Nightingale, F. (1992). Notes on nursing: What it is, and what it is not: New York Cambridge University Press.

Oudman, E., \& Veurink, B. (2014). Quality of life in nursing home residents with advanced dementia: a 2-year follow-up. Psychogeriatrics, 14(4), 235-240. doi:10.1111/psyg.12062

Painter, V., Le Couteur, D. G., \& Waite, L. M. (2017). Texture-modified food and fluids in dementia and residential aged care facilities. Clin Interv Aging, 12, 1193-1203. doi:10.2147/cia.S140581

Pennacchini, M., Bertolaso, M., Elvira, M. M., \& De Marinis, M. G. (2011). A brief history of the Quality of Life: its use in medicine and in philosophy. Clin Ter, 162(3), e99-e103.

Petersen, R. C. (2016). Mild Cognitive Impairment. Continuum (Minneap Minn), 22(2 Dementia), 404-418. doi:10.1212/con.0000000000000313

Popham, C., \& Orrell, M. (2012). What matters for people with dementia in care homes? Aging Ment Health, 16(2), 181-188. doi:10.1080/13607863.2011.628972

Prince, M., Bryce, R., Albanese, E., Wimo, A., Ribeiro, W., \& Ferri, C. P. (2013). The global prevalence of dementia: a systematic review and metaanalysis. Alzheimers Dement, 9(1), 63-75.e62. doi:10.1016/j.jalz.2012.11.007

Rehm, J., Gmel, G. E., Sr., Gmel, G., Hasan, O. S. M., Imtiaz, S., Popova, S., . . Shuper, P. A. (2017). The relationship between different dimensions of alcohol use and the burden of disease-an update. Addiction, 112(6), 968-1001. doi:10.1111/add.13757

Reimer, M. A., Slaughter, S., Donaldson, C., Currie, G., \& Eliasziw, M. (2004). Special care facility compared with traditional environments for dementia care: a longitudinal study of quality of life. J Am Geriatr Soc, 52(7), 1085-1092. doi:10.1111/j.1532-5415.2004.52304.x 
Reinar, L. M., Fure, B., Kirkehei, I., Dahm, K. T., Landmark, B., \& Nasjonalt kunnskapssenter for, h. (2011). Effekten av tilrettelagt dagsentertilbud til personer med demens. In Rapport fra Kunnskapssenteret, Vol. nr 21-2011.

Reisberg, B. (1988). Functional assessment staging (FAST). Psychopharmacol Bull, 24(4), 653-659.

Richter, T., Meyer, G., Mohler, R., \& Kopke, S. (2012). Psychosocial interventions for reducing antipsychotic medication in care home residents. Cochrane Database Syst Rev, 12, Cd008634. doi:10.1002/14651858.CD008634.pub2

Rickham, P. P. (1964). Human experimentation. Code of ethics of the World Medical Association. Declaration of Helsinki. Br Med J, 2(5402), 177.

Roberts, R., \& Knopman, D. S. (2013). Classification and epidemiology of MCl. Clin Geriatr Med, 29(4), 753-772. doi:10.1016/j.cger.2013.07.003

Robertson, A., Gilloran, A., McGlew, T., McKee, K., McKinley, A., \& Wight, D. (1995). Nurses' job satisfaction and the quality of care received by patients in psychogeriatric wards. Int $\mathrm{J}$ Geriatr Psychiatry, 10(7), 575-584. doi:doi:10.1002/gps.930100708

Robertson, S., Cooper, C., Hoe, J., Hamilton, O., Stringer, A., \& Livingston, G. (2017). Proxy rated quality of life of care home residents with dementia: a systematic review. Int Psychogeriatr, 29(4), 569-581. doi:10.1017/s1041610216002167

Roen, I., Selbaek, G., Kirkevold, O., Engedal, K., Lerdal, A., \& Bergh, S. (2015). The Reliability and Validity of the Norwegian Version of the Quality of Life in Late-Stage Dementia Scale. Dement Geriatr Cogn Disord, 40(3-4), 233-242. doi:10.1159/000437093

Rogers, C. R. (1961). On Becoming a Person: a Therapist's View of Psychotherapy. Boston: Houghton Miffin.

Rogne, A. F., Syse, A., \& Statistisk Sentralbyrå. (2017). Framtidens eldre i by og bygd: befolkningsframskrivinger, sosiodemografiske mønstre og helse (978-82-537-9619-2). Retrieved from Oslo:

Rokstad, A. (2012). Bedre hverdag for personer med demens. Tønsberg: Aldring og helse.

Rokstad, A. M., Engedal, K., Edvardsson, D., \& Selbaek, G. (2012). Psychometric evaluation of the Norwegian version of the Person-centred Care Assessment Tool. Int J Nurs Pract, 18(1), 99105. doi:10.1111/j.1440-172X.2011.01998.x

Rokstad, A. M., Rosvik, J., Kirkevold, O., Selbaek, G., Saltyte Benth, J., \& Engedal, K. (2013). The effect of person-centred dementia care to prevent agitation and other neuropsychiatric symptoms and enhance quality of life in nursing home patients: a 10-month randomized controlled trial. Dement Geriatr Cogn Disord, 36(5-6), 340-353. doi:10.1159/000354366

Rokstad, A. M., Vatne, S., Engedal, K., \& Selbaek, G. (2015). The role of leadership in the implementation of person-centred care using Dementia Care Mapping: a study in three nursing homes. J Nurs Manag, 23(1), 15-26. doi:10.1111/jonm.12072

Rosness, T. A., Engedal, K., \& Chemali, Z. (2016). Frontotemporal Dementia: An Updated Clinician's Guide. J Geriatr Psychiatry Neurol, 29(5), 271-280. doi:10.1177/0891988716654986

Rostad, H. M., Puts, M. T. E., Cvancarova Smastuen, M., Grov, E. K., Utne, I., \& Halvorsrud, L. (2017). Associations between Pain and Quality of Life in Severe Dementia: A Norwegian CrossSectional Study. Dement Geriatr Cogn Dis Extra, 7(1), 109-121. doi:10.1159/000468923

Rosvik, J., Kirkevold, M., Engedal, K., Brooker, D., \& Kirkevold, O. (2011). A model for using the VIPS framework for person-centred care for persons with dementia in nursing homes: a qualitative evaluative study. Int J Older People Nurs, 6(3), 227-236. doi:10.1111/j.17483743.2011.00290.x

Røen, I., Selbaek, G., \& Lerdal, A. (2009). The reliability and validity of the Norwegian version of the Quality of life in Late-stage Dementia (QUALID) scale. Paper presented at the Interantional Psychogeriatric Association Montreal, CA.

Røen, I., \& Storlien, M. S. (2015). Strukturert miljøbehandling i demensomsorgen. Tønsberg: Aldring og helse.

Sandvoll, A. M., Kristoffersen, K., \& Hauge, S. (2012). New quality regulations versus established nursing home practice: a qualitative study. BMC Nurs, 11, 7. doi:10.1186/1472-6955-11-7 
Schmitt, F. A., Saxton, J. A., Xu, Y., McRae, T., Sun, Y., Richardson, S., \& Li, H. (2009). A brief instrument to assess treatment response in the patient with advanced Alzheimer disease. Alzheimer Dis Assoc Disord, 23(4), 377-383. doi:10.1097/WAD.0b013e3181ac9cc1

Schneider, J. A., Arvanitakis, Z., Bang, W., \& Bennett, D. A. (2007). Mixed brain pathologies account for most dementia cases in community-dwelling older persons. Neurology, 69(24), 21972204. doi:10.1212/01.wnl.0000271090.28148.24

Schwarzinger, M., Pollock, B. G., Hasan, O. S. M., Dufouil, C., \& Rehm, J. (2018). Contribution of alcohol use disorders to the burden of dementia in France 2008-13: a nationwide retrospective cohort study. Lancet Public Health, 3(3), e124-e132. doi:10.1016/s24682667(18)30022-7

Seitz, D., Purandare, N., \& Conn, D. (2010). Prevalence of psychiatric disorders among older adults in long-term care homes: a systematic review. Int Psychogeriatr, 22(7), 1025-1039. doi:10.1017/s1041610210000608

Selbaek, G., \& Engedal, K. (2012). Stability of the factor structure of the Neuropsychiatric Inventory in a 31-month follow-up study of a large sample of nursing-home patients with dementia. Int Psychogeriatr, 24(1), 62-73. doi:10.1017/s104161021100086x

Selbaek, G., Engedal, K., Benth, J. S., \& Bergh, S. (2014). The course of neuropsychiatric symptoms in nursing-home patients with dementia over a 53-month follow-up period. Int Psychogeriatr, 26(1), 81-91. doi:10.1017/s1041610213001609

Selbaek, G., Engedal, K., \& Bergh, S. (2013). The prevalence and course of neuropsychiatric symptoms in nursing home patients with dementia: a systematic review. J Am Med Dir Assoc, 14(3), 161-169. doi:10.1016/j.jamda.2012.09.027

Selbaek, G., Kirkevold, O., \& Engedal, K. (2007). The prevalence of psychiatric symptoms and behavioural disturbances and the use of psychotropic drugs in Norwegian nursing homes. Int J Geriatr Psychiatry, 22(9), 843-849. doi:10.1002/gps.1749

Selbaek, G., Kirkevold, O., \& Engedal, K. (2008). Psychiatric and behavioural symptoms and the use of psychotropic medication in Special Care Units and Regular Units in Norwegian nursing homes. Scand J Caring Sci, 22(4), 568-573. doi:10.1111/j.1471-6712.2007.00576.x

Selbaek, G., Kirkevold, O., Sommer, O. H., \& Engedal, K. (2008). The reliability and validity of the Norwegian version of the Neuropsychiatric Inventory, nursing home version (NPI-NH). Int Psychogeriatr, 20(2), 375-382. doi:10.1017/s1041610207005601

Sjogren, K., Lindkvist, M., Sandman, P. O., Zingmark, K., \& Edvardsson, D. (2013). Personcentredness and its association with resident well-being in dementia care units. J Adv Nurs, 69(10), 2196-2205. doi:10.1111/jan.12085

Sjogren, K., Lindkvist, M., Sandman, P. O., Zingmark, K., \& Edvardsson, D. (2015). To what extent is the work environment of staff related to person-centred care? A cross-sectional study of residential aged care. J Clin Nurs, 24(9-10), 1310-1319. doi:10.1111/jocn.12734

Sjögren, K., Lindkvist, M., Sandman, P.-O., Zingmark, K., \& Edvardsson, D. (2017). Organisational and environmental characteristics of residential aged care units providing highly person-centred care: a cross sectional study. BMC Nurs, 16(1), 44. doi:10.1186/s12912-017-0240-4

Sjögren, K., Lindkvist, M., Sandman, P. O., Zingmark, K., \& Edvardsson, D. (2015). To what extent is the work environment of staff related to person-centred care? A cross-sectional study of residential aged care. J Clin Nurs, 24. doi:10.1111/jocn.12734

Sloane, P. D., Mitchell, C. M., Weisman, G., Zimmerman, S., Foley, K. M., Lynn, M., . . Montgomery, R. (2002). The Therapeutic Environment Screening Survey for Nursing Homes (TESS-NH): an observational instrument for assessing the physical environment of institutional settings for persons with dementia. J Gerontol B Psychol Sci Soc Sci, 57(2), S69-78.

Smith, S. C., Lamping, D. L., Banerjee, S., Harwood, R., Foley, B., Smith, P., . . Knapp, M. (2005). Measurement of health-related quality of life for people with dementia: development of a new instrument (DEMQOL) and an evaluation of current methodology. Health Technol Assess, 9(10), 1-93, iii-iv. 
Sommer, O. H., \& Engedal, K. (2011). Reliability and validity of the Norwegian version of the Brief Agitation Rating Scale (BARS) in dementia. Aging Ment Health, 15(2), 252-258. doi:10.1080/13607863.2010.519318

Spector, A., Revolta, C., \& Orrell, M. (2016). The impact of staff training on staff outcomes in dementia care: a systematic review. Int J Geriatr Psychiatry, 31(11), 1172-1187. doi:10.1002/gps.4488

St.meld. nr. 25 (2005-2006). (2006). Mestring, muligheter og mening: framtidas omsorgsutfordringer. Oslo: Helse- og omsorgsdepartementet.

Steinberg, M., Shao, H., Zandi, P., Lyketsos, C. G., Welsh-Bohmer, K. A., Norton, M. C., . . Tschanz, J. T. (2008). Point and 5-year period prevalence of neuropsychiatric symptoms in dementia: the Cache County Study. Int J Geriatr Psychiatry, 23(2), 170-177. doi:10.1002/gps.1858

Steinberg, M., Tschanz, J. T., Corcoran, C., Steffens, D. C., Norton, M. C., Lyketsos, C. G., \& Breitner, J. C. (2004). The persistence of neuropsychiatric symptoms in dementia: the Cache County Study. Int J Geriatr Psychiatry, 19(1), 19-26. doi:10.1002/gps.1025

Strand, B. H., Tambs, K., Engedal, K., Bjertness, E., Selbaek, G., \& Rosness, T. A. (2014). [How many have dementia in Norway?]. Tidsskr Nor Laegeforen, 134(3), 276-277. doi:10.4045/tidsskr.13.1601

Surr, C. A., Griffiths, A. W., \& Kelley, R. (2018). Implementing Dementia Care Mapping as a practice development tool in dementia care services: a systematic review. Clin Interv Aging, 13, 165177. doi:10.2147/cia.S138836

Taft, L. B., Delaney, K., Seman, D., \& Stansell, J. (1993). Dementia care creating a therapeutic milieu. J Gerontol Nurs, 19(10), 30-39.

Teri, L., McCurry, S. M., \& Logsdon, R. G. (1997). Memory, thinking, and aging. What we know about what we know. West J Med, 167(4), 269-275.

Terwee, C. B., Bot, S. D., de Boer, M. R., van der Windt, D. A., Knol, D. L., Dekker, J., . . . de Vet, H. C. (2007). Quality criteria were proposed for measurement properties of health status questionnaires. J Clin Epidemiol, 60(1), 34-42. doi:10.1016/j.jclinepi.2006.03.012

Testad, I., Corbett, A., Aarsland, D., Lexow, K. O., Fossey, J., Woods, B., \& Ballard, C. (2014). The value of personalized psychosocial interventions to address behavioral and psychological symptoms in people with dementia living in care home settings: a systematic review. Int Psychogeriatr, 26(7), 1083-1098. doi:10.1017/s1041610214000131

The National Institute for Health and Care Excellence. (2018). Dementia: assessment, management and support for people living with dementia and their carers. NICE Guidance. Retrieved from https://www.nice.org.uk/guidance/ng97

Tune, L. E. (2001). Anticholinergic effects of medication in elderly patients. J Clin Psychiatry, 62 Suppl 21, 11-14.

Ulstein, I., Bruun Wyller, T., \& Engedal, K. (2007). The relative stress scale, a useful instrument to identify various aspects of carer burden in dementia? Int J Geriatr Psychiatry, 22(1), 61-67. doi:10.1002/gps.1654

van de Ven, G., Draskovic, I., Adang, E. M., Donders, R., Zuidema, S. U., Koopmans, R. T., \& VernooijDassen, M. J. (2013). Effects of dementia-care mapping on residents and staff of care homes: a pragmatic cluster-randomised controlled trial. PLOS ONE, 8(7), e67325. doi:10.1371/journal.pone.0067325

van den Pol-Grevelink, A., Jukema, J. S., \& Smits, C. H. (2012). Person-centred care and job satisfaction of caregivers in nursing homes: a systematic review of the impact of different forms of person-centred care on various dimensions of job satisfaction. Int J Geriatr Psychiatry, 27(3), 219-229. doi:10.1002/gps.2719

van der Zon, A., Wetzels, R. B., Bor, H., Zuidema, S. U., Koopmans, R., \& Gerritsen, D. L. (2018). TwoYear Course of Quality of Life in Nursing Home Residents with Dementia. Am J Geriatr Psychiatry, 26(7), 754-764. doi:10.1016/j.jagp.2018.01.202 
Vann Jones, S. A., \& O'Brien, J. T. (2014). The prevalence and incidence of dementia with Lewy bodies: a systematic review of population and clinical studies. Psychol Med, 44(4), 673-683. doi:10.1017/s0033291713000494

Forskrift av 12. Nov $2010 \mathrm{nr}$. 1426 om en verdig eldreomsorg (verdighetsgarantien) (2011).

Vossius, C., Selbæk, G., Benth, J., \& Bergh, S. (2018). Ressursbruk og sykdomsforløp ved demens (REDIC). Videreføring av prosjektet. Retrieved from Ottestad:

Vossius, C., Selbæk, G., Ydstebø, A., Benth, J., Godager, G., Lurås, H., \& Bergh, S. (2015). Ressursbruk og sykdomsforløp ved demens (REDIC). Retrieved from http://www.sykehusetinnlandet.no/fagfolk /forskning/alderpsykiatriskforskningssenter /Documents/53528 REDIC rapport A4 web.pdf

Walker, Z., Possin, K. L., Boeve, B. F., \& Aarsland, D. (2015). Lewy body dementias. Lancet, 386(10004), 1683-1697. doi:10.1016/s0140-6736(15)00462-6

Wang, S. Y., Shamliyan, T. A., Talley, K. M., Ramakrishnan, R., \& Kane, R. L. (2013). Not just specific diseases: systematic review of the association of geriatric syndromes with hospitalization or nursing home admission. Arch Gerontol Geriatr, 57(1), 16-26. doi:10.1016/j.archger.2013.03.007

Weiner, M., Martin-Cook, K., Svetlik, D., Saine, K., Foster, B., \& Fontaine, C. (2000). The quality of life in late-stage dementia (QUALID) scale. J Am Med Dir Assoc, 1(3), 114-116.

Wergeland, J. N., Selbaek, G., Bergh, S., Soederhamn, U., \& Kirkevold, O. (2015). Predictors for Nursing Home Admission and Death among Community-Dwelling People 70 Years and Older Who Receive Domiciliary Care. Dement Geriatr Cogn Dis Extra, 5(3), 320-329. doi:10.1159/000437382

Wetzels, R., Zuidema, S., Jansen, I., Verhey, F., \& Koopmans, R. (2010). Course of neuropsychiatric symptoms in residents with dementia in long-term care institutions: a systematic review. Int Psychogeriatr, 22(7), 1040-1053. doi:10.1017/s1041610210000918

Wetzels, R. B., Zuidema, S. U., de Jonghe, J. F., Verhey, F. R., \& Koopmans, R. T. (2010). Determinants of quality of life in nursing home residents with dementia. Dement Geriatr Cogn Disord, 29(3), 189-197. doi:10.1159/000280437

WHOQOL-GROUP. (1995). The World Health Organization Quality of Life assessment (WHOQOL): position paper from the World Health Organization. Soc Sci Med, 41(10), 1403-1409.

Wilberforce, M., Challis, D., Davies, L., Kelly, M. P., Roberts, C., \& Loynes, N. (2016). Personcentredness in the care of older adults: a systematic review of questionnaire-based scales and their measurement properties. BMC Geriatr, 16, 63. doi:10.1186/s12877-016-0229-y

Wimo, A., Jonsson, L., \& Zbrozek, A. (2010). The Resource Utilization in Dementia (RUD) instrument is valid for assessing informal care time in community-living patients with dementia. $J$ Nutr Health Aging, 14(8), 685-690.

Winblad, B., Palmer, K., Kivipelto, M., Jelic, V., Fratiglioni, L., Wahlund, L. O., . . Petersen, R. C. (2004). Mild cognitive impairment--beyond controversies, towards a consensus: report of the International Working Group on Mild Cognitive Impairment. J Intern Med, 256(3), 240246. doi:10.1111/j.1365-2796.2004.01380.x

Wood, S., Cummings, J. L., Hsu, M. A., Barclay, T., Wheatley, M. V., Yarema, K. T., \& Schnelle, J. F. (2000). The use of the neuropsychiatric inventory in nursing home residents. Characterization and measurement. Am J Geriatr Psychiatry, 8(1), 75-83.

Woods, B., Aguirre, E., Spector, A. E., \& Orrell, M. (2012). Cognitive stimulation to improve cognitive functioning in people with dementia. Cochrane Database Syst Rev(2), Cd005562. doi:10.1002/14651858.CD005562.pub2

World Health Organization (WHO). (2018). ICD-11 for Mortality and Morbidity Statistics (ICD-11 MMS) 2018 version In. Geneve: World Health Organization.

World Health Organization (WHO) (Ed.) (1993). The ICD-10 Classification of Mental and Behavioural Disorders - Diagnostic Criteria for Research. Geneva. 
Ydstebo, A. E., Bergh, S., Selbaek, G., Benth, J. S., Bronnick, K., \& Vossius, C. (2018). Longitudinal changes in quality of life among elderly people with and without dementia. Int Psychogeriatr, 1-12. doi:10.1017/s1041610218000352

Zekry, D., Hauw, J. J., \& Gold, G. (2002). Mixed dementia: epidemiology, diagnosis, and treatment. J Am Geriatr Soc, 50(8), 1431-1438. 


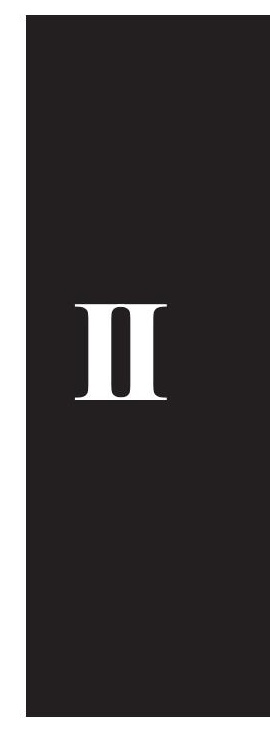





\title{
Resource Use and Disease Course in dementia - Nursing Home (REDIC-NH), a longitudinal cohort study; design and patient characteristics at admission to Norwegian nursing homes
}

Irene Røen ${ }^{1^{*}}$, Geir Selbæk ${ }^{1,2,3}, \varnothing y v i n d$ Kirkevold ${ }^{1,2,4}$, Knut Engedal $^{2}$, Ingelin Testad ${ }^{5}$ and Sverre Bergh ${ }^{1,2}$

\begin{abstract}
Background: Earlier studies of nursing home patients show a high prevalence of dementia, neuropsychiatric symptoms (NPS), pain, and dependency in activities of daily living. The REDIC-NH cohort was set up to study the disease course and the resources used in patients with dementia in Norway. The aim of this paper was to describe the methods and the data collection, and to present selected data about patients at admission to a nursing home.

Methods: We included 696 patients at admission to a nursing home and followed them with biannual assessments until death. Baseline data were collected between March 2012 and November 2014. In October 2016, patients had either completed an 18-month follow-up $(n=349)$, passed 18 months without assessments $(n=22)$, or left the study $(n=324)$. Data on demographics, cognition, NPS, activities of daily living (ADL) functioning, physical health, medication, Quality of Life (QoL), resource use, and caregiver burden, in addition to DNA samples were collected.

Results: Mean age of the participants at inclusion was 84.5 years (SD 7.5, range 50 - 105), 63.9\% were women. According to data collected in the study, $83.8 \%$ had dementia, but only 55.9\% of them had a diagnosis of dementia registered in their records. The most frequent dementia diagnosis was Alzheimer's disease, which was present in $71 \%$ of those with dementia. Patients with dementia more often experienced delusions, hallucinations, agitation, anxiety, disinhibition, irritability, and aberrant motor behaviour compared to patients without dementia. Depression and anxiety were the most common NPS symptoms.
\end{abstract}

Conclusions: Dementia and NPS were highly prevalent among persons admitted to nursing homes. Only 55.9\% of the patients with dementia had a diagnosis of dementia registered in their records.

Keywords: Nursing homes, Dementia, Neuropsychiatric symptoms, Resource use, Cohort-study, Longitudinal

\section{Background}

Dementia is a syndrome caused by a variety of brain disorders, characterised by a decline in cognition, decreased ability to perform activities of daily living (ADL), and deterioration in emotional control, social behaviour, or motivation. The syndrome is usually of a chronic or progressive nature. Age-specific prevalence rates for

\footnotetext{
* Correspondence: irroee@sykehuset-innlandet.no

${ }^{1}$ Centre for Old Age Psychiatric Research, Innlandet Hospital Trust, Ottestad, Norway

Full list of author information is available at the end of the article
}

dementia show an increase from $1.6 \%$ in the $60-64$ age group to $21.7 \%$ in the $85-89$ age group and to $43.1 \%$ in the $90+$ age group [1]. Consequently, as the population ages, the number of persons with dementia is increasing worldwide, and is expected to double in the next 20 years [1]. A systematic review from 2013 reported that dementia is one of the most strongly associated factors to nursing home admission [2]. The prevalence of dementia in Norway in 2016 was estimated to be 78,000 [1], 1.5\% of the total population. A Norwegian cross-sectional study showed that more than $80 \%$ of Norwegian nursing home 
(NH) patients had dementia defined with a Clinical Dementia Rating scale (CDR) score of 1 or above, and $72 \%$ of the patients with dementia had clinically significant neuropsychiatric symptoms (NPS) [3]. NPS include psychiatric symptoms such as delusions, hallucinations, depression, anxiety, and euphoria, and behavioural symptoms such as agitation, aggression, apathy, and disinhibition. According to a systematic review by Selbæk et al, NPS are common among patients with dementia, and the course of individual NPS varies considerably. Agitation (36\%), apathy (36\%), aggression (32\%) and depression (28\%) are the most prevalent symptoms [4]. Agitation and apathy are the most persistent NPS over time [4], and the prevalence of individual NPS changes with the progression of the dementia [2, 5-7]. Recent NPS studies have included genetic association designs, due to the strong familial aggregation of symptoms implicating genetic variation as a mediating factor [8]. Genetic polymorphism in serotonin and dopamine receptors have been found of importance both in the development of NPS as well as in treatment efficacy [9]. Psychotropic drugs are often used to treat NPS, despite uncertain efficacy and considerable risks for serious adverse events [10]. Data from randomised controlled trials and large registrybased studies indicate that the use of antipsychotic drugs is associated with increased mortality and an increased risk of cerebrovascular adverse events [11]. However, results from observational studies of clinical samples have been conflicting [12]. Depression is associated with increased mortality, but how antidepressant use and gender influence mortality is unclear [13-15]. Dementia leads to severe disability and causes a high burden on caregivers and costs to society. The economic burden in Europe has been estimated to be $€ 55-66$ billion annually [16]. The cost of dementia in Norway is estimated to be $€ 3.02$ billion a year [17].

Previous $\mathrm{NH}$ studies from Scandinavian have been cross-sectional [3, 18], but few studies have examined the course of dementia symptoms and the use of resources, from admission to NHs until death [5]. Only one grey paper in Norwegian has presented numbers for resource use in dementia in Norway [17], and a review of international studies has reported a large variation in cost estimates [16]. Previous studies have shown that more than $80 \%$ of the patients in Norwegian NHs have dementia, but only about $50 \%$ of those with dementia receive a diagnose of dementia. Thus, we decided to include all patients above 65 years at admission to NHs, in addition to those under 65 years with a diagnose of dementia. The present study is the first reporting the prevalence of dementia at admission.

The aim of the REDIC-NH study is to follow longterm $\mathrm{NH}$ patients from admission to the $\mathrm{NH}$ and until death. The study is designed to collect broad information to describe the course of dementia and other psychiatric and somatic diseases in $\mathrm{NH}$ patients from admission until death. These data will be used in several studies. More specifically:

- To describe the course of dementia in $\mathrm{NH}$ patients from admission until death.

- To identify predictors of progression of dementia in $\mathrm{NH}$ patients, with a particular focus on predictors of the course of neuropsychiatric symptoms.

- To investigate predictors of mortality in NH patients.

- To explore the impact of genetic polymorphism on the occurrence and course of neuropsychiatric symptoms in dementia.

- To study health resource use at admission and over the follow-up period.

In this paper, we describe the methods and the data collection in the REDIC-NH study. We will also present demographic data and data on dementia and NPS from the patients at admission to NHs.

\section{Methods \\ Study design and setting}

The REDIC-NH study was an observational longitudinal study including patients from a convenience sample of $47 \mathrm{NHs}$ in four Norwegian counties, representing small and large NHs, located in urban and rural areas. Inclusion was at admission to the $\mathrm{NH}$, and participants were followed until death. Due to substantial workloads, four NHs withdrew from the study during the study period.

The baseline data were collected within one month of admission to the $\mathrm{NH}$. Baseline data were collected between March 2012 and November 2014. Follow-up data were collected every six months until the death of the patient, and were on-going.

\section{Participants}

Participants were recruited at admission to the $\mathrm{NH}$ $(n=696)$. Patients eligible for inclusion in the study were 65 years or older, or younger than 65 years with established dementia, with an expected stay in the $\mathrm{NH}$ of more than four weeks. The only exclusion criterion was a life expectancy of less than six weeks.

\section{Data collection}

The data collection was performed by healthcare workers in the NHs, mainly registered nurses (74\%), under supervision of 10 research nurses. The research nurses completed a five-day training program, and the data collectors completed a two-day training program. Data were collected through structured interviews with the patient, their next of kin, and the caregivers in the NHs. Demographic data were collected through a review 
of patient documentation (see Table 1). DNA samples were obtained by collected saliva samples from the patients. The diagnosis of dementia was based on a review of data collected from the patients, their family members, and their caregivers after three physicians with ample clinical experience made a dementia diagnosis according to established criteria [19-22].

The data collected at baseline and follow-up are summarised in Table 1. Due to collaboration with other research groups and input from research assistants in the field, changes in the baseline dataset were implemented during the inclusion period. Some assessment tools were removed because they were too demanding for the patients to complete and/or for the $\mathrm{NH}$ staff to implement. Other assessment tools were added to the baseline data collection due to input from other researchers.

\section{Measures \\ Cognitive function and severity of dementia}

The Mini Mental Status Examination (MMSE), ranging from 0-30, and the eight-question version of Severe Impairment Battery (SIB-8), ranging from 0-16, were used to assess cognitive functioning. A higher score indicates better cognitive function on both scales [23, 24]. Changes in ADL and cognitive functioning over the last 10 years were assessed with the Informant Questionnaire of Cognitive Decline in the Elderly (IQCODE), a proxybased scale with 16 items scored 1-5 [25, 26]. A mean score of 3.44 and above indicates dementia [27]. Detailed clinical information on debut, course, and symptoms of the dementia were collected based on a structured questionnaire.

Dementia severity was assessed with the Clinical Dementia Rating Scale (CDR), a global rating scale covering six domains of cognitive and functional performance [28]. The CDR can be scored according to an algorithm, giving a total score of 0 (no cognitive impairment), 0.5 (mild cognitive impairment), 1 (mild dementia), 2 (moderate dementia), 3 (severe dementia); however, CDR can also be scored by the CDR sum of boxes (CDR-SOB), ranging from 0 to 18 , where a higher score indicates more severe dementia [29]. The two scoring systems intercorrelate highly with kappa scores ranging between 0.86 and 0.94 and a $93 \%$ overall correct classification rate [29].

The Functional Assessment Staging of Alzheimer Disease (FAST) scale, ranging from 0-7 with a higher score defining lower function, was used to give a more detailed assessment at the severe stage of dementia [30].

Based on all available information, no cognitive impairment, mild cognitive impairment (MCI) and dementia, as well as dementia subtypes were independently diagnosed by two of the authors (G.S. and S.B.), one psychiatrist and one intern specialising in psychiatry, both of whom were experienced old age psychiatrists and researchers, with the possibility of consulting a third specialist, also a psychiatrist (K.E.) to reach a consensus. Dementia was diagnosed according to the international classification of diseases, version 10, research criteria (ICD-10) [22], and MCI was diagnosed according to Winblad's criteria [21]. Alzheimer's disease, vascular dementia, and mixed $\mathrm{AD} / \mathrm{VaD}$ were diagnosed according to the ICD-10 criteria [22]; Lewy body dementia was diagnosed according to the DLB consortium criteria [19]; and Frontotemporal dementia was diagnosed according to the Manchester-Lund criteria [20].

\section{Physical health status}

Blood pressure, pulse, weight, and height were measured following a standardised procedure. General physical health was assessed using the General Medical Health Rating (GMHR) scale, a one-item, global rating scale with four categories (excellent, good, fair, poor) [31].

Pain was assessed by the Mobilization-ObservationBehaviour-Intensity-Dementia Pain Scale (MOBID-2), consisting of 10 items, each item ranging from 0 to 10 , where a higher score indicates more severe pain. Additionally, the overall pain was assessed on a 10-point visual analogue scale (VAS) [32].

Extrapyramidal symptoms were assessed through observations with the six-item version of the Unified Parkinson's Disease Rating Scale (UPDRS-6), ranging from 0-24, where a higher score indicates more severe symptoms [33].

Physical symptoms were assessed with the Edmonton symptom assessment system (ESAS), ranging from 0-10, where a higher score indicates more severe symptoms [34]. Overall functioning was assessed with the Karnofsky performance status scale (KPS), an 11-step rating scale from normal functioning (100) to dead (0) [35]. Two subscales from the Residents Assessment Instrument (RAI-NH) were used to evaluate the patients' skin and nutrition condition [36].

For assessment of comorbidity, the Charlson's comorbidity index, with 18 different groups of diseases, was used [37].

\section{Neuropsychiatric and depressive symptoms}

Neuropsychiatric symptoms (NPS) were assessed using the Neuropsychiatric Inventory 12-item nursing home version (NPI-NH) [38, 39]. Severity (score 1 -3) was multiplied by frequency (score $1-4$ ), giving an item score ranging from $0-12$, where a higher score indicates more severe symptoms. A clinically significant NPS (CS-NPS) was defined as an NPI item score of four and above [40].

NPI sub-syndrome scores were calculated based on a previous principal component analysis: NPI agitation (agitation/aggression, disinhibition, and irritability), NPI psychosis (delusions and hallucinations), and NPI 


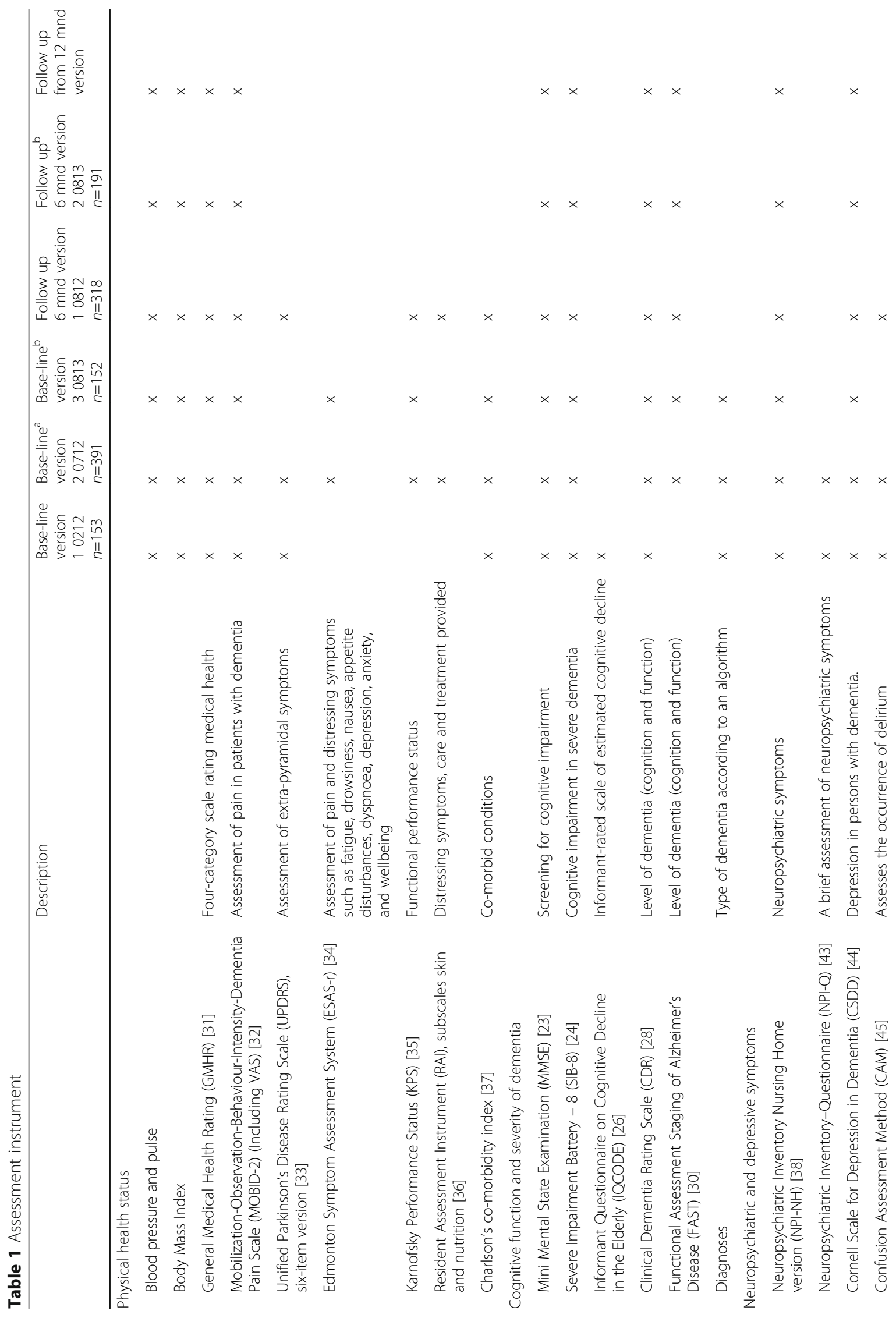




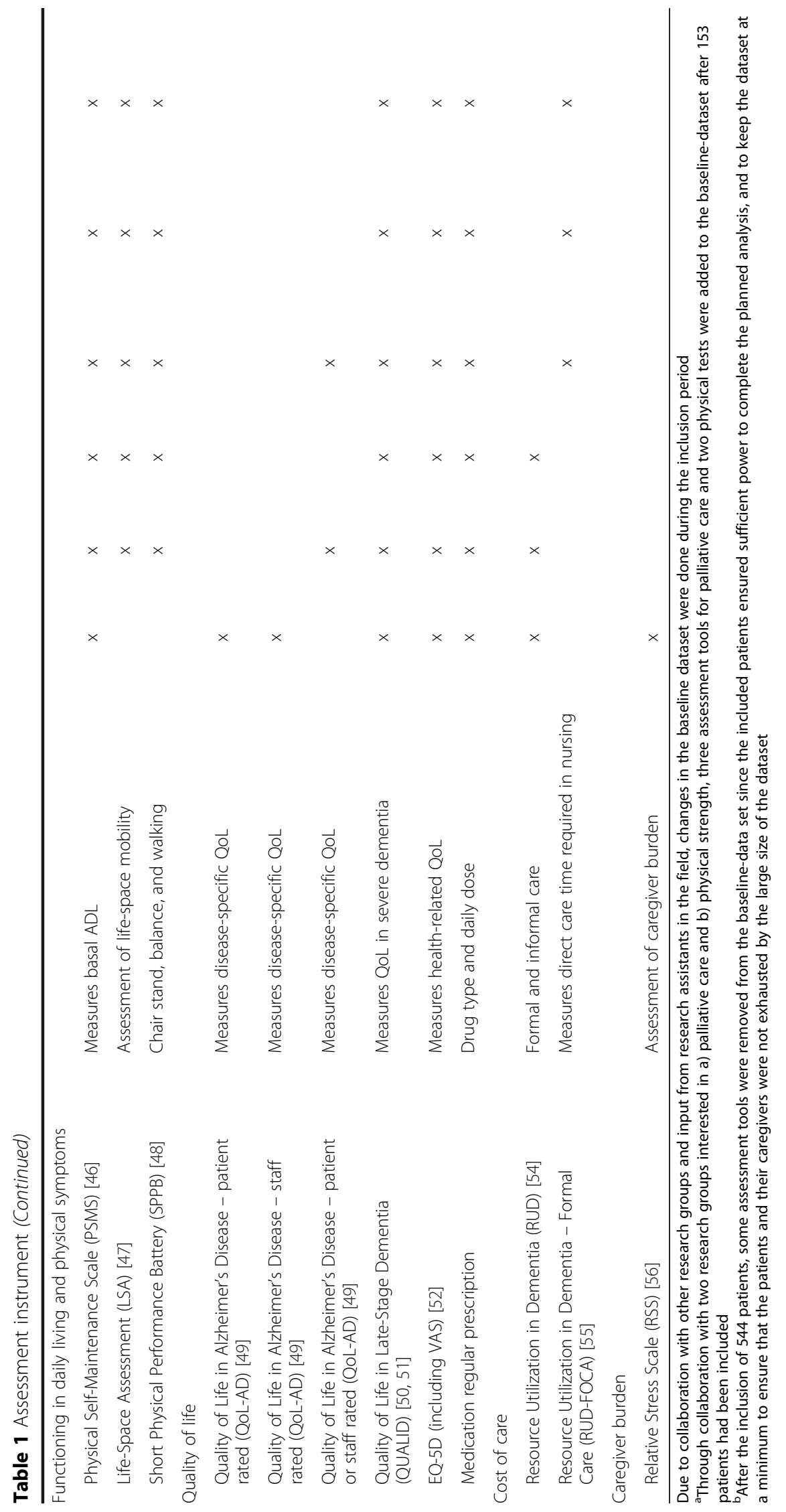


affective (depression and anxiety) [41, 42]. The brief Neuropsychiatric Inventory-Questionnaire (NPI-Q) was completed at baseline by the patient's next of kin in order to assess NPS symptoms from the debut of dementia and prior to nursing home admission [43].

Depressive symptoms were assessed with the Cornell scale for depression in dementia (CSDD), a 19-item scale (0-2 points) ranging from 0-38, where a higher score indicates more severe symptoms [44]. To detect delirium, the Confusion Assessment Method (CAM), a four-step algorithm assessing delirium symptoms, was performed [45].

\section{Functioning in daily living and physical symptoms}

Functional status was assessed with the Physical SelfMaintenance Scale (PSMS), a six-item scale (scored 1-5) ranging from 6-30, where a higher score indicates lower level of functioning [46]. The Life-Space Assessment (LSA) was performed to assess the range, independence, and frequency of the patient's movement over the last two weeks [47]. Balance and gait speed were assessed with the Short Physical Performance Battery (SPPB), ranging from 0-12, where a higher score indicates better physical performance [48].

\section{Quality of life}

Quality of life (QoL) was assessed with the Quality of Life in Alzheimer's Disease (QoL-AD) scale; 13 items rated from 1 to 4 (range 13-52), with a higher score indicating a better QoL [49]. The QoL-AD was completed by both the patient and the caregiver, when possible.

The Quality of Life in Late-Stage Dementia scale (QUALID) is a proxy-based assessment scale consisting of 11 items with scores from 1 to 5 , ranging from 11-55, with lower scores indicating a better QoL [50, 51].

The EQ-5D is a brief five-dimension self-reported instrument for generic health status (mobility, self-care, usual activities, pain/discomfort, and anxiety/depression), scored 0-2, with a sum score ranging from 0-10 and a lower score indicating better functioning. The EQ-5D includes a visual analogue scale ranging from 0 (worst imaginable health state) to 100 (best imaginable health state) [52].

\section{Medication}

Regular medication use from admission to the nursing home and onward was recorded from the patients' medical records using the Anatomic Therapeutic Chemical (ATC) classification system and defined daily doses (DDD) [53]. Psychotropic medications were grouped as: antipsychotics (N05A except lithium), antidepressants (N06A), anxiolytics (N05B), hypnotic/sedatives (N05C), and anti-dementia medication (N06D).

\section{Cost of care}

The use of formal and informal care the last month before admission to the $\mathrm{NH}$ was assessed with the Resource Utilization in Dementia Questionnaire (RUD) [54]. To assess formal care after admission to the NHs, the Resource Utilization in Dementia - Formal Care (RUD-FOCA) was used at the follow-up assessments [55].

\section{Caregiver burden}

To assess caregiver burden during the last month before the patients' admission to the $\mathrm{NH}$, the Relative Stress Scale (RSS), a 15-item scale scored from 0 to 4 , where a higher score denotes a higher burden, was used [56, 57].

\section{Linkage to registry and databases}

Data can be linked to the Norwegian Prescription Database (NorPD), containing data about dispensed drugs in Norway; the Norwegian Patient Register (NPR), which contains information on all patients referred to or having received treatment in the specialist health services; the IPLOS register, a Norwegian statutory health register for municipal health services; The Cancer Registry of Norway, containing information about all cancer cases in Norway; and the Cause of Death Registry.

\section{Ethical and legal considerations}

The patients' capacity to consent to participation in the study was considered by the $\mathrm{NH}$ staff, including the physician. Written consent for participation was obtained from all participants with the capacity to consent. For participants lacking the capacity to consent, their next of kin gave consent on behalf of the patients. The next of kin gave written consent for their own participation in the study, as they provided information about themselves. The Regional Ethics Committee for Medical Research in South-Eastern Norway approved the study (2011/1738a).

\section{Results}

Of the 696 included patients, 2.4\% had no cognitive impairment, $13.8 \%$ had mild cognitive impairment, and $83.8 \%$ had dementia. Twelve persons were under the age of 65,10 of whom (83.3\%) had dementia. Saliva samples for DNA testing were taken from 611 patients (87.7\%). Table 2 presents demographic characteristics and level of functioning at baseline for the total cohort and for participants with and without dementia. The patients with dementia were younger $(p=0.002)$, more often married or had partners (vs. unmarried, divorced, or widowed) $(p=0.015)$, had better physical health $(p=0.013)$, and few had very impaired vision (vs. mildly impaired or normal vision) compared to patients without dementia $(p=0.036)$. Sedatives were more often prescribed to the patients without dementia than to patients with dementia $(p=0.004)$, 
Table 2 Demographic and clinical data of the patients at admission to nursing homes $(\mathrm{NH})$

\begin{tabular}{|c|c|c|c|c|}
\hline & All patients & Patients with dementia & Patients without dementia & $p$-value* \\
\hline & $n=696$ & $n=583$ & $n=113$ & \\
\hline Age mean (SD) & $84.5(7.5)$ & $84.1(7.5)$ & $86.5(7.0)$ & $0.002^{\mathrm{a})}$ \\
\hline Female gender & $445(63.9)$ & $375(64.3)$ & $70(61.9)$ & $0.630^{b)}$ \\
\hline \multirow[t]{2}{*}{ Unmarried/divorced/widowed vs. married/partner n/N } & $478 / 687(69.6)$ & $390 / 576(67.6)$ & 88/111 (79.3) & $0.015^{\mathrm{b})}$ \\
\hline & $n=516$ & $n=428$ & $n=88$ & \\
\hline Education in years - mean (SD) & $8.34(2.8)$ & $8.30(2.9)$ & $8.50(2.4)$ & $0.549^{\mathrm{a})}$ \\
\hline Residence before admission & $n=520$ & $n=428$ & $n=92$ & \\
\hline Private home & $230(44.2)$ & $194(45.3)$ & $36(39.1)$ & $0.278^{b)}$ \\
\hline Sheltered flat & $71(13.7)$ & $59(13.8)$ & $12(13.0)$ & $0.851^{\mathrm{b})}$ \\
\hline Care Home $(\mathrm{CH})$ & $5(1.0)$ & $5(1.2)$ & - & $0.592^{c)}$ \\
\hline $\mathrm{CH}$ with Nursing & $134(25.8)$ & $110(25.7)$ & $24(26.1)$ & $0.939^{b)}$ \\
\hline Hospital & $78(15.0)$ & $58(13.6)$ & $20(21.7)$ & $0.046^{\mathrm{b})}$ \\
\hline Other & $2(0.4)$ & $2(0.5)$ & - & $1.000^{c)}$ \\
\hline Type of unit & $n=696$ & $n=583$ & $n=113$ & \\
\hline Regular unit (RU) & $385(55.3)$ & $303(52.0)$ & $82(72.6)$ & $<0.001^{\text {b) }}$ \\
\hline Respite and rehabilitation unit (RRU) & $85(12.2)$ & $64(11.0)$ & $21(18.6)$ & $0.024^{b)}$ \\
\hline Special care unit (SCU) & $226(32.5)$ & $216(37.0)$ & $10(8.8)$ & $<0.001^{\text {b) }}$ \\
\hline GMHR & $n=666$ & $n=557$ & $n=109$ & \\
\hline GMHR dichotomized; poor/fair & $349(52.4)$ & $280(50.3)$ & $69(63.3)$ & $0.013^{b)}$ \\
\hline \multicolumn{5}{|l|}{ MOBID-2 } \\
\hline Total score & $n=667$ & $n=557$ & $n=110$ & \\
\hline mean (SD) & $2.1(2.2)$ & $1.96(2.1)$ & $2.84(2.4)$ & $<0.001^{\text {a) }}$ \\
\hline Overall pain at a 10-point scale & $n=597$ & $n=490$ & $n=107$ & \\
\hline mean $(S D)$ & $2.4(2.5)$ & $2.17(2.4)$ & $3.42(2.8)$ & $<0.001^{\text {a) }}$ \\
\hline UPDRS-6 & $n=528$ & $n=446$ & $n=82$ & \\
\hline mean $(S D)$ & $3.6(3.7)$ & $3.6(3.7)$ & $3.6(3.4)$ & $0.870^{\mathrm{a})}$ \\
\hline Vision & $n=681$ & $n=569$ & $n=112$ & \\
\hline Normal & $161(23.6)$ & $138(24.3)$ & $23(20.5)$ & $0.036^{b)}$ \\
\hline Mildly impaired & $431(63.3)$ & $365(64.1)$ & $66(58.9)$ & \\
\hline Very impaired & $89(13.1)$ & $66(11.6)$ & $23(20.5)$ & \\
\hline Hearing & $n=682$ & $n=571$ & $n=111$ & \\
\hline Normal & $299(43.8)$ & $259(45.4)$ & $40(36.0)$ & $0.193^{b)}$ \\
\hline Mildly impaired & $290(42.5)$ & $236(41.3)$ & $54(48.6)$ & \\
\hline Very impaired & $93(13.6)$ & $76(13.3)$ & $17(15.3)$ & \\
\hline Use of psychotropic medication** & $n=696$ & $n=583$ & $n=113$ & \\
\hline Antipsychotics & $84(12.1)$ & $72(12.4)$ & $12(10.6)$ & $0.605^{\mathrm{b})}$ \\
\hline Antidepressants & $199(28.6)$ & $167(28.6)$ & $32(28.3)$ & $0.944^{b)}$ \\
\hline Anxiolytics & $108(15.5)$ & $89(15.3)$ & $19(16.8)$ & $0.677^{\mathrm{b})}$ \\
\hline Sedatives & $167(23.9)$ & $128(21.9)$ & $39(34.5)$ & $0.004^{b)}$ \\
\hline Anti-dementia drugs & $169(24.3)$ & $163(28.0)$ & $6(5.3)$ & $<0.001^{\text {b) }}$ \\
\hline CSDD & $n=657$ & $n=548$ & $n=109$ & \\
\hline mean $(S D)$ & $6.4(5.2)$ & $6.6(5.3)$ & $5.7(4.7)$ & $0.094^{\mathrm{a})}$ \\
\hline PSMS & $n=694$ & $n=582$ & $n=112$ & \\
\hline mean (SD) & $15.3(4.5)$ & $15.3(4.5)$ & $15.4(4.7)$ & $0.797^{\mathrm{a})}$ \\
\hline
\end{tabular}


Table 2 Demographic and clinical data of the patients at admission to nursing homes (NH) (Continued)

\begin{tabular}{|c|c|c|c|c|}
\hline \multicolumn{5}{|l|}{$\overline{Q o L-A D * * *}$} \\
\hline Patient rated & $n=276$ & $n=227$ & $n=49$ & \\
\hline mean (SD) & $33.1(5.5)$ & $32.7(5.4)$ & $34.7(5.6)$ & $0.025^{\mathrm{a})}$ \\
\hline Staff rated & $n=346$ & $n=300$ & $n=46$ & \\
\hline mean (SD) & $31.8(5.8)$ & $31.7(5.7)$ & $32.6(6.8)$ & $0.327^{\mathrm{a})}$ \\
\hline QUALID & $n=691$ & $n=579$ & $n=112$ & \\
\hline mean (SD) & $20.0(7.2)$ & $20.0(7.2)$ & $19.4(7.1)$ & $0.402^{a)}$ \\
\hline \multicolumn{5}{|l|}{ EQ-5D } \\
\hline Patient rated & $n=219$ & $n=172$ & $n=47$ & \\
\hline mean $(S D)$ & $3.3(2.2)$ & $2.9(2.1)$ & $4.7(2.3)$ & $<0.001^{\text {a) }}$ \\
\hline Staff rated & $n=455$ & $n=392$ & $n=63$ & \\
\hline mean (SD) & $5.3(1.7)$ & $5.3(1.7)$ & $5.5(1.9)$ & $0.393^{\mathrm{a})}$ \\
\hline Overall QoL VAS-scale & $n=520$ & $n=421$ & $n=99$ & \\
\hline mean (SD) & $60.4(23.5)$ & $62.1(23.1)$ & $53.1(23.7)$ & $0.001^{\mathrm{a})}$ \\
\hline Patient rated & $n=197$ & $n=153$ & $n=44$ & \\
\hline mean (SD) & $61.6(23.5)$ & $63.7(23.2)$ & $54.2(23.4)$ & $0.018^{\mathrm{a})}$ \\
\hline Staff rated & $n=314$ & $n=260$ & $n=54$ & \\
\hline mean (SD) & $59.2(23.2)$ & $60.6(22.9)$ & $52.7(24.0)$ & $0.023^{\mathrm{a})}$ \\
\hline
\end{tabular}

All figures in (\%) if not otherwise stated

$S D$ standard deviation

GMHR General Medical Health Rating Scale

MOBID-2 Mobilization-Observation-Behaviour-Intensity-Dementia Pain Scale

UPDRS-6 Unified Parkinson's Disease Rating Scale, six-item version

CSDD Cornell scale for depression in dementia

PSMS Physical Self-Maintenance Scale

QoL-AD Quality of Life Alzheimer Disease

QUALID Quality of Life in Late Stage Dementia

$E Q-5 D$ a standardised instrument for use as a measure of health outcome

QoL Quality of Life

VAS Visual Analogue Scale

${ }^{*} p$-value for difference in patients with and without dementia

**Psychotropic medications were grouped as: antipsychotics (N05A except lithium), antidepressants (N06A), anxiolytics (N05B), hypnotic/sedatives (N05C), and anti-dementia medication (N06D)

***In this sample, 132 patients had their QoL-AD score assessed by both themselves and staff:

Patient scored: mean 31.5 (4.9)

Staff scored: mean 34.0 (5.6)

$p$-value $0.000^{\mathrm{a})}$

a) Independent Student's t-test

b) Pearson Chi-square Test

c) Fisher's Exact Test

d) Mann-Whitney U Test

and anti-dementia medications were more often prescribed to patients with dementia $(p<0.001)$. Patients without dementia had more pain than patients with dementia $(p<0.001)$. Patients without dementia scored higher on self-rated scores quality of life assessments, both on the QoL-AD $(p=0.025)$ and the EQ-5D $(p<0.001)$, while patients with dementia scored higher on all the overall QoL VAS scales, both patient-rated $(p=0.018)$ and staff-rated $(p=0.023)$.

At the 18-month follow-up, 371 of 696 patients were still in the study. However, 22 were not assessed at the 18-month follow-up, and 324 left the study: 261 due to death and 63 due to other reasons. A summary of the number of participants at each assessment is given in
Table 3. Differences in age, sex, cognition, and physical health between remaining patients and those lost to follow-up are described in Table 4.

To compare the age and sex of included vs. excluded patients, 38 out of the $47 \mathrm{NHs}$ collected data on the gender and age of all residents eligible for inclusion. Of 1331 eligible patients in these $38 \mathrm{NHs}, 607$ were included and 724 were excluded (205 declined inclusion, 191 died before inclusion took place, and 328 for reasons not known). The mean age of participants was 84.5 years (SD 7.5), while for non-participants it was 83.6 years (SD 9.3) (independent student $t$-test, $p=0.048) ; 64.4 \%$ of participants were women, while $56.6 \%$ of non-participants were women (Chisquare test, $p=0.004$ ). 
Table 5 presents dementia diagnoses and scores on cognitive tests at baseline. The MMSE mean score was higher for patients without dementia than for patients with dementia. Alzheimer's disease was the most prevalent dementia diagnosis. Only $55.9 \%$ of the patients with dementia had a diagnosis of dementia registered in their nursing home records.

Table 6 presents the prevalence of NPS at baseline. Of the patients with dementia, $62.9 \%$ had at least one clinically significant NPS, vs. $48.6 \%$ of the patients without dementia $(p=0.005)$. Anxiety and depression were the most prevalent NPS. Patients with dementia had a higher NPI-12 sum-score, compared to patients without dementia (sum score 10.0 vs. 4.0, $t$-test $p<0.001$ ). Anxiety, depression, and irritability were the most prevalent NPS among the patients with dementia. Patients with dementia more often experienced delusions, hallucinations, agitation, anxiety, disinhibition, irritability, and aberrant motor behaviour compared to patients without dementia.

The most common comorbidity diseases, according to the Charlson's comorbidity index, in both patients with and without dementia were cardiovascular diseases (coronary diseases, congestive heart failure, and cerebrovascular disease), diabetes, and cancer (see Table 7). Patients without dementia more often had cardiovascular diseases (coronary diseases $(p=0.009)$, congestive heart failure $(p=0.009)$, pulmonary disease $(p=0.018)$, connective tissue disease $(p=0.013)$, diabetes with complications $(p=0.001)$, hemiplegia/paraplegia $(p=0.003)$, and renal disease $(p=0.002)$, while patients with dementia more often had dementia $(p<0.001)$, according to the Charlson's comorbidity index. Nevertheless, only $80.6 \%$ of patients diagnosed with dementia in the study had dementia according to the Charlson's comorbidity index, while $20.6 \%$ of the patients not diagnosed with dementia in the study had a diagnosis of dementia according to the Charlson's comorbidity index.

Table 3 Number of participants at each assessment in the REDIC-NH cohort

\begin{tabular}{lllll}
\hline & Baseline & 6. month & 12 month & 18. month \\
\hline Number included & 696 & 543 & 446 & 372 \\
Number assessed & 696 & 508 & 427 & 349 \\
Number that left the study & & 153 & 250 & 324 \\
- Due to death & 115 & 191 & 261 \\
- Due to other reasons & 38 & 59 & 63 \\
- NH withdrawn & 2 & 2 & 3 \\
- Patient withdrawn & 4 & 8 & 9 \\
- Moved to another & 15 & 21 & 23 \\
$\quad$ unit or NH & 17 & 28 & 28 \\
- Moved home & & & & \\
\hline
\end{tabular}

\section{Discussion}

The present study is the first Norwegian study and one of few international studies following long-term $\mathrm{NH}$ patients from admission to the $\mathrm{NH}$ and until death or up to 36 months, assessed regularly with standardised assessment tools.

The main finding of this study is the high prevalence of dementia (83.8\%) at admission to the $\mathrm{NH}$, comparable to figures in cross-sectional studies of Norwegian NHs showing a prevalence of $81.5 \%$ [3] and $78.5 \%$ [6], but different from a descriptive study from Belgium [7] in which $48 \%$ had dementia at admission. The patients with dementia at admission were younger, had better physical health, less pain, and better vision than patients without dementia, indicating that they were not admitted to the NH for physical health problems, but for their dementia. Furthermore, $62.9 \%$ of the patients with dementia had at least one clinically significant NPS, where anxiety and depression were most prevalent. A review by Selbæk et al. reported a $82 \%$ prevalence of at least one clinically significant NPS in patients with dementia living in nursing homes, and although the prevalence of individual symptoms varied, the highest prevalence figures were found for agitation and apathy [4]. Two longitudinal NH studies reported that NPS in patients with dementia are common and that individual NPS have a fluctuating course. A Norwegian study reported irritability, agitation, and disinhibition to be most prevalent in patients with dementia [5], and a study from the Netherlands reported apathy, depression, and aberrant motor behaviour to be the most frequent NPS [58].

Of the $83.8 \%$ participants with dementia, according to the two experienced psychiatrists, only $55.9 \%$ had a dementia diagnosis documented in their records, and $80.6 \%$ had dementia according to the Charlson's comorbidity index. Of the patients without a dementia diagnosis, according to the two experienced psychiatrists, 7.1\% had a dementia diagnosis documented in their records, and $20.6 \%$ had dementia according to the Charlson's comorbidity index. All cognitive measures showed significantly lower scores for persons with dementia compared to those without dementia. However, persons without dementia also scored quite low on the cognitive scales, especially on the MMSE (mean 22.6), and a large proportion had a FAST score $\geq 4(41.8 \%)$, see Table 5 . The discrepancy between the prevalence of dementia and a dementia diagnosis in the patient records in this study are in line with several other studies, both previous Norwegian [3] and international studies [59-62], and could be explained by the lack of clinical examination of the patients in the study as well as nursing home doctors underdiagnosing dementia. In addition, the discrepancy between dementia diagnoses set by the researcher and documentation in $\mathrm{NH}$ records can be due to various definitions and diagnostic criteria for 
Table 4 Difference in baseline assessments between patients participating at 18-month assessment vs. lost to follow-up

\begin{tabular}{|c|c|c|c|c|c|}
\hline & \multirow[t]{2}{*}{ Still participating after 18-months } & \multicolumn{4}{|c|}{ Lost to follow-up before 18-months } \\
\hline & & Due to death & $p$-value* & Due to other reasons & $p$-value $* *$ \\
\hline Age $n$ - year (SD) & $372-83.7(7.9)$ & $261-86.2(6.4)$ & $<0.001^{\text {a) }}$ & $63-82.2(8.0)$ & $0.173^{\mathrm{a})}$ \\
\hline Women n/N - \% & $252 / 372-67.7 \%$ & $151 / 261-57.9 \%$ & $0.011^{b)}$ & $43 / 63-68.3 \%$ & $0.936^{\mathrm{b})}$ \\
\hline CDR-SOB n - mean score (SD) & $369-10.2(4.1)$ & $257-10.7(4.6)$ & $0.108^{a)}$ & $61-8.9(4.0)$ & $0.026^{\mathrm{a})}$ \\
\hline GMHR n/N - \% dichotomized; poor/fair & $154 / 357-43.1 \%$ & $160 / 250-64.0 \%$ & $<0.001^{\text {b) }}$ & $35 / 59-59.3 \%$ & $0.021^{b)}$ \\
\hline
\end{tabular}

SD Standard deviation

CDR-SOB Clinical Dementia Rating Scale sum of boxes

GMHR General Medical Health Rating Scale

${ }^{*} p$-value for difference between patients participating at 18-month follow up vs. lost to follow-up due to death

${ }^{* *} p$-value for difference between patients participating at 18-month follow-up vs. lost to follow-up due to all other reasons

a) Independent Student's t-test

b) Pearson Chi-square Test

dementia. Physicians in the municipality and in the NHs mainly use the International Classification of Primary Care second version (ICPC-2) [63], whereas researchers use other criteria, such as the international classification of diseases, version 10 (ICD-10 criteria), Winblad's criteria, the DLB consortium criteria, and the Manchester-Lund criteria [19-22]. Physicians are not constantly present in nursing homes, and resources for dementia diagnostics in primary care are scarce; hence, diagnostics are often superficial and performed rapidly [64]. Another explanation for the discrepancy can be that the diagnosis of dementia is not given priority in nursing homes, as it is often claimed that there is no curative treatment for dementia and the diagnosis does not benefit the patient. However, a lot of other interventions for preventing functional decline and improving the quality of life for

Table 5 Cognition and prevalence of dementia at admission to nursing homes (NH)

\begin{tabular}{|c|c|c|c|c|c|}
\hline & & $\begin{array}{l}\text { All patients } \\
n=696\end{array}$ & $\begin{array}{l}\text { Patients with } \\
\text { dementia } \\
n=583\end{array}$ & $\begin{array}{l}\text { Patients without } \\
\text { dementia } \\
n=113\end{array}$ & $p$-value* \\
\hline \multirow[t]{3}{*}{ Prevalence of Dementia $^{1}$} & No dementia & $17(2.4)$ & & & \\
\hline & Mild Cognitive Impairment & $96(13.8)$ & & & \\
\hline & Dementia & $583(83.8)$ & & & \\
\hline \multirow[t]{6}{*}{ Dementia sub-types ${ }^{1}$} & Alzheimer disease (AD) & & $414(71.0)$ & & \\
\hline & Vascular Dementia (VaD) & & $46(7.9)$ & & \\
\hline & Mixed ADNaD & & $11(1.9)$ & & \\
\hline & Frontotemporal Dementia & & $47(8.1)$ & & \\
\hline & Lewy Body Dementia & & $22(3.7)$ & & \\
\hline & Other & & $43(7.4)$ & & \\
\hline Dementia diagnosis according to $\mathrm{NH}$-records & & & $326(55.9)$ & $8(7.1)$ & $<0.001^{\text {b) }}$ \\
\hline \multirow[t]{5}{*}{ Cognition } & MMSE sum (n) mean (SD) & (611) $16.0(6.3)$ & (511) $14.7(5.5)$ & (100) $22.6(5.6)$ & $<0.001^{\mathrm{a})}$ \\
\hline & CDR-SOB (n) mean (SD) & (687) $10.3(4.3)$ & (576) $11.2(3.6)$ & (111) $5.3(4.2)$ & $<0.001^{\mathrm{a})}$ \\
\hline & SIB-8 sum (n) mean (SD) & (601) $12.2(3.7)$ & (502) $11.8(3.8)$ & (99) $14.6(2.7)$ & $<0.001^{\text {a) }}$ \\
\hline & IQCODE score $>3.44$ & $121(17.4)$ & 115 (95) & $6(5)$ & $<0.001^{\text {b) }}$ \\
\hline & FAST value $\geq 4 \mathrm{n} / \mathrm{N}$ & $472 / 540(87.4)$ & $449 / 434(96.7)$ & $91 / 38(41.8)$ & $<0.001^{b)}$ \\
\hline
\end{tabular}

All figures in (\%) if not otherwise stated

MMSE Mini-Mental-State-Examination

$S D$ standard deviation

$C D R-S O B$ Clinical Dementia Rating Scale sum of boxes

SIB-8 Severe Impairment Battery, the eight-question version

IQCODE Informant Questionnaire of Cognitive Decline in the Elderly

FAST Functional Assessment Staging of Alzheimer Disease

${ }^{*} p$-value for difference between patients with and without dementia

${ }^{1}$ Assessed by two experienced researchers/clinicians independently based on all given information

a) Independent Student's t-test

b) Pearson Chi-square Test

c) Fisher's Exact Test 
Table 6 Clinically significant neuropsychiatric symptoms at admission to nursing homes $(\mathrm{NH})$

\begin{tabular}{|c|c|c|c|c|}
\hline Prevalence of CS-NPS & $\begin{array}{l}\text { All patients } \\
\text { Total } N=696\end{array}$ & $\begin{array}{l}\text { Patients with } \\
\text { dementia } \\
\text { Total N=583 }\end{array}$ & $\begin{array}{l}\text { Patients without } \\
\text { dementia } \\
\text { Total } N=113\end{array}$ & $p$-value \\
\hline & $\mathrm{n} / \mathrm{N}$ & $\mathrm{n} / \mathrm{N}$ & $n / N$ & \\
\hline Delusions & $97 / 686(14.1)$ & 90/575 (15.7) & 7/111 (6.3) & $0.010^{\mathrm{a})}$ \\
\hline Hallucinations & $34 / 688(4.9)$ & $33 / 576(5.7)$ & $1 / 112(0.9)$ & $0.031^{\mathrm{a})}$ \\
\hline Agitation & $99 / 689(14.4)$ & $93 / 577(16.1)$ & $6 / 112(5.4)$ & $0.003^{\mathrm{a})}$ \\
\hline Depression & $148 / 688(21.5)$ & $125 / 576(21.7)$ & 23/112 (20.5) & $0.784^{a)}$ \\
\hline Anxiety & $141 / 690(20.4)$ & $126 / 578(21.8)$ & $15 / 112(13.4)$ & $0.043^{\mathrm{a})}$ \\
\hline Euphoria & 23/687 (3.3) & $21 / 567(3.6)$ & 2/111 (1.8) & $0.562^{b)}$ \\
\hline Apathy & 109/687 (15.9) & 95/575 (16.5) & $14 / 112(12.5)$ & $0.287^{\mathrm{a})}$ \\
\hline Disinhibition & $101 / 687(14.7)$ & 92/575 (16.0) & $9 / 112(8.0)$ & $0.029^{a)}$ \\
\hline Irritability & 122/684 (17.8) & $110 / 572(19.2)$ & $12 / 112(10.7)$ & $0.031^{\mathrm{a})}$ \\
\hline Aberrant Motor Behaviour & 73/687 (10.6) & 69/575 (12.0) & 4/112 (3.6) & $0.008^{\mathrm{a})}$ \\
\hline Night-time Behaviour & $112 / 689(16.3)$ & 98/577 (17.0) & $14 / 112(12.5)$ & $0.239^{\mathrm{a})}$ \\
\hline Eating Change & $71 / 688(10.3)$ & $58 / 576(10.1)$ & 13/112 (11.6) & $0.625^{a)}$ \\
\hline Any symptom & $413 / 682(60.6)$ & $359 / 571(62.9)$ & $54 / 111(48.6)$ & $0.005^{\mathrm{a})}$ \\
\hline NPI 12 sum median (range) & $n=6938.0(0-123)$ & $n=58110.0(0-123)$ & $n=1124.0(0-66)$ & $<0.001^{\mathrm{c})}$ \\
\hline NPI-AGITATION median (range) & $n=6781.0(0-36)$ & $n=5661.0(0-36)$ & $n=1120.0(0-36)$ & $<0.001^{c)}$ \\
\hline NPI-PSYCHOSIS median (range) & $n=6830.0(0-24)$ & $n=5720.0(0-24)$ & $n=1110.0(0-12)$ & $<0.001^{\mathrm{c})}$ \\
\hline NPI-AFFECTIVE median (range) & $n=6871.0(0-24)$ & $n=5751.0(0-24)$ & $n=1120.5(0-24)$ & $0.125^{c)}$ \\
\hline
\end{tabular}

All figures in (\%) if not otherwise stated

CS-NPS - clinically significant NPS, defined as an NPI sub-symptom of 4 and above

NPI 12 sum - Neuropsychiatric Inventory sum of 12 items

NPI-AGITATION sum of agitation/aggression, disinhibition, and irritability

NPI-PSYCHOSIS sum of delusion and hallucination

NPI-AFFECTIVE sum of depression and anxiety

a) Pearson Chi-square test

b) Fisher's Exact Test

c) Mann-Whitney $U$ test

persons with dementia can be performed $[65,66]$ if patients are diagnosed adequately.

QoL was assessed with three different assessment scales: QoL-AD, QUALID, and EQ-5D, and the results differed considerably between the different scales. Assessed with the QoL-AD, rated by the patients themselves, patients without dementia had better QoL than patients with dementia. When patients rated themselves with EQ-5D (including VAS), the patients with dementia reported better QoL than patients without dementia. Regarding QUALID scored by proxy, there was no difference between persons with or without dementia. The disagreement between these scales may be due to the difference between the scales. QoL-AD measures the domains of physical condition, mood, memory, functional abilities, interpersonal relationships, ability to participate in meaningful activities, financial situation, global assessments of self as a whole, and QoL as a whole, and is filled out by the patients, caregivers, or both, while QUALID is a proxy-report instrument that measures 11 observable behaviours about activity and emotional states over the last seven days. The EQ-5D focuses on generic health status, such as specific problems with performing specific physical tasks as mobility, self-care, and usual activities, and whether the patient experiences pain or discomfort, or is anxious or depressed. QoL-AD and QUALID are both designed specifically to measure QoL in persons with dementia, while the EQ-5D is a standardised instrument for use as a measure of health outcomes applicable to a variety of different illnesses and treatments. The disagreement between different assessment methods for QoL, and the difficulties in conceptualising QoL, should lead to caution in interpreting the results.

Compared to a Finnish study from 2011, reporting antidementia drug use in $66.8 \%$ of persons with dementia [67], the prescription rate of anti-dementia medication in this study seems to be low. But, the result is in line with cross-sectional studies from Norway and Sweden done in 2004/2005, 2007 and 20110/2011, reporting a prevalence range from $11.3 \%$ to $18 \%[68,69]$. That only $55.9 \%$ of the participants with dementia according to the two experienced psychiatrists, had a dementia diagnosis documented in their records, can be an explanation for the low antidementia medication rate. In addition, the dementia was 
Table 7 Prevalence of diseases according to Charlson Comorbidity Index at admission to nursing homes (NH)

\begin{tabular}{|c|c|c|c|c|}
\hline & All patients & Patients with dementia & Patients without dementia & $p$-value \\
\hline Coronary disease & $167 / 664(25.2)$ & 130/559 (23.3) & 37/105 (35.2) & $0.009^{\mathrm{a})}$ \\
\hline Acute myocardial infarction & $97 / 664(14.6)$ & 77/558 (13.8) & 20/106 (18.9) & $0.176^{\mathrm{a})}$ \\
\hline Congestive heart failure & 137/654 (20.9) & 105/549 (19.1) & 32/105 (30.5) & $0.009^{\mathrm{a})}$ \\
\hline Peripheral vascular disease & $91 / 656(13.9)$ & 75/551 (13.6) & 16/105 (15.2) & $0.659^{\mathrm{a})}$ \\
\hline Cerebrovascular disease & $161 / 664(24.2)$ & 135/556 (24.3) & 26/108 (24.1) & $0.963^{\mathrm{a})}$ \\
\hline Dementia & 467/659 (70.9) & 445/552 (80.6) & 22/107 (20.6) & $<0.001^{\mathrm{a})}$ \\
\hline Pulmonary disease & $82 / 666(12.3)$ & $61 / 556(11.0)$ & 21/110 (19.1) & $0.018^{\mathrm{a})}$ \\
\hline Connective tissue disease & $58 / 664(8.7)$ & $42 / 557(7.5)$ & 16/107 (15.0) & $0.013^{\mathrm{a})}$ \\
\hline Peptic ulcer disease & $58 / 667(8.7)$ & 44/558 (7.9) & $14 / 109$ (12.8) & $0.093^{\mathrm{a})}$ \\
\hline Liver disease & 3/673 (0.4) & 3/564 (0.5) & 0 & $1.000^{b)}$ \\
\hline Diabetes & $101 / 676(14.9)$ & 79/566 (14.0) & 22/110 (20.0) & $0.104^{\mathrm{a})}$ \\
\hline Diabetes with complications & 25/676 (3.7) & $14 / 564(2.5)$ & $11 / 110(10.0)$ & $0.001^{b)}$ \\
\hline Hemiplegia or paraplegia & 21/664 (3.2) & $12 / 555(2.2)$ & $9 / 109(8.3)$ & $0.003^{b)}$ \\
\hline Renal disease & $86 / 670(12.8)$ & $62 / 560(11.1)$ & 24/110 (21.8) & $0.002^{\mathrm{a})}$ \\
\hline Cancer & 98/671 (14.6) & 77/563 (13.7) & 21/108 (19.4) & $0.120^{\mathrm{a})}$ \\
\hline Metastatic cancer & $17 / 667(2.5)$ & $12 / 559(2.1)$ & $5 / 108(4.6)$ & $0.172^{b)}$ \\
\hline Severe liver disease & $3 / 674(0.4)$ & $3 / 565(0.5)$ & 0 & $1.000^{b)}$ \\
\hline HIV disease & $1 / 668(0.1)$ & $1 / 558(0.2)$ & 0 & $1.000^{b)}$ \\
\hline
\end{tabular}

All figures in (\%)

a) Pearson Chi-square test

b) Fisher's Exact Test

severe at time for admission to the $\mathrm{NH}$, and anti-dementia medication may have been discontinued due to lack of effect, side effects or polypharmacy.

\section{Strengths and weaknesses}

The longitudinal design with a broad assessment and inclusion of the patients at admission to the $\mathrm{NH}$ is a strength of the study. This will allow researchers to analyse and present associations between different patient characteristics and symptoms, and to analyse the stability of these variables over time. It will also be possible to analyse how different baseline characteristics are associated with the course of dementia, in addition to implementing analyses with time-dependent variables. The use of standardised assessment tools - widely used both clinically and in research - will make it possible to compare findings from studies based on this dataset with other studies, both in Norway and internationally.

Furthermore, the high number of participants recruited from different NHs in a large geographical area, covering both urban and rural areas, was a strength of the study. Data were registered using standard and validated assessment tools, covering a broad range of symptoms and topics. The broad data collection allowed researchers to diagnose dementia according to international criteria without a clinical examination of the patients. Even with broad data collection at regular intervals in 696 patients, this study had relatively few missing data. The collection of DNA in a sub-sample of 611 patients is another strength of the study.

Furthermore, data collected in the study can be linked to the unique personal identification numbers of the participants, enabling linkage of data for each patient to five health registers: the Norwegian Prescription Database (NorPD), containing data about dispensed drugs in Norway; the Norwegian Patient Register (NPR), which contains information for all patients referred to or having received treatment in the specialist health services; the IPLOS-register, a Norwegian statutory health register for municipal health services; The Cancer Registry of Norway, containing information about all cancer cases in Norway; and the Cause of Death Registry.

One limitation to the study was that the participants might not have been representative of all patients at admission to NHs, because respite care patients were excluded. Another limitation was that only 38 of the 47 NHs collected data about the patients who were eligible for inclusion, but did not participate, and less than half of the residents eligible for inclusion in these 38 nursing homes were included in the study. There were also more women in the included sample compared to those who did not participate $(64.4 \%$ vs. $56.6 \%$, Chi-square test $p=0.004)$. These factors may have influenced the representativeness of the sample. From baseline to 18 months, 324 (46.5\%) of the participants dropped out of the study, 261 of them 
(80.5\%) dropped out due to death. Only nine $(2.7 \%)$ of the participants who dropped out before the 12-month assessment withdrew their consent, indicating that the high dropout rate probably did not bias the representativeness significantly. A high number of $\mathrm{NH}$ staff participated in the data collection. Even though they had participated in a training program, this could be a limitation to the study.

The statistical differences between persons with and without dementia in some variables were, in this paper, descriptively presented, and these results should be interpreted with caution.

\section{Conclusions}

In this paper, we describe the methods of our study in detail and our cohort's baseline demographic characteristics. The prevalence rates of dementia and NPS reported in this study could contribute to a greater understanding of the needs of nursing home patients and, thus, increase the knowledge in order to improve the quality of care for nursing home residents. In addition, the findings could be valuable to stakeholders and organisations when planning nursing home care for these patients.

\section{Acknowledgements}

This project was developed collaboratively, including the following research partners:

Centre for Old Age Psychiatric Research, Innlandet Hospital Trust (leader of the project); Dept. of Health Management and Health Economics, University of Oslo; South-Eastern Norway Regional Health Authority's Health Services

Research Centre, Akershus University Hospital; Centre for Elderly and Nursing Home Medicine (SEFAS); Department of Global Public Health and Primary Care; Faculty of Medicine and Dentistry, University of Bergen; and The Regional Centre for Elderly Medicine and Cooperation (SESAM), Stavanger University Hospital.

The REDIC-NH study was administrated by the Centre for Old Age Psychiatric Research, Innlandet Hospital Trust, and was initiated by the Norwegian Health Directorate, which also provided funding for the data collection. The first author's Ph.D. study was funded by the Research Council of Norway. Nursing Homes in Hedmark, Oppland, Hordaland, and Nord-Trøndelag counties participated in the study.

We would thank the patients and their next of kin for participating in the study and giving us their information. We would also thank the nursing home managers for their cooperation, the staff members in the nursing home that filled out the questionnaires, and the research nurses that collected the data.

\section{Funding}

The REDIC-NH study was administrated by the Centre for Old Age Psychiatric Research, Innlandet Hospital Trust, and was initiated by the Norwegian Health Directorate, which also provided funding for the data collection. The Research Council of Norway funded the first author's Ph.D. study.

\section{Availability of data and materials}

The datasets generated and/or analysed during the current study are available for researchers in cooperation with the data owner, the research centre for old age psychiatry research - Innlandet Hospital Trust. Information is available on the following page link: https://sykehuset-innlandet.no/ avdelinger/alderspsykiatrisk-forskningssenter.

\section{Authors' contributions}

GS, SB, KE and IR were responsible for the study concept and design. SB and IR coordinated the data collection. ØK provided expert advice and assistance in the selection of statistical analyses. IR carried out the statistical analysis with assistance from $\varnothing K$. IR, ØK, IT and SB analysed and interpreted the data and prepared the manuscript. All authors critically revised the manuscript, and added their comments and approved the final version.

\section{Competing interests}

The authors declare that they have no competing interests.

\section{Consent for publication}

Not applicable.

\section{Ethics approval and consent to participate}

The patient's capacity to consent to participation in the study was considered by the $\mathrm{NH}$ staff, including the physician. Written consent for participation was obtained from all participants with the capacity to consent. For participants lacking the capacity to consent, their next of kin gave consent on behalf of the patients. The next of kin gave written consent for their own participation in the study, as they provided information about themselves. The Regional Ethics Committee for Medical Research in South-Eastern Norway approved the study (2011/1738a).

\section{Publisher's Note}

Springer Nature remains neutral with regard to jurisdictional claims in published maps and institutional affiliations.

\section{Author details}

${ }^{1}$ Centre for Old Age Psychiatric Research, Innlandet Hospital Trust, Ottestad, Norway. ${ }^{2}$ Norwegian National Advisory Unit on Ageing and Health, Vestfold Hospital Trust, Tønsberg, Norway. ${ }^{3}$ Faculty of Medicine, University of Oslo, Oslo, Norway. ${ }^{4}$ Norwegian University of Science and Technology (NTNU), Department of Health Science in Gjøvik, Gjøvik, Norway. ${ }^{5}$ Centre for Age-Related Medicine, Stavanger University Hospital, Stavanger, Norway.

Received: 15 February 2017 Accepted: 3 May 2017

Published online: 22 May 2017

\section{References}

1. Prince M, Bryce R, Albanese E, Wimo A, Ribeiro W, Ferri CP. The global prevalence of dementia: a systematic review and metaanalysis. Alzheimer's Dement. 2013;9(1):63-75. e2

2. Wang SY, Shamliyan TA, Talley KM, Ramakrishnan R, Kane RL. Not just specific diseases: systematic review of the association of geriatric syndromes with hospitalization or nursing home admission. Arch Gerontol Geriatr. 2013;57(1):16-26.

3. Selbaek G, Kirkevold O, Engedal K. The prevalence of psychiatric symptoms and behavioural disturbances and the use of psychotropic drugs in Norwegian nursing homes. International journal of geriatric psychiatry. 2007; 22(9):843-9.

4. Selbaek G, Engedal K, Bergh S. The prevalence and course of neuropsychiatric symptoms in nursing home patients with dementia: a systematic review. J Am Med Dir Assoc. 2013;14(3):161-9.

5. Bergh S, Engedal K, Roen I, Selbaek G. The course of neuropsychiatric symptoms in patients with dementia in Norwegian nursing homes. Int Psychoger. 2011;23(8):1231-9.

6. Iden KR, Engedal K, Hjorleifsson S, Ruths S. Prevalence of depression among recently admitted long-term care patients in Norwegian nursing homes: associations with diagnostic workup and use of antidepressants. Dement Geriatr Cogn Disord. 2014;37(3-4):154-62.

7. Van Rensbergen G, Nawrot T. Medical conditions of nursing home admissions. BMC geriatrics. 2010;10:46

8. Sweet RA, Nimgaonkar VL, Devlin B, Lopez OL, DeKosky ST. Increased familial risk of the psychotic phenotype of Alzheimer disease. Neurology. 2002;58(6):907-11.

9. Dombrovski AY, Mulsant BH, Ferrell RE, Lotrich FE, Rosen Jl, Wallace M, et al. Serotonin transporter triallelic genotype and response to citalopram and risperidone in dementia with behavioral symptoms. Int Clin Psychopharmacol. 2010;25(1):37-45.

10. Ballard C, Orrell M, YongZhong S, Moniz-Cook E, Stafford J, Whittaker R, Woods B, Corbett A, Garrod L, Khan Z, Woodward-Carlton B, Wenborn J, Fossey J. Impact of Antipsychotic Review and Nonpharmacological Intervention on Antipsychotic Use, Neuropsychiatric Symptoms, and Mortality in People With Dementia Living in Nursing Homes: A Factorial Cluster-Randomized Controlled 
Trial by the Well-Being and Health for People With Dementia (WHELD) Program. Am J Psychiatry. 2016;173(3):252-62.

11. Ballard C, Creese B, Corbett A, Aarsland D. Atypical antipsychotics for the treatment of behavioral and psychological symptoms in dementia, with a particular focus on longer term outcomes and mortality. Expert Opin Drug Saf. 2011;10(1):35-43.

12. Selbaek G, Aarsland D, Ballard C, Engedal K, Langballe EM, Benth JS, et al. Antipsychotic drug use is not associated with long-term mortality risk in Norwegian nursing home patients. J Am Med Dir Assoc. 2016;17(5):464.

13. Almeida OP, Alfonso $H$, Hankey GJ, Flicker L. Depression, antidepressant use and mortality in later life: the health in men study. PloS One. 2010;5(6):e11266.

14. Bostrom G, Hornsten C, Brannstrom J, Conradsson M, Nordstrom P. Allard P, et al. Antidepressant use and mortality in very old people. Int Psychogeriatr. 2016;28(7):1201-10

15. Ryan J, Carriere I, Ritchie K, Stewart R, Toulemonde G, Dartigues JF, et al. Late-life depression and mortality: influence of gender and antidepressant use. Br J Psychiatry J Ment Sci. 2008;192(1):12-8.

16. Jonsson L, Wimo A. The cost of dementia in Europe: a review of the evidence, and methodological considerations. Pharmacoeconomics. 2009; 27(5):391-403.

17. Vossius C, Selbaek G, Ydstebo AE, Benth JS, Godager G, Luraas H, et al. Ressursbruk og sykdomsforløp ved demens (REDIC). Sykehuset Innlandet, Report. 2015;1-155.

18. Bjork S, Juthberg C, Lindkvist M, Wimo A, Sandman PO, Winblad B, et al, Exploring the prevalence and variance of cognitive impairment, pain, neuropsychiatric symptoms and ADL dependency among persons living in nursing homes; a cross-sectional study. BMC Geriatr. 2016;16:154.

19. McKeith IG, Dickson DW, Lowe J, Emre M, O'Brien JT, Feldman H, et al. Diagnosis and management of dementia with Lewy bodies: third report of the DLB Consortium. Neurology. 2005;65(12):1863-72.

20. Neary D, Snowden JS, Gustafson L, Passant U, Stuss D, Black S, et al, Frontotemporal lobar degeneration: a consensus on clinical diagnostic criteria. Neurology. 1998;51(6):1546-54.

21. Winblad B, Palmer K, Kivipelto M, Jelic V, Fratiglioni L, Wahlund LO, et al. Mild cognitive impairment-beyond controversies, towards a consensus: report of the International Working Group on mild cognitive impairment. J Intern Med. 2004;256(3):240-6.

22. World Health Organization. The ICD-10 Classification of Mental and Behavioural Disorders - Diagnostic Criteria for Research. Geneva: World Health Organization; 1993

23. Folstein MF, Folstein SE, McHugh PR. "Mini-mental state". A practical method for grading the cognitive state of patients for the clinician. $J$ Psychiatr Res. 1975;12(3):189-98.

24. Schmitt FA, Saxton JA, Xu Y, McRae T, Sun Y, Richardson S, et al. A brief instrument to assess treatment response in the patient with advanced Alzheimer disease. Alzheimer Dis Assoc Disord. 2009;23(4):377-83.

25. Harrison JK, Fearon P, Noel-Storr AH, McShane R, Stott DJ, Quinn TJ. nformant Questionnaire on Cognitive Decline in the Elderly (IQCODE) for the diagnosis of dementia within a secondary care setting. The Cochrane database of systematic reviews. 2015;3:Cd010772

26. Jorm AF, Jacomb PA. The Informant Questionnaire on Cognitive Decline in the Elderly (IQCODE): socio-demographic correlates, reliability, validity and some norms. Psychol Med. 1989;19(4):1015-22.

27. Jorm AF. The Informant Questionnaire on cognitive decline in the elderly (IQCODE): a review. Int Psychogeriatr. 2004;16(3):275-93.

28. Hughes CP, Berg L, Danziger WL, Coben LA, Martin RL. A new clinical scale for the staging of dementia. Br J Psychiatry J Ment Sci. 1982;140:566-72.

29. O'Bryant SE, Waring SC, Cullum CM, Hall J, Lacritz L, Massman PJ, et al. Staging dementia using clinical dementia rating scale sum of boxes scores: a Texas Alzheimer's research consortium study. Arch Neurol. 2008:65(8):1091-5.

30. Reisberg B. Functional assessment staging (FAST). Psychopharmacol Bull. 1988;24(4):653-9

31. Lyketsos CG, Galik E, Steele C, Steinberg M, Rosenblatt A, Warren A, et al. The general medical health rating: a bedside global rating of medical comorbidity in patients with dementia. J Am Geriatr Soc. 1999:47(4):487-91.

32. Husebo BS, Strand LI, Moe-Nilssen R, Husebo SB, Snow AL, Ljunggren AE. Mobilization-Observation-Behavior-Intensity-Dementia Pain Scale (MOBID): development and validation of a nurse-administered pain assessment too for use in dementia. J Pain Symptom Manage. 2007;34(1):67-80.

33. Ballard C, McKeith I, Burn D, Harrison R, O'Brien J, Lowery K, et al. The UPDRS scale as a means of identifying extrapyramidal signs in patients suffering from dementia with Lewy bodies. Acta Neurol Scand. 1997;96(6):366-71.
34. Bruera E, Kuehn N, Miller MJ, Selmser P, Macmillan K. The Edmonton Symptom Assessment System (ESAS): a simple method for the assessment of palliative care patients. J Palliat Care. 1991;7(2):6-9.

35. Crooks V, Waller S, Smith T, Hahn TJ. The use of the karnofsky performance scale in determining outcomes and risk in geriatric outpatients. J Gerontol. 1991;46(4):M139-44.

36. Morris JN, Hawes C, Fries BE, Phillips CD, Mor V, Katz S, et al. Designing the national resident assessment instrument for nursing homes. Gerontologist 1990;30(3):293-307.

37. Charlson ME, Pompei P, Ales KL, MacKenzie CR. A new method of classifying prognostic comorbidity in longitudinal studies: development and validation. J Chronic Dis. 1987;40(5):373-83.

38. Cummings JL, Mega M, Gray K, Rosenberg-Thompson S, Carusi DA, Gornbein J. The Neuropsychiatric Inventory: comprehensive assessment of psychopathology in dementia. Neurology. 1994;44(12):2308-14.

39. Selbaek G, Kirkevold O, Sommer OH, Engedal K. The reliability and validity of the Norwegian version of the Neuropsychiatric Inventory, nursing home version (NPI-NH). Int Psychogeriatr. 2008;20(2):375-82.

40. Steinberg M, Tschanz JT, Corcoran C, Steffens DC, Norton MC, Lyketsos CG, et al. The persistence of neuropsychiatric symptoms in dementia: the cache county study. Int J Geriatr Psychiatry. 2004;19(1):19-26.

41. Selbaek G, Engedal K. Stability of the factor structure of the Neuropsychiatric Inventory in a 31-month follow-up study of a large sample of nursing-home patients with dementia. Int Psychogeriatr. 2012;24(1):62-73.

42. Selbaek G, Engedal K, Benth JS, Bergh S. The course of neuropsychiatric symptoms in nursing-home patients with dementia over a 53-month follow-up period. Int Psychogeriatr. 2014;26(1):81-91.

43. Kaufer DI, Cummings JL, Ketchel P, Smith V, MacMillan A, Shelley T, et al. Validation of the NPI-Q, a brief clinical form of the neuropsychiatric inventory. J Neuropsychiatry Clin Neurosci. 2000;12(2):233-9.

44. Alexopoulos GS, Abrams RC, Young RC, Shamoian CA. Cornell scale for depression in dementia. Biol Psychiatry. 1988;23(3):271-84.

45. Inouye SK, van Dyck CH, Alessi CA, Balkin S, Siegal AP, Horwitz RI. Clarifying confusion: the confusion assessment method. A new method for detection of delirium. Ann Intern Med. 1990:113(12):941-8.

46. Lawton MP, Brody EM. Assessment of older people: self-maintaining and instrumental activities of daily living. Gerontologist. 1969;9(3):179-86.

47. Baker PS, Bodner EV, Allman RM. Measuring life-space mobility in community-dwelling older adults. J Am Geriatr Soc. 2003;51(11):1610-4.

48. Guralnik JM, Simonsick EM, Ferrucci L, Glynn RJ, Berkman LF, Blazer DG, et al. A short physical performance battery assessing lower extremity function: association with self-reported disability and prediction of mortality and nursing home admission. J Gerontol. 1994;49(2):M85-94.

49. Logsdon RG, Gibbons LE, McCurry SM, Teri L. Assessing quality of life in older adults with cognitive impairment. Psychosom Med. 2002;64(3):510-9.

50. Roen I, Selbaek G, Kirkevold O, Engedal K, Lerdal A, Bergh S. The reliability and validity of the Norwegian version of the quality of life in late-stage dementia scale. Dement Geriatr Cogn Disord. 2015:40(3-4):233-42.

51. Weiner M, Martin-Cook K, Svetlik D, Saine K, Foster B, Fontaine C. The quality of life in late-stage dementia (QUALID) scale 2000 [cited 13 3. 114-6].

52. Euro Q. Group Euro QOL: A new facility for the measurement of health related QOL. Health Policy. 1990;161:99-208.

53. Organization WH. WHO Collaborating Centre for Drug Statistics Methodology ATC/DDD index 2011. Available at https:/www.whocc.no/atc_ddd_index/. 2013. Accessed 7 May 2017

54. Wimo A, Jonsson L, Zbrozek A. The Resource Utilization in Dementia (RUD) instrument is valid for assessing informal care time in community-living patients with dementia. J Nutr Health Aging. 2010;14(8):685-90.

55. Luttenberger $\mathrm{K}$, Graessel E. Recording care time in nursing homes: development and validation of the "RUD-FOCA" (Resource Utilization in Dementia-Formal Care). Int Psychogeriatr. 2010;22(8):1291-300.

56. Greene JG, Smith R, Gardiner M, Timbury GC. Measuring behavioura disturbance of elderly demented patients in the community and its effects on relatives: a factor analytic study. Age Ageing. 1982;11(2):121-6.

57. Ulstein I, Bruun Wyller T, Engedal K. The relative stress scale, a useful instrument to identify various aspects of carer burden in dementia? Int J Geriatr Psychiatry. 2007;22(1):61-7.

58. Aalten $P$, de Vugt ME, Jaspers $N$, Jolles J, Verhey FR. The course of neuropsychiatric symptoms in dementia. Part I: findings from the two-year longitudinal Maasbed study. Int J Geriatr Psychiatry. 2005; 20(6):523-30. 
59. Feldman $\mathrm{H}$, Clarfield AM, Brodsky J, King Y, Dwolatzky T. An estimate of the prevalence of dementia among residents of long-term care geriatric institutions in the Jerusalem area. Int Psychogeriatr. 2006;18(4):643-52.

60. Lithgow S, Jackson GA, Browne D. Estimating the prevalence of dementia: cognitive screening in Glasgow nursing homes. Int J Geriatr Psychiatry. 2012;27(8):785-91.

61. Mansdorf IJ, Harrington M, Lund J, Wohl N. Neuropsychological testing in skilled nursing facilities: the failure to confirm diagnoses of dementia. J Am Med Dir Assoc. 2008;9(4):271-4.

62. Palm R, Junger S, Reuther S, Schwab CG, Dichter MN, Holle B, et al. People with dementia in nursing home research: a methodological review of the definition and identification of the study population. BMC Geriatr. 2016;16(1):78.

63. Lamberts H, Okkes I. ICPC-2, International Classification of Primary Care. 1998

64. Iden KR, Hjorleifsson S, Ruths S. Treatment decisions on antidepressants in nursing homes: a qualitative study. Scand J Prim Health Care. 2011;29(4):252-6.

65. Laver K, Dyer S, Whitehead C, Clemson L, Crotty M. Interventions to delay functional decline in people with dementia: a systematic review of systematic reviews. BMJ Open. 2016;6(4):e010767.

66. Testad I, Corbett A, Aarsland D, Lexow KO, Fossey J, Woods B, et al. The value of personalized psychosocial interventions to address behavioral and psychological symptoms in people with dementia living in care home settings: a systematic review. Int Psychogeriatr. 2014;26(7):1083-98.

67. Kuronen M, Koponen H, Nykanen I, Karppi P, Hartikainen S. Use of anti-dementia drugs in home care and residential care and associations with neuropsychiatric symptoms: a cross-sectional study. BMC Geriatrics. 2015;15:100

68. Gustafsson M, Sandman PO, Karlsson S, Gustafson Y, Lovheim H. Association between behavioral and psychological symptoms and psychotropic drug use among old people with cognitive impairment living in geriatric care settings. Int Psychogeriatr. 2013;25(9):1415-23.

69. Helvik AS, Engedal K, Wu B, Benth JS, Corazzini K, Roen I, et al. Severity of neuropsychiatric symptoms in nursing home residents. Dement Geriatr Cogn Dis Extra. 2016;6(1):28-42.

\section{Submit your next manuscript to BioMed Central and we will help you at every step:}

- We accept pre-submission inquiries

- Our selector tool helps you to find the most relevant journal

- We provide round the clock customer support

- Convenient online submission

- Thorough peer review

- Inclusion in PubMed and all major indexing services

- Maximum visibility for your research 



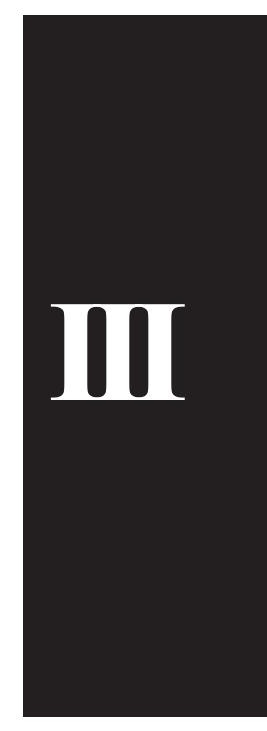





\title{
Person-centered care in Norwegian nursing homes and its relation to organizational factors and staff characteristics: a cross-sectional survey
}

\author{
Irene Rфen, ${ }^{1} \not$ yvind Kirkevold, ${ }^{1,2,3}$ Ingelin Testad, ${ }^{4,5,6}$ Geir Selbæk, ${ }^{1,2,7}$ \\ Knut Engedal ${ }^{2}$ and Sverre Bergh ${ }^{1,2}$ \\ ${ }^{1}$ Centre for Old Age Psychiatric Research, Innlandet Hospital Trust, Ottestad, Norway \\ ${ }^{2}$ Norwegian National Advisory Unit on Ageing and Health, Vestfold Hospital Trust, Tonsberg, Norway \\ ${ }^{3}$ Department of Health Science in Gjøvik, Norwegian University of Science and Technology (NTNU), Gjøvik, Norway \\ ${ }^{4}$ Centre for Age-Related Medicine - SESAM, Stavanger University Hospital, Stavanger, Norway \\ ${ }^{5}$ Department of Old Age Psychiatry, Institute of Psychiatry, Psychology \& Neuroscience, King's College London, London, UK \\ ${ }^{6}$ Medical School, St Luke's Campus, University of Exeter, Exeter, UK \\ ${ }^{7}$ Faculty of Medicine, University of Oslo, Oslo, Norway
}

Background: Person-centered care (PCC) is regarded as good quality care for persons with dementia. This study aimed to explore and understand the association between PCC and organizational, staff and unit characteristics in nursing homes (NHs).

Methods: Staff from $175 \mathrm{NH}$ units in Norway $(\mathrm{n}=1,161)$ completed a survey, including measures of PCC and questions about staff characteristics and work-related psychosocial factors. In addition, data about organizational and structural factors and assessment of the physical environment in the units were obtained. The distribution of these factors in regular units (RUs) and special care units (SCUs) is described, and the differences between the two types of units are analyzed. Furthermore, multilevel linear regression analyses explored the extent to which variables were associated with PCC.

Results: Higher levels of PCC were associated with a greater job satisfaction, three years or more of healthrelated education, a lower level of quantitative demands and role conflict, a higher level of perception of mastery, empowering leadership, innovative climate and perception of group work, in addition to the type of unit and the physical environment in the NH unit designed for people with dementia. SCU and staff job satisfaction explained most of the variation in PCC.

Conclusion: This study shows an association between PCC and organizational, staff and unit characteristics in NH. These findings indicate that providing PCC in NH care is closely linked to how the staff experiences their job situation in addition to both organizational and structural factors and the physical environment. Attention needs to be given to such factors when planning $\mathrm{NH}$ care.

Key words: cross-sectional, nursing home, person-centered care, organizational factors, job satisfaction, physical environment

\section{Introduction}

Dementia is a syndrome caused by a variety of brain disorders, which leads to cognitive decline and decreased function in the activities of daily living. The syndrome is usually chronic and progressive in nature. As dementia increases in severity, the need for institutionalization increases, and more than

Correspondence should be addressed to: I. Røen, Centre for Old Age Psychiatric Research, Innlandet Hospital Trust, p.b.68, 2312 Ottestad, Norway. Phone: +47 90652165. Email: irroee@sykehuset-innlandet.no. Received 9 Aug 2017; revision requested 27 Sep 2017; revised version received 31 Oct 2017; accepted 31 Oct 2017.
$80 \%$ of Norwegian nursing home $(\mathrm{NH})$ patients have dementia (Selbaek et al., 2007).

Furthermore, dementia is a condition compounded of the personality of the person with dementia, and his or her physical health, life story, neurologic impairment, and social psychology, all preserving the person's personhood (Kitwood, 1997). According to Kitwood (1977), the person with dementia and their psychological needs is the focus of the care and treatment; person-centered care (PCC) (Kitwood, 1997) rather than the person's disease (Edvardsson and Innes, 2010). PCC is widely accepted as good-quality care for persons with 
dementia in $\mathrm{NH}$ and is a guiding principle in care services (Brooker, 2004; Li and Porock, 2014; Manthorpe and Samsi, 2016). There is an increase in the literature evaluating psychosocial interventions and PCC ( $\mathrm{Li}$ and Porock, 2014; Testad et al., 2014) showing significant benefits on decreasing behavioral symptoms (Chenoweth et al., 2009), psychotropic medication use (Fossey et al., 2006), increase in mood (Brooker et al., 2011), and health-related quality of life (Ballard et al., 2015) in persons with dementia in longterm care. Theories for implementing PCC have been developed over the years, such as the VIPS framework by Brooker (2004). This framework constitutes four major elements; $V$ stands for valuing people with dementia and those who care for them; $I$ for treating people as individuals; $P$ for looking at the world from the perspective of the person with dementia; and $S$ for a positive social environment in which the person living with dementia can experience relative well-being (Brooker, 2004).

In PCC, the relationship between $\mathrm{NH}$ staff and the person with dementia is essential (Wilberforce et al., 2016), and consequently, the staff's attitude and work methods are important (Anderson et al., 2016). Several factors have in previous studies been associated with PCC, such as job satisfaction and capacity to provide individualized care (van den Pol-Grevelink et al., 2012; Brownie and Nancarrow, 2013), gender, beliefs about personhood in dementia, burnout, collaboration in care, the physical environment, the social environment of care (Hunter et al., 2015), and the psychosocial factors at work (Testad et al., 2010). A recent review article concluded that the physical environment in care settings is important for improving the patients' quality of life and quality of care practices (Chaudhury et al., 2017). Essential aspects of quality of life and care include the influence of unit size, the spatial layout, its homelike character, sensory stimulation, and specific areas for dining, bathing, and outdoor activities, all of which emphasize the relationship between the therapeutic physical environment, organizational factors, and care practices (Chaudhury et al., 2017). Although the published work on PCC is quite substantial, the number of included respondents is low and the need for larger studies is warranted. Furthermore, insight on how organizational structures can stimulate or hinder person centeredness in staff and whether levels of person centeredness correlate with individual staff variables, such as education, clinical experience, job satisfaction, and experience of organizational variables, such as type of ward (regular unit (RU) or special care unit (SCU)), unit size, leadership, staff-to-patient ratios, and physical environment, is needed.

Thus, we designed this study to explore and understand the association between PCC, assessed with the Person-centered Care Assessment Tool (P-CAT), and organizational, $\mathrm{NH}$ staff and unit characteristics.

\section{Methods}

\section{Study design and sample}

This is a cross-sectional study, with a convenience sample of $175 \mathrm{NH}$ units from $45 \mathrm{NHs}$ in 29 municipalities in four Norwegian counties. An $\mathrm{NH}$ unit participating in the study was defined as a group of patients living together with a common living area and having their own care staff during the daytime. NH staff, which the head nurse defined as those familiar to the care provided and the structural and organizational conditions in the unit, were considered eligible for the study.

\section{Data collection}

The data were collected during the period from October 2013 to December 2014. Three case report files (CRF), including both a standardized questionnaire and questions developed for this study by the research group, were constructed; one to the $\mathrm{NH}$ manager, one to the head nurse of the unit, and one to the NH staff. The members of the research group all have wide experience in both clinical work and research projects in NHs. The questions developed by the research group for the study were based on factors identified in the literature referring to organizational and structural factors, such as culture, leadership, management, staff education, staffing levels, and physical environment.

\section{Measures}

\section{Person-centered care}

Several tools have been developed to assess PCC (de Silva, 2014; Wilberforce et al., 2016), but the P-CAT (Edvardsson et al., 2010) is the only tool designed for self-assessing PCC by staff in long-term care facilities, which has been tested beyond the initial development stages (Wilberforce et al., 2016). The Norwegian version of the P-CAT has satisfactory psychometric properties for the use in a nursing home-care setting (Rokstad et al., 2012) and was chosen in this study. The P-CAT consists of 13 items expressed as statements about the content of care, the environment, and the organization, formulated to measure staff 
Textbox 1. Organizational and psychosocial factors*

\begin{tabular}{|c|c|}
\hline Subscales & QPS-Nordic items \\
\hline Quantitative demands & $\begin{array}{l}\text { - Is your work load irregular so that the work piles up? } \\
\text { - Do you have to work overtime? } \\
\text { - Is it necessary to work at a rapid pace? } \\
\text { - Do you have too much to do? }\end{array}$ \\
\hline$\overline{\text { Decision demands }}$ & $\begin{array}{l}\text { - Does your work require quick decisions? } \\
\text { - Does your work require maximum attention? } \\
\text { - Does your work require complex decisions? }\end{array}$ \\
\hline Learning demands & $\begin{array}{l}\text { - Are your work tasks too difficult for you? } \\
\text { - Do you perform work tasks for which you need more training? } \\
\text { - Does your job require that you acquire new knowledge and new skills? }\end{array}$ \\
\hline$\overline{\text { Perception of mastery }}$ & $\begin{array}{l}\text { - Are you content with the quality of the work you do? } \\
\text { - Are you content with the amount of work that you get done? } \\
\text { - Are you content with your ability to solve problems at work? } \\
\text { - Are you content with your ability to maintain a good relationship with your coworkers at } \\
\text { work? }\end{array}$ \\
\hline Empowering leadership & $\begin{array}{l}\text { - Does your immediate superior encourage you to participate in important decisions? } \\
\text { - Does your immediate superior encourage you to speak up, when you have different opinions? } \\
\text { - Does your immediate superior help you develop your skills? }\end{array}$ \\
\hline Fair leadership & $\begin{array}{l}\text { - Does your immediate superior distribute the work fairly and impartially? } \\
\text { - Does your immediate superior treat the workers fairly and equally? } \\
\text { - Is the relationship between you and your immediate superior a source of stress to you? }\end{array}$ \\
\hline Role clarity & $\begin{array}{l}\text { - Have clear, planned goals and objectives been defined for your job? } \\
\text { - Do you know what your responsibilities are? } \\
\text { - Do you know exactly what is expected of you at work? }\end{array}$ \\
\hline$\overline{\text { Role conflict }}$ & $\begin{array}{l}\text { - Do you have to do things that you feel should be done differently? } \\
\text { - Are you given assignments without adequate resources to complete them? } \\
\text { - Do you receive incompatible requests from two or more people? }\end{array}$ \\
\hline Innovative climate & $\begin{array}{l}\text { - Do workers take initiatives at your workplace? } \\
\text { - Are workers encouraged to think of ways to do things better at your workplace? } \\
\text { - Is there sufficient communication in your department? }\end{array}$ \\
\hline Perception of group work & $\begin{array}{l}\text { - Do you appreciate belonging to this group or team? } \\
\text { - Is your group or team work flexible? } \\
\text { - Is your group or team successful at problem solving? }\end{array}$ \\
\hline
\end{tabular}

*Thirty-two QPS-Nordic items, distributed in 10 scales were used in the study. Each scale consists of 3 or 4 items, giving a subscale score of 3-15 or $4-20$.

perceptions of the practice in the unit where they work. The participants indicate on a five-point Likert scale ranging from 1 (disagree completely) to 5 (agree completely) how they perceive the care in the unit. The total score ranges from 13 to 65, where higher scores indicate a higher level of PCC.

\section{NH staff factors}

$\mathrm{NH}$ staff data were obtained through questionnaires. The questionnaire contained demographic information about the participants, such as age, gender, Norwegian as a first language, number of years of health-related and relevant continuing education, experience in the current job, and percentage of full-time position.

Work-related psychosocial factors were assessed with the General Nordic Questionnaire for Psychosocial and Social Factors at Work (QPSNordic), covering essential social and psychological factors at work (Dallner et al., 2000). Of the 129 items in QPS-Nordic, 11 are background items, 38 are single items, and 80 are distributed in 13 scales. In this study, 32 items distributed in the following 10 scales were included: quantitative demands, decision demands, learning demands, perception of mastery, empowering mastership, fair leadership, role clarity, role conflict, innovative climate, and perception of group work. Respondents indicated how relevant each statement was for their situation on a five-point Likert scale from 1 (very seldom or never) to 5 (very often or always). Each scale consists of 3 or 4 items, giving a subscale score of 3-15 or 4-20 (see textbox 1).

A single question about general job satisfaction was added: "How will you describe your general experience of your job satisfaction?" The alternatives were "very bad - bad - unsure - quite good - good - excellent." 
To ensure staff anonymity, the head nurse did not have access to the staffs' answers in the questionnaires, with $\mathrm{NH}$ staff returning the questionnaire in a stamped envelope directly to the researchers.

\section{NH unit characteristics}

The following data about organizational and structural factors in the $\mathrm{NH}$ unit were obtained through a questionnaire distributed to the head nurse of the 175 units: type of unit (SCU or RU); the unit size (number of patients); the daytime staff/patient ratio (the number of $\mathrm{NH}$ staff working per patient during the daytime); the number of units per head nurse; and the number of hours the nursing home physician was working per patient per week in the nursing home/unit. To categorize $\mathrm{NH}$ units as either RU or SCU, we used the definition of SCU from the Therapeutic Environment Screening Survey for Nursing Home (TESS-NH) (Sloane et al., 2002): an SCU must be physically separated from the rest of the facility by closed doors or it is free-standing, and the unit must self-designate the unit as a specialized dementia care unit. In addition, the unit must meet two of the following three criteria: (1) the unit serves a population in which $75 \%$ or more of the residents have a diagnosis of Alzheimer's disease or related dementias; (2) unit programming and activities are dementia specific; or (3) the staff is trained in dementia care. $\mathrm{NH}$ units not fulfilling this SCU definition were defined as RUs, including regular somatic units, short-time units, and rehabilitation units.

\section{Physical environment}

To assess the physical environment of the unit, we used the Special Care Unit Environmental Quality Scale (SCUEQS), which is a summary scale embedded in the Therapeutic Environment Screening Survey for Nursing Homes (TESS-NH) (Sloane et al., 2002). TESS-NH was translated into Norwegian and back-translated according to the procedures described by Acquadro et al. (1996). Three translators, two medical doctors, and one registered nurse translated the American version of TESS-NH into Norwegian. These translations were aggregated into one Norwegian version, and a faculty research group agreed on a preliminary version. This version was translated back into English by Allegro Language Services. The English back-translated version was sent to Sloane, who developed the original TESS-NH, to get her comments. The final Norwegian version of TESS$\mathrm{NH}$ was agreed upon after a revision based on Sloane's responses and a discussion in the research group. The Norwegian version is not tested for psychometric properties. The TESS-NH contains 84 discrete items and one global rating and was developed to describe the ability of physical environments in NHs to address therapeutic goals for persons with dementia. The SCUEQS consists of 18 of the TESS-NH items and measures maintenance, cleanliness, safety, lighting, physical appearance/home likeness, orientation/cueing, and noise (Sloane et al., 2002). Scores range from 0 to 41 , where higher scores indicate a better physical environment.

\section{Statistical analyses}

IBM SPSS Statistics for Windows, version 23.0 (Armonk, NY: IBM Corp.) was used to perform descriptive statistics of P-CAT scores, QPSNordic and quality indicators, and staff and unit characteristics.

Of the 1,161 respondents, 77 had missing data on at least one P-CAT item and imputation was performed on cases with fewer than $50 \%$ missing values ( 6 at most). Four respondents had missing data on more than six P-CAT items, and data were not imputed. The empirical distribution for each item in the scale was generated. A random number was drawn from that distribution and used to replace the missing value. The process was repeated until all missing values were imputed. This algorithm mimics the bootstrap described by Efron and Tibshirani (1994).

As data were on two levels (unit and staff level), MLwiN version 2.36 (Centre for Multilevel Modeling, University of Bristol) was used to check for a clustering effect (Intra-Class Correlation (ICC)) of the units. After a clear cluster effect was found, three multilevel linear regression models were built using P-CAT sum scores as the dependent variable. Independent variables were added to the model in blocks: NH-staff characteristics (model 1), QPS-Nordic (model 2), and variables collected at unit level (level 2, model 3). The multilevel analysis generates two different values for variance $\sigma_{\text {en }}^{2}$ for between groups and $\sigma_{\text {un }}^{2}$ for within groups, and with this the proportion of the ICC explained by the models $\left(R_{2}^{2}\right)$ and of the portion of variance within groups $\left(R_{1}^{2}\right)$ were calculated at each step.

\section{Results}

\section{Staff characteristics and work-related psychosocial factors}

Characteristics of nursing staff are presented in Table 1 . The total staff response rate was $67.5 \%$. 
Table 1. Characteristics of nursing staff $n=1,161$

\begin{tabular}{|c|c|}
\hline & $\mathrm{N} / \%$ \\
\hline Female Gender $\mathrm{n}=1,098$ & $1,061 / 96.6$ \\
\hline Norwegian as first language $\mathrm{n}=1,113$ & $1,023 / 91.9$ \\
\hline \multicolumn{2}{|l|}{ Age $n=1,136$} \\
\hline$<20$ & $8 / 0.7$ \\
\hline $20-29$ & $155 / 13.6$ \\
\hline $30-39$ & $187 / 16.5$ \\
\hline $40-49$ & $295 / 26.0$ \\
\hline $50-59$ & $346 / 30.5$ \\
\hline $60-67$ & $133 / 11.7$ \\
\hline$>67$ & $12 / 1.1$ \\
\hline \multicolumn{2}{|l|}{ Years of health-related education $\mathrm{n}=1,157$} \\
\hline$\geq 3$ & $346 / 29.9$ \\
\hline$<3$ & $811 / 70.1$ \\
\hline \multicolumn{2}{|l|}{ Relevant continuing education $\mathrm{n}=1,161$} \\
\hline Yes & $318 / 27.4$ \\
\hline No & $843 / 72.6$ \\
\hline \multicolumn{2}{|l|}{ Experience in current job $\mathrm{n}=1,123$} \\
\hline$<1$ year & $84 / 7.5$ \\
\hline $1-4.99$ years & $262 / 23.3$ \\
\hline $5-14.99$ years & $457 / 40.7$ \\
\hline 15 years and more & $320 / 28.5$ \\
\hline Staff working at least $75 \%$ of full-time $n=1,151$ & $700 / 60.8$ \\
\hline \multicolumn{2}{|l|}{ Job satisfaction $\mathrm{n}=1,151$} \\
\hline Very poor & $5 / 0.4$ \\
\hline Poor & $18 / 1.6$ \\
\hline Unsure & $38 / 3.3$ \\
\hline Quite good & $293 / 25.5$ \\
\hline Good & $550 / 47.8$ \\
\hline Excellent & $247 / 21.5$ \\
\hline QPS-Nordic $^{1}$ subscales $^{2}$ & $\mathrm{n} / \mathrm{mean}\left(\mathrm{SD}^{3}\right)$ \\
\hline QPS-N, quantitative demands (4 items) & $1,149 / 11.23(2.84)$ \\
\hline QPS-N, decision demands ( 3 items) & $1,149 / 10.10(1.99)$ \\
\hline QPS-N, learning demands (3 items) & $1,149 / 7.21(1.76)$ \\
\hline QPS-N, perception of mastery (4 items) & $1,149 / 16.24(1.93)$ \\
\hline QPS-N, empowering leadership (3 items) & $1,150 / 8.74(2.96)$ \\
\hline QPS-N, fair leadership (3 items) & $1,151 / 11.87(2.66)$ \\
\hline QPS-N, role clarity (3 items) & $1,151 / 13.00(1.95)$ \\
\hline QPS-N, role conflict ( 3 items) & $1,151 / 7.38(2.13)$ \\
\hline QPS-N, innovative climate ( 3 items) & $1,153 / 11.57(2.10)$ \\
\hline QPS-N, perception of group work (3 items) & $1,145 / 12.12(2.01)$ \\
\hline
\end{tabular}

${ }^{1}$ QPS-Nordic $=$ the General Nordic Questionnaire for Psychosocial and Social Factors at Work.

${ }^{2}$ QPS-Nordic subscales each consist of 3 or 4 items, giving a subscale score of 3-15 or 4-20.

${ }^{3} \mathrm{SD}=$ standard deviation.

The mean staff response rate within the units was $70.7 \%$ (SD 20.3\%), indicating that the response rates were lower in the large units. Nearly all the $\mathrm{NH}$ staffs were female $(96.6 \%), 56.4 \%$ were between 40 and 59 years old, and $91.9 \%$ had Norwegian as their first language. Most of the staff $(60.8 \%)$ had a position of $75 \%$ of full time or more, $29.9 \%$ had 3 years or more of healthrelated education, and $27.4 \%$ had received relevant continuing education. Regarding work experience, the largest group was those who had worked
5-15 years at the NH unit (49.7\%). Finally, $69.2 \%$ rated their job satisfaction as good or excellent.

\section{Unit characteristics and person-centered care assessment}

All leaders of the units except one returned the questionnaire, giving a response rate of $99.5 \%$. Of the 175 units, $62(35.4 \%)$ were SCUs. Table 2 presents differences between the RUs and the SCUs in the number of beds, the physical 
Table 2. Unit ${ }^{1}$ characteristics and P-CAT score in regular and special care units

\begin{tabular}{|c|c|c|c|c|}
\hline VARIABLES & $\begin{array}{l}\operatorname{ALL} N / \operatorname{MEAN} \\
\left(\mathrm{SD}^{2}\right)\end{array}$ & $\begin{array}{l}\text { REGULAR UNIT } \\
\text { N/MEAN (SD) }\end{array}$ & $\begin{array}{l}\text { SPECIAL CARE } \\
\text { UNIT N/MEAN (SD) }\end{array}$ & $\mathrm{p}-\mathrm{VALUE}$ \\
\hline Number of beds in unit & $175 / 10.86(5.68)$ & $113 / 12.16(6.42)$ & $62 / 8.48(2.72)$ & $<0.001^{5}$ \\
\hline Staff/patient ratio & $174 / 0.32(0.09)$ & $113 / 0.30(0.06)$ & $61 / 0.35(0.13)$ & $0.007^{5}$ \\
\hline $\begin{array}{l}\text { Head nurse for number of } \\
\text { units }\end{array}$ & $174 / 2.81(1.23)$ & $113 / 2.60(0.90)$ & $61 / 3.20(1.60)$ & $0.009^{5}$ \\
\hline $\begin{array}{l}\text { Physician; minutes per resident } \\
\text { per week } \\
\text { SCUEQS }^{3}\end{array}$ & $174 / 26.09(18.52)$ & $113 / 25.03(16.47)$ & $61 / 28.05(21.84)$ & $0.348^{5}$ \\
\hline \multicolumn{5}{|l|}{ Maintenance } \\
\hline $\begin{array}{l}\text { 7a Maintenance of social } \\
\text { spaces }\end{array}$ & $175 / 1.35(0.67)$ & $113 / 1.32(0.67)$ & $62 / 1.40(0.66)$ & $0.405^{6}$ \\
\hline $7 \mathrm{~b}$ Maintenance of halls & $175 / 1.39(0.68)$ & $113 / 1.34(0.68)$ & $62 / 1.50(0.67)$ & $0.093^{6}$ \\
\hline $\begin{array}{l}\text { 7c Maintenance of resident } \\
\text { rooms }\end{array}$ & $175 / 1.34(0.68)$ & $113 / 1.31(0.72)$ & $62 / 1.40(0.61)$ & $0.526^{6}$ \\
\hline $\begin{array}{l}\text { 7d Maintenance of resident } \\
\text { bathrooms }\end{array}$ & $175 / 1.31(0.72)$ & $113 / 1.23(0.74)$ & $62 / 1.45(0.65)$ & $0.063^{6}$ \\
\hline \multicolumn{5}{|l|}{ Cleanliness } \\
\hline 8a Cleanliness of social spaces & $175 / 1.32(0.64)$ & $113 / 1.33(0.63)$ & $62 / 1.31(0.64)$ & $0.842^{6}$ \\
\hline 8b Cleanliness of halls & $175 / 1.37(0.61)$ & $113 / 1.37(0.62)$ & $62 / 1.35(0.60)$ & $0.826^{6}$ \\
\hline $\begin{array}{l}\text { 9a Bodily excretion odor in } \\
\text { public areas }\end{array}$ & $175 / 1.84(0.43)$ & $113 / 1.84(0.43)$ & $62 / 1.84(0.41)$ & $0.845^{6}$ \\
\hline $\begin{array}{l}9 \mathrm{~b} \text { Bodily excretion odor in } \\
\text { residents rooms }\end{array}$ & $175 / 1.82(0.40)$ & $113 / 1.81(0.39)$ & $62 / 1.82(0.43)$ & $0.722^{6}$ \\
\hline \multicolumn{5}{|l|}{ Safety } \\
\hline $10 \mathrm{~b}$ Floor surface in halls & $175 / 1.08(0.83)$ & $113 / 0.98(0.88)$ & $62 / 1.26(0.74)$ & $0.045^{6}$ \\
\hline \multicolumn{5}{|l|}{ Lightning } \\
\hline $\begin{array}{l}12 \mathrm{~b} \text { Light intensity in activity } \\
\text { areas }\end{array}$ & $173 / 1.30(0.68)$ & $111 / 1.24(0.95)$ & $62 / 1.29(0.64)$ & $0.736^{6}$ \\
\hline $\begin{array}{l}\text { 12c Light intensity in residents } \\
\text { rooms }\end{array}$ & $175 / 0.98(0.67)$ & $113 / 0.90(0.67)$ & $62 / 1.13(0.64)$ & $0.031^{6}$ \\
\hline \multicolumn{5}{|l|}{ Visual/tactile stimulation } \\
\hline $\begin{array}{l}\text { 25b Visual stimulation } \\
\text { opportunities }\end{array}$ & $175 / 1.86(0.83)$ & $113 / 1.90(0.79)$ & $62 / 1.79(0.91)$ & $0.458^{6}$ \\
\hline \multicolumn{5}{|l|}{ Noise } \\
\hline $\begin{array}{l}\text { 31d Load speaker/intercom } \\
\text { noise }\end{array}$ & $172 / 1.91(0.40)$ & $112 / 1.88(0.46)$ & $62 / 1.97(0.26)$ & $0.176^{6}$ \\
\hline \multicolumn{5}{|l|}{ Familiarity/homelikeness } \\
\hline 19 Public areas homelike & $173 / 1.42(1.02)$ & $111 / 1.24(0.95)$ & $62 / 1.73(1.09)$ & $0.005^{6}$ \\
\hline 20 Kitchen in the unit & $175 / 0.64(0.89)$ & $113 / 0.60(0.88)$ & $62 / 0.71(0.89)$ & $0.373^{6}$ \\
\hline $\begin{array}{l}21 \text { Pictures/mementos in } \\
\text { residents room }\end{array}$ & $175 / 2.81(0.58)$ & $113 / 2.78(0.64)$ & $62 / 2.87(0.46)$ & $0.375^{6}$ \\
\hline 23 Resident appearance & $175 / 1.97(0.18)$ & $113 / 1.98(0.13)$ & $62 / 1.94(0.25)$ & $0.105^{6}$ \\
\hline \multicolumn{5}{|l|}{ Orientation } \\
\hline $\begin{array}{l}28 \mathrm{c}+\mathrm{d} \text { Current or old picture } \\
\text { of resident }\end{array}$ & $175 / 0.06(0.24)$ & $113 / 0.06(0.24)$ & $62 / 0.06(0.25)$ & $0.947^{6}$ \\
\hline SCUEQS total sum & $175 / 25.72(4.79)$ & $113 / 25.15(4.61)$ & $62 / 26.76(4.50)$ & $0.033^{5}$ \\
\hline $\mathrm{P}^{-\mathrm{CAT}^{4}}$ total sum & $1,157 / 46.16(7.46)$ & $763 / 44.82(7.43)$ & $394 / 48.74(6.83)$ & $<0.001^{5}$ \\
\hline
\end{tabular}

${ }^{1} \mathrm{~A}$ unit is defined as a group of residents living together with a common living area and having their own care staff during daytime.

${ }^{2} \mathrm{SD}=$ Standard deviation.

${ }^{3}$ SCUEQS = Special Care Unit Environmental Quality Scale.

${ }^{4} \mathrm{P}-\mathrm{CAT}=$ Person-Centered Care Assessment Tool.

${ }^{5} t$-test

${ }^{6}$ Mann-Whitney $U$ test. 
environment, staffing ratio, and the number of units the head nurse was leader of. All P-CAT scores except for one item - the environment feels chaotic - were higher in SCUs than in RUs. Four SCUEQS items - cleanliness of social spaces and halls, visual stimulation opportunities, and resident appearance - had higher scores in RU than in SCU, for all other SCUEQS items SCU had higher scores. Three items - floor surface in halls, light intensity in resident's rooms, and public areas homelike - in addition to the total sum score were significantly higher in SCU, indicating that SCU have a more dementia-friendly environment.

\section{Variables associated with P-CAT score}

Multilevel linear regression analyses were conducted to analyze the associations between staff variables; QPS-N variables, unit variables, and the P-CAT score (Table 3).

High job satisfaction was associated with a higher P-CAT score in the univariate analysis, as well as all the three models in the multivariate analysis. Having three years or more health-related education was not associated with a higher P-CAT score in the univariate analysis or in model 1 of the multivariate analysis, but was associated with a higher P-CAT score in models 2 and 3 of the multivariate analysis, compared to having lower education.

In the univariate analysis, all the QPS$\mathrm{N}$ subscales, except decision demands, were associated with the P-CAT score. Adjusted for staff variables and the other QPS-N subscale scores (model 2), decision demands, perception of mastery, empowering leadership, innovative climate, and perception of group work were positively associated with the P-CAT score, while quantitative demands and role conflict were negatively associated with the P-CAT score. This pattern was sustained in model 3 where unit variables were added to the model, except that decision demands were no longer significant.

In the univariate analysis, type of unit, number of beds, SCUEQS sum, and staff at daytime/patient were all associated with the P-CAT score. Adjusted for all the other variables (model 3), SCUs were associated with a higher P-CAT score compared to RUs, and a higher SCUEQS sum was associated with a higher P-CAT score.

\section{Discussion}

The main finding of this study was that high job satisfaction in care staff and care organized in small, specialized units were both strongly associated with a high level of PCC. More specifically, we found that staff with three years or more of health-related education, a lower level of quantitative demands and role conflict, a higher level of perception of mastery, empowering leadership, innovative climate, and perception of group work, in addition to a physical environment in the $\mathrm{NH}$ unit designed for people with dementia, were all associated with higher levels of PCC. To our knowledge, this is the first study exploring the complex association between PCC, organizational, NH staff and unit characteristics in Norwegian $\mathrm{NH}$.

The strongest association with high levels of PCC was a high score on job satisfaction, even when adjusted for all the QPS-Nordic subscales. This finding is supported by a previous review article from 2013 (Brownie and Nancarrow, 2013), which reported that facility-specific PCC interventions were found to impact the nurses' sense of job satisfaction, a Dutch study which analyzed the association between PCC and job satisfaction, and concluded that PCC may contribute to higher job satisfaction (van den Pol-Grevelink et al., 2012), and, finally, a Swedish study, which also found that higher levels of staff job satisfaction were associated with higher levels of PCC (Sjogren et al., 2015). Together, these findings should be taken into account when planning care for residents in $\mathrm{NH}$, even though we were not able to show if the staff's job satisfaction leads to higher degree of PCC or if it is the other way around.

In the univariate analysis, both the size of the units (number of beds) and the daytime staff/patient ratio were associated with higher levels of PCC, but these associations vanished when adjusted for other factors. However, SCUs were associated with higher levels of PCC, and as the average sizes of the SCUs were smaller and SCUs had on average a higher daytime staff/patient ratio (Table 2), both the size of the unit and the staff/patient ratio were important elements explaining the association between the type of ward and PCC.

Previous studies comparing SCUs and RUs have looked at patient outcomes, such as behavior, functioning in activities of daily living, cognitive function, and quality of life, to our knowledge, no other studies have specifically investigated the effect of SCU on PCC. A review from 2013 shows that patient characteristics only to a minor extent are different in SCU compared to RU (Kok et al., 2013). Other studies have looked at quality indicators such as the use of restraints and the prescription of antipsychotics (Kirkevold and Engedal, 2008), and provision of case conferences (Palm et al., 2016). These studies show that the literature is not consistent according to quality indicators. A review from 2009 evaluating the 
Table 3. Multilevel linear regression with person-centered care assessment tool (P-CAT) sum as dependent variable

\begin{tabular}{|c|c|c|c|c|c|c|c|c|c|}
\hline \multirow[b]{3}{*}{ Staff variables } & \multirow[b]{3}{*}{$\mathrm{n}$} & \multirow{2}{*}{\multicolumn{2}{|c|}{$\begin{array}{l}\text { UNIVARIATE } \\
\text { ANALYSIS }\end{array}$}} & \multicolumn{2}{|c|}{$\begin{array}{c}\text { MODEL } 1 \\
\mathrm{~N}=1,026\end{array}$} & \multicolumn{2}{|c|}{$\begin{array}{c}\text { MODEL } 2 \\
\mathrm{~N}=1,002\end{array}$} & \multicolumn{2}{|c|}{$\begin{array}{l}\text { MODEL } 3 \\
\mathrm{~N}=996\end{array}$} \\
\hline & & & & \multicolumn{2}{|c|}{ DATA FROM } & \multicolumn{2}{|c|}{ DATA FROM } & \multicolumn{2}{|c|}{ DATA FROM } \\
\hline & & coefficient & $\mathrm{p}$-value & coefficient & $\mathrm{p}$-value & coefficient & $\mathrm{p}$-value & coefficient & $\mathrm{p}$-value \\
\hline Age & 1,132 & -0.206 & 0.175 & 0.063 & 0.704 & 0.079 & 0.601 & 0.046 & 0.761 \\
\hline Gender & 1,094 & 0.507 & 0.642 & 0.821 & 0.423 & 0.882 & 0.332 & 0.797 & 0.377 \\
\hline Job satisfaction & 1,148 & 3.235 & $<0.001$ & 3.275 & $<0.001$ & 1.451 & $<0.001$ & 1.453 & $<0.001$ \\
\hline $\begin{array}{l}3 \text { years or more health-related } \\
\text { education }\end{array}$ & 1,153 & 0.234 & 0.571 & 0.840 & 0.050 & 1.333 & 0.001 & 1.289 & 0.001 \\
\hline$\geq 75 \%$ of full time position & 1,135 & 0.183 & 0.641 & -0.506 & 0.212 & -0.543 & 0.135 & -0.477 & 0.189 \\
\hline Experience in profession ${ }^{1}$ & 1,119 & -0.285 & 0.197 & -0.340 & 0.148 & -0.243 & 0.254 & -0.212 & 0.317 \\
\hline Advanced education & 1,157 & 0.653 & 0.132 & 0.992 & 0.021 & 0.674 & 0.082 & 0.59 & 0.125 \\
\hline \multicolumn{10}{|l|}{ QPS-Nordic ${ }^{2}$} \\
\hline QPS-N. Quantitative demands & 1,145 & -0.916 & $<0.001$ & & & -0.644 & $<0.001$ & -0.601 & $<0.001$ \\
\hline QPS-N. Decision demands & 1,145 & -0.085 & 0.391 & & & 0.222 & 0.021 & 0.173 & 0.069 \\
\hline QPS-N. Learning demands & 1,145 & -0.509 & $<0.001$ & & & 0.023 & 0.840 & 0.015 & 0.894 \\
\hline QPS-N. Perception of mastery & 1,145 & 1.210 & $<0.001$ & & & 0.260 & 0.015 & 0.260 & 0.015 \\
\hline $\begin{array}{l}\text { QPS-N. Empowering } \\
\text { leadership }\end{array}$ & 1,146 & 0.759 & $<0.001$ & & & 0.341 & $<0.001$ & 0.343 & $<0.001$ \\
\hline QPS-N. Fair leadership & 1,147 & 0.879 & $<0.001$ & & & 0.061 & 0.462 & 0.075 & 0.360 \\
\hline QPS-N. Role clarity & 1,147 & 0.931 & $<0.001$ & & & 0.009 & 0.934 & 0.034 & 0.753 \\
\hline QPS-N. Role conflict & 1,147 & -0.969 & $<0.001$ & & & -0.286 & 0.003 & -0.281 & 0.003 \\
\hline QPS-N. Innovative climate & 1,150 & 1.379 & $<0.001$ & & & 0.515 & $<0.001$ & 0.523 & $<0.001$ \\
\hline $\begin{array}{l}\text { QPS-N. Perception of group } \\
\text { work }\end{array}$ & 1,142 & 1.338 & $<0.001$ & & & 0.453 & $<0.001$ & 0.443 & $<0.001$ \\
\hline Unit variables & $n$ & & & & & & & & \\
\hline Type of unit ${ }^{3}$ & 175 & 3.825 & $<0.001$ & & & & & 1.773 & 0.002 \\
\hline Number of beds & 175 & -0.168 & 0.007 & & & & & -0.026 & 0.555 \\
\hline SCUEQS $^{4}$ sum & 175 & 0.181 & 0.020 & & & & & 0.142 & 0.005 \\
\hline Staff/patient ratio & 174 & 10.607 & 0.007 & & & & & 4.361 & 0.109 \\
\hline Head nurse/number of units & 174 & 0.438 & 0.158 & & & & & 0.303 & 0.172 \\
\hline $\begin{array}{l}\text { Physician (minutes per } \\
\text { patient) }\end{array}$ & 174 & -0.008 & 0.703 & & & & & -0.006 & 0.668 \\
\hline \multicolumn{10}{|l|}{$\mathrm{ICC}^{5}=0.341$} \\
\hline $\mathrm{R}_{1}^{2}$ (Within units) & & & & \multicolumn{2}{|c|}{0.166} & \multicolumn{2}{|c|}{0.348} & \multicolumn{2}{|c|}{0.346} \\
\hline $\mathrm{R}_{2}^{2}$ (Between units) & & & & \multicolumn{2}{|c|}{0.298} & \multicolumn{2}{|c|}{0.591} & \multicolumn{2}{|c|}{0.722} \\
\hline
\end{tabular}

${ }^{1}$ Experience in profession (current job) in groups in years; $0=\leq 1,1=>1-4.99,2=5-14.99,3=\geq 15$.

${ }^{2}$ QPS-Nordic $=$ The General Nordic Questionnaire for Psychosocial and Social Factors at Work.

${ }^{3}$ Type of unit; $0=$ Regular Unit (RU), 1 = Special Care Unit (SCU).

${ }^{4} \mathrm{SCUEQS}=$ Special Care Unit Environmental Quality Scale.

${ }^{5}$ ICC $=$ Intra-Class Correlation Coefficient.

effect of SCUs concluded that it is probably more important to implement best practices than to provide a specialized care environment (Lai et al., 2009). The definitions of an SCU vary across countries and across studies, and nursing homes implement different features in the units (Palm et al., 2014), thus there are challenges in comparing studies of SCUs. In the present study, the average size of an SCU was 8.5 beds, while in a Canadian study the average size of the SCUs was 18.9 beds (Morgan et al., 2004).

A Norwegian study concluded that SCUs had fewer quality deficiencies, probably due to the smaller units and a higher staff ratio (Kirkevold and Engedal, 2008). Together with the strong association between SCU and a high level of PCC, we argue that smaller, more homelike units, with a higher staff ratio, which are dedicated to persons with dementia, are a better option for persons with dementia than RUs.

Additionally, this study shows that not only the size of the unit, but also education and job satisfaction in care staff, leadership, and environment, impact the quality of care for this vulnerable group of persons. Care staff with three years or more of health-related education had a 
stronger association with a higher level of PCC in this study, similar to what was reported by Sjøgren et al. (2015), who found that a higher proportion of staff with continuing education in dementia care at the ward were associated with higher levels of PCC. With an aging population and the warranted decrease of care staff, this finding shows that not only do we need more staff, we need more staff with high education to care for our elderly.

Quantitative demands and role conflicts were both negatively associated with PCC in the present study. Similarly, Sjøgren et al., who explored the relationship between PCC and the staffs work environment and job-related well-being, reported that $\mathrm{NH}$ units where staff felt supported by their leaders had higher levels of PCC (Sjogren et al., 2015). Willemse et al. also found that leader support is associated with the nursing staff's person centeredness (Willemse et al., 2015). To create a work environment where the leaders support the $\mathrm{NH}$ staff, it is important to provide PCC in NH.

The QPS-Nordic subscale perception of mastery was positively associated with PCC. This association is again supported by Sjøgren's study, which found that a lower level of stress of conscience among staff was associated with higher levels of PCC (Sjogren et al., 2015). Even though perception of mastery focuses on the degree to which a carer is content with the job (Table 1), and the scale used by Siøgren et al. focuses on factors that gives a "troubled conscience," (Glasberg et al., 2006) these two scales have overlapping themes, and it seems reasonable to argue that to work in a unit where a carer often has a troubled conscience is the opposite to being content with their work.

One can also assume that the perception of mastery is closely linked to job satisfaction, but as job satisfaction remained strongly associated to PCC even when adjusted for all QPS-Nordic subscales, job satisfaction probably includes more than just perception of mastery.

Several studies enhance the role of leaders in promoting PCC. Brownie and Nancarrow found in a review that leadership is important in culturechange processes towards PCC, as introduction of democratized approaches to decision-making that involve residents and staff (Brownie and Nancarrow, 2013). Rokstad et al. found that leaders have a central role in drawing up a clear and consistent professional vision, being continuously supportive to the care staff and taking an active part in the care practice as role models when implementing PCC using Dementia Care Mapping (DCM) in nursing homes (Rokstad et al., 2015). The finding in the present study shows that especially "empowering leadership" is associated with PCC. Empowering leadership is a managerial style supporting and encouraging the caregivers to take the initiative and to participate in decisions. Thus, the caregivers closest to the patients have greater influence on making decisions regarding daily care. These findings are in line with the findings from a literature review conducted by Brownie and Nancarrow, who concluded that the introduction of democratized approaches to decision-making involving both staff and patients and models focusing on staff empowerment are important elements to support PCC (Brownie and Nancarrow, 2013). Kitwood also underlined the importance of staff being free to take their own decisions when taking care of persons with dementia and described this as an important part of conducting PCC (Kitwood, 1997).

In the present study, an innovative climate was associated with PCC. To our knowledge, this finding has not been reported earlier. However, the components in an innovative climate, such as taking the initiative and encouraging staff to find alternative ways to do things, corresponds with the theory of PCC (Kitwood, 1997; Brooker, 2004).

Furthermore, the present study showed that the perception of group work was positively associated with PCC. This finding is supported by Hunter et al., who found that collaboration in care is important for PCC (Hunter et al., 2015). Rokstad et al. found that leaders who participated in the daily care saw themselves as role models and encouraged the staff more than leaders not taking part in the daily care of the patients (Rokstad et al., 2015). The results of these studies (Hunter et al., 2015; Rokstad et al., 2015) support the finding of a positive association between PCC and empowered staff in the present study.

The positive association between perception of group work and PCC in the present study is supported by Hunter et al. (2015). Hunter measured PCC with self-rated measurements, creating five subscales (autonomy, personhood, knowing the person, comfort care, and support for relationships) and found that in four of the five subscales collaboration was the only environmental variable that was associated with PCC. Further, they suggested that focusing on changing organizational processes to create PCC may be more fruitful than a focus on individual behavior, concluding that collaboration in care is important to promote PCC (Hunter et al., 2015).

In a recent literature review, Chaudhury et al. (2017) stated that the physical environment of the unit plays an important role in the care of persons with dementia, both in enhancing the patient's quality of life and in the quality of care. In addition, they highlighted the influence of the unit size, the spatial layout, the homelike character, sensory 
stimulation, and specific spaces on the patients' behavior and well-being, but they emphasized that the potential of a therapeutic physical milieu is meaningfully utilized only when taking into account the unit's organizational policies and relational care practices (Chaudhury et al., 2017). These findings are supported by Brownie and Nancarrow, who in a review investigated the evidence for the impact of person-centered interventions on aged-care residents and nursingstaff support, concluding that person-centered interventions are multifactorial, where elements of environmental enhancement are included (Brownie and Nancarrow, 2013). The findings in the present study support this conclusion. As the assessment of the physical environment (measured with the SCUEQS) remains significantly associated with PCC after adjusting for size and type of ward, other variables describing the physical environment are as important as size of ward when the staff assess PCC with P-CAT. It is also worth highlighting that "Public areas homelike" was the variable that differs most between SCUs and RUs (Table 2).

It is important to underline that the staff variables and the QPS-N variables contributed more to the model than the environmental variables (Table 3, $R_{1}^{2}$ and $R_{2}^{2}$ ) and indicated that it is important to focus on these factors independent of type of ward.

\section{Strengths and weaknesses}

To our knowledge, this is the first study exploring the complex associations between PCC, organizational, $\mathrm{NH}$ staff and unit characteristics in Norwegian NH. The strengths of this study are the large number of $\mathrm{NH}$ units and care staff that participated and the use of standardized and reliable assessment tools which made it possible to compare findings with other studies, both in Norway and internationally. The high number of care staff included in the study is also a strength, enabling inclusion of several potential important variables in the regression analyses. The distribution of the care-staff questionnaire was done in cooperation with the head nurse of the unit, and the procedure for returning the answers enhanced the care staff's anonymity. The physical environmental assessments (TESS$\mathrm{NH}$ ) were conducted by five researchers, which have had the same training doing the TESS-HN. The NH staff had no information about the score of the physical environment when scoring the PCAT. The high response rate from both the leaders of the unit and the care staff, $99.5 \%$ and $67.5 \%$, respectively, is a strength of the study.
There are number of limitations to this study, and we consider the complex causal pathways as the most important. The NH staff rated both PCC, their work-related psychosocial factors and job satisfaction, giving only the staffs' perception and possibly leading to biased data. A limitation of the study is that the participating units were not selected randomly, but they were a convenient sample of NHs geographically distributed throughout Norway and representing small and large units, SCUs and RUs. We used the SCUEQS to assess the physical environment in the $\mathrm{NH}$, which is an American scale developed in 2002. Although there may be differences due to cultural issues between Norway and the U.S., using a standardized instrument gives better data quality than just select arbitrary environmental variables. Thus, the SCUEQS scale is the most proper environmental scale for this study.

\section{Conclusion}

The association between PCC and several organizational, $\mathrm{NH}$ staff and unit characteristics identified in this study indicates that providing PCC in NH care is closely linked to how the staff experiences their job situation in addition to both organizational and structural factors and the physical environment. This knowledge is important for creating better care for persons with dementia, and attention needs to be given to this when planning $\mathrm{NH}$ care.

\section{Conflict of interest}

None.

\section{Description of authors' roles}

I. Røen designed the study, collected the data, and wrote the paper. $\varnothing$. Kirkevold was involved in designing the study, performed the statistical analysis, and assisted with the writing. I. Testad assisted with the writing and revised the article critically. G. Selbæk was involved in designing the study and revised the article critically for important intellectual content. K. Engedal revised the article critically for important intellectual content. S. Bergh was involved in designing the study, supervised the data collection, and assisted with the writing. All authors approved the final version. 


\section{Acknowledgments}

The Research Council of Norway funded the first author's PhD study. NHs in Hedmark, Oppland, Hordaland, and Nord-Trøndelag counties participated in the study.

We would like to thank the staff, the head nurses, and the managers in the nursing homes for participating in the study. We also thank the research nurses at Innlandet Hospital Trust for contributing in the data collection effort in the NHs.

\section{References}

Acquadro, C., Jambon, B., Ellis, D. and Marquis, P. (1996). Language and translation issues.In B. Spilker (ed.), Quality of Life and Pharmacoeconomics in Clinical Trials (pp. 575-585), 2 edn. Philadelphia: Lippincott-Raven.

Anderson, K., Bird, M., Macpherson, S. and Blair, A. (2016). How do staff influence the quality of long-term dementia care and the lives of residents? a systematic review of the evidence. International Psychogeriatrics, 28, 1263-1281.

Ballard, C. et al. (2015). Impact of antipsychotic review and nonpharmacological intervention on antipsychotic use, neuropsychiatric symptoms, and mortality in people with dementia living in nursing homes: a factorial cluster-randomized controlled trial by the well-being and health for people with dementia (WHELD) program. American fournal of Psychiatry, 173(3), 252-262.

Brooker, D. J., Argyle, E., Scally, A. J. and Clancy, D. (2011). The enriched opportunities programme for people with dementia: a cluster-randomised controlled trial in 10 extra care housing schemes. Aging and Mental Health, 15, 1008-1017.

Brooker, D. (2004). What is person-centered care in dementia? Reviews in Clinical Gerontology, 13, 215-222.

Brownie, S. and Nancarrow, S. (2013). Effects of person-centered care on residents and staff in aged-care facilities: a systematic review. Clinical Interventions in Aging, $8,1-10$.

Chaudhury, H., Cooke, H. A., Cowie, H. and Razaghi, L. (2017). The influence of the physical environment on residents with dementia in long-term care settings: a review of the empirical literature. Gerontologist, doi:10.1093/geront/gnw259.

Chenoweth, L. et al. (2009). Caring for aged dementia care resident study (CADRES) of person-centred care, dementia-care mapping, and usual care in dementia: a cluster-randomised trial. The Lancet Neurology, 8, 317-325.

Dallner, M., Elo, A.-L., Gamberale, F., Hottinen, V., Knardahl, S. and Lindström, K. (2000). Validation of the General Nordic Questionnaire (QPSNordic) for Psychological and Social Factors at Work. Copenhagen: Nordic Council of Ministers, Nord.

De Silva, D. (2014). Helping Measure Person-Centred Care. London: The Health Foundation.

Edvardsson, D., Fetherstonhaugh, D., Nay, R. and Gibson, S. (2010). Development and initial testing of the person-centered care assessment tool (P-CAT). International Psychogeriatrics, 22, 101-108.

Edvardsson, D. and Innes, A. (2010). Measuring person-centered care: a critical comparative review of published tools. Gerontologist, 50, 834-846.

Efron, B. and Tibshirani, R. J. (1994). An Introduction to the Bootstrap. London: Taylor \& Francis.

Fossey, J. et al. (2006). Effect of enhanced psychosocial care on antipsychotic use in nursing home residents with severe dementia: cluster randomised trial. BMF, 332, 756-761.

Glasberg, A. L. et al. (2006). Development and initial validation of the stress of conscience questionnaire. Nursing Ethics, 13, 633-648.

Hunter, P. V., Hadjistavropoulos, T., Thorpe, L., Lix, L. M. and Malloy, D. C. (2015). The influence of individual and organizational factors on person-centred dementia care. Aging and Mental Health, 20, 1-9.

Kirkevold, O. and Engedal, K. (2008). Quality of care in Norwegian nursing homes-deficiencies and their correlates. Scandinavian fournal of Caring Sciences, 22, 560-567.

Kitwood, T. (1997). Dementia Reconsidered: The Person Comes First. Buckingham, UK: Open University Press.

Kok, J. S., Berg, I. J. and Scherder, E. J. (2013). Special care units and traditional care in dementia: relationship with behavior, cognition, functional status and quality of life - a review. Dementia and Geriatric Cognitive Disorders Extra, 3, 360-375.

Lai, C. K., Yeung, J. H., Mok, V. and Chi, I. (2009). Special care units for dementia individuals with behavioural problems. The Cochrane Database of Systematic Reviews, Article ID: CD006470.

Li, J. and Porock, D. (2014). Resident outcomes of person-centered care in long-term care: a narrative review of interventional research. International fournal of Nursing Studies, 51, 1395-1415.

Manthorpe, J. and Samsi, K. (2016). Person-centered dementia care: current perspectives. Clinical Interventions in Aging, 11, 1733-1740.

Morgan, D. G., Stewart, N. J., D'arcy, K. C. and Werezak, L. J. (2004). Evaluating rural nursing home environments: dementia special care units versus integrated facilities. Aging $\mathcal{E}$ Mental Health, 8, 256-265.

Palm, R., Bartholomeyczik, S., Roes, M. and Holle, B. (2014). Structural characteristics of specialised living units for people with dementia: a cross-sectional study in German nursing homes. International fournal of Mental Health Systems, 8, 39.

Palm, R., Trutschel, D., Simon, M., Bartholomeyczik, S. and Holle, B. (2016). Differences in case conferences in dementia specific vs traditional care units in German nursing homes: results from a cross-sectional study. fAMDA, 17, 91.e9-13.

Rokstad, A. M., Engedal, K., Edvardsson, D. and Selbaek, G. (2012). Psychometric evaluation of the Norwegian version of the person-centred care assessment tool. International fournal of Nursing Practice, 18, 99-105.

Rokstad, A. M., Vatne, S., Engedal, K. and Selbaek, G. (2015). The role of leadership in the implementation of person-centred care using dementia care mapping: a study in three nursing homes. Fournal of Nursing Management, 23, 15-26. 
Selbaek, G., Kirkevold, O. and Engedal, K. (2007). The prevalence of psychiatric symptoms and behavioural disturbances and the use of psychotropic drugs in Norwegian nursing homes. International fournal of Geriatric Psychiatry, 22, 843-849.

Sjogren, K., Lindkvist, M., Sandman, P. O., Zingmark, K. and Edvardsson, D.(2015). To what extent is the work environment of staff related to person-centred care? a cross-sectional study of residential aged care. Fournal of Clinical Nursing, 24, 1310-1319.

Sloane, P. D. et al. (2002). The therapeutic environment screening survey for nursing homes (TESS-NH): an observational instrument for assessing the physical environment of institutional settings for persons with dementia. The fournals of Gerontology. Series B, Psychological Sciences and Social Sciences, 57, S69-78.

Testad, I. et al. (2014). The value of personalized psychosocial interventions to address behavioral and psychological symptoms in people with dementia living in care home settings: a systematic review. International Psychogeriatrics, 26, 1083-1098.
Testad, I., Mikkelsen, A., ballard, C. and Aarsland, D. (2010). Health and well-being in care staff and their relations to organizational and psychosocial factors, care staff and resident factors in nursing homes. International fournal of Geriatric Psychiatry, 25, 789-797.

Van den pol-grevelink, A., Jukema, J. S. and Smits, C. H. (2012). Person-centred care and job satisfaction of caregivers in nursing homes: a systematic review of the impact of different forms of person-centred care on various dimensions of job satisfaction. International fournal of Geriatric Psychiatry, 27, 219-229.

Wilberforce, M., Challis, D., Davies, L., Kelly, M. P., Roberts, C. and Loynes, N. (2016). Person-centredness in the care of older adults: a systematic review of questionnaire-based scales and their measurement properties. BMC Geriatrics, 16, 63.

Willemse, B. M., De Jonge, J., Smit, D., Visser, Q., Depla, M. F. and Pot, A. M. (2015). Staff's person-centredness in dementia care in relation to job characteristics and job-related well-being: a cross-sectional survey in nursing homes. Fournal of Advanced Nursing, 71, 404-416. 